\title{
The contribution of N-terminally modified amyloid beta to the etiology of Alzheimer's disease
}

\author{
Dissertation \\ for the award of the degree \\ "Doctor of Philosophy" \\ Division of Mathematics and Natural Sciences \\ of the Georg-August-Universität Göttingen
}

submitted by

Jessica L. Wittnam

from Billings, MT, USA

Göttingen, 2012 


\section{PhD thesis committee:}

Prof. Dr. Thomas A. Bayer (Reviewer)

Department for Psychiatry

Division of Molecular Psychiatry

Georg August University

Göttingen

Prof. Dr. André Fischer (Reviewer)

Laboratory of Aging and Cognitive Diseases

European Neuroscience Institute

Göttingen

Prof. Dr. Dr. Hannelore Ehrenreich

Division of Clinical Neurosciences

Max Planck Institute of Experimental Medicine

Göttingen

Date of the oral examination: May 21, 2012 


\section{Declaration:}

I hereby declare that the $\mathrm{PhD}$ thesis entitled "The contribution of $\mathrm{N}$ terminally modified amyloid beta to the etiology of Alzheimer's disease" was written independently and with no other sources and aids than quoted.

Jessica Wittnam

Göttingen, 2012 


\section{Contents}

Contents $\quad$ i

1 Introduction $\quad 3$

1.1 Clinical presentation of Alzheimer's disease . . . . . . . . . . . . . . . 4

1.1.1 Epidemiology . . . . . . . . . . . . . . . . . 4

1.1 .2 Risk factors . . . . . . . . . . . . . . . . . . 4

1.1.3 Disease progression . . . . . . . . . . . . . . . . 4

1.1.4 Diagnosis . . . . . . . . . . . . . . . . 5

1.1.5 Treatment ...................... 6

1.2 Neuropathology of Alzheimer's disease . . . . . . . . . . . . . . . . 7

1.2.1 Amyloid deposits . . . . . . . . . . . . . . . . . 7

1.2.2 Neurofibrillary tangles . . . . . . . . . . . . . . . . 8

1.2 .3 Brain atrophy . . . . . . . . . . . . . . . . . . . . 9

1.2.4 Microglia and astrocyte activation . . . . . . . . . . . . . . . 10

1.3 The amyloid precursor protein . . . . . . . . . . . . . . . . . . 10

1.3.1 Non-amyloidogenic processing of the amyloid precursor protein . . . 12

1.3.2 Amyloidogenic processing of the amyloid precursor protein . . . . . 13

1.4 Genetics . . . . . . . . . . . . . . . . . . . . . 14

1.5 The amyloid hypothesis . . . . . . . . . . . . . . . 17

1.5.1 Soluble amyloid hypothesis . . . . . . . . . . . . . . . . . 17

1.5.2 Intraneuronal amyloid hypothesis . . . . . . . . . . . . . . . . . . . . . . . . . . 19

1.6 Amyloid beta variants . . . . . . . . . . . . . . . . . . . 21

1.7 Pyroglutamate-modified amyloid beta . . . . . . . . . . . . . . . 22

1.7.1 Generation of pyroglutamate-modified amyloid beta . . . . . . . . 23

1.7.2 Biochemical properties of pyroglutamate-modified amyloid beta . . 25

1.7.3 Toxicity of pyroglutamate-modified amyloid beta . . . . . . . . . 25

1.8 Amyloid beta $4-42 \ldots \ldots \ldots$. . . . . . . . . . . . . . . 26

1.9 Transgenic mouse models of Alzheimer's disease . . . . . . . . . . . . . . 27

1.9.1 5XFAD mouse model . . . . . . . . . . . . . . . . . 29 
1.10 Project objectives . . . . . . . . . . . . . . . . . . . . . 32

1.10.1 Project I: Generation and characterization of the TBA42 mouse model 32

1.10.2 Project II: Exploring the pyroglutamate-modified amyloid beta seeding hypothesis using the FAD42 mouse model . . . . . . . . . 33

1.10.3 Project III: Generation and characterization of the TBA83 mouse

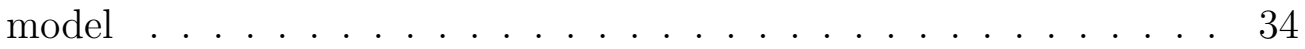

2 Materials and Methods 35

2.1 Animals . . . . . . . . . . . . . . . . . . 35

2.1.1 Housing and general considerations . . . . . . . . . . . . 35

2.1.2 TBA42 transgenic mice . . . . . . . . . . . . . . . . . . . . . . . . . . . 35

2.1.3 5XFAD transgenic mice . . . . . . . . . . . . . 36

2.1.4 FAD42 transgenic mice . . . . . . . . . . . . . . . . . . . . . . . . . . . 36

2.1.5 TBA83 transgenic mice . . . . . . . . . . . . . . . . . . 36

2.1.6 Tissue preparation for biochemistry . . . . . . . . . . . . . . 37

2.1.7 Tissue preparation for immunohistochemistry . . . . . . . . . 37

2.2 Behavioral analysis of mice . . . . . . . . . . . . . . . . 38

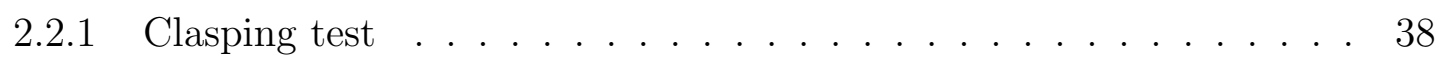

2.2.2 Balance beam . . . . . . . . . . . . . . . . . . . . . . . . . . . . . . . . . . . . . . 39

2.2 .3 String suspension . . . . . . . . . . . . . . . . . . . . 39

2.2 .4 Inverted grip hang . . . . . . . . . . . . . . . . . . . . . . . . . . . . . . . . . . .

2.2 .5 Y-maze . . . . . . . . . . . . . . . . . . 40

2.2 .6 Cross maze . . . . . . . . . . . . . . . . . . . . . 40

2.2.7 Elevated plus maze . . . . . . . . . . . . . . . . . . . . . . . . . . . . . . . . . . . 41

2.2 .8 Open field . . . . . . . . . . . . . . . . . . . . . . . . . . . . . . . . . . . . . . 41

2.2 .9 Morris water maze . . . . . . . . . . . . . . . . . . . . . . . . . . . . . . . . . .

2.3 Molecular biology and biochemistry . . . . . . . . . . . . . . . . . . . . . . . . . 43

2.3.1 Media preparation for Escherichia coli culturing . . . . . . . . . . . 43

2.3.2 TBA1 plasmid mutagenesis . . . . . . . . . . . . . . . 44

2.3.3 Escherichia coli transformation ................. . . . . . . . . . . . . . . 44

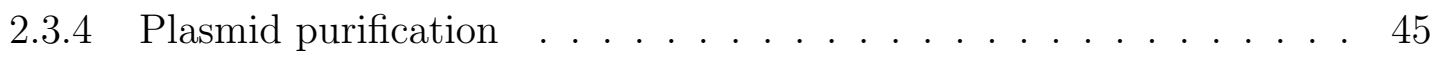

2.3.5 DNA sequencing . . . . . . . . . . . . . . . . . . . 45

2.3.6 Isolation and purification of TBA8 transgene . . . . . . . . . . . . 46

2.3.7 Pronuclear injection of TBA8 transgene . . . . . . . . . . . . . 47

2.3.8 DNA isolation for genotyping of transgenic mice . . . . . . . . . 47

2.3.9 RNA isolation from mouse brain . . . . . . . . . . . . . . . . 48

2.3.10 Nucleic acid concentration measurement . . . . . . . . . . . . . 48

2.3.11 Reverse transcription . . . . . . . . . . . . . . . . . . . . . . . . . . . . . . . 48

2.3 .12 Primers . . . . . . . . . . . . . . . . . . . . . . 49

2.3.13 Quantitative real-time polymerase chain reaction (qPCR) . . . . . 49

2.3.14 Polymerase chain reaction $(\mathrm{PCR}) \ldots \ldots . \ldots . \ldots 51$ 
2.3.15 DNA electrophoresis . . . . . . . . . . . . . 54

2.3.16 Protein isolation from mouse brain . . . . . . . . . . . . 55

2.3.17 Protein concentration determination . . . . . . . . . . . . 56

2.3.18 Enzyme-linked immunosorbent assay (ELISA) . . . . . . . . . . 56

2.3.19 Glutaminyl cyclase enzyme activity measurement . . . . . . . . . 57

2.4 Mass spectrometric analysis of mouse brain . . . . . . . . . . . . . 57

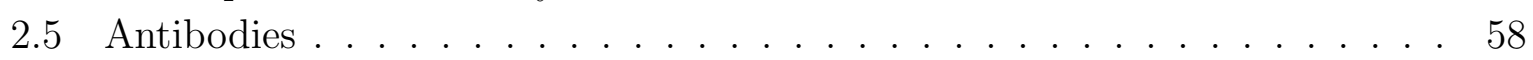

2.6 Immunohistochemistry . . . . . . . . . . . . . . . . . . . . . . . 59

2.6.1 Paraffin embedding of mouse brain and spinal cord . . . . . . . . . 59

2.6.2 3,3'-Diaminobenzidine (DAB) immunohistochemistry . . . . . . . 59

2.6.3 Combined DAB/HistoGreen immunohistochemistry . . . . . . . . . 61

2.6.4 Fluorescent immunohistochemistry . . . . . . . . . . . . . 61

2.6.5 Microscopy and image preparation . . . . . . . . . . . . . 61

2.6.6 Plaque load analysis . . . . . . . . . . . . . . . . . . . . . . . . . . . . . . . . 62

2.7 Data analysis . . . . . . . . . . . . . . . . . . . . 62

$\begin{array}{lll}3 & \text { Results } & \mathbf{6 3}\end{array}$

3.1 Project I: Generation and characterization of the TBA42 mouse model . . 63

3.1.1 Selection of the TBA42 mouse line . . . . . . . . . . . . . . 63

3.1.2 Amyloid beta accumulation in TBA42 mice . . . . . . . . . . . 65

3.1 .3 Gliosis in TBA42 mice . . . . . . . . . . . . . . . 66

3.1.4 Intracellular localization of amyloid beta in TBA42 mice . . . . . . 69

3.1.5 General physical assessment of TBA42 mice . . . . . . . . . . . 70

3.1.6 Motor function in TBA42 mice . . . . . . . . . . . . . . 71

3.1.7 Working memory in TBA42 mice . . . . . . . . . . . . . . . 72

3.1.8 Anxiety and exploratory behavior in TBA42 mice . . . . . . . . . . 72

3.2 Project II: Exploring the pyroglutamate-modified amyloid beta seeding hypothesis using the FAD42 mouse model . . . . . . . . . . . . . . . . . 75

3.2.1 Behavioral analysis of FAD42 mice . . . . . . . . . . . . 75

3.2.2 Immunoprecipitation and mass spectrometric (IP/MS) characterization of wild-type, TBA42, 5XFAD and FAD42 mouse brain . . . 76

3.2.3 Localization of cortical amyloid beta in 5XFAD and TBA42 mice . 78

3.2.4 Analysis of cortical plaque load in 5XFAD and FAD42 mice . . . . 78

3.2.5 Measurement of soluble and insoluble amyloid beta in TBA42, 5XFAD and FAD42 mice . . . . . . . . . . . . . . . . . . . 81

3.2.6 Glutaminyl cyclase activity in wild-type, TBA42, 5XFAD and FAD42 mouse brain . . . . . . . . . . . . . . . . 81

3.3 Project III: Generation and characterization of the TBA83 mouse model . 83

3.3.1 Selection of the TBA83 mouse line . . . . . . . . . . . . . . . 83

3.3.2 Amyloid beta accumulation in TBA83 mice . . . . . . . . . . . . 85

3.3.3 Gliosis in TBA83 mice . . . . . . . . . . . . . . . . . . . 85 
3.3.4 General physical assessment and motor function in TBA83 mice . . 87

3.3.5 Working memory in TBA83 mice . . . . . . . . . . . . . . 88

3.3.6 Anxiety and exploratory behavior in TBA83 mice . . . . . . . . . . 88

3.3.7 Spatial reference memory in TBA83 mice . . . . . . . . . . . . . . 89

\section{Discussion}

4.1 Project I: Generation and characterization of the TBA42 mouse model . . 92

4.1.1 TBA42 mice develop intraneuronal and sparse extracellular amyloid deposits . . . . . . . . . . . . . . . . . . . . 93

4.1.2 Intraneuronal amyloid beta found in the endosomal/ lysosomal system in TBA42 mice . . . . . . . . . . . . . . . . . . . . 95

4.1.3 Age-dependent increase in gliosis in TBA42 mice . . . . . . . . . 96

4.1.4 Age-dependent motor deficits and weight loss in TBA42 mice . . . . 97

4.1.5 Age-dependent working memory deficits in TBA42 mice . . . . . . 98

4.1.6 Decreased anxiety and altered exploratory activity in TBA42 mice . 100

4.1 .7 Conclusions of Project I . . . . . . . . . . . . . . . . . . . 101

4.2 Project II: Exploring the pyroglutamate-modified amyloid beta seeding hypothesis using the FAD42 mouse model . . . . . . . . . . . . . . . . . . 102

4.2.1 Enhanced behavioral deficits in FAD42 mice . . . . . . . . . . . . . 102

4.2.2 Minor alterations in the amyloid beta profile of FAD42 mice as determined by IP $/ \mathrm{MS} \ldots$. . . . . . . . . . . . . . . 103

4.2.3 Altered levels of pyroglutamate-modified amyloid beta and increased plaque pathology in FAD42 mice . . . . . . . . . . . . . . . 104

4.2.4 Elevated glutaminyl cyclase activity in FAD42 mice . . . . . . . . . 106

4.2.5 Conclusions of Project II . . . . . . . . . . . . . . . . . 107

4.3 Project III: Generation and characterization of the TBA83 mouse model . 108

4.3.1 Age-dependent gliosis and amyloid beta accumulation in TBA83 mice108

4.3.2 Selective deficits in motor function and spatial working memory in

TBA83 mice . . . . . . . . . . . . . . . . . . . . . . 109

4.3 .3 Conclusions of Project III . . . . . . . . . . . . . . . . . . 111

$\begin{array}{llr}5 & \text { Summary } & 112\end{array}$

$\begin{array}{lr}\text { Bibliography } & 114\end{array}$

$\begin{array}{ll}\text { List of Symbols and Abbreviations } & 137\end{array}$

$\begin{array}{ll}\text { List of Figures } & 141\end{array}$

$\begin{array}{ll}\text { List of Tables } & 143\end{array}$ 


\section{Acknowledgments}

My doctoral work would not have been possible without the encouragement and guidance of Prof. Dr. Thomas Bayer. I truly appreciate the patience and understanding he displayed regarding the challenges I encountered during my project. I thank Prof. Dr. André Fischer and Prof. Dr. Dr. Hannelore Ehrenreich for agreeing to serve as members of my $\mathrm{PhD}$ committee. Their support and advice were indispensable. I also express my gratitude toward PD Dr. Oliver Wirths for his help and willingness to share his extensive knowledge of all things scientific.

I am deeply grateful to Daniela Reich-Erkelenz, Prof. Dr. Stefan Treue and all the other members of the CSN board for being so kind and supportive during my term as CSN student representative. Working with them added a wonderful dimension to my PhD.

A huge thanks to Kirsten Pöhlker, Christina Bach and the other members of the GGNB office. Despite their workload, they were always able to offer assistance. To an oft-stressed $\mathrm{PhD}$ student, that small gesture is a lifesaver.

Additional acknowledgments go to the former and current members of the Bayer lab: Ditte Christensen, Marie-Caroline Cotel, Andrea Marcello, Vivek Venkataramani, Katharina Dietrich, and Yvonne Bouter. Together they set the stage for my work and will keep it running once I leave.

I thank Anika Saul for her pluck and general insightfulness. Her vivid personality made all those conference trips memorable.

I am forever indebted to Nadine Ilse, Nina Karbe and the other members of the Klinikum animal facility. Without them, my work would have literally gone extinct.

My sincerest thanks go to Petra Tucholla for always providing support, technical and otherwise. I will not forget her amazing ability to discern when I needed a kind word or some emergency chocolate.

I appreciate the opportunity that all the rotation students of the Bayer lab have given me to teach and learn at the same time. 
I will always be eternally grateful to Sadeem Jawhar and Antje Hillmann. They have been the best of friends at the worst of times, and my $\mathrm{PhD}$ would not have been the same in their absence. I am thankful to Sadeem for her willingness to share her scientific acumen, culture and generally fabulous sense of style. I hope I have proven to her that I am more than my picture implies. Antje has been one of the few people to understand and appreciate my idiosyncrasies. Without her, I would still be mired in the German bureaucracy. May these wonderful ladies and I remain close in the coming years.

I also thank my parents for supporting and respecting me during my time in Germany. Their ability to accept my unconventional plans says volumes about what wonderful people they are.

Finally, to Ivan Rajkovic: The love, kindness and unselfish support you have shown me throughout the years is beyond measure. Who knows where I would be without you. 


\section{Chapter 1}

\section{Introduction}

"You have to begin to lose your memory, if only in bits and pieces, to realize that memory is what makes our lives. Life without memory is no life at all, just as an intelligence without the possibility of expression is not really an intelligence. Our memory is our coherence, our reason, our feeling, even our action. Without it, we are nothing." - Luis Buñuel

Auguste Deter likely represents the most famous embodiment of this quotation by Spanish filmmaker Luis Buñuel. Over 100 years ago, Auguste's failing memory and erratic behavior made her the patient of Dr. Alois Alzheimer at the Institution for the Mentally Ill and for Epileptics in Frankfurt, Germany. Alzheimer recalled Auguste as a woman confused by her surroundings and devoid of comprehension. Despite repeated questioning, she only seemed capable of providing one coherent description of her state, "It is like I have lost myself "(Alzheimer, 1907).

Following Auguste's death in 1906, her brain was given to Alzheimer for postmortem analysis. He then described the histopathological features now commonly associated with Alzheimer's disease (AD): neuron loss, extracellular plaques and intracellular tangles. Ultimately, Alzheimer's case report on Auguste Deter gave this "lost woman" a place in history as the first AD patient. Millions of people have since been diagnosed with AD, making it the most common form of dementia. No cure for $\mathrm{AD}$ presently exists. As a result, $\mathrm{AD}$ has become a pressing medical, social and economic issue. 


\subsection{Clinical presentation of Alzheimer's disease}

\subsubsection{Epidemiology}

In 2010, it was estimated that 35.6 million people were living with dementia worldwide. This number is expected to reach 115.4 million by the year 2050 (World Alzheimer Report, 2010). Currently, 1.2 million people suffer from dementia in Germany, with AD accounting for approximately $66 \%$ of these cases (Deutsche Alzheimer Gesellschaft, 2010). Estimates of AD prevalence in the United States put the number of affected individuals at 5.4 million in 2011, and it was the sixth leading cause of death in all age groups (Alzheimer's Association, 2011). Nearly 15 million people provided over $\$ 202$ billion worth of unpaid care for AD patients in the United States last year. At the current rate of diagnosis for $\mathrm{AD}$ and other dementias, projected healthcare costs for these conditions in the United States alone will reach $\$ 1.1$ trillion by 2050 (Alzheimer's Association, 2011).

\subsubsection{Risk factors}

Aging is the primary risk factor for AD. After the age of 65 , an individual's chances of developing $\mathrm{AD}$ double every five years, reaching a cumulative lifetime risk of over $16 \%$ beyond the age of 85 (Hebert et al., 1995; Seshadri et al., 2006). Cognitive elements, such as low educational level and poor occupational achievement, further elevate the probability of developing AD (Stern et al., 1994; Evans et al., 1997). There are also links between AD and general health status. For example, cardiovascular risk factors like midlife hypercholesterolemia, hypertension, obesity and type II diabetes are associated with an increased likelihood of AD and other dementias later in life (Kivipelto et al., 2005; Solomon et al., 2009; Tsivgoulis et al., 2009; Cheng et al., 2011). Conversely, individuals who remain physically active, challenge themselves mentally or consume an antioxidantrich diet lower their risk for a future AD diagnosis (Laurin et al., 2001; Wilson et al., 2002; Hall et al., 2009; Polidori et al., 2009; Gu et al., 2010).

\subsubsection{Disease progression}

The initial clinical presentation of $\mathrm{AD}$ is a departure from the benign cognitive changes associated with normal aging. Increased perception time, slower mental processing and some minor memory impairments are commonplace in healthy, non-demented elderly (Walsh et al., 1979; Birren and Fisher, 1995). These deficits remain relatively stable with increasing age and do not hinder an individual's ability to function on a daily basis (Rubin et al., 1998). In contrast, early AD manifests as a progressive decline in previous 
cognitive abilities that noticeably interferes with an individual's routine life (McKhann et al., 1984).

Mild cognitive impairment (MCI) represents a mid-ground between normal cognitive aging and full-blown dementia. Neuropsychological testing reveals that MCI patients have a general preservation of daily functions but perform worse than education- and agematched controls in multiple cognitive domains. A diagnosis of "amnestic" MCI is given if memory impairments are identified during cognitive screening (Petersen et al., 2009). While amnestic MCI does increase the likelihood of a future AD diagnosis, it has limited predictive value in determining whether a patient ultimately converts to AD (Gauthier et al., 2006; Fischer et al., 2007). As a result, it was recently proposed that a separate MCI category be designated to more accurately reflect prodromal AD (Albert et al., 2011).

Deficits in episodic memory and a decreased ability to retain new information are the initial and most prominent manifestations of clinically-diagnosed AD (Knopman and Ryberg, 1989; Welsh et al., 1991). Subtle alterations in personality, language disturbances and spatial orientation problems also gradually appear during the disease course (Petry et al., 1988; Locascio et al., 1995; Kalová et al., 2005). Eventually, multiple cognitive domains are affected; impairments in attention, semantic memory (knowledge of facts, concepts and definitions) and executive function (problem solving, planning and abstract thinking) grow more pronounced with time (Hodges et al., 1991; Perry and Hodges, 1999). Mid-to-late-stage AD patients suffer from worsening retrograde amnesia (Beatty et al., 1988). Loss of daily life skills, aggressiveness, agitation and wandering makes AD patients dependent on outside caregivers (Devanand et al., 1997). In the terminal phase of the disease, nearly all cognitive faculties are severely impaired. An inability to perform basic motor functions, such as swallowing, is common, and this may ultimately contribute to the cause of death (Wada et al., 2001).

\subsubsection{Diagnosis}

The differential diagnosis of $\mathrm{AD}$ is based on medical history, neurological testing and neuropsychological screening. A positive AD diagnosis requires evidence of memory impairment and deficits in one of the following other areas: language (aphasia), motor activity (apraxia), object recognition (agnosia) or executive function (planning, organizing, etc.). The decline in these functions must be gradual, continual and sufficient to interfere with daily activities. Furthermore, an AD diagnosis should not be made in the presence of delirium, and neurological and psychiatric illnesses should be ruled-out as the underlying cause of symptoms (American Psychiatric Association, 2000). 
A variety of tests are available to the clinician for assessing mental status. These tests measure cognitive dimensions such as alertness, attention, short and long-term memory, visuospatial abilities and executive function. Among other dementia screening tools, the Mini-Mental State Exam, Short Blessed Test, and Clock Drawing are widely used (Folstein et al., 1975; Katzman et al., 1983; Brodaty and Moore, 1997). In addition, blood tests and magnetic-resonance imaging (MRI) may aid in excluding dementia due to comorbidities and other processes unrelated to AD (Hort et al., 2010).

A definitive AD diagnosis can only be given upon autopsy. The present criteria for neuropathological confirmation of AD are based upon the progression of neurofibrillary tangle formation and the analysis of neuritic plaques (Braak and Braak, 1991; Mirra et al., 1991). There is a high likelihood that dementia is due to AD when postmortem brain shows frequent neuritic plaque deposition in the neocortex and abundant neurofibrillary tangles in the entorhinal cortex, hippocampus and neocortex (Hyman and Trojanowski, 1997).

\subsubsection{Treatment}

Currently available $\mathrm{AD}$ treatments only manage symptoms rather than target the underlying pathological processes of the disease. Four drugs are routinely prescribed to alleviate cognitive deficits: donepezil, rivastigmine, galantamine, and memantine. The use of these compounds is based on the impairments of the cholinergic and glutamatergic neurotransmitter systems that occur in AD.

A decrease in glutamatergic neurons and dysfunction of glutamatergic synapses were observed in early studies AD. (Mann et al., 1985; Greenamyre et al., 1985; Hardy et al., 1987). It was accordingly proposed that malfunctioning glutamatergic clearance mechanisms cause excitotoxic cell death in the AD brain (Greenamyre and Young, 1989; Francis, 2003). Memantine acts as a non-competitive N-methyl- D-aspartate (NMDA) receptor antagonist that blocks NMDA channels in a voltage-dependent manner. This blockage prevents glutamate-mediate excitotoxicity while still allowing for physiological NMDA receptor function (Chen et al., 1992; Parsons et al., 1993, 2007). Clinical studies have shown that memantine delays cognitive decline in patients with moderate to severe AD. It may provide further benefits when used in combination with the acetylcholinesterase inhibitors donepezil, rivastigmine or galantamine (Wilkinson and Andersen, 2007; Atri et al., 2008). 


\subsection{Neuropathology of Alzheimer's disease}

\subsubsection{Amyloid deposits}

Extracellular deposits of amyloid beta $(\mathrm{A} \beta)$ are one of the most prominent histopathological features of AD. These so-called amyloid plaques fall into two broad morphological categories: diffuse and neuritic (Fig. 1.1). Both plaque types are detectable with anti-A $\beta$ antibodies, but only neuritic plaques are prominently stained by $\beta$-sheet-binding dyes, such as Congo Red and Thioflavin S. A variety of pathological events occur in proximity to neuritic plaques; focal neuron and synapse loss, gliosis and neuritic dystrophies have all been reported (Lenders et al., 1989; Pike et al., 1995a; Masliah et al., 1990; Urbanc et al., 2002). Neuritic dystrophies are swollen and distorted processes of axonal or dendritic origin that radiate from the core of a neuritic plaque. They are detectable with antibodies against the amyloid precursor protein (APP), phospho-tau, neurofilaments and ubiquitin, indicating a disruption of protein transport and attempts to degrade this blockage (Dickson et al., 1990; Cras et al., 1991; Su et al., 1993; Dickson et al., 1999).
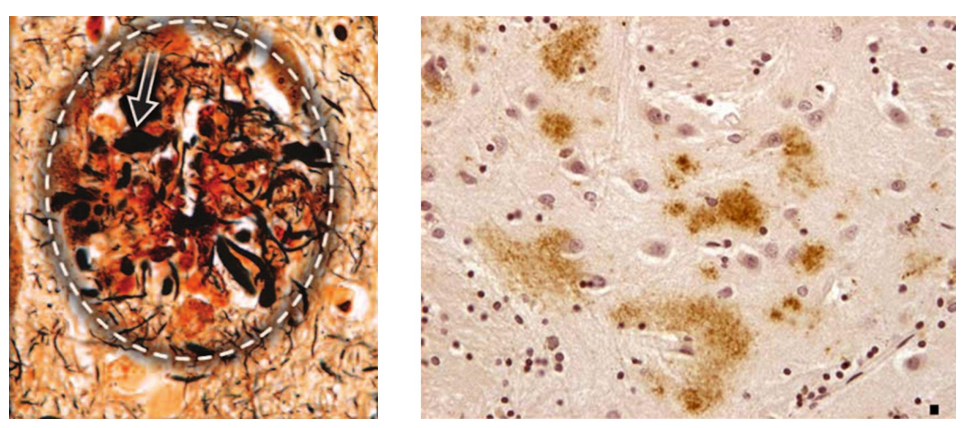

FiguRE 1.1:

Amyloid plaques. (Left) An example of a silver-stained neuritic plaque containing dystrophic neurites (arrow). Adapted from (Holtzman et al., 2011a). (Right) A diffuse amyloid plaque visualized by immunohistochemistry. Adapted from (Duyckaerts et al., 2009).

Progressive neuritic plaque deposition is a hallmark of AD. Neuritic plaque formation commonly begins in the neocortex and later affects the hippocampus and amygdala. By the end stage of the disease, neuritic plaques are present in the brainstem and other subcortical structures (Arnold et al., 1991; Thal et al., 2002). Predominantly diffuse plaques are found in cognitively normal aged individuals. It has therefore been suggested that a substantial increase in plaque burden is associated with the preclinical stages of AD (Dickson et al., 1992; Knopman et al., 2003; Vlassenko et al., 2011). However, plaque load ultimately correlates poorly with cognitive decline and dementia severity (Arriagada et al., 1992; Giannakopoulos et al., 2003; Villemagne et al., 2011). 


\subsubsection{Neurofibrillary tangles}

Neurofibrillary tangles (NFTs) are another primary feature of AD histopathology (Fig. 1.2). Alois Alzheimer first described NFTs as intraneuronal, filamentous aggregates in the perikarya and processes of neurons (Alzheimer, 1907). Over 50 years later, it was discovered that these inclusions consist of paired helical filaments (PHFs), pairs of 10-nmdiameter fibrils wound into a helical structure (Kidd, 1963). Later studies revealed that PHFs are composed of hyperphosphorylated, insoluble tau (Grundke-Iqbal et al., 1986; Lee et al., 1991).

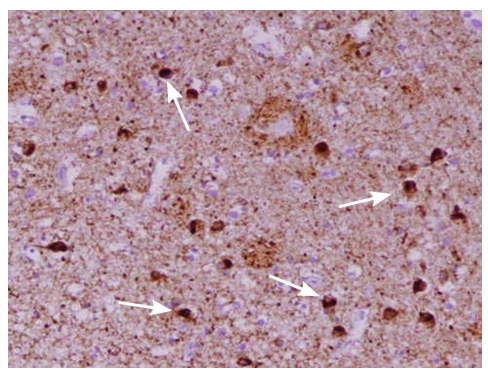

FiguRE 1.2: Neurofibril-
lary tangles. Neurofib-
rillary tangles (arrows) vi-
sualized by immunostain-
ing with an anti-tau anti-
body. Adapted from (Brun-
den et al., 2009).

Tau is a microtubule assembly factor and a member of the microtubule-associated protein (MAP) family (Weingarten et al., 1975; Witman et al., 1976). Its expression is highest in the nervous system, where it mainly localizes to neuronal axons (Trojanowski et al., 1989; Gu et al., 1996). The gene encoding tau is found on chromosome 17 and consists of 16 exons (Neve et al., 1986). Six major tau isoforms are expressed in the human central nervous system (CNS), and they result from the alternative splicing of exons 2, 3, and 10 of the tau transcript (Goedert et al., 1989; Lee et al., 1989).

A critical function of neuronal tau is microtubule stabilization (Drechsel et al., 1992; Gustke et al., 1994). Tau phosphorylation reduces its microtubule binding ability and promotes its assembly into PHFs (Alonso et al., 1996, 2001). To date, several kinases are known to phosphorylate tau at its multiple serine or threonine phosphorylation sites. They include glycogen synthase kinase 3 (GSK-3), cyclin-dependent kinase 5 (Cdk5) and mitogen-activated protein kinase (MAPK) (Drewes et al., 1992; Mandelkow et al., 1992; Baumann et al., 1993).

Despite many recent insights into tau biology, the precise mechanisms through which tau contributes to AD pathogenesis remain to be clarified. Nevertheless, the stereotypical progression of NFTs is a mainstay for the diagnosis and staging of AD (Arnold et al., 1991; Braak and Braak, 1991). Unlike neuritic plaque burden, NFT abundance strongly correlates with the severity of cognitive deficits and the duration of illness (Arriagada et al., 1992; Gómez-Isla et al., 1997). 


\subsubsection{Brain atrophy}

Cortical atrophy is the most obvious macroscopic characteristic of AD brain (Fig. 1.3). Decreased temporal lobe volume and ventricular dilation are present early in the disease course (Nestor et al., 2008; Bakkour et al., 2009; Dickerson et al., 2011). Neuron loss is the primary cause of these atrophic changes, and it occurs in a region-specific manner. Among other areas, reduced neuronal numbers have been documented in the entorhinal cortex, CA1 region of the hippocampus, nucleus basalis of Meynert and locus coeruleus (Arendt et al., 1983; West et al., 1994; Gomez-Isla et al., 1996; Busch et al., 1997). The cause of neuron death in $\mathrm{AD}$ is presently debated. Early studies found variable correlations between neuron loss and the presence of NFTs (Cras et al., 1995; Gómez-Isla et al., 1997). Contradicting findings were also reported regarding the prevalence of apoptotic markers in AD brain (Troncoso et al., 1996; Selznick et al., 1999). More recent evidence suggests that intraneuronal and/or oligomeric $\mathrm{A} \beta$ might be key mediators of neurotoxicity and cell death (Bayer and Wirths, 2010; Larson and Lesné, 2011).

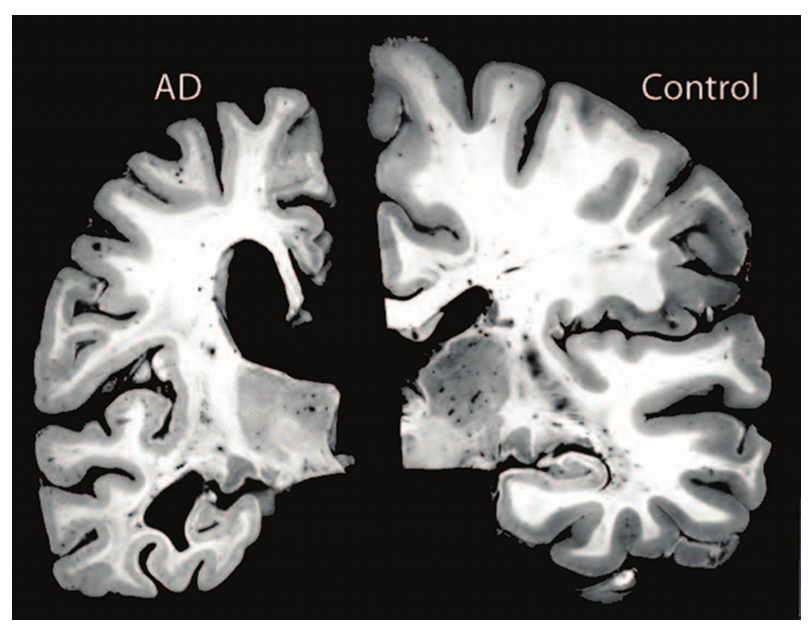

Figure 1.3: Brain atrophy in AD. A comparison of postmortem brain sections from an $\mathrm{AD}$ patient (left) and a cognitively normal individual (right) reveals the severe brain atrophy accompanying AD. Adapted from (Holtzman et al., 2011b).

Synapse loss also contributes to brain atrophy in AD. Alterations in synaptic density are believed to be a product of neurodegenerative events rather than normal aging (Scheff et al., 2001). Decreases in synaptic number serve as early indicators of AD pathological processes, and they occur in brain regions that later experience neuron loss. In support of this notion, it was recently shown that individuals with mild AD have significantly fewer synapses in the hippocampal CA1 region than both MCI patients and healthy controls (Scheff et al., 2007). A direct correlation between the degree of synapse loss and the severity of dementia has also been proposed (Ingelsson et al., 2004). In fact, decreased synaptic density correlates better with cognitive decline than either neuron loss or NFTs (Terry et al., 1991; DeKosky and Scheff, 1990; Ingelsson et al., 2004). 


\subsubsection{Microglia and astrocyte activation}

Activated microglia and astrocytes associate with neuritic but not diffuse amyloid deposits in AD brain (Fig. 1.4) (Pike et al., 1995a; Itagaki et al., 1989). Studies using transgenic AD mouse models demonstrated that microglia are attracted to and readily interact with new amyloid deposits (Meyer-Luehmann et al., 2008; Koenigsknecht-Talboo et al., 2008). In vitro experiments suggested that such interactions with $\mathrm{A} \beta$ promote a proinflammatory profile (Lue et al., 2001; Walker et al., 2001; Colton, 2009). Further in vitro work involving microglia cultured on $\mathrm{AD}$ brain sections revealed the ability of these cells to remove amyloid (Bard et al., 2000). However, the capacity of microglia to effectively degrade A $\beta$ has been questioned (Paresce et al., 1997; Majumdar et al., 2007).

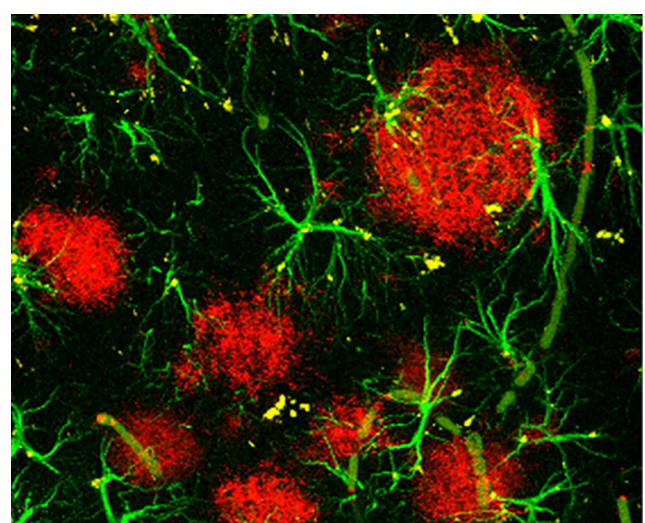

Figure 1.4: Gliosis in AD. Double-labeling of AD brain sections reveals activated astrocytes (green, anti-GFAP antibody) surrounding amyloid plaques (red, anti-A $\beta$ antibody). Adapted from (Verkhratsky et al., 2010).

Recent experiments showed that plaque-associated astrocytes endocytose and degrade A $\beta$ (Nagele et al., 2003; Wyss-Coray et al., 2003). A $\beta$ disrupts astrocytic calcium homeostasis, resulting in increased expression of glial fibrillary acidic protein (GFAP), a marker for astrocyte activation and neurodegeneration (Abramov et al., 2004; Chow et al., 2010). Astrocytes exposed to $\mathrm{A} \beta$ oligomers were also revealed to contribute to neuron death (Abdul et al., 2009).

\subsection{The amyloid precursor protein}

The similarities between AD and Down Syndrome (DS) brain pathology spurred genetic studies that eventually linked an FAD mutation to the DS region of chromosome 21 (St George-Hyslop et al., 1987; Tanzi et al., 1987). Isolation of the defective gene resulted in the discovery of APP, a single transmembrane glycoprotein with its carboxy-terminus oriented toward the cytosol (Kang et al., 1987; Dyrks et al., 1988).

APP is a member of an evolutionarily conserved gene family with two mammalian homologs, amyloid precursor-like proteins (APLP) 1 and 2 (Wasco et al., 1992, 1993). 


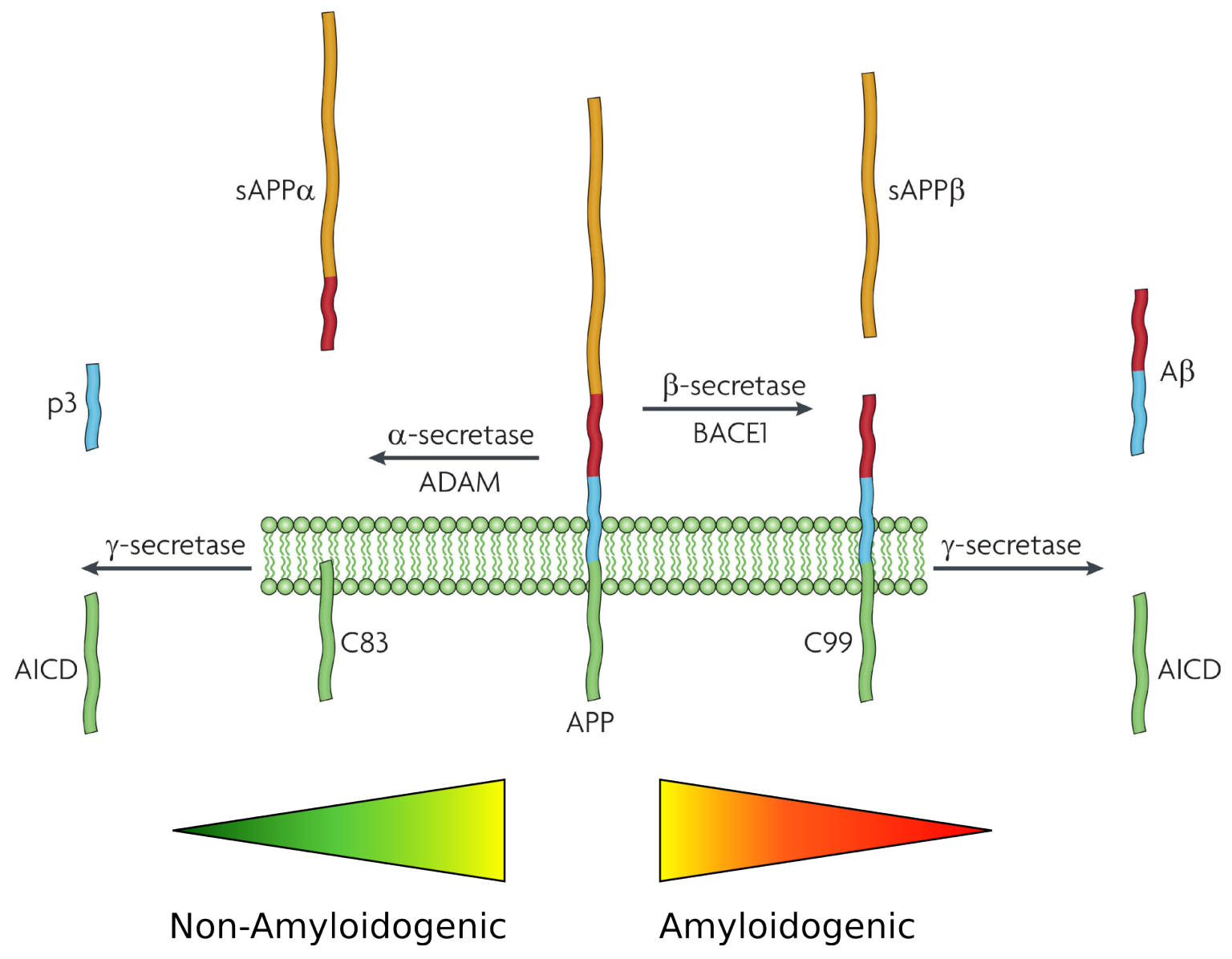

Figure 1.5: APP processing. In non-amyloidogenic processing (left), APP is sequentially cleaved by $\alpha$-secretase and $\gamma$-secretase to release the p3 fragment. Amyloidogenic processing (right) initiates with BACE1 cleavage of APP. Subsequent cleavage by $\gamma$-secretase releases the $\mathrm{A} \beta$ peptide. Adapted from (Thathiah and De Strooper, 2011).

These proteins contain highly similar sequences in their ectodomains and intracellular carboxy-termini, but the transmembrane region comprising the $\mathrm{A} \beta$ peptide is unique to APP (Bayer et al., 1999). Although its primarily physiological function remains unclear, APP has been implicated in a variety of processes, such as intracellular signaling, synapse adhesion, trophic support, axon remodeling and and apoptosis (Zheng and Koo, 2011). Interestingly, knockout (KO) experiments suggested there is some functional redundancy between APP and APLP1/2. APP KO mice are viable and fertile, although lower body weight, increased gliosis, reduced locomotor activity and cognitive impairment have been reported (Zheng et al., 1995; Dawson et al., 1999).

APP is ubiquitously expressed. There are three major APP isoforms resulting from alternative splicing of its 18 exon gene: APP695, APP751 and APP770 (Kang et al., 
1987; Kitaguchi et al., 1988; Tanzi et al., 1988; Yoshikai et al., 1990). APP751/770 are the main transcripts found in non-neuronal tissue (Kitaguchi et al., 1988). APP695 is the most abundant isoform in the brain, where its expression is primarily limited to neurons (Sola et al., 1993). Brain region-specific variation in APP695 expression occurs in both mouse and human, with the highest transcript levels found in the cortex, hippocampus and cerebellum (Sola et al., 1993)

Intracellularly, APP is found within the perikarya, dendrites and axons of neurons. Trafficking of APP to presynaptic compartments involves anterograde fast axonal transport (Koo et al., 1990). After synthesis in the endoplasmic reticulum (ER), APP undergoes a variety of posttranslational modifications prior to reaching the plasma membrane. Glycosylation occurs as APP transits from the ER into the Golgi, and this processes regulates its maturation and secretory trafficking (Weidemann et al., 1989; Tomita et al., 1998). Most APP is retained in the Golgi network under basal conditions. However, a small percentage of APP is transported to the plasma membrane where it is rapidly internalized if proteolytic processing does not occur (Thinakaran and Koo, 2008). Endocytosed APP is trafficked into endosomes where it is either recycled to the cell surface or undergoes lysosomal degradation (Haass et al., 1992b). Furthermore, phosphorylation of APP on its cytoplasmic domain can influence its trafficking, interaction with binding partners and proteolytic processing (Suzuki and Nakaya, 2008).

\subsubsection{Non-amyloidogenic processing of the amyloid precursor protein}

APP is processed via two major pathways that utilize different enzymes and result in distinct cleavage products. The non-amyloidogenic pathway precludes the formation of $\mathrm{A} \beta$ due to constitutive $\alpha$-secretase-mediated cleavage in the middle of the $\mathrm{A} \beta$ domain (Fig. 1.5, left) (Esch et al., 1990; Sisodia et al., 1990). It was initially proposed that a zinc-dependent, transmembrane protease served as $\alpha$-secretase (Roberts et al., 1994). Three members of the a disintegrin and metalloproteinase (ADAM) family were later found to possess $\alpha$-secretase activity: ADAM-10, ADAM-17, ADAM-9 (Buxbaum et al., 1998; Koike et al., 1999; Lammich et al., 1999). More recent evidence, though, suggests that ADAM-10 serves as the primary $\alpha$-secretase in neurons (Kuhn et al., 2010).

Alpha-cleavage of APP occurs mainly at the plasma membrane. It releases a soluble $\alpha$-APP fragment ( $\mathrm{APP} \alpha)$ into the lumen/extracellular space and creates a membranebound, 83-residue C-terminal fragment (C83) (Sisodia, 1992). Subsequent intramembranous cleavage of C83 by $\gamma$-secretase liberates a soluble, 3 kilodalton (kDa) fragment (p3) 
and the APP intracellular domain (AICD) (Zheng and Koo, 2011). The p3 fragment is rapidly degraded, while the AICD may act as a transcriptional regulator (Haass et al., 1993; Cao and Südhof, 2001; Gu et al., 2001).

\subsubsection{Amyloidogenic processing of the amyloid precursor pro- tein}

Recent evidence suggests that the amyloidogenic processing of APP primarily occurs in the endocytic pathway (Thinakaran and Koo, 2008). $\beta$-secretase initiates the sequence of amyloidogenic cleavage events (Fig. 1.5, right). Cleavage of APP at the $\beta$-site generates a soluble amino-terminal fragment $(\operatorname{sAPP} \beta)$ and a membrane-associated, 99-residue $\mathrm{C}$ terminal fragment (C99). $\gamma$-secretase then performs a stepwise, intramembrane cleavage of the $\mathrm{C} 99$ fragment, thereby liberating $\mathrm{A} \beta$ and the AICD. $\mathrm{A} \beta$ peptides range from 37 to 43 amino acids in length. However, under physiological conditions, the majority of $\mathrm{A} \beta$ produced is 40 amino acids long $\left(\mathrm{A} \beta_{1-40}\right)$. The 42 amino acid variant $\left(\mathrm{A} \beta_{1-42}\right)$ normally only comprises a minor fraction of the total A $\beta$ (Haass et al., 1992b; Citron et al., 1995; Zhang et al., 2011).

The $\beta$-site cleaving enzyme 1 (BACE1) was identified as the enzyme responsible for APP $\beta$-cleavage in 1999 (Hussain et al., 1999; Sinha et al., 1999; Vassar et al., 1999). BACE1 is a type 1 membrane-bound aspartyl protease with its active site facing the lumen. It is capable of cleaving APP at two positions: the aspartate at position 1 of the $\mathrm{A} \beta$ sequence or the glutamate at position 11 (Sinha et al., 1999; Vassar et al., 1999). Other BACE1 substrates include neuregulin 1 and voltage-gated sodium channels (Kim et al., 2005; Wong et al., 2005; Hu et al., 2006).

BACE1 is found in a variety of tissues, but it is predominantly expressed in neurons (Sinha et al., 1999; Vassar et al., 1999). Intracellularly, BACE1 mainly localizes to the trans-Golgi network and endosomes (Vassar et al., 1999; Capell et al., 2000; Lin et al., 2000). However, BACE1 is also trafficked between the Golgi and the plasma membrane, where it is enriched in lipid rafts (Huse et al., 2000; Riddell et al., 2001; Walter et al., 2001) From the plasma membrane, BACE1 is internalized and sorted into endosomes or recycled to the trans-Golgi network (Walter et al., 2001). The acidic environment of early endosomes favors the $\beta$-cleavage of APP and production of $\mathrm{A} \beta$ since BACE1 functions optimally at a low pH (Vassar et al., 1999; He et al., 2005; Wahle et al., 2005). This phenomenon explains the accumulation of C99 fragments in endosomes when endosomal/lysosomal proteolysis is inhibited (Golde et al., 1992; Haass et al., 1992a). In fact, $\mathrm{BACE} 1$ serves as the primary $\beta$-secretase and is the rate-limiting enzyme in $\mathrm{A} \beta$ pro- 
duction. Genetic KO of BACE1 in primary neuronal cultures or in AD transgenic mice effectively prevents A $\beta$ generation (Cai et al., 2001; Luo et al., 2003; Ohno et al., 2007).

There are currently four known components of $\gamma$-secretase: presenilin (PS1 or PS2), nicastrin, anterior pharynx defective 1 (APH1) and presenilin enhancer 2 (PEN-2). These proteins assemble into the $\gamma$-secretase complex while cycling through the ER/Golgi (Edbauer et al., 2003; Kimberly et al., 2003; Takasugi et al., 2003; De Strooper and Annaert, 2010). Once mature, $\gamma$-secretase is primarily found at the plasma membrane and in the endosomal/lysosomal system (De Strooper and Annaert, 2010). Although PS, nicastrin, APH1 and PEN-2 are all required for $\gamma$-secretase activity, PS contains the catalytic active site needed for $\gamma$-cleavage of APP (Esler et al., 2000; Li et al., 2000; Edbauer et al., 2003; Kimberly et al., 2003; Takasugi et al., 2003). In addition to APP, several other $\gamma$-secretase substrates are known, including Notch, cadherins, CD44 and neuregulin (De Strooper and Annaert, 2010).

Although $\mathrm{A} \beta$ was first recognized for its pathogenic role in $\mathrm{AD}$, in vitro studies eventually established it as a normal metabolic product (Haass et al., 1992b; Shoji et al., 1992). The physiological function of $\mathrm{A} \beta$, however, remains largely unknown. $\mathrm{A} \beta$ has been observed to modulate synaptic function in a concentration-dependent manner. Administration of low picomolar amounts of $\mathrm{A} \beta_{1-42}$ enhances long-term potentiation (LTP) in hippocampal slice cultures, while a higher nanomolar dose of $\mathrm{A} \beta_{1-42}$ impairs LTP. Accordingly, infusion of picomolar concentrations of $\mathrm{A} \beta_{1-42}$ into the mouse hippocampus facilitated learning in the Morris water maze and contextual fear conditioning paradigms (Puzzo et al., 2008). Later in vivo work in mice demonstrated that $\mathrm{A} \beta$ levels in brain interstitial fluid vary proportionally with neuronal activity, both during the natural sleepwake cycle and when the perforant pathway is directly stimulated (Cirrito et al., 2005; Kang et al., 2009). Taken together, these data suggest an important function for A $\beta$ in normal cognitive processes.

\subsection{Genetics}

Most AD cases occur after the age of 65 and are classified as late-onset AD (LOAD). Although the precise cause of LOAD is unknown, genetics are believed to account for over $60 \%$ of LOAD susceptibility (Gatz et al., 2006). The strongest genetic risk factor for LOAD is the $\varepsilon 4$ allele of apolipoprotein $\mathrm{E}$ (ApoE). ApoE comes in three variants $(\varepsilon 2$, $\varepsilon 3, \varepsilon 4)$ and serves as a major lipoprotein carrier within the CNS. Linkage analysis studies initially revealed associations between markers on chromosome 19 and LOAD (PericakVance et al., 1991). Later work identified $A p o E$ on this chromosome and highlighted its 
abilities to bind A $\beta$ (Strittmatter et al., 1993). The Apoc 4 variant was found to raise the risk for developing LOAD (Corder et al., 1993), with heterozygous Apoc 4 carriers being three times more likely to develop AD than non-carriers (Farrer et al., 1997). In contrast, Apo\&2 is protective against LOAD (Chartier-Harlin et al., 1994).

Aside from $A p o E$, recent genome-wide association studies have described gene variants that increase the risk of developing AD by a much smaller extent. These gene products are affiliated with processes as diverse as immune system function (complement receptor 1, CR1), endocytosis/cell membrane dynamics (phosphatidylinositol-binding clathrin assembly protein, PICALM) and lipid processing (clusterin, CLU) (Harold et al., 2009; Lambert et al., 2009; Hollingworth et al., 2011; Naj et al., 2011).

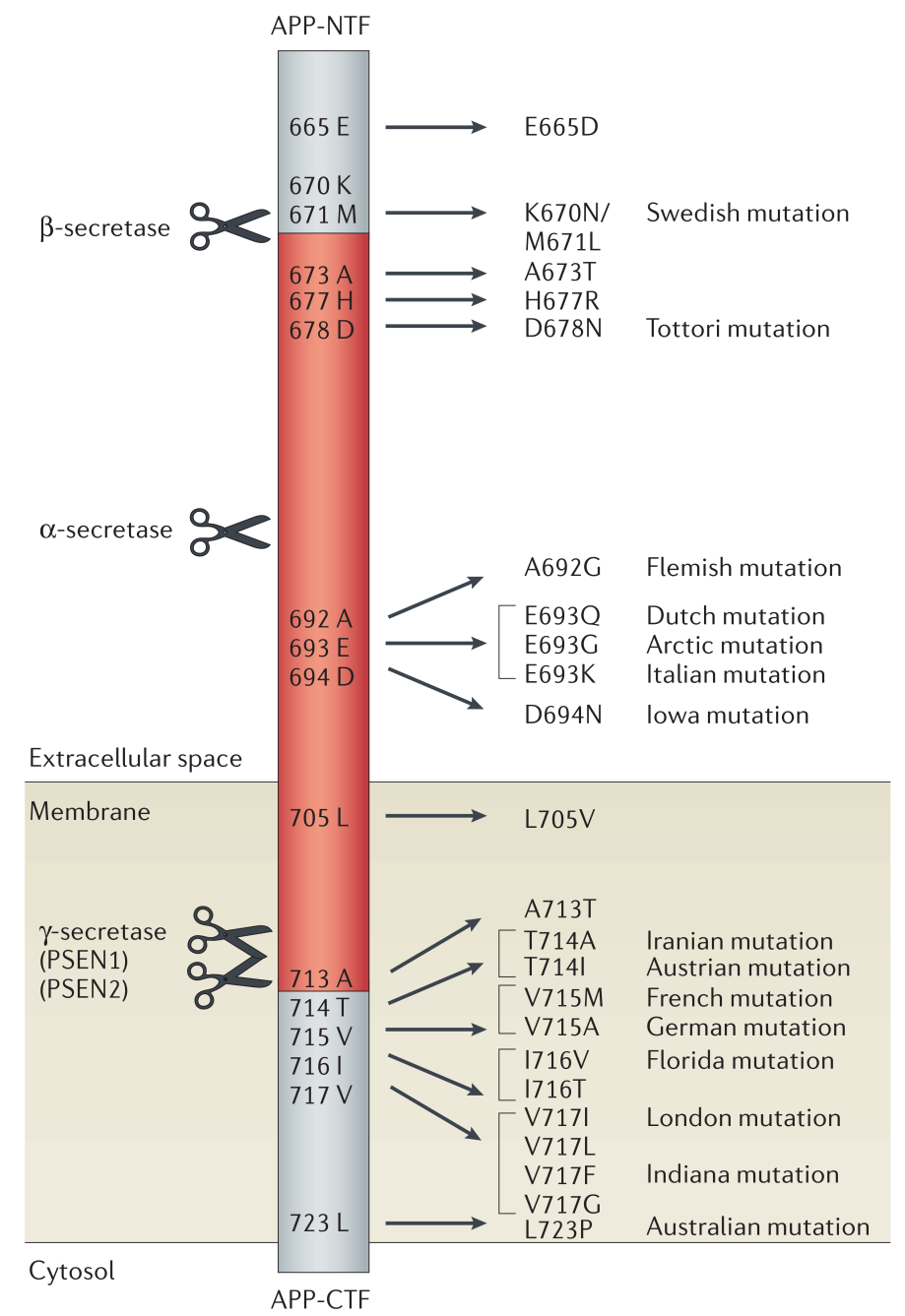

Figure 1.6: $\quad$ APP mutations in AD. A diagram of some of the APP mutations associated with FAD. Mutations near the $\beta$-secretase cleavage site increase overall $\mathrm{A} \beta$ production, while mutations near the $\alpha$-secretase site inhibit $\alpha$-secretase cleavage and/or increase $\mathrm{A} \beta$ aggregation. Increased production of $\mathrm{A} \beta_{x-42}$ or elevation of the $\mathrm{A} \beta_{x-42} / \mathrm{A} \beta_{x-40}$ ratio results from mutations near the $\gamma$-secretase cleavage site. Adapted from (Van Dam and De Deyn, 2006).

Early-onset AD (EOAD) manifests before the age of 65 and accounts for $5-10 \%$ of all AD diagnoses. Approximately half of the individuals suffering from EOAD have at 
least one affected first-degree relative. Autosomal-dominant inheritance of AD, referred to as familial AD (FAD), comprises roughly 10\% of the remaining EOAD cases (Campion et al., 1999). All instances of FAD identified thus far are linked to mutations in proteins involved in the generation of $\mathrm{A} \beta$ (see Section 1.3.2). Genetic analysis of families afflicted with FAD found associations with markers on chromosomes 21, 14 and 1 (Goate et al., 1989; Schellenberg et al., 1992; Levy-Lahad et al., 1995b). The point mutations on these chromosomes were later mapped onto the APP, PS1 and PS2 genes, respectively (Goate et al., 1991; Levy-Lahad et al., 1995a; Rogaev et al., 1995; Sherrington et al., 1995).

To date, 32 FAD-associated mutations have been identified in the APP gene (Fig.1.6) (Cruts and Brouwers, 1999). Most APP mutations occur in proximity to secretase cleavage sites (see Section 1.3.2), thereby affecting the absolute amounts or relative proportions of $\mathrm{A} \beta$ isoforms produced. The first FAD-linked $A P P$ missense mutation was discovered in a British kindred, subsequently earning it the moniker the "London" mutation (Goate et al., 1991). This mutation (APPV717I) alters $\gamma$-secretase cleavage and increases the ratio of $\mathrm{A} \beta_{x-42}$ to $\mathrm{A} \beta_{x-40}$ without impacting total $\mathrm{A} \beta$ production (Suzuki et al., 1994a). The Florida mutation (APP1716V) elevates $\mathrm{A} \beta_{x-42}$ levels in a similar manner. APP mutations near the $\beta$-secretase cleavage site, such as the Swedish mutation (APPK670N/M671L), produce greater overall $\mathrm{A} \beta$ levels by augmenting liberation of the $\mathrm{A} \beta$ N-terminus (Citron et al., 1992; Mullan et al., 1992; Cai et al., 1993). Alternatively, mutations near the central portion of the $\mathrm{A} \beta$ sequence, like the Flemish (APPA692G) and Arctic (APPE693G) mutations, can have several consequences: they can impair the APP cleavage events that preclude $\mathrm{A} \beta$ formation and/or alter $\mathrm{A} \beta$ aggregation properties, thereby enhancing oligomer/protofibril generation (see Sections 1.3.1 and 1.5.1) (Hendriks et al., 1992; Haass et al., 1994; Kamino et al., 1992; Stenh et al., 2002).

Presenilin mutations account for most FAD cases (Cruts and Van Broeckhoven, 1998). Presently, 182 PS1 and 13 PS2 mutations have been identified (Cruts and Brouwers, 1999). PS1 and PS2 mutations usually occur as missense mutations in exon 8, where residues are conserved between the two proteins (Perez-Tur et al., 1996; Crook et al., 1997). The primary result of these mutations is an increased ratio of $\mathrm{A} \beta_{x-42}$ to $\mathrm{A} \beta_{x-40}$ (Citron et al., 1997). This change is achieved by either raising $\mathrm{A} \beta_{x-42}$ production, lowering $\mathrm{A} \beta_{x-40}$ production or a combination of both (Scheuner et al., 1996; Kumar-Singh et al., 2000). 


\subsection{The amyloid hypothesis}

The amyloid hypothesis has been an important tenet guiding AD research for over 20 years. It states that the deposition of $\mathrm{A} \beta$ is the causative event leading to the NFTs, neuron loss, vascular damage and cognitive deficits associated with AD (Hardy and Allsop, 1991). Various observations support this theory. For example, duplication or mutations in $\mathrm{APP}$ and PS1, two proteins responsible for the production of $\mathrm{A} \beta$, alters $\mathrm{A} \beta$ levels, thereby leading to FAD (Rovelet-Lecrux et al., 2006; Bertram et al., 2010). Transgenic mouse models that express FAD-linked mutations replicate multiple aspects of AD pathology, such as gliosis, age-dependent plaque deposition and cognitive deficits (Duyckaerts et al., 2008). Furthermore, DS patients with a triplication of the APP gene locus on chromosome 21 develop amyloid plaques and NFTs characteristic of AD brain (Wisniewski et al., 1985). Additionally, Apos4, the major genetic risk factor for LOAD, is linked with increased deposition and reduced clearance of $\mathrm{A} \beta$ (Strittmatter et al., 1993; Kim et al., 2009). Mutations in tau, on the other hand, cause tauopathies like frontotemporal dementia rather than AD (Hutton et al., 1998; Spillantini et al., 1998). This suggests that NFTs are a consequence of $\mathrm{A} \beta$ aggregation and not responsible for initiating $\mathrm{AD}$ pathological cascades.

Several of the major flaws in the amyloid hypothesis were highlighted by autopsy studies of AD patients and healthy controls. There is a poor link between the degree of amyloid deposition and both the duration of illness and the cognitive status of people with AD (Arnold et al., 1991; Arriagada et al., 1992). Cognitively normal individuals can also possess massive plaque pathology, despite never showing signs of dementia during life (Snowdon, 2003). Although some patients involved in the clinical trial of the anti-A $\beta$ active vaccine AN1792 had massively reduced cortical plaque burden, cognitive testing revealed no long-term improvements in mental status (Holmes et al., 2008). As a result of these and other observations, revisions to the amyloid hypothesis have been proposed.

\subsubsection{Soluble amyloid hypothesis}

The formation of insoluble, plaque-forming amyloid fibrils from soluble, $4 \mathrm{kDa} \mathrm{A} \beta$ monomers is admittedly complex. Monomeric $\mathrm{A} \beta$ has been shown to transition through a variety of intermediate aggregation states before reaching fibrillar form, including dimers, trimers and higher-order aggregates larger than $100 \mathrm{kDa}$ (Fig. 1.7) (Benilova et al., 2012). Broadly speaking, these prefibrillar aggregates are classified as oligomers: soluble $\mathrm{A} \beta$ assemblies that do not precipitate from solution following high-speed centrifugation (Haass and Selkoe, 2007). 


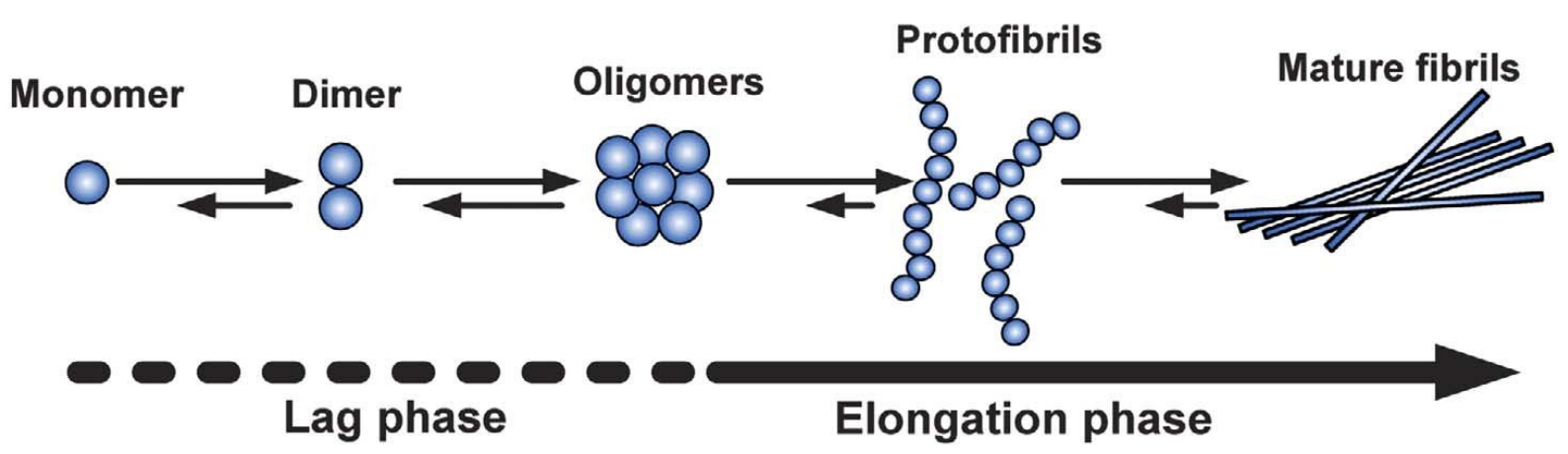

Figure 1.7: A schematic of $\mathbf{A} \beta$ aggregation. $\mathrm{A} \beta$ monomers slowly accumulate to form oligomers during the "lag phase"(dashed line). Once assembled, oligomeric nuclei promote protofibril formation in the "elongation phase" (solid line). Protofibrils then aggregate to create mature amyloid fibrils. Adapted from (Kumar et al., 2011).

Considerable experimental evidence emphasizes the contribution of soluble/oligomeric $\mathrm{A} \beta$ to $\mathrm{AD}$ pathogenesis. Sodium dodecyl sulfate (SDS)-stable $\mathrm{A} \beta$ dimers were isolated during some of the earliest analyses of amyloid plaques (Masters et al., 1985b; McLean et al., 1999). Furthermore, levels of soluble $\mathrm{A} \beta$ were found to correlate strongly with synaptic loss and disease severity in AD patients (Lue et al., 1999; McLean et al., 1999). Studies utilizing AD model systems also lend support to a pathogenic role for soluble A $\beta$. Several transgenic AD mouse lines display deficits in cognition or altered synaptic structure prior to the formation of A $\beta$ plaques (Holcomb et al., 1998; Hsia et al., 1999; Mucke et al., 2000). In addition, SDS-stable dimers derived from the microsomes of APPV714E transfected cells were shown to block LTP in hippocampal slice cultures (Walsh et al., 2002). These findings subsequently prompted a reappraisal of the amyloid hypothesis to account for soluble $\mathrm{A} \beta$ species in $\mathrm{AD}$ neurodegenerative processes (Hardy and Selkoe, 2002).

Recent work has further clarified the potential pathophysiological effects of soluble $\mathrm{A} \beta$. Examination of the plaque-proximal neuropil in AD transgenic mice using array tomography revealed that local plaque toxicity might result from oligomers (Koffie et al., 2009). In vitro, human-derived $\mathrm{A} \beta$ dimers were shown to damage the neuronal cytoskeleton in a tau-dependent manner (Jin et al., 2011). Ultimately, the various effects of soluble A $\beta$ on neuronal networks may help to explain the deficits present in AD (Palop and Mucke, 2010). 


\subsubsection{Intraneuronal amyloid hypothesis}

Intraneuronal $\mathrm{A} \beta$ was reported in some of the earliest immunohistochemical studies of $\mathrm{AD}$ brain. $\mathrm{A} \beta$ was found in close association with tangle-bearing neurons (Masters et al., 1985a; Grundke-Iqbal et al., 1989). However, the antibodies used to detect this immunoreactivity cross-reacted with tau or lipofuscin, thus calling into question the original observations (Gouras et al., 2010). Subsequent development of C-terminal specific antibodies enabled $\mathrm{A} \beta_{x-40}$ and $\mathrm{A} \beta_{x-42}$ to be unambiguously distinguished from $\mathrm{APP}$ and its other cleavage products (Iwatsubo et al., 1994). Later work implementing A $\beta$-specific antibodies confirmed the presence of intraneuronal $\mathrm{A} \beta$ in $\mathrm{AD}$ brain. Using laser-capture microdissection combined with ELISA, an increased $\mathrm{A} \beta_{x-42} / \mathrm{A} \beta_{x-40}$ ratio was observed in the CA1 pyramidal neurons and Purkinje neurons of AD patients relative to controls (Aoki et al., 2008; Hashimoto et al., 2010). Another biochemical study employed a sequential extraction protocol to enrich $\mathrm{A} \beta$ from different cellular compartments of AD cortical neurons. It was then demonstrated that levels of intracellular/membrane-associated $\mathrm{A} \beta_{x-42}$ corresponded best with dementia severity prior to death (Steinerman et al., 2008). Immunohistochemistry identified prominent intraneuronal $\mathrm{A} \beta$ in brain regions and cell types susceptible to AD pathology before the development of extensive neuritic plaques or PHFs (Gouras et al., 2000; Cataldo et al., 2004; Fernández-Vizarra et al., 2004). Decreased intraneuronal $\mathrm{A} \beta$ equated with increased plaque pathology, suggesting a role in extracellular plaque development (Gouras et al., 2000; Cataldo et al., 2004; Fernández-Vizarra et al., 2004). An intracellular origin for amyloid plaques was further substantiated by recent in vitro studies. Cell culture experiments revealed that uptake of extracellular $\mathrm{A} \beta$ into the endosomal/lysosomal system is sufficient to promote $\mathrm{A} \beta$ aggregation and the release of seeds capable of inducing additional A $\beta$ fibrillization (Hu et al., 2009; Friedrich et al., 2010).

In vitro and in vivo model systems have further elucidated the contribution of intraneuronal A $\beta$ to AD. Studies using neuronally-differentiated NT2 cells (NT2N) confirmed the presence of intracellular A $\beta$ in vitro. NT2N cells were shown to constitutively produce intracellular $\mathrm{A} \beta$ and secrete greater amounts of $\mathrm{A} \beta$ extracellularly as the cultures aged (Wertkin et al., 1993; Turner et al., 1996). The majority of this intracellular A $\beta$ consisted of a pool of insoluble $\mathrm{A} \beta_{1-42}$ that accumulated in a time-dependent manner (Skovronsky et al., 1998). Experiments employing primary neuronal cultures have shown that intraneuronal $\mathrm{A} \beta$ localizes to endosomes, lysosomes and multivesicular bodies (MVBs), regions where oligomerization can occur (Runz et al., 2002; Takahashi et al., 2004; Almeida et al., 2006).

The presence of intraneuronal $\mathrm{A} \beta$ in these compartments can lead to a variety of con- 
The Modified $\beta$-Amyloid Cascade

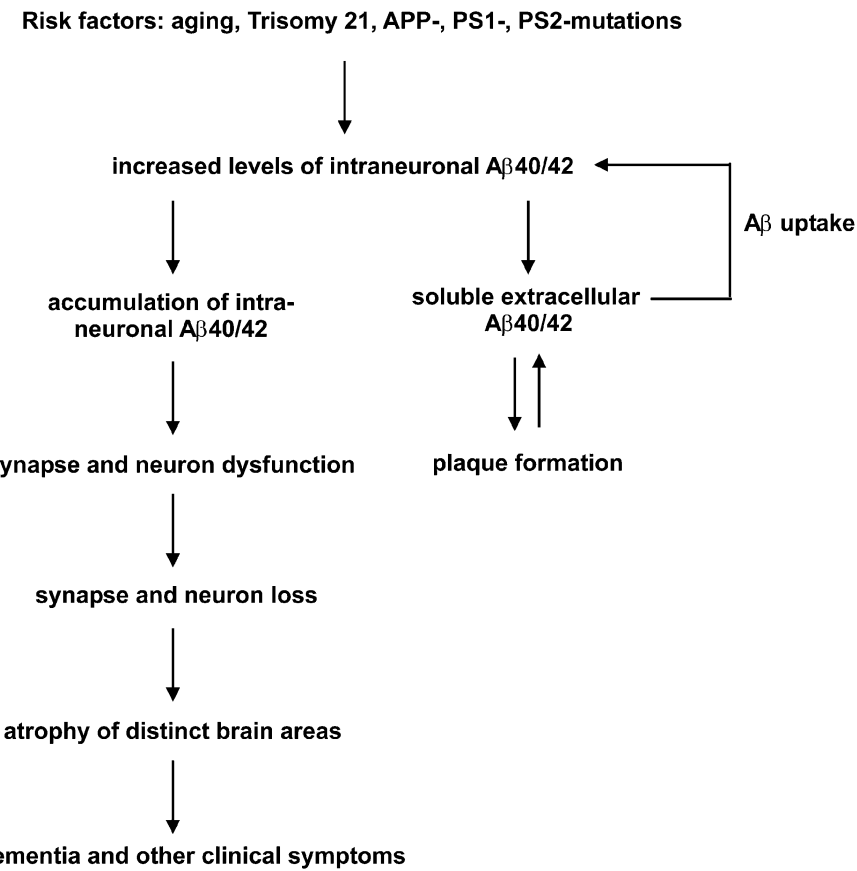

Figure 1.8: A diagram illustrating the intraneuronal A $\beta$ hypothesis. Taken from (Wirths et al., 2004).

sequences. Accumulation of $\mathrm{A} \beta$ in neuronal MVBs caused abnormal neuronal processes, impaired MVB sorting and deficits in the ubiquitin/proteasome system in Tg2576 mice (Takahashi et al., 2002; Almeida et al., 2006). Additionally, exogenously applied A $\beta$ was able to insert into endosomal/lysosomal membranes and cause lysosomal leakage in both neuronal and non-neuronal cells, potentially contributing to cell death (Ditaranto et al., 2001; Liu et al., 2010). In line with this, neuron loss in a number of AD mouse models occurs in regions with prominent intraneuronal $\mathrm{A} \beta$ accumulation (Casas et al., 2004; Christensen et al., 2008, 2010; Jawhar et al., 2012).

Intraneuronal $\mathrm{A} \beta$ can potentially originate from two sources: intracellular processing of $\mathrm{APP}$ and retention of $\mathrm{A} \beta$ or reuptake of secreted $\mathrm{A} \beta$ from the extracellular space. As mentioned earlier, $\mathrm{A} \beta$ is primarily generated in the endocytic pathway (Thinakaran and Koo, 2008). Theoretically, the compact space and acidic environment of endosomes/lysosomes could promote $\mathrm{A} \beta$ aggregation and cause it to remain intraneuronally. Conversely, it may be necessary for $\mathrm{A} \beta$ to be collected from the extracellular space before intraneuronal $\mathrm{A} \beta$ aggregates form. Thus far, several receptors have been proposed to mediate the reuptake of $\mathrm{A} \beta$, including ApoE receptors, nicotinic acetylcholine receptors, NMDA receptors, integrins and receptors for advanced glycation end products (RAGE) (Mohamed and Posse de Chaves, 2011). However, which of these receptors, if any, is primarily responsible for 
intraneuronal $\mathrm{A} \beta$ accumulation remains to be determined.

In light of these findings, intraneuronal $\mathrm{A} \beta$ is considered to be a potentially key contributor to the development and progression of AD pathology (Fig. 1.8)(Wirths et al., 2004).

\subsection{Amyloid beta variants}

The first purification and sequencing of parenchymal amyloid deposits identified numerous $\mathrm{A} \beta$ species. These $\mathrm{A} \beta$ isoforms ranged from 39-to-43 amino acids in length, and they appeared to possess a variety N-termini in addition to the aspartate normally found at the first position of the $\mathrm{A} \beta$ peptide (Masters et al., 1985a; Selkoe et al., 1986; Mori et al., 1992; Roher et al., 1993b). Aside from truncated A $\beta$ species, amino acid modifications such as racemization of aspartate and serine residues, isomerization of aspartate residues, and pyroglutamate formation at the glutamate residues were also found (Shapira et al., 1988; Roher et al., 1993a; Mori et al., 1992). More recent work has added to the list of $\mathrm{A} \beta$ variants, with phosphorylated and nitrated $\mathrm{A} \beta$ being described (Kumar et al., 2011; Kummer et al., 2011).

Immunohistochemical characterization of amyloid aggregates subsequently verified these sequencing studies. $\mathrm{A} \beta_{1-40}$ was shown to be the major component of cerebral vascular amyloid deposits (Suzuki et al., 1994b). In contrast, neuritic plaques were found to consist mainly of $\mathrm{A} \beta_{1-42}$, a large portion of which was suggested to be pyroglutamatemodified at position 3 (Iwatsubo et al., 1994; Saido et al., 1995). Variations in the N- and C-terminal length of $\mathrm{A} \beta$ can have direct biological consequences. In vitro experiments demonstrated that $\mathrm{N}$-terminal truncation enhances $\mathrm{A} \beta$ aggregation relative to full-length $\mathrm{A} \beta$ peptides (Pike et al., 1995b). Similarly, A $\beta$ aggregation propensity increases with greater C-terminal length, with $\mathrm{A} \beta_{1-42}$ and $\mathrm{A} \beta_{1-43}$ acting as highly effective seeds for amyloid deposition (Burdick et al., 1992; Jarrett et al., 1993). Transgenic mouse studies corroborated these findings. Expression of additional $\mathrm{A} \beta_{1-42}$ in $\operatorname{Tg} 2576$ mice enhanced pathology, while expression of $\mathrm{A} \beta_{1-40}$ reduced $\mathrm{A} \beta$ deposition and alleviated the premature death phenotype (McGowan et al., 2005; Kim et al., 2007). In addition, mice that overproduce $\mathrm{A} \beta_{1-43}$ exhibit memory deficits and accelerated amyloid pathology (Saito et al., 2011).

A recent paper by Portelius and colleagues newly emphasizes the myriad of $\mathrm{A} \beta$ isoforms found in AD brain. Using immunoprecipitation followed by mass spectrometry (IP/MS), they analyzed cortical, cerebellar and hippocampal tissue from healthy individuals, LOAD and FAD patients. In agreement with previous observations, $\mathrm{A} \beta_{1-42}$ was 
identified as a dominant $\mathrm{A} \beta$ species in $\mathrm{AD}$ brain. Interestingly, $\mathrm{A} \beta_{1-42}$ with a pyroglutamate modification at position $3\left(\mathrm{~A} \beta_{p E 3-42}\right)$ and $\mathrm{A} \beta_{4-42}$ were also found to be prominent isoforms (Portelius et al., 2010). Most research performed to date has focused on the contributions of $\mathrm{A} \beta_{1-40}$ and $\mathrm{A} \beta_{1-42}$ to $\mathrm{AD}$ pathology. Importantly, the work of Portelius et al. highlights how other understudied $\mathrm{A} \beta$ variants, such as $\mathrm{A} \beta_{p E 3-42}$ and $\mathrm{A} \beta_{4-42}$, might be significant contributors to the development and progression of $\mathrm{AD}$.

\subsection{Pyroglutamate-modified amyloid beta}

N-terminally modified $\mathrm{A} \beta$ initially confounded some of the first attempts to purify and sequence $\mathrm{AD}$ amyloid cores. Masters and colleagues reported that the majority of $\mathrm{A} \beta$ peptides isolated from the amyloid plaque cores of $\mathrm{AD}$ and $\mathrm{DS}$ patients possessed a ragged N-terminus (Masters et al., 1985a). In contrast, Selkoe et al. failed to obtain an unambiguous protein sequence from $\mathrm{AD}$ plaque cores. They therefore postulated that the $\mathrm{A} \beta$ amino terminus was blocked (Selkoe et al., 1986). Mori and coworkers later discovered that pyroglutamate-modified $\mathrm{A} \beta$ was responsible for the earlier discrepancies in amyloid core sequencing. By using pyroglutamate amino peptidase, they revealed that $15-20 \%$ of the $\mathrm{A} \beta$ extracted from $\mathrm{AD}$ brain carries a pyroglutamate modification at its $\mathrm{N}$-terminus (Mori et al., 1992).

The development of $\mathrm{A} \beta_{p E 3-x^{-}}$-specific antibodies prompted various studies examining the involvement of $\mathrm{A} \beta_{p E 3-x}$ in AD pathology. Through immunohistological and biochemical analyses of senile plaques from AD and DS brain, Saido et al. determined that $\mathrm{A} \beta_{p E 3-x}$ is present in amounts equal to or greater than N-terminally intact $\mathrm{A} \beta\left(\mathrm{A} \beta_{1-x}\right)$. Based on observations made from DS brains, they also proposed that deposition of $\mathrm{A} \beta_{p E 3-x}$ precedes that of other A $\beta$ species (Saido et al., 1995). Despite the presence of amyloid plaques at an early age, studies characterizing the sequential deposition of various $\mathrm{A} \beta$ species in DS brain failed to detect $\mathrm{A} \beta_{p E 3-x}$ in young patients. Nevertheless, the number of $\mathrm{A} \beta_{p E 3-x}$ bearing plaques in older DS individuals always exceeded those positive for $\mathrm{A} \beta_{1-x}$, thereby supporting the findings of Saido and colleagues (Lemere et al., 1996). Later biochemical experiments revealed that levels of $\mathrm{A} \beta_{p E 3-42}$ are greater than those of $\mathrm{A} \beta_{p E 3-40}$ in $\mathrm{AD}$ and DS brain (Russo et al., 1997; Hosoda et al., 1998). Since these findings, multiple groups have used various methods to confirm that $\mathrm{A} \beta_{p E 3-x}$ is a major $\mathrm{A} \beta$ species in $\mathrm{AD}$ (Kuo et al., 1997; Russo et al., 1997; Harigaya et al., 2000; Sergeant et al., 2003; Portelius et al., 2010; Härtig et al., 2010; Sullivan et al., 2011). Intriguingly, the ability of the positron emission tomography (PET) tracer Pittsburgh compound B (PiB) to detect extracellular plaques correlates with the amount of $\mathrm{A} \beta_{p E 3-x}$ present in these deposits (Maeda et al., 
2007).

$\mathrm{A} \beta_{p E 3-x}$ is also found outside of the context of AD brain. Several other species share the human $\mathrm{A} \beta$ sequence and are known to develop plaques and vascular amyloid deposits with age. For example, $\mathrm{A} \beta_{p E 3-x}$ has been observed in the brains of aged monkeys, dogs and bears (Tekirian et al., 1998; Härtig et al., 2010). In addition, $\mathrm{A} \beta_{p E 3-x}$ accumulates in the brains of non-demented individuals (Sergeant et al., 2003; Tabaton and Piccini, 2005; Wirths et al., 2010c). In such cases, the absolute amount of $\mathrm{A} \beta_{p E 3-x}$ appears to be an important determinant of cognitive status. Compared to non-demented individuals, $\mathrm{AD}$ patients have a higher ratio of $\mathrm{A} \beta_{p E 3-42}$ to $\mathrm{A} \beta_{1-42}$ in water-soluble brain extracts, and this ratio was shown to correlate with disease severity in FAD patients (Tabaton and Piccini, 2005).

\subsubsection{Generation of pyroglutamate-modified amyloid beta}

In order to form $\mathrm{A} \beta_{p E}$, the $\mathrm{A} \beta$ sequence must first undergo proteolytic processing to expose a glutamate residue at its $\mathrm{N}$-terminus. For the shorter $\mathrm{A} \beta_{p E}$ variant, $\mathrm{A} \beta_{p E 11-x}$, alternative BACE1 cleavage occurring in the trans-Golgi network reveals the glutamate residue at position 11 (Huse et al., 2002). The cleavage steps required to generate $\mathrm{A} \beta_{p E 3-x}$ are more unclear. It was initially hypothesized that $\mathrm{A} \beta_{p E 3-x}$ is derived from $\mathrm{A} \beta_{1-x}$ prior to its deposition (Saido et al., 1996). However, FAD mutations that produce increased levels of N-terminally truncated $\mathrm{A} \beta$ were discovered, suggesting that the glutamate at position 3 could be liberated during amyloidogenic processing of APP (Ancolio et al., 1999; Russo et al., 2000; Miravalle et al., 2005a; Piccini et al., 2007). Recent studies of brains from AD patients and APP/PS1 KI mice support the hypothesis of Saido and coworkers; they found that $\mathrm{A} \beta \mathrm{N}$-terminal truncation increases with disease progression, and formation of $\mathrm{A} \beta_{p E 3-x}$ appears to occur at the expense of $\mathrm{A} \beta_{1-x}$ (Güntert et al., 2006; Wirths et al., 2010a). The enzymes responsible for removing the N-terminal aspartate and alanine residues of $\mathrm{A} \beta_{1-x}$ in vivo remain unidentified. Cell culture experiments revealed that aminopeptidase $\mathrm{A}$ can initiate the truncation of secreted $\mathrm{A} \beta_{1-x}$ by cleaving the aspartate residue at position 1 (Sevalle et al., 2009). Alternatively, it was proposed that $\mathrm{Cu}^{2+}$ mediated amide hydrolysis could remove the first two residues from $\mathrm{A} \beta_{1-x}$ simultaneously (Drew et al., 2010).

After their exposure, N-terminal glutamate residues were initially believed to spontaneously cyclize to form $\mathrm{A} \beta_{p E}$ (Hashimoto et al., 2002). While non-catalyzed pyroglutamate conversion is possible, it may take from years to decades to occur under physiological conditions (Chelius et al., 2006; Yu et al., 2006). Injection of A $\beta$ into wild-type (WT) rat 
brain resulted in some of the peptide undergoing conversion into $\mathrm{A} \beta_{p E}$ in as little as one day after administration (Shin et al., 1997). The rapidity of this process indicated that enzymes are present in vivo that can process $\mathrm{A} \beta$ and catalyze the formation of $\mathrm{A} \beta_{p E}$. It was later shown that glutaminyl cyclase (QC) could facilitate the generation of $\mathrm{A} \beta_{p E}$ in vitro (Fig. 1.9) (Schilling et al., 2004).

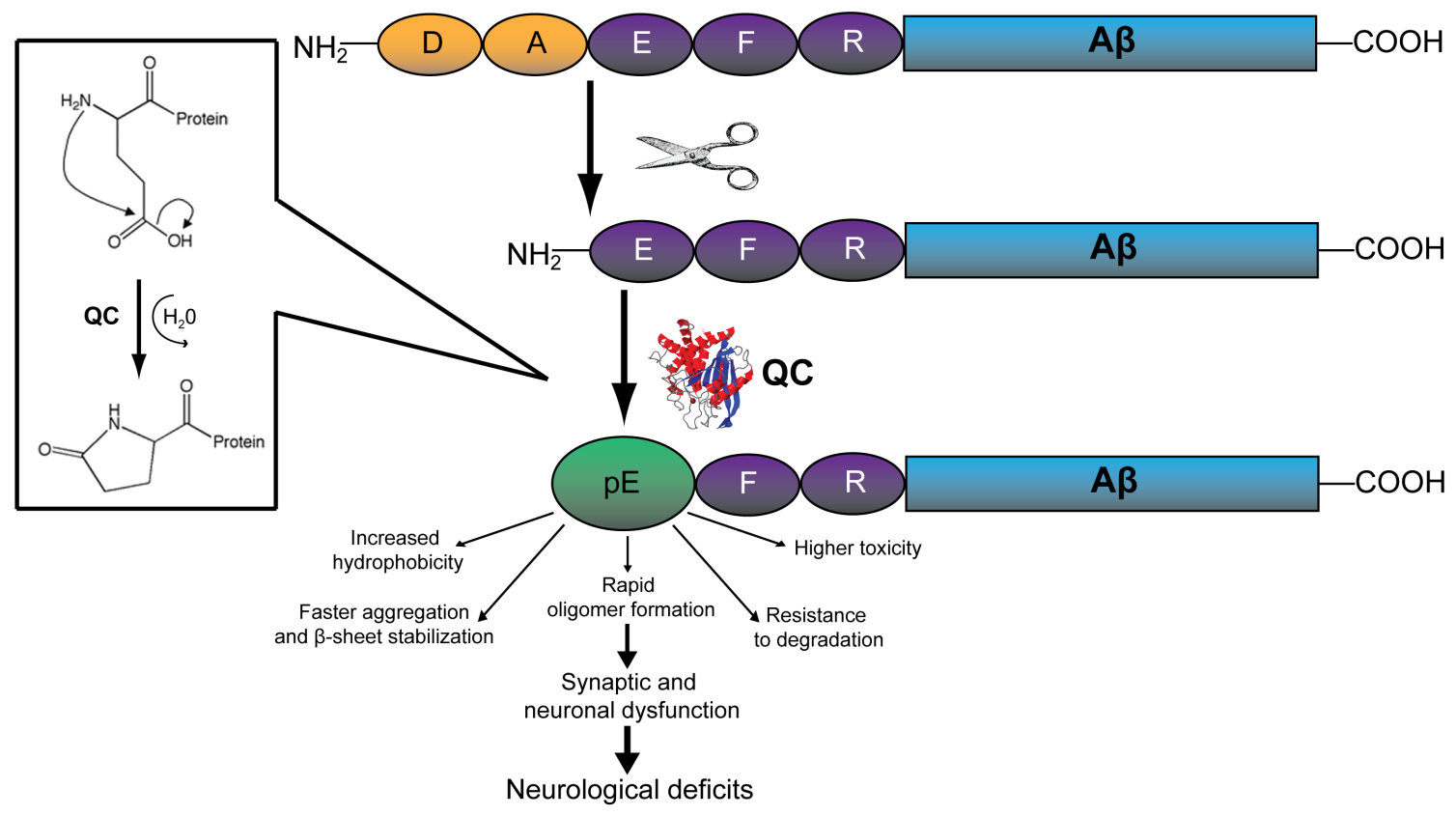

Figure 1.9: The generation of $\mathbf{A} \beta_{p E 3-x}$. The first two amino acids at the N-terminus of $\mathrm{A} \beta$ are removed through unknown mechanisms. This process exposes a glutamate residue, thereby allowing glutaminyl cyclase (QC) to catalyze the dehydration reaction needed to form pyroglutamate $(\mathrm{pE})$. The altered aggregation kinetics and longer bioavailability of $\mathrm{A} \beta_{p E}$ ultimately enhance its toxicity relative to N-terminally unmodified species of $\mathrm{A} \beta$. Adapted from (Jawhar et al., 2011a).

QC is a zinc-dependent acyltransferase that converts glutamine or glutamate to pyroglutamate via the liberation of ammonia or water, respectively (Schilling et al., 2003). In WT mouse brain, QC expression is highest in the hypothalamus. The hippocampus and cortex have moderate levels of QC, with the enzyme detected most strongly in interneurons. Intracellularly, QC localizes to the Golgi, ER and secretory granules of neurons. QC has been found in cultured astrocytes, but the protein was undetectable in mouse brain astrocytes under physiological conditions (Hartlage-Rubsamen et al., 2009; Schilling et al., 2011). Consistent with its presence in the secretory pathway, QC-catalyzed conversion of glutamate to pyroglutamate preferentially occurs at a mildly acidic $\mathrm{pH}(\mathrm{pH}$ 
6) (Schilling et al., 2004). QC can be secreted, but cell culture experiments have indicated that the $\mathrm{QC}$-mediated generation of $\mathrm{A} \beta_{p E}$ is favored in intracellular compartments (Cynis et al., 2008). However, secreted QC may still contribute to extracellular A $\beta_{p E}$ formation in vivo (Hartlage-Rübsamen et al., 2011a). Immunohistochemical evaluation of AD brain disclosed that QC is found in neuronal populations that are particularly vulnerable to degeneration, such as the Edinger-Westphal nucleus, locus coeruleus and the nucleus basalis of Meynert. The presence of $\mathrm{QC}$ correlated with intraneuronal $\mathrm{A} \beta_{p E}$ formation and plaque deposition in these areas (Morawski et al., 2010). Suppressing QC activity using an enzyme-specific inhibitor was found to substantially reduce $\mathrm{A} \beta_{p E}$ formation in a variety of experimental settings, including cell culture, $\mathrm{A} \beta$-injected rat brain and $\mathrm{AD}$ transgenic mice (Cynis et al., 2006; Schilling et al., 2008c,a). Taken together, these data strongly suggest that $\mathrm{QC}$ is a primary enzyme responsible for $\mathrm{A} \beta_{p E}$ generation.

\subsubsection{Biochemical properties of pyroglutamate-modified amy- loid beta}

The loss of one positive charge and two negative charges, combined with the formation of the lactam ring, greatly increases the hydrophobicity of $\mathrm{A} \beta_{p E}$ relative to $\mathrm{N}$-terminally intact $\mathrm{A} \beta$ (He and Barrow, 1999). The presence of the pyroglutamate moiety also makes $\mathrm{A} \beta_{p E}$ uniquely resistant to proteolysis (Saido et al., 1996; Kuo et al., 1998). As a result, the aggregation propensity and biochemical characteristics of $\mathrm{A} \beta_{p E}$ are substantially altered. In vitro aggregation assays have repeatedly shown that $\mathrm{A} \beta_{p E 3}$ forms fibrillar, $\beta$-sheet containing structures more rapidly than $\mathrm{A} \beta_{1-x}$ (He and Barrow, 1999; Kuo et al., 1998; D'Arrigo et al., 2009; Schlenzig et al., 2009). A $\beta_{p E 3-x}$ also oligomerizes more quickly and at lower concentrations than $\mathrm{A} \beta_{1-x}$ (Kuo et al., 1998; Harigaya et al., 2000; Schilling et al., 2005). When combined with $\mathrm{N}$-terminally intact $\mathrm{A} \beta, \mathrm{A} \beta_{p E 3}$ can seed the aggregation of the other isoforms (Schilling et al., 2006). However, $\mathrm{A} \beta_{p E 3}$ may also delay fibrillization of the mixture, thereby stabilizing toxic oligomeric intermediates (Kuo et al., 1998; D'Arrigo et al., 2009; Sanders et al., 2009).

\subsubsection{Toxicity of pyroglutamate-modified amyloid beta}

Multiple experimental paradigms have demonstrated the pathogenicity of $\mathrm{A} \beta_{p E 3}$. Mixtures of $\mathrm{A} \beta_{p E}$ and $\mathrm{A} \beta_{1-42}$ at ratios similar to those found in $\mathrm{AD}$ patients were more toxic to neuroblastoma cell lines than mixtures reflecting the $\mathrm{A} \beta$ composition in nondemented brain (Piccini et al., 2005). Transgenic mouse lines designed to exclusively produce $\mathrm{A} \beta_{p E 3-42}$, the truncated beta-amyloid (TBA)2 and TBA2.1/2.2 mice, display 
significant intraneuronal $\mathrm{A} \beta_{p E}$ accumulations, progressive motor deficits and neurodegeneration (Wirths et al., 2009; Alexandru et al., 2011). Targeted removal of $\mathrm{A} \beta_{p E}$, on the other hand, effectively alleviates $\mathrm{AD}$ pathology. Reducing $\mathrm{A} \beta_{p E}$ levels, either through treatment with a $\mathrm{QC}$ inhibitor, genetic $\mathrm{KO}$ of $\mathrm{QC}$ or passive vaccination with an $\mathrm{A} \beta_{p E 3-x^{-}}$ specific antibody, has been shown to decrease plaque load and reverse behavioral deficits in several different AD mouse models (Schilling et al., 2008b; Wirths et al., 2010c; Jawhar et al., 2011b; Frost et al., 2012).

While the aforementioned studies demonstrate the harmful effects of $\mathrm{A} \beta_{p E}$ accumulation, there are contradicting reports as to whether it is more toxic than $\mathrm{A} \beta_{1-40 / 42}$. Russo and colleagues found $\mathrm{A} \beta_{p E 3-40 / 42}$ to be more toxic than $\mathrm{A} \beta_{1-40 / 42}$ in neuronal and glial cultures and more resistant to degradation by astrocytes (Russo et al., 2002). Similarly, oligomeric $\mathrm{A} \beta_{p E}$ induced apoptosis and necrosis in human neuroblastoma cell lines at a greater rate than $\mathrm{A} \beta_{1-42}$ (Acero et al., 2009). In contrast, pre-aggregated $\mathrm{A} \beta_{p E 3-42}$ displayed toxicity equivalent to $\mathrm{A} \beta_{1-42}$ when applied to hippocampal neuronal cultures of varying ages (Tekirian et al., 1999). A study employing viral vectors to drive $\mathrm{A} \beta$ production in primary cortical neurons provided comparable results; the authors failed to detect differences in cell viability between neurons that secreted $\mathrm{A} \beta_{1-x} ; \mathrm{A} \beta_{3-x}$ or $\mathrm{A} \beta_{p E 3-x}$ (Shirotani et al., 2002). In vivo experiments were also inconclusive. Administering soluble oligomers comprised of $\mathrm{A} \beta_{p E 3-42}$ or $\mathrm{A} \beta_{1-42}$ to WT mice via intracerebroventricular injection induced analogous deficits in the Y-maze and Morris water maze (Youssef et al., 2008). Differences in $\mathrm{A} \beta$ preparations, treatment paradigms and modes of inducing $\mathrm{A} \beta$ production may partially explain these discrepant results.

\subsection{Amyloid beta 4-42}

Relatively little is known about the role of $\mathrm{A} \beta_{4-42}$ in $\mathrm{AD}$ pathology. The enzyme responsible for cleaving $\mathrm{A} \beta_{1-42}$ to expose the N-terminal phenylalanine of $\mathrm{A} \beta_{4-42}$ is unidentified. However, $\mathrm{A} \beta$ degrading enzymes, such as neprilysin, might be involved (Carson and Turner, 2002). Sedimentation studies indicate that $\mathrm{A} \beta_{4-42}$ aggregates more quickly than $\mathrm{A} \beta$ variants with longer $\mathrm{N}$-termini (Pike et al., 1995b). As a result, $\mathrm{A} \beta_{4-42}$ could be one of the earliest and most prominent $\mathrm{A} \beta$ species deposited in $\mathrm{AD}$ brain. In line with this notion, sequencing of amyloid plaque cores found that $64 \%$ of the isolated $\mathrm{A} \beta$ had a phenylalanine at its N-terminus (Masters et al., 1985a). Later work suggested that $\mathrm{A} \beta_{4-42}$ is less abundant in AD brain (Miller et al., 1993; Naslund et al., 1994). Although the precise amounts of $\mathrm{A} \beta_{4-42}$ are still unclear, a recent IP/MS experiment supports the initial findings of Masters et al. by identifying $\mathrm{A} \beta_{4-42}$ as a major $\mathrm{A} \beta$ species in $\mathrm{AD}$ patients. 
(Portelius et al., 2010). Additionally, A $\beta_{4-42}$ was found to be a component of cotton wool plaques in FAD patients with the V261I PS1 mutation (Miravalle et al., 2005b). Other pathological studies have discovered $\mathrm{A} \beta_{4-42}$ in amyloid deposits from vascular dementia and familial Danish dementia patients (Tomidokoro et al., 2005; Lewis et al., 2006). Based on these observations, $\mathrm{A} \beta_{4-42}$ may contribute to the development of multiple CNS diseases.

\subsection{Transgenic mouse models of Alzheimer's disease}

Animal models that faithfully recapitulate the molecular origin, lesions and symptoms of a human illness are rare in disease-based research. To date, there is no AD model that accurately replicates all aspects of AD pathology. Some species, such as dogs, cats and nonhuman primates, spontaneously develop age-related cognitive decline and some of the histopathological hallmarks of AD. However, cost, availability, long life-span and ethical considerations greatly restrict their experimental use. As a result, transgenically modified animal models have become critical tools in the study of AD. Several non-mammalian organisms, such as the fruit fly Drosophila melanogaster and the nematode Caenorhabditis elegans, have been transgenically manipulated in order to examine particular aspects of AD pathology. Although these animals offer powerful molecular and genetic tools, their anatomy and physiology are vastly different from that of humans. Consequently, most transgenic AD models have been created in a less evolutionarily-distant mammalian species, the laboratory mouse Mus musculus.

Rodents do not spontaneously develop AD histopathology as they age. The discovery of FAD-linked mutations in the $A P P$ and $P S$ genes afforded the opportunity to study AD pathology in mice carrying transgenes with these mutations. The first mouse models to robustly replicate some of the histopathological hallmarks of AD carried APP transgenes with a single FAD mutation. The PDAPP mouse model expresses a human APP (hAPP) minigene bearing the V717F Indiana mutation under the control of the platelet-derived growth factor promoter. Extracellular amyloid plaques, composed primarily of $\mathrm{A} \beta_{x-42}$, first appear in PDAPP mice between the ages of 6 and 9 months. Amyloid deposition increases with age and is accompanied by progressive synaptic loss, phospho-tau-positive dystrophic neurites, microgliosis and astrocytosis (Games et al., 1995; Rockenstein et al., 1995; Masliah et al., 2001). In addition, PDAPP mice experience age-dependent deficits in spatial reference memory and object recognition, both of which occur in the absence of neuron loss (Irizarry et al., 1997; Chen et al., 2000; Dodart et al., 2000).

One of the most widely used transgenic mouse models, the Tg2576 mouse, also contains 
a single APP mutation. Tg2576 mice overexpress the hAPP 695 isoform containing the Swedish mutation K670N/M671L under the control of the hamster prion promoter. They develop sparse plaque pathology at the age of approximately 12 months. Like the PDAPP model, plaque deposition increases with age and occurs with astrocytosis, microgliosis and dystrophic neurites. Interestingly, Tg2576 mice exhibit deficits in working memory and spatial reference memory prior to significant plaque formation (Hsiao et al., 1996; Holcomb et al., 1998).

Efforts to create more aggressive AD models resulted in transgenic mice that combine multiple $A P P$ mutations or $A P P$ and $P S 1$ mutations. A series of mouse lines was developed carrying transgenes containing $h A P P 751$ with the Swedish and London mutations $(\mathrm{K} 670 \mathrm{M} / \mathrm{N} 671 \mathrm{~L}+\mathrm{V} 717 \mathrm{I})$ under the control of the murine Thy1.2 promoter. It was discovered that the age at which plaques formed in the different lines depended on the levels of $\mathrm{A} \beta_{1-42}$ produced (Rockenstein et al., 2001). In agreement with this finding, TgCRND8 mice, a model with $\mathrm{A} \beta_{1-42}$ levels comparable to those found in the brains of sporadic AD patients, develop early and robust pathology. TgCRND8 mice express hAPP695 with the Swedish and Indiana mutations (K670N/M671L + V717F) under a hamster prion promoter. Plaque pathology in these mice is observable from 3 months of age and occurs in parallel with spatial reference memory deficits. Co-expression of PS1 containing the M146L and L286V mutations and Swedish/Indian hAPP produced "double"transgenic TgCRND8 mice in which plaques develop from the age of one month (Chishti et al., 2001). Other APP/PS double transgenic mouse models demonstrate similar enhancements of pathology relative to single transgenic APP mice. (Holcomb et al., 1998; Duyckaerts et al., 2008).

Although levels of $\mathrm{A} \beta_{x-42}$ are elevated in single transgenic mice expressing mutant PS, no plaque pathology is observed in these models. This likely results from differences in the solubility of human and murine $\mathrm{A} \beta$ (Jankowsky et al., 2007). It should be noted, however, that expression of mutated PS alone does result in some impairments. Various PS mouse models were found to have mild behavioral deficits, altered axonal transport and perturbed calcium homeostasis in the ER (Duyckaerts et al., 2008).

While mouse models can recreate many aspects of AD pathology, they fail to reproduce two key features of the disease: widespread neuron loss and NFT formation. Regionspecific neuron loss is most robustly observed in mice harboring both APP and PS1 mutations. Mouse models with documented neuron loss include the APP751 Swedish/London x PS1 M233T/L235P knockin (KI), APP751 Swedish/London x PS1 M146L, and mice carrying five FAD mutations (5XFAD), among others (Casas et al., 2004; Schmitz et al., 2004; Oakley et al., 2006). To produce NFTs, transgenes containing FAD mutations and 
tau mutations linked to frontotemporal dementia have been combined. The first APP/tau mouse was the result of crossing Tg2576 and P301 tau mice. Tau pathology was enhanced in the APP/tau mice relative to tau P301 single transgenics (Lewis et al., 2001). Later, the triple-transgenic 3xTg mouse was generated by coinjecting separate Thy1.2-driven transgenes containing APP695 Swedish and tau-P301 into the pronuclei of single-celled PS1 M146V KI embryos. 3xTg mice develop A $\beta$ plaques at around 12 months of age and NFT-like pathology when they are between 12 and 15 months old (Oddo et al., 2003). Despite representing a genetic state not present in human patients, combined FAD/tau transgenic mouse models have provided important evidence that $\mathrm{A} \beta$ drives tau pathology in AD (Lewis et al., 2001; Oddo et al., 2004).

\subsubsection{XFAD mouse model}

The 5XFAD mouse is a double transgenic APP/PS1 mouse model. It harbors five FAD mutations in order to accelerate plaque development and produce high levels of $\mathrm{A} \beta$. The model was created by co-pronuclear injection of two transgenes, hAPP695 containing the Swedish, Florida and London mutations, and PS1 containing the M146L and L286V mutations (Fig. 1.10). Both transgenes are under the control of the Thy1 promoter. These transgenes successfully cointegrated, as demonstrated by their stable germline transmission and coinheritance over multiple generations. As a result, 5XFAD mice breed as if they are a single transgenic model (Oakley et al., 2006). Since 5XFAD mice were originally generated as a C57/B6xSJL hybrid strain, they were recently backcrossed onto a pure C57BL/6J background to facilitate mating and comparison with other AD mouse models (Jawhar et al., 2012).

The particular mutations found in 5XFAD mice drive the overproduction of $\mathrm{A} \beta_{x-42}$, making it an amyloid-predominant model. The Swedish mutation elevates levels of total $\mathrm{A} \beta$, while the Florida, London, M146L and L286V mutations promote the formation of $\mathrm{A} \beta_{x-42}$ specifically. As a result, Thioflavin $\mathrm{S}$ positive plaques are present in the brains of 5XFAD mice beginning from the age of 2 months. Microgliosis and astrocytosis occur concomitantly with plaque deposition, and these pathologies massively increase with age (Oakley et al., 2006). Extracellular plaques were also identified in the spinal cords of 3-month-old 5XFAD mice (Jawhar et al., 2012). Young female 5XFAD mice initially have higher $\mathrm{A} \beta_{x-42}$ levels than age-matched males, suggesting a gender-dependent difference in disease progression. Although this trend seems to disappear in older animals, restraintstress experiments increased plaque deposition only in female 5XFAD mice (Oakley et al., 2006; Devi and Ohno, 2010b). 


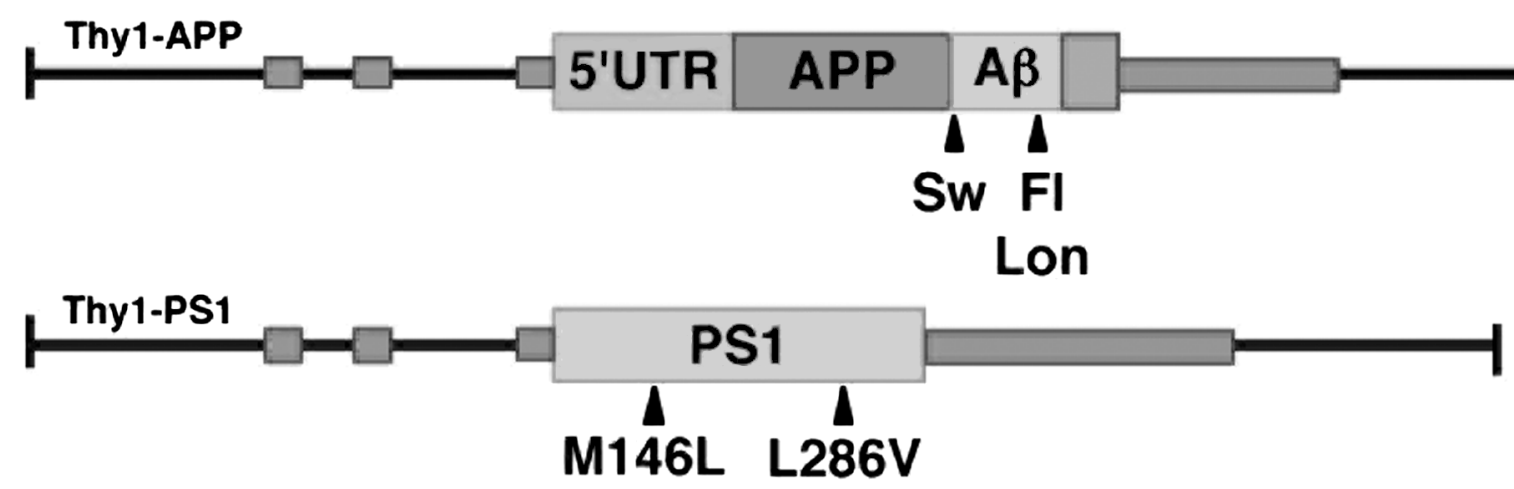

Figure 1.10: The 5XFAD transgenes. A schematic diagram of the Thy1-APP and the Thy1-PS1 transgenes used to create the 5XFAD mouse. Grey rectangles represent the coding regions of APP and PS1. FAD mutations in the transgenes are indicated by arrowheads. Sw, Swedish mutation; Lon, London mutation; Fl, Florida mutation. Taken from (Oakley et al., 2006).

In addition to extracellular amyloid plaques, 5XFAD mice accumulate intraneuronal $\mathrm{A} \beta$ in cortical layer $\mathrm{V}$, the subiculum and the spinal cord. In the cortex, intraneuronal $\mathrm{A} \beta$ puncta first appear at 1.5 months of age, prior to plaque deposition. The presence of intraneuronal $\mathrm{A} \beta$ in these regions correlates with neuron loss and was suggested to spur plaque deposition and axonal spheroid formation (Oakley et al., 2006; Jawhar et al., 2012; Moon et al., 2012). Stereological cell counts performed on 12-month-old 5XFAD mice have confirmed an approximately $40 \%$ decrease in neuronal numbers in cortical layer V. No such neuron loss was observed in the hippocampal CA1 region, which lacks intraneuronal A $\beta$ (Jawhar et al., 2012).

Synaptic alterations also occur in the 5XFAD model. Synaptic markers undergo an age-dependent decrease beginning in 4-month-old mice (Oakley et al., 2006). Prior to plaque formation and overt synaptic loss, swollen presynaptic terminals and axonal processes develop intracellular $\mathrm{BACE} 1$ and $\mathrm{A} \beta$ accumulations. Local $\mathrm{A} \beta$ overproduction and dystrophic changes in these structures coincide with the deposition of extracellular amyloid plaques (Zhang et al., 2009).

Behavioral impairments manifest in 5XFAD mice at a relatively young age. The initial description of the 5XFAD model identified working memory deficits in the Y-maze in 4-to5-month-old mice (Oakley et al., 2006). Similarly, a recharacterization of the model on the C57BL/6J background revealed that 6-month-old mice display a reduced alternation rate in the cross maze and exhibit decreased anxiety in the elevated plus maze. Additionally, this study showed that 5XFAD mice experience a decline in motor function from the age 
of 9 months, as demonstrated in the balance beam and string suspension tasks (Jawhar et al., 2012). Impaired performance in the conditioned taste aversion task, MWM and contextual fear conditioning paradigm have also been documented in 5XFAD mice (Ohno et al., 2006; Kimura and Ohno, 2009; Devi and Ohno, 2010a).

Despite the aggressive pathology that develops in the 5XFAD model, these mice still respond to therapeutic interventions. Different passive immunization strategies have effectively decreased plaque load and alleviated behavioral impairments (Wirths et al., 2010b; Chauhan et al., 2011). Likewise, short-term treatment of 5XFAD mice with a TrkB agonist restored Y-maze performance to WT levels, while long-term administration of a protein kinase $\mathrm{C}(\mathrm{PKC})$ activator ameliorated synaptic loss, plaque pathology and cognitive deficits (Hongpaisan et al., 2011; Devi et al., 2012). Oral dosage of a peroxisome proliferator activated receptor delta $(\operatorname{PPAR} \delta)$ agonist was also shown to reduce plaque burden and astrocyte activation in 3-month-old 5XFAD mice (Kalinin et al., 2009). Conversely, 3 months of ibuprofen treatment decreased levels of inflammatory markers, but left plaque load unaffected, elevated levels of soluble $\mathrm{A} \beta_{x-42}$ and impaired behavioral performance (Hillmann et al., 2012). As a whole, the biochemical, histopathological and behavioral features of the 5XFAD mouse make it a useful model for AD research. 


\section{$1.10 \quad$ Project objectives}

\subsubsection{Project I: Generation and characterization of the TBA42 mouse model}

$\mathrm{A} \beta_{p E}$ is an abundant $\mathrm{A} \beta$ isoform in $\mathrm{AD}$ brain. It displays altered aggregation kinetics, increased resistance to proteolytic degradation and marked toxicity (see Section 1.7). Directly determining the pathological function of $\mathrm{A} \beta_{p E}$ in vivo, though, remains challenging. Most $\mathrm{AD}$ mouse models generate more than one $\mathrm{A} \beta$ isoform, making it difficult to examine the detrimental effects of one particular species (Duyckaerts et al., 2008). To study the toxicity of $\mathrm{A} \beta_{p E}$ in isolation, the TBA2 and TBA2.1/2.2 transgenic mouse lines were created. These mice express a truncated and modified $\mathrm{A} \beta_{3-42}$ sequence fused to a thyrotropin-releasing hormone signal peptide. The N-terminal residue of this sequence is a glutamine rather than the glutamate normally found at the third position of the $\mathrm{A} \beta$ peptide. Together, these alterations promote the QC-catalyzed formation of $\mathrm{A} \beta_{p E 3-42}$.

Although $\mathrm{A} \beta_{p E 3-42}$ neuronal toxicity has been successfully demonstrated in these models, the TBA2 and TBA2.1/2.2 lines have several drawbacks. The prominent cerebellar $\mathrm{A} \beta$ pathology in TBA2 mice caused pronounced motor deficits and the loss of the line (Wirths et al., 2010c). In contrast, TBA2.1 and TBA2.2 mice are viable and fertile. However, to observe a phenotype, it is necessary to create homozygous (Hom) mice or mice heterozygous for both the TBA2.1 and TBA2.2 transgenes (Alexandru et al., 2011). This greatly complicates breeding with other transgenic mouse models.

To overcome the weaknesses of the aforementioned TBA mouse models, we used the same transgene to create the TBA42 mouse, a new transgenic line that accumulates $\mathrm{A} \beta_{p E 3-42}$. Transgene expression levels in TBA42 mice were measured via quantitative real-time polymerase chain reaction (qPCR). We then performed a longitudinal characterization of female mice at the ages of 3,6 and 12 months. Brain and spinal cord pathology were examined using immunohistochemistry. In addition, a battery of motor and cognitive tasks were employed to evaluate behavioral performance.

\section{Objectives of Project I:}

- Establish a new transgenic mouse line that that generates $\mathrm{A} \beta_{p E 3-42}$ in the heterozygous state but does not possess a lethal phenotype.

- Assess $\mathrm{A} \beta / \mathrm{A} \beta_{p E 3-42}$ accumulation and gliosis in 3, 6 and 12-month-old mice.

- Determine if age-dependent behavioral changes occur by measuring general motor function, working memory and anxiety. 


\subsubsection{Project II: Exploring the pyroglutamate-modified amy- loid beta seeding hypothesis using the FAD42 mouse model}

In certain $\mathrm{AD}$ transgenic mice, $\mathrm{A} \beta_{p E}$ appears to contribute greatly to underlying neuropathology. Reducing the levels of $\mathrm{A} \beta_{p E}$ decreases plaque burden, lowers levels of soluble and insoluble $\mathrm{A} \beta$ and ameliorates behavioral deficits (Schilling et al., 2008b; Wirths et al., 2010c; Jawhar et al., 2011b; Frost et al., 2012). However, few studies have addressed whether elevating $\mathrm{A} \beta_{p E}$ levels is sufficient to aggravate ongoing disease processes. Previous work from our lab attempted to answer this question by overexpressing hQC in 5XFAD mice. Since QC is responsible for catalyzing the formation of $\mathrm{A} \beta_{p E}$, it was not surprising that $\mathrm{A} \beta_{p E}$ levels were increased in $5 \mathrm{XFAD} / \mathrm{hQC}$ mice. Furthermore, in agreement with the pathogenic role of $\mathrm{A} \beta_{p E}$, both plaque burden and behavioral deficits were exacerbated relative to 5XFAD single transgenic mice. A disadvantage of this approach was the reliance on the ectopic overexpression of hQC. As QC is an enzyme with multiple targets, it cannot be excluded that alterations in these other substrates contributed to the phenotype observed in 5XFAD/hQC mice.

The primary aim of this project was to investigate how additional $\mathrm{A} \beta_{p E 3-42}$ impacts the progression of $\mathrm{AD}$ pathology in the absence of $\mathrm{QC}$ manipulations. To accomplish this, we crossed transgenic mice that produce $\mathrm{A} \beta_{p E 3-42}$ (TBA42) with the 5XFAD mouse, a model with aggressive amyloid pathology (See Section 1.9.1). We assessed the impact of elevated $\mathrm{A} \beta_{p E 3-42}$ by analyzing 6-month-old mice that carried both the TBA42 and 5XFAD transgenes - the so-called FAD42 mice. Comparisons were then made between WT, TBA42, 5XFAD and FAD42 mice on the levels of behavioral phenotype, A $\beta$ biochemistry, QC-activity and cortical plaque load.

\section{Objectives of Project II:}

- Elucidate the effects of elevated $\mathrm{A} \beta_{p E 3-42}$ on the 5XFAD behavioral phenotype using the FAD42 mouse.

- Determine whether increased levels of $\mathrm{A} \beta_{p E 3-42}$ impact the co-precipitation of other $\mathrm{A} \beta$ variants.

- Evaluate changes in the pools of soluble and insoluble $\mathrm{A} \beta$ induced by additional $\mathrm{A} \beta_{p E 3-42}$.

- Measure possible alterations in QC activity.

- Analyze the ability of $\mathrm{A} \beta_{p E 3-42}$ to seed plaque deposition in vivo. 


\subsubsection{Project III: Generation and characterization of the TBA83 mouse model}

$\mathrm{A} \beta_{4-42}$ is another dominant $\mathrm{A} \beta$ species in $\mathrm{AD}$ brain (Portelius et al., 2010). Like $\mathrm{A} \beta_{p E 3-42}$, generation of $\mathrm{A} \beta_{4-42}$ requires the $\mathrm{N}$-terminal truncation of the $\mathrm{A} \beta_{1-42}$ peptide. However, after liberation of its N-terminus, $\mathrm{A} \beta_{4-42}$ does not undergo further enzymecatalyzed modification. As a result, use of the appropriate construct would allow for the direct expression of $\mathrm{A} \beta_{4-42}$ in transgenic mice. A major criticism of conventional $\mathrm{AD}$ mouse models is their overexpression of the mutated forms of APP and PS1 seen in FAD. Such mutations cause AD in only a minority of patients, and no case has been reported in which there is more than one mutation. Therefore, moderate expression of an $\mathrm{A} \beta$ peptide that naturally accumulates in $\mathrm{AD}$ brain, such as $\mathrm{A} \beta_{4-42}$, could be considered more akin to the situation found in human AD.

Little is currently known about the toxicity of $\mathrm{A} \beta_{4-42}$. Sedimentation studies suggest that the rapid aggregation kinetics of $\mathrm{A} \beta_{4-42}$ may greatly influence how it and other $\mathrm{A} \beta$ isoforms deposit in the brain (Pike et al., 1995b). In order to elucidate the effects of $\mathrm{A} \beta_{4-42}$ expression in vivo, we generated and characterized the TBA83 mouse model.

\section{Objectives of Project III:}

- Develop a mouse model that expresses $\mathrm{A} \beta_{4-42}$ without relying on transgenes carrying mutated $\mathrm{A} \beta, A P P$, or PS1.

- Examine the neuropathology resulting from $\mathrm{A} \beta_{4-42}$ expression.

- Determine if $\mathrm{A} \beta_{4-42}$ is capable of inducing behavioral deficits in transgenic mice. 


\section{Chapter 2}

\section{Materials and Methods}

\subsection{Animals}

\subsubsection{Housing and general considerations}

Mice were group-housed with an average of four individuals per cage and kept on a 12 hour/12 hour inverted light cycle (lights off at 8 a.m.). Free access to food and water was provided. Handling and behavioral testing were performed during the dark phase ( 8 am 8 pm) under red lighting. Only female mice were used for the current studies. All animal experiments were conducted in accordance with the German guidelines for animal care and approved by the local legal authorities.

\subsubsection{TBA42 transgenic mice}

The generation of the transgenic vector expressing murine thyrotropin-releasing hormone$\mathrm{A} \beta$ (mTRH-A $\left.\beta_{3-42}\right)$ under the control of the murine Thy1.2 regulatory sequence was described previously (Cynis et al., 2006; Wirths et al., 2009). The glutamate at position three of the $\mathrm{A} \beta$ amino acid sequence was mutated into glutamine in order to facilitate enhanced pyroglutamate formation. The mice thus express unmodified $\mathrm{A} \beta_{3 Q-42}$ (hereafter named $\mathrm{A} \beta_{3-42}$ ) which can be readily converted to $\mathrm{A} \beta_{p E 3-42}$ by $\mathrm{QC}$. TBA42 mice were generated by male pronuclear injection of fertilized C57BL/6J oocytes. The resulting offspring were screened for transgene integration by polymerase chain reaction (PCR) analysis. Three founder animals (TBA41, TBA42, and TBA45) were identified and subsequently bred to C57BL/6J mice to establish independent lines. Transgene expression was assessed in the $\mathrm{F} 1$ generation of each line using quantitative real-time (qPCR). The line 
with the highest levels of transgene messenger ribonucleic acid (mRNA) was selected for further breeding (named truncated beta-amyloid 42; TBA42). For behavioral analyses, the following numbers of female mice were used: WT: $\mathrm{n}=12(3$ months $($ mon $)), \mathrm{n}=10$ (6 mon), $\mathrm{n}=8$ (12 mon); TBA42: $\mathrm{n}=12$ (3 mon), $\mathrm{n}=10$ (6 mon), $\mathrm{n}=9$ (12 mon).

\subsubsection{XFAD transgenic mice}

Generation of the 5XFAD mouse line was described previously (Oakley et al., 2006). These mice carry an APP695 transgene with the Swedish, Florida and London mutations and a PS1 transgene containing the M146L and L286V mutations. The APP and PS1 transgenes co-segregate and are both under the control of the murine Thy1.2 regulatory sequence. All 5XFAD mice were backcrossed for more than 10 generations onto a C57BL/6J genetic background.

\subsubsection{FAD42 transgenic mice}

FAD42 mice were generated by breeding transgene positive 5XFAD mice to transgene positive TBA42 mice. WT and transgenic offspring were subsequently identified using PCR. Mice were designated as FAD42 when they carried both the TBA42 and 5XFAD transgenes. For behavioral analyses, the following numbers of 6 -month-old female mice were used: WT $\mathrm{n}=9,5 \mathrm{XFAD} \mathrm{n}=8$, TBA42 $\mathrm{n}=8$, FAD42 $\mathrm{n}=5$.

\subsubsection{TBA83 transgenic mice}

The TBA8 transgenic vector was derived from the mutagenesis of the TBA42 transgenic vector (see Sections 2.1.2, 2.3.2 and 2.3.6). TBA83 mice were generated by pronuclear microinjection of C57BL/6J oocytes (see Section 2.3.7). The resulting offspring were screened for transgene integration by PCR analysis. Seven founder animals were identified and subsequently bred to C57BL/6J mice to establish independent lines. Transgene expression was assessed in the F1 generation of each line using qPCR. The line with the highest transgene mRNA levels was selected for further breeding (named truncated betaamyloid 83; TBA83). For behavioral analyses, the following numbers of female mice were used: WT: $\mathrm{n}=12$ (3-4 mon), $\mathrm{n}=10$ (6-7 mon), $\mathrm{n}=10$ (11-12 mon); TBA83 $\mathrm{n}=7$ (3-4 mon), $\mathrm{n}=7$ (6-7 mon), $\mathrm{n}=9$ (11-12 mon). 


\subsubsection{Tissue preparation for biochemistry}

All mice were sacrificed via carbon dioxide anesthetization followed by cervical dislocation. Mouse cadavers were decapitated using large surgical scissors, and brains and spinal cords were rapidly dissected on ice.

For brain isolation, an incision was first made over the dorsal midline of the skull with a disposable surgical scalpel. The skin and tissue surrounding the skull were then carefully removed. The skull bones were fractured using fine surgical scissors. A dorsal incision was made along the median fissure and a lateral incision along the temporal bones. Skull fragments were removed with fine tweezers, and the whole brain was extracted from the skull using a small spatula. The olfactory bulb was excised from the intact brain and discarded. Using a surgical scalpel, the brain hemispheres were separated down the midline. The cerebellum and brainstem were removed and retained individually.

To prepare the spinal cord, an incision was made over the spinal column and down the dorsal midline using a surgical scalpel. The skin and muscle were then removed from around the spinal column. A lateral incision was made on each side of the spinal column neural arch with fine surgical scissors. The dorsal bone of the spinal column was pealed away using fine tweezers. Spinal nerves were cut with a surgical scalpel, thereby allowing the spinal cord to be removed with a small spatula.

The right and/or left brain hemisphere and a sample of cervical/thoracic spinal cord were immediately frozen on dry ice. All samples were stored at $-80{ }^{\circ} \mathrm{C}$ until use.

\subsubsection{Tissue preparation for immunohistochemistry}

\section{Drop-fixation}

Mice were sacrificed, and brain and spinal cord tissue were dissected as described in Section 2.1.6. The right and/or left hemisphere and a sample of cervical/thoracic spinal cord were placed into embedding cassettes (Simport). Samples were fixed in a solution of $4 \%$ formalin prepared in phosphate buffered saline (PBS) (Roth) for a minimum of 72 hours (h) prior to paraffin embedding (see Section 2.6.1).

\section{Perfusion}

Mice were deeply anesthetized with an intraperitoneal injection of a mixture of ketamine (10\% stock solution; Medistar) and xylazine (Xylareim, $23.3 \mathrm{mg} / \mathrm{mL}$; Riemser) diluted in an $0.09 \%$ isotonic saline solution (Braun). The anesthetic was administered at a dosage of $150 \mathrm{mg} / \mathrm{kg}$ and $17 \mathrm{mg} / \mathrm{kg}$ of ketamine and xylazine, respectively. A peristaltic 
pump was equipped with tubing, and the ice-cold perfusion solutions (0.01 M PBS (Pan Biotech); $4 \%$ (weight/volume (w/v)) paraformaldehyde (PFA; Merck) in $0.01 \mathrm{M} \mathrm{PBS}$ ) were measured into separate $100 \mathrm{~mL}$ graduated cylinders. A sterile needle was affixed onto one end of the pump's tubing, and the opposite end was inserted into the graduated cylinder containing the PBS. The tubing was then flushed with roughly $15 \mathrm{~mL}$ of PBS to remove any air present in the system. Once the mouse was no longer responsive to pain stimuli, it was pinned by its limbs onto a foam perfusion stage. Using surgical scissors, the abdominal wall of the mouse was opened, the diaphragm was cut and the rib cage was split to reveal the beating heart. An incision was made in the right atrium of the heart to allow for blood to drain from the circulatory system. The sterile needle attached to the tubing of the peristaltic pump was inserted into the left ventricle. The mouse was then perfused with $40 \mathrm{~mL}$ of ice-cold 0.01 M PBS to flush the blood from its body. This process was monitored by observing the color change of the mouse's liver from red to grayish-white. Thereafter, the pump was stopped and the perfusion tubing was placed into the graduated cylinder containing ice-cold 4\% PFA. Perfusion was then continued until $40 \mathrm{~mL}$ of PFA solution was administered. Twitching of the mouse's tail indicated optimal perfusion.

Following perfusion, the mouse was removed from the foam perfusion stage and decapitated. Brain and spinal cord tissue were prepared as described in Section 2.1.6. The right brain hemisphere and cervical/thoracic spinal cord were prepared for paraffin embedding as outlined in Section 2.6.1. The left brain hemisphere was cryoprotected by placing it in $50 \mathrm{~mL}$ of $30 \%(\% \mathrm{w} / \mathrm{v})$ sucrose solution (Roth) prepared in $0.01 \mathrm{M}$ PBS. The brain tissue was incubated in this solution overnight $(\mathrm{ON})$ at $4{ }^{\circ} \mathrm{C}$ or until it sank to the bottom of its container. The brain tissue was then removed from the sucrose solution, and excess liquid was carefully absorbed with a lab-grade wipe. The brain tissue was subsequently wrapped in foil and frozen on dry ice for 10-to-15 minutes (min). Once frozen solid, the brain tissue was stored at $-80{ }^{\circ} \mathrm{C}$ until use.

\subsection{Behavioral analysis of mice}

\subsubsection{Clasping test}

Clasping behavior was tested by suspending mice by their tails for $30 \mathrm{sec}$ and observing their fore- and hindpaws. Mice were scored on a scale from 0 to 3 , where $0=$ no clasping, $1=$ forepaw clasping, 2 = forepaw and one hindpaw clasped, and $3=$ all paws clasped (Miller et al., 2008). 


\subsubsection{Balance beam}

A beam walking task was used to assess balance and general motor function (Arendash et al., 2001). The balance beam consisted of a wooden dowel $1 \mathrm{~cm}$ in diameter and 50 $\mathrm{cm}$ in length elevated $44 \mathrm{~cm}$ above a padded surface. The beam was supported at both ends by a column attached to a 9 x $15 \mathrm{~cm}$ escape platform. Each mouse underwent three, 60 -second (sec) trials with a minimum of 5 min between trials. At the start of every trial, the mouse was placed on the center of the beam facing one of the platforms. The latency to fall off the beam or to reach one of the platforms was then recorded. If a mouse remained on the beam for the entire trial or escaped to a platform, the maximum time of $60 \mathrm{sec}$ was awarded. Between trials, the apparatus was cleaned with $70 \% \mathrm{EtOH}$ to diminish odor cues. The average latency of all three trials was taken as the final score for each mouse.

\subsubsection{String suspension}

Motor coordination and grip strength were evaluated using the string suspension task. The testing apparatus was comprised of a $50 \mathrm{~cm}$ cotton string, $2 \mathrm{~mm}$ in diameter, tied between two wooden support beams at a height of $35 \mathrm{~cm}$. Padding was placed immediately below the string. Mice underwent a single $60 \mathrm{sec}$ trial in which they were initially suspended by their forepaws in the middle of the string. Their ability to traverse the string during this trial was assessed using a 0 to 5 rating scale: $0=$ unable to remain on the string; 1 = stationary hanging by fore- or hindpaws; 2 = stationary hanging by foreor hindpaws with unsuccessful attempts to grasp string with all four paws; $3=$ hanging onto string by all four paws but no lateral movement; $4=$ hanging onto string using all four paws and tail and moving laterally; $5=$ escaping to edge of string and contacting wooden support beam. Unless the mouse fell off the string at any point during the test (thereby earning a score of 0 ), the maximum score obtained during the trial was recorded. The trial was terminated immediately if a score of 5 was achieved (Moran et al., 1995). Between mice, the apparatus was cleaned with $70 \%$ EtOH to diminish odor cues.

\subsubsection{Inverted grip hang}

Vestibular function and muscle strength were tested with the inverted grip hang. The testing apparatus consisted of a wire grid of the following dimensions: $45 \mathrm{~cm}$ long and $30 \mathrm{~cm}$ wide, with a grid spacing of $1 \mathrm{~cm}^{2}$. Foam supports were used to suspended the grid $40 \mathrm{~cm}$ above a padded surface. Mice were placed onto the center of the grid, and 
the grid was inverted. The amount of time the mice were able to remain on the grid was recorded during a single $60 \mathrm{sec}$ trial. If the mice remained on the grid for the entire trial, or escaped over the edge of the grid, the maximum time of $60 \mathrm{sec}$ was given. Otherwise, the latency to fall from the grid was recorded (Erbel-Sieler et al., 2004). Between mice, the apparatus was cleaned with $70 \%$ EtOH to diminish odor cues.

\subsubsection{Y-maze}

Working memory was analyzed by observing spontaneous alternation behavior in the Y-maze. The maze was constructed of black plastic material and consisted of three arms (30 cm long x $8 \mathrm{~cm}$ wide x $15 \mathrm{~cm}$ high) extending at $120^{\circ}$ angles from a triangular central region (side length, $8 \mathrm{~cm}$; wall height, $15 \mathrm{~cm}$ ). Prior to use, the maze was cleaned with a $70 \%$ EtOH solution to diminish odor cues. Each mouse was placed randomly at the end of one of the arms and allowed to freely explore the maze for $10 \mathrm{~min}$. The sequence of arm entries was manually recorded, and a successful arm entry was noted when all four paws of the mouse crossed the entrance of an arm. Immediate arm re-entries (e.g. moving from arm 1 into the center and then back to arm 1) were counted as a single arm entry. Alternation was defined as successive entries into all three arms of the maze in overlapping triplet sets (e.g., 1, 3, 2 or 2, 3, 1 but not 1,2,1). The maximum number of alternations possible was calculated as the total number of recorded arm entries minus two. Alternation percentage was then determined using the following equation: (number of alternations made/maximum number of alternations possible) x 100 (Arendash et al., 2001; Jawhar et al., 2012).

\subsubsection{Cross maze}

Spontaneous alternation behavior was also analyzed in the cross maze. The maze was constructed of black plastic material and consisted of four arms $(30 \mathrm{~cm}$ long x $8 \mathrm{~cm}$ wide x $15 \mathrm{~cm}$ high) extending at $90^{\circ}$ angles from a square central region (side length, $8 \mathrm{~cm}$; wall height, $15 \mathrm{~cm}$ ). Trials were conducted and data were recorded as for the Y-Maze. However, alternation was defined as successive entries into all four arms of the maze in overlapping quadruplet sets (e.g., 1, 3, 2, 4 or 2, 3, 4, 1 but not 1, 2, 3, 1). The maximum number of alternations possible was calculated as the total number of recorded arm entries minus three. Alternation percentage was determined as for the Y-Maze (Jawhar et al., 2012). 


\subsubsection{Elevated plus maze}

The elevated plus maze was used to measure anxiety. It consisted of four arms $(15 \mathrm{~cm}$ long $\mathrm{x} 5 \mathrm{~cm}$ wide) extending at $90^{\circ}$ angles from a square central region (side length, $5 \mathrm{~cm}$ ). The entire maze was elevated $75 \mathrm{~cm}$ above a padded surface. Two of the arms situated $180^{\circ}$ from each other were enclosed on three sides by a $15 \mathrm{~cm}$ high clear plastic wall. The remaining two arms were open to the surroundings on all sides. At the start of testing, each mouse was placed in the central region facing one of the open arms. Mice were then allowed to freely explore the apparatus during a single 5 min trial. The percentage of time spent in the open arms relative to the total test duration and the distance traveled were measured using the ANY-maze video tracking system (v4.81; Stoelting) (Lister, 1987).

\subsubsection{Open field}

The open field was employed to assess exploratory behavior and general motor activity. The open field apparatus consisted of a 50 x $50 \mathrm{~cm}$ square arena with $40 \mathrm{~cm}$ high walls. The mice were given a single trial in which they were placed into the center of the open field and allowed to freely explore the enclosure for $5 \mathrm{~min}$. Total distance traveled was automatically measured by the ANY-Maze video tracking system. During the trial, rearing behavior was manually scored by an observer through the ANY-software. Rearing was defined as any instance in which the mouse stood on its hind legs to explore the environment. Rearing was scored identically regardless of whether it occurred against a wall or toward the center of the arena. Separate rearing episodes were counted if a mouse briefly returned to all four paws before standing vertically again (Archer, 1973; Hillmann et al., 2012).

\subsubsection{Morris water maze}

The Morris water maze (MWM) was used to evaluate spatial reference memory. This task was originally developed for rats but has since been modified for mice (Morris, 1981; Vorhees and Williams, 2006). The goal of the MWM is for mice to learn to use spatial cues to locate a hidden platform in a pool of water. For this experiment, a circular pool (110 cm diameter) and a circular platform (10 cm diameter) were employed. The pool was filled with tap water until the platform was submerged to a depth of $1 \mathrm{~cm}$. The water was made opaque by adding non-toxic white paint and maintained at $20 \pm 2{ }^{\circ} \mathrm{C}$ for the test duration. The pool was placed in a room with both proximal (distinct shapes taped to the north, south, east and west edges of the pool) and distal (e.g. furniture and other equipment in the room) visual cues. Overhead incandescent lights provided even 
illumination of the pool's surface. Using the ANY-Maze video tracking software, the pool was divided into four virtual quadrants and a goal region that contained the platform. These quadrants were defined based on their spatial relationship to the platform: left, right, opposite and goal quadrant, which contained the platform. Trial duration, distance traveled, swimming speed, swimming path and quadrant preference were all recorded by the ANY-Maze software.

Testing began with cued training trials. For these trials, the proximal visual cues were removed, and the platform was marked with a triangular flag. Mice were introduced into the water at the edge of the pool facing the wall. They were then given 1 min to find the submerged platform. If a mouse located the platform and remained on it for 1-2 sec, the trial automatically ended. Mice that failed to find the platform in 60 sec were gently guided to it. All mice were allowed to sit on the platform for $10 \mathrm{sec}$ before being removed from the pool. To prevent hypothermia, all mice were kept in front of a heat lamp for 3 min before being returned to their home cage. Each mouse received four training trials per day with an average inter-trial interval of $15 \mathrm{~min}$. Both the location of the platform and the position at which mice were introduced into the pool changed between trials (see (Vorhees and Williams, 2006)). Cued training continued until all groups of mice reached criterion (an average latency to locate the platform of $\leq 10 \mathrm{sec}$ for one day of trials).

After reaching criterion in the cued training trials, mice began acquisition training 24 $\mathrm{h}$ later. For this phase, the flag was removed from the platform and proximal visual cues were returned. The platform location remained stationary for each mouse throughout training. At the start of every trial, mice were introduced into the pool from one of four predefined entry points. The order in which these entry points were used varied between training days (see (Vorhees and Williams, 2006)). To avoid quadrant bias, the experimental cohorts were randomly split and trained to find one of two different platform locations. Trials were conducted as during the cued training phase. Acquisition training was terminated once all groups of mice reached criterion (see above).

Twenty-four hours after the last acquisition trial, a probe test was performed to measure spatial reference memory. The platform was removed from the pool, and mice were introduced into the water from a novel entry point. Mice were then allowed to swim freely for $1 \mathrm{~min}$ while their swimming path was recorded. Mice that have acquired a spatial search strategy tend to swim more directly to the platform location and remain close to it for the duration of the probe trial. This leads to a clear preference for the goal quadrant, indicating robust spatial memory. However, mice that learned the platform location by chance, or have weaker spatial memories, generally fail to demonstrate goal quadrant preference. 


\subsection{Molecular biology and biochemistry}

\subsubsection{Media preparation for Escherichia coli culturing}

The following media were used for culturing Escherichia coli (E. coli) bacteria.

\section{Lysogeny broth (LB) - ampicillin medium}

10 g Bacto-Tryptone (Roth), 5 g Bacto-Yeast (Roth) and $10 \mathrm{~g} \mathrm{NaCl}$ (Roth) were dissolved in $1 \mathrm{~L}$ distilled, deionized water $\left(\mathrm{ddH}_{2} \mathrm{O}\right)$. The $\mathrm{pH}$ was adjusted to 7.0 with 10 $\mathrm{M} \mathrm{NaOH}$ (Applichem), and the solution was sterilized by autoclaving. Before use, $1 \mathrm{~mL}$ ampicillin (50 mg/mL stock; Roth) was added to the medium to give a final concentration of $50 \mu \mathrm{g} / \mathrm{mL}$.

\section{LB-ampicillin agar plates}

$15 \mathrm{~g}$ of agar (Roth) were added to $1 \mathrm{~L}$ LB medium. The agar was dissolved by autoclaving. After cooling to $50{ }^{\circ} \mathrm{C}, 1 \mathrm{~mL}$ of ampicillin was added to the medium for a final ampicillin concentration of $50 \mu \mathrm{g} / \mathrm{mL}$. The sterile LB-ampicillin-agar was poured into $10 \mathrm{~cm}$ sterile Petri dishes (Greiner Bio One) and allowed to solidify under a laminar flow hood.

\section{Super optimal broth with catabolite repression (SOC) medium}

20 g Bacto-Tryptone, 5 g Bacto-Yeast, $0.5 \mathrm{~g} \mathrm{NaCl}$ and $2.5 \mathrm{~mL} 1 \mathrm{M} \mathrm{KCl}$ (Roth) were diluted in $970 \mathrm{~mL}$ in $\mathrm{ddH}_{2} \mathrm{O}$. The $\mathrm{pH}$ was adjusted to 7.0 using $10 \mathrm{M} \mathrm{NaOH}$, and the solution was sterilized by autoclaving. Immediately before use, the following filter-sterilized supplements were added to the solution: $10 \mathrm{~mL} 1 \mathrm{M} \mathrm{MgCl}_{2}$ (Sigma) and $20 \mathrm{~mL} 1 \mathrm{M}$ glucose (Sigma).

\section{$\mathrm{NZY}+$ medium}

$10 \mathrm{~g}$ NZ amine (casein hydrolysate; Fluka), 5 g Bacto-Yeast and $5 \mathrm{~g} \mathrm{NaCl}$ were added

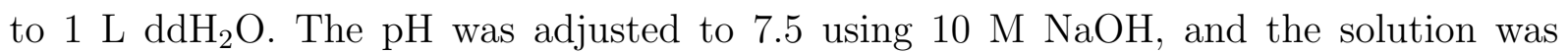
sterilized by autoclaving. The following filter-sterilized supplements were added to the solution prior to use: $12.5 \mathrm{~mL} 1 \mathrm{M} \mathrm{MgCl}_{2}, 12.5 \mathrm{~mL} 1 \mathrm{M} \mathrm{MgSO}_{4}$ (Roth) and $10 \mathrm{~mL} 2 \mathrm{M}$ glucose. 


\subsubsection{TBA1 plasmid mutagenesis}

The TBA8 plasmid was created from the TBA1 plasmid through mutagenesis performed with the QuickChange II XL Kit (Stratagene). The mutagenesis PCR reaction was set up as outlined in Table 2.6. Amplification was carried out using the cycling parameters detailed in Table 2.7. Following amplification, $1 \mu \mathrm{L}$ of $D p n$ I was added to the PCR products. Reaction mixtures were gently pipetted and then incubated in an agitating heat block (Thermomixer Compact; Eppendorf) for $1 \mathrm{~h}$ at $37^{\circ} \mathrm{C}$ and 300 revolutions per minute (rpm). XL10-Gold ultracompetent E. coli cells were thawed on ice. Forty-five $\mu \mathrm{L}$ of cells were then aliquoted into pre-chilled $15 \mathrm{~mL}$ conical tubes (Grenier Bio One) and $2 \mu \mathrm{L}$ of $\beta$-mercaptoethanol ( $\beta$-ME) were added to each aliquot. Mixtures were incubated for $10 \mathrm{~min}$ on ice, swirling gently every $2 \mathrm{~min}$. Two $\mu \mathrm{L}$ of $D p n \mathrm{I}$ - treated deoxyribonucleic acid (DNA) were added to each aliquot of $\beta$-ME treated cells, the reactions were swirled gently and then incubated $30 \mathrm{~min}$ ice. After incubation, samples were heat-pulsed for 30 sec in a $42{ }^{\circ} \mathrm{C}$ water bath and returned to ice for 2 min. NYZ+ medium (see Section 2.3.1) was preheated to $42{ }^{\circ} \mathrm{C}$, and $0.5 \mathrm{~mL}$ was added to each sample. Samples were incubated on an orbital shaker (GFL) at $250 \mathrm{rpm}$ for $1 \mathrm{~h}$ at $37^{\circ} \mathrm{C}$. Transformation reactions were then spread onto pre-warmed LB-ampicillin agar plates (see Section 2.3.1) at various dilutions (total plating volume: $250 \mu \mathrm{L}$ ). Plates were inverted and incubated for $>16 \mathrm{~h}$ at $37^{\circ} \mathrm{C}$. To screen for bacteria containing the mutagenized plasmid, individual bacterial colonies were picked and cultured in $100 \mu \mathrm{L}$ of LB-ampicillin medium (see Section 2.3.1) in a sterile 96-well plate (Grienier Bio One). Cultures were incubated on an orbital shaker at $250 \mathrm{rpm}$ for $4 \mathrm{~h}$ at $37^{\circ} \mathrm{C}$. The resulting bacterial suspensions served as templates for mutagenesis screening PCR (see Tables 2.8 and 2.9).

\subsubsection{Escherichia coli transformation}

Fifty $\mu \mathrm{L}$ aliquots of NEB $5 \alpha$ Competent E. coli (Subcloning efficiency; New England Biolabs (NEB)) were thawed on ice. Approximately 20 - 80 ng of TBA1 or TBA8 plasmid DNA were added to each aliquot at volumes of 1 or $2 \mu \mathrm{L}$. The bacteria/plasmid solutions were gently mixed by flicking the tubes, followed by $30 \mathrm{~min}$ incubation on ice. Heatshock was performed by immersing the mixtures for $30 \mathrm{sec}$ in a $42{ }^{\circ} \mathrm{C}$ water bath without mixing. After heat shock, mixtures were returned to ice for 5 min. Nine hundred fifty $\mu \mathrm{L}$ of room temperature (RT) SOC medium (see Section 2.3.1) were added to each sample, and samples were incubated on an orbital shaker at $250 \mathrm{rpm}$ for $1 \mathrm{~h}$ at $37^{\circ} \mathrm{C}$. The SOC bacterial suspension cultures were spread onto pre-warmed LB-ampicillin agar plates (see Section 2.3.1) at various dilutions (total plating volume: $100 \mu \mathrm{L}$ ). Plates were inverted 
and then incubated $\mathrm{ON}(14-16 \mathrm{~h})$ at $37{ }^{\circ} \mathrm{C}$.

\subsubsection{Plasmid purification}

Plasmid purification was performed using the reagents from the GeneJET ${ }^{T M}$ Plasmid Miniprep Kit (Fermentas). Individual colonies of transformed E. coli (see Section 2.3.3) or $5 \mu \mathrm{L}$ of $4 \mathrm{~h}$ mutagenesis screening culture (see Section 2.3.2) were introduced into a $15 \mathrm{~mL}$ tube containing $5 \mathrm{~mL}$ of LB-ampicillin medium (see Section 2.3.1). Cultures were incubated on an orbital shaker $\mathrm{ON}$ at $250 \mathrm{rpm}$ and $37^{\circ} \mathrm{C}$. After incubation, bacterial pellets were collected by centrifuging cultures at $5500 \mathrm{rpm}$ (Heraeus Megafuge 10R; Thermo Fischer Scientific) for $5 \mathrm{~min}$ at room temperature and subsequently removing the supernatant. Pellets were resuspended in $250 \mu \mathrm{L}$ of Resuspension Solution, vortexed to remove clumps and transferred to a $1.5 \mathrm{~mL}$ microcentrifuge tube. Lysis Solution was added at a volume of $250 \mu \mathrm{L}$ per sample, and samples were mixed by inverting the tubes 6 times. Samples were then incubated at RT for $4 \mathrm{~min}$. Next, $350 \mu \mathrm{L}$ of Neutralization Solution were added and immediately mixed by inverting the tubes 6 times. After centrifuging samples at 13,000 g (Heraeus Biofuge Stratos; Thermo Fischer Scientific) for 5 min at RT, the resulting supernatants were carefully removed and transferred to GeneJET ${ }^{T M}$ spin columns. Columns were centrifuged at 13,000 g for $1 \mathrm{~min}$ at RT, and the flow-through was discarded. Five hundred $\mu \mathrm{L}$ of Wash Solution were added to each column, and columns were centrifuged again at 13,000 $\mathrm{g}$ for $1 \mathrm{~min}$ at RT. Flow-through was discarded, and the column washing step was repeated an additional time. After the final wash, dry columns were centrifuged at 13,000 g for $1 \mathrm{~min}$ at RT to remove residual EtOH. Columns were then transferred to fresh $1.5 \mathrm{~mL}$ microcentrifuge tubes. Fifty $\mu \mathrm{L}$ of Elution Buffer were added to the center of each column. Columns were incubated $2 \mathrm{~min}$ at RT followed by centrifugation at 13,000 g for $2 \mathrm{~min}$ at RT. To increase plasmid recovery, the elution step was repeated with an additional $50 \mu \mathrm{L}$ of Elution Buffer, bringing the total flow-through volume to $100 \mu \mathrm{L}$. Purified plasmid was stored at $-20{ }^{\circ} \mathrm{C}$ until use.

\subsubsection{DNA sequencing}

Mutagenized plasmids were prepared for sequencing by diluting them to a concentration of $50-100 \mathrm{ng} / \mu \mathrm{L}$ in a total volume of $50 \mu \mathrm{L} \mathrm{ddH}_{2} \mathrm{O}$. Gx2425 and Gx2426 primers (see Table 2.2) were diluted to a concentration of $2 \mathrm{pmol} / \mu \mathrm{L}$ in a total volume of $20 \mu \mathrm{L}$ $\mathrm{dd}_{2} \mathrm{O}$. Plasmids and primers were sent to Eurofins MWG Operon (Ebersberg, Germany) to be sequenced using their "Value Read Tube"service. Sequencing results for the mutagenized plasmids were input into the nucleotide basic local alignment search tool (BLASTn; 
http://blast.ncbi.nlm.nih.gov/Blast.cgi) and compared against the unaltered parent sequence. Plasmid samples with the desired mutation were selected for further amplification and purification.

\subsubsection{Isolation and purification of TBA8 transgene}

EcoRI (NEB) restriction digestions were performed to isolate the TBA8 transgene cDNA insert from its pUC18 plasmid backbone. The digestion reactions were set up as follows:

\begin{tabular}{|l|c|}
\hline Reagent & Volume \\
\hline$E c o R I$ restriction enzyme $(20$ units $/ \mu \mathrm{L})$ & $5.0 \mu \mathrm{L}$ \\
\hline NEB 10 x reaction buffer I & $5.0 \mu \mathrm{L}$ \\
\hline $5 \mu \mathrm{g}$ TBA8 plasmid & $35.0 \mu \mathrm{L}$ \\
\hline $\mathrm{ddH}_{2} \mathrm{O}$ & $5.0 \mu \mathrm{L}$ \\
\hline Total volume per sample & $50.0 \mu \mathrm{L}$ \\
\hline
\end{tabular}

TABLE 2.1: Reaction mixture for EcoRI digestion of TBA8 plasmid.

Digestion reactions were incubated at $350 \mathrm{rpm}$ for $2 \mathrm{~h}$ at $37{ }^{\circ} \mathrm{C}$ in a Thermomixer Compact. The digestion products were mixed with $5 \mu \mathrm{L}$ of $10 \mathrm{x}$ agarose gel loading buffer and resolved on a $1 \% 1 \mathrm{x}$ Tris base acetic acid (TAE) agarose gel (see Section 2.3.15). Five $\mu \mathrm{L}$ of Quick-Load 1 kilobase (kb) DNA ladder (NEB) were also loaded onto the gel to serve as a standard. The gel was visualized using the low-intensity ultraviolet (UV) light setting on a GelDoc 2000 (Biorad). Bands corresponding to the TBA8 transgene insert $(7.2 \mathrm{~kb})$ were excised with a sterile scalpel. The TBA8 transgene insert was purified using the QIAquick Gel Extraction Kit (Qiagen). The manufacturer's instructions were used with the following modifications: Incubation of the gel slices with Buffer QG was performed at $1000 \mathrm{rpm}$ for $10 \mathrm{~min}$ at $50{ }^{\circ} \mathrm{C}$ in a Thermomixer Compact. All centrifugation steps were performed at RT and 16,900 g (Heraeus Biofuge Stratos). The Qiaquick spin columns were washed once with $0.5 \mathrm{~mL}$ Buffer QG and once with Buffer PE. Columns were incubated for 5 min with PE buffer prior to centrifugation. DNA was eluted from the columns using $50 \mu \mathrm{L}$ of Tris/ethylenediaminetetraacetic acid (TE) buffer ( $5 \mathrm{mM}$ Tris (pH 7.4; Roth), $0.1 \mathrm{mM}$ ethylenediaminetetraacetic acid (EDTA; Applichem)) per column.

The purified TBA8 transgene was prepared for pronuclear microinjection by diluting it to a final concentration of $30 \mathrm{ng} / \mu \mathrm{L}$ in a minimum volume of $200 \mu \mathrm{L}$ TE buffer (see above). The diluted transgene was then centrifuged twice at 14,000 g for $15 \mathrm{~min}$ at RT 
(Heraeus Biofuge Stratos). The top $80 \%$ of the transgene solution was reserved after each centrifugation, and the bottom $20 \%$ was discarded. Proof of transgene purity was provided by resolving $\approx 40 \mathrm{ng}$ of TBA 8 transgene cDNA on a $1 \%$ TAE agarose gel and comparing it against $5 \mu \mathrm{L}$ of Quick-Load $1 \mathrm{~kb}$ DNA ladder (See Section 2.3.15).

\subsubsection{Pronuclear injection of TBA8 transgene}

Pronuclear injection of the purified TBA8 transgene (see Section 2.3.6) was performed by the Transgenic Service of the Animal Facility at the Max-Planck-Institute for Experimental Medicine (Göttingen, Germany). The TBA8 transgene was injected into the pronuclei of fertilized C57BL/6J mice according to standard protocols (Ittner and Götz, 2007).

\subsubsection{DNA isolation for genotyping of transgenic mice}

Genomic DNA isolated from ear or tail biopsies was used to genotype all transgenic mouse lines. Lysis buffer (100 mM Tris/HCl (pH 8.5), 5 mM EDTA, 0.2\% SDS ((\%w/v); Roth) $200 \mathrm{mM} \mathrm{NaCl}$ and $10 \mu \mathrm{L}$ Proteinase K (20 mg/mL stock; Peqlab)) was added to ear or tail biopsies at a volume of 200 or $500 \mu \mathrm{L}$, respectively. Biopsies were incubated at $400 \mathrm{rpm}$ for $14-16 \mathrm{~h}$ at $55^{\circ} \mathrm{C}$ in a Thermomixer Compact. After incubation, samples were centrifuged at 17,000 rpm for $20 \mathrm{~min}$ at $4{ }^{\circ} \mathrm{C}$ (Heraeus Biofuge Stratos). The resulting supernatants were transferred to $1.5 \mathrm{~mL}$ microcentrifuge tubes containing $200 \mu \mathrm{L}$ (ear biopsy samples) or $500 \mu \mathrm{L}$ (tail biopsy samples) of isopropanol (Roth) and gently mixed. Solutions were then centrifuged at 13,000 rpm for $10 \mathrm{~min}$ at RT (Heraeus Biofuge 15; Sepatech). Following centrifugation, the supernatants were discarded. The DNA pellets were washed with $200 \mu \mathrm{L}$ (ear biopsy samples) or $500 \mu \mathrm{L}$ (tail biopsy samples) of $70 \%$ EtOH (Merck) and centrifuged again at 13,000 rpm for 10 min at RT. Supernatants were discarded, and the DNA pellets were dried for $30 \mathrm{~min}$ at $37^{\circ} \mathrm{C}$ in a Thermomixer Compact. Molecular-grade water (Braun) was added to each sample at a volume of $30 \mu \mathrm{L}$ (ear biopsy samples) or $50 \mu \mathrm{L}$ (tail biopsy samples). DNA was allowed to dissolve for $2-3 \mathrm{~h}$ at $55^{\circ} \mathrm{C}$ in a Thermomixer Compact before being stored at $4{ }^{\circ} \mathrm{C}$. All DNA samples were diluted to a concentration of $20 \mathrm{ng} / \mu \mathrm{L}$ in a $30 \mu \mathrm{L}$ volume of molecular grade water prior to being used for genotyping PCR. 


\subsubsection{RNA isolation from mouse brain}

Total RNA was isolated from mouse brain tissue using Trifast ${ }^{\circledR}$ reagent (Peqlab). Frozen brain hemispheres (minus the olfactory bulb) were weighed and added to $1 \mathrm{~mL}$ Trifast ${ }^{\circledR}$ per $100 \mathrm{mg}$ tissue. Samples were homogenized with 10 strokes of an R50D homogenizer (CAT) set at $800 \mathrm{rpm}$ and then incubated $5 \mathrm{~min}$ at RT for dissociation of nucleoprotein complexes. Chloroform (Merck) was added to each sample at a volume of $0.2 \mathrm{~mL}$ per $1 \mathrm{~mL}$ Trifast ${ }^{\circledR}$, samples were vigorously shaken for $15 \mathrm{sec}$ and then incubated for $10 \mathrm{~min}$ at RT. To separate the RNA, samples were centrifuged at 12,000 g for $15 \mathrm{~min}$ at $4{ }^{\circ} \mathrm{C}$ (Heraeus Biofuge Stratos). After centrifugation, the upper, RNA-containing aqueous phase was carefully transferred to a sterile $2 \mathrm{~mL}$ microcentrifuge tube. RNA was precipitated by adding $0.5 \mathrm{~mL}$ isopropanol per $1 \mathrm{~mL}$ Trifast ${ }^{\circledR}$ to each sample, gently mixing and then incubating for $20 \mathrm{~min}$ on ice. Samples were subsequently centrifuged at 12,000 $\mathrm{g}$ for $10 \mathrm{~min}$ at $4{ }^{\circ} \mathrm{C}$. The supernatant was discarded. RNA pellets were washed twice by adding a volume of $75 \% \mathrm{EtOH}$ equivalent to that of the isopropanol and centrifuging at 7,500 g for $10 \mathrm{~min}$ at $4{ }^{\circ} \mathrm{C}$. After washing, residual EtOH was carefully removed. RNA pellets were then dried for $15 \mathrm{~min}$ at RT. To dissolve the RNA, $30 \mu \mathrm{L}$ of $\mathrm{ddH}_{2} \mathrm{O}$ were added to each sample, and samples were incubated 20 min on ice. RNA was stored at -80 ${ }^{\circ} \mathrm{C}$ until use.

\subsubsection{Nucleic acid concentration measurement}

DNA and RNA concentrations were measured using the double-stranded DNA (dsDNA) and RNA settings of the Biophotometer (Eppendorf). Two $\mu \mathrm{L}$ of each sample

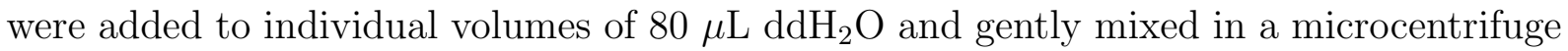
tube. Prior to sample measurement, $82 \mu \mathrm{L}$ of molecular grade water was used as a blank for the photometry readings. Samples were added to Uvette ${ }^{\circledR}$ 220-1600 nm cuvettes (Eppendorf), and the volumes of sample and diluent were input into the photometer. Concentration measurements were considered accurate if the 260/280 and 260/230 absorbance ratios were between 1.6 and 2.0.

\subsubsection{Reverse transcription}

Total RNA isolated from brain tissue (see Section 2.3.9) was used as a template for cDNA synthesis. Prior to reverse transcription, RNA was digested by deoxyribonuclease I (DNase I) (Fermentas). In brief, $1 \mu \mathrm{g}$ of RNA was added to a $500 \mu \mathrm{L}$ microcentrifuge tube containing $1 \mu \mathrm{L}$ of $10 \mathrm{x}$ reaction buffer with $\mathrm{MgCl}_{2}$ and $1 \mu \mathrm{L}$ of $(1$ unit/ $\mu \mathrm{L}$ ) DNase 
I. The reaction mixtures were brought to a total volume of $10 \mu \mathrm{L}$ using $\mathrm{ddH}_{2} \mathrm{O}$. Samples were then incubated 30 min at $37^{\circ} \mathrm{C}$ in an UNO-Thermoblock thermal cycler (Biometra). To inactivate the DNase, $1 \mu \mathrm{L}$ of $25 \mathrm{mM}$ EDTA was added to each reaction mixture, and samples were incubated for $10 \mathrm{~min}$ at $65{ }^{\circ} \mathrm{C}$. The entire volume $(11 \mu \mathrm{L})$ of DNase-digested sample was used as a template for reverse transcription.

cDNA was synthesized using the First Strand cDNA Synthesis Kit (Fermentas). Reverse transcription reaction mixtures were prepared by adding reagents into a sterile 500 $\mu \mathrm{L}$ microcentrifuge tube in the following order: DNase digested RNA template $(11 \mu \mathrm{L}), 1$ $\mu \mathrm{L}$ random hexamer primer, $4 \mu \mathrm{L} 5$ x reaction buffer, $1 \mu \mathrm{L}$ RiboLock ${ }^{\circledR}$ RNase inhibitor $(20$ units $/ \mu \mathrm{L}), 2 \mu \mathrm{L} 10 \mathrm{mM}$ dNTP mix and $2 \mu \mathrm{L}$ M-MuLV reverse transcriptase $(20 \mathrm{units} / \mu \mathrm{L})$. Total reaction volume equaled $21 \mu \mathrm{L}$. Reaction mixtures were incubated $5 \mathrm{~min}$ at $25{ }^{\circ} \mathrm{C}$, $1 \mathrm{~h}$ at $37^{\circ} \mathrm{C}$ and 5 min at $70{ }^{\circ} \mathrm{C}$ in an UNO-Thermoblock thermal cycler.

\subsubsection{Primers}

All primers were used at a final concentration of $10 \mathrm{pmol} / \mu \mathrm{L}$ (1:10 dilution of the 100 $\mathrm{pmol} / \mu \mathrm{L}$ primer stock, prepared in $\mathrm{dd}_{2} \mathrm{O}$ ). In the table below, amplicon size (A; third column) is given in base pairs.

\begin{tabular}{|c|c|c|c|}
\hline Name & Sequence $\left(\mathbf{5}^{\prime} \mathbf{- 3} \mathbf{\prime}^{\prime}\right)$ & A & Usage \\
\hline A $\beta 3$-42v2 for & TCC GGC CAG AAC GTC GAT TC & 248 & genotyping, qPCR \\
\hline A $\beta 3-42 \mathrm{v} 2$ rev & GGA GAA GCA AGA CCT CTG C & 248 & genotyping, qPCR \\
\hline Gx2425 & AGT AAT GAA GTC ACC CAG CAG GGA GG & 505 & $\begin{array}{c}\text { mutagenesis screening, } \\
\text { sequencing }\end{array}$ \\
\hline Gx3426 & TGA TCC AGG AAT CTA AGG CAG CAC C & 505 & $\begin{array}{c}\text { mutagenesis screening, } \\
\text { sequencing }\end{array}$ \\
\hline TBA1-delGlu3-for & CCT GGA TCA CAA AAC GCT TCC GAC ATG ACT CAG G & - & TBA1 mutagenesis \\
\hline TBA1-delGlu3-rev & CCT GAG TCA TGT CGG AAG CGT TTT GTG ATC CAG G & - & TBA1 mutagenesis \\
\hline hAPP for & GTA GCA GAG GAA GAA GTG & 250 & genotyping \\
\hline hAPP rev & CAT GAC CTG GGA CAT TCT C & 250 & genotyping \\
\hline $\begin{array}{c}\text { Qiagen mouse } \\
\beta \text {-actin mix }\end{array}$ & proprietary sequence & 149 & qPCR \\
\hline
\end{tabular}

TABLE 2.2: List of primers used for qPCR, mouse genotyping and plasmid mutagenesis.

\subsubsection{Quantitative real-time polymerase chain reaction ( $\mathrm{qPCR}$ )}

Analysis of brain transgene expression in the TBA4 and TBA8 lines was performed using the DyNAmo ${ }^{T M}$ Flash SYBR ${ }^{\circledR}$ Green qPCR Kit (Thermo Fischer Scientific). cDNA prepared as described in Section 2.3.11 was diluted 1:10 in $\mathrm{ddH}_{2} \mathrm{O}$ to serve as the sample 
qPCR template. Undiluted cDNA from all samples was pooled and serially diluted (undiluted, 1:10, 1:100, 1:1000) in $\mathrm{ddH}_{2} \mathrm{O}$ to create a standard curve of fluorescence intensity versus cDNA concentration. qPCR reactions were set up on ice as described in Tables 2.3 and 2.4. The primers used in the reactions are listed in Table 2.2. cDNA dilutions were first pipetted into $200 \mu \mathrm{L}$ PCR tubes (Biozym Scientific) followed by the qPCR reaction mix. Before starting the qPCR, tubes were briefly centrifuged using the Spectrafuge Mini (Labnet Inc.) to remove air bubbles. The mouse $\beta$-actin gene was used as an internal reference for normalizing transgene $\mathrm{CT}$ values. Mouse $\beta$-actin primers were purchased as a mix from Qiagen. qPCR reactions were performed in the Mx3000P cycler (Stratagene) according to the program outlined in Table 2.5. Data were collected using the MxPro Mx3000P software (Stratagene).

\begin{tabular}{|l|c|}
\hline Reagent & Volume \\
\hline 1:10 cDNA dilution & $1.0 \mu \mathrm{L}$ \\
\hline DyNAmo $^{T M}$ Flash master mix & $10.0 \mu \mathrm{L}$ \\
\hline Rox dye & $0.2 \mu \mathrm{L}$ \\
\hline Qiagen mouse $\beta$-actin primer mix & $2.5 \mu \mathrm{L}$ \\
\hline ddH $_{2} \mathrm{O}$ & $6.3 \mu \mathrm{L}$ \\
\hline Total volume per sample & $20.0 \mu \mathrm{L}$ \\
\hline
\end{tabular}

TABLE 2.3: qPCR reaction mixture using Qiagen primers.

\begin{tabular}{|l|c|}
\hline Reagent & Volume \\
\hline 1:10 cDNA dilution & $1.0 \mu \mathrm{L}$ \\
\hline DyNAmo $^{T M}$ Flash master mix & $10.0 \mu \mathrm{L}$ \\
\hline Rox dye & $0.2 \mu \mathrm{L}$ \\
\hline $\mathrm{A} \beta 3-42 \mathrm{v} 2$ for primer & $1.5 \mu \mathrm{L}$ \\
\hline $\mathrm{A} \beta 3-42 \mathrm{v} 2$ rev primer & $1.5 \mu \mathrm{L}$ \\
\hline ddH $_{2} \mathrm{O}$ & $5.8 \mu \mathrm{L}$ \\
\hline Total volume per sample & $20.0 \mu \mathrm{L}$ \\
\hline
\end{tabular}

TABLE 2.4: qPCR reaction mixture using TBA transgene primers. 


\begin{tabular}{|c|c|c|}
\hline Step & Temperature & Duration \\
\hline 1 & $95{ }^{\circ} \mathrm{C}$ & $10 \mathrm{~min}$ \\
\hline 2 & $95{ }^{\circ} \mathrm{C}$ & $15 \mathrm{sec}$ \\
\hline 3 & $64{ }^{\circ} \mathrm{C}$ & $20 \mathrm{sec}$ \\
\hline 4 & $72{ }^{\circ} \mathrm{C}$ & $30 \mathrm{sec}$ \\
\hline 5 & repeat steps $2-4$ & a total of 40 times \\
\hline 6 & $95{ }^{\circ} \mathrm{C}$ & $1 \mathrm{~min}$ \\
\hline 7 & $55{ }^{\circ} \mathrm{C}$ & $30 \mathrm{sec}$ \\
\hline 8 & $4{ }^{\circ} \mathrm{C}$ & $\infty$ \\
\hline
\end{tabular}

TABLE 2.5: qPCR program for TBA transgene expression analysis.

\subsubsection{Polymerase chain reaction (PCR)}

All reactions were carried out in $0.2 \mu \mathrm{L}$ PCR tubes (Greiner Bio One) using the LabCycler (SensoQuest). Reagents for the reaction mixtures listed in Tables 2.8, 2.10 and 2.11 were provided from the following companies: 10x reaction buffer, $25 \mathrm{mM} \mathrm{MgCl}$ and Taq polymerase (Axon); dNTPs (100 mM dNTP set, diluted to $2 \mathrm{mM}$ stock; Invitrogen). Refer to Table 2.2 for primer details.

\section{Mutagenesis PCR}

\begin{tabular}{|l|c|}
\hline Reagent & Volume \\
\hline 10x reaction buffer & $5.0 \mu \mathrm{L}$ \\
\hline TBA1 plasmid (150 ng) & $6.7 \mu \mathrm{L}$ \\
\hline TBA1-delGlu3-for primer $(125 \mathrm{ng})$ & $1.2 \mu \mathrm{L}$ \\
\hline TBA1-delGlu3-rev primer $(125 \mathrm{ng})$ & $1.2 \mu \mathrm{L}$ \\
\hline dNTPs & $1.0 \mu \mathrm{L}$ \\
\hline QuickSolution & $3.0 \mu \mathrm{L}$ \\
\hline dd ${ }_{2} \mathrm{O}$ & $31.9 \mu \mathrm{L}$ \\
\hline PfuUltra HF DNA polymerase $(2.5$ units $/ \mu \mathrm{L})$ & $1.0 \mu \mathrm{L}$ \\
\hline Total volume per sample & $51.0 \mu \mathrm{L}$ \\
\hline
\end{tabular}

TABLE 2.6: PCR reaction mixture for TBA1 plasmid mutagenesis. 


\begin{tabular}{|c|c|c|}
\hline Step & Temperature & Duration \\
\hline 1 & $95{ }^{\circ} \mathrm{C}$ & $1 \mathrm{~min}$ \\
\hline 2 & $95{ }^{\circ} \mathrm{C}$ & $50 \mathrm{sec}$ \\
\hline 3 & $60{ }^{\circ} \mathrm{C}$ & $50 \mathrm{sec}$ \\
\hline 4 & $68{ }^{\circ} \mathrm{C}$ & 25 min \\
\hline 5 & repeat steps $2-4$ & a total of 18 times \\
\hline 6 & $68{ }^{\circ} \mathrm{C}$ & 7 min \\
\hline 7 & $4{ }^{\circ} \mathrm{C}$ & $\infty$ \\
\hline
\end{tabular}

TABLE 2.7: PCR program for TBA1 plasmid mutagenesis.

\section{Mutagenesis screening PCR}

PCR reactions were prepared using $4 \mathrm{~h}$ bacterial suspension cultures as a template (see Section 2.3.2). Cultures known to carry the unaltered TBA1 plasmid or no plasmid were used as positive and negative controls, respectively. Samples that produced PCR products smaller than those resulting from the unaltered TBA1 plasmid were considered to potentially contain the TBA8 mutation (deletion). The appropriate bacterial cultures were then selected for further expansion, plasmid purification and sequencing.

\begin{tabular}{|l|c|}
\hline Reagent & Volume \\
\hline Bacterial suspension & $3.0 \mu \mathrm{L}$ \\
\hline Gx3425 primer & $1.0 \mu \mathrm{L}$ \\
\hline Gx3426 primer & $1.0 \mu \mathrm{L}$ \\
\hline $\mathrm{dNTPs}(2 \mathrm{mM})$ & $2 \mu \mathrm{L}$ \\
\hline $\mathrm{MgCl}_{2}(25 \mathrm{mM})$ & $1.6 \mu \mathrm{L}$ \\
\hline $10 \mathrm{x}$ reaction buffer & $2.0 \mu \mathrm{L}$ \\
\hline $\mathrm{ddH}_{2} \mathrm{O}$ & $9.4 \mu \mathrm{L}$ \\
\hline Taq polymerase $(5$ units $/ \mu \mathrm{L})$ & $0.2 \mu \mathrm{L}$ \\
\hline Total volume per sample & $20.2 \mu \mathrm{L}$ \\
\hline
\end{tabular}

TABLE 2.8: PCR reaction mixture for screening bacterial cultures for mutagenized plasmids. 


\begin{tabular}{|c|c|c|}
\hline Step & Temperature & Duration \\
\hline 1 & $94{ }^{\circ} \mathrm{C}$ & $2 \mathrm{~min}$ \\
\hline 2 & $94{ }^{\circ} \mathrm{C}$ & $30 \mathrm{sec}$ \\
\hline 3 & $65{ }^{\circ} \mathrm{C}$ & $30 \mathrm{sec}$ \\
\hline 4 & $68{ }^{\circ} \mathrm{C}$ & 5 min \\
\hline 5 & repeat steps $2-4$ & a total of 35 times \\
\hline 6 & $68{ }^{\circ} \mathrm{C}$ & 8 min \\
\hline 7 & $4{ }^{\circ} \mathrm{C}$ & $\infty$ \\
\hline
\end{tabular}

TABLE 2.9: PCR program for screening bacterial cultures for mutagenized plasmids.

\section{Mouse genotyping PCR}

\begin{tabular}{|l|c|}
\hline Reagent & Volume \\
\hline DNA $(20 \mathrm{ng} / \mu \mathrm{L})$ & $2.0 \mu \mathrm{L}$ \\
\hline $\mathrm{A} \beta 3-42 \mathrm{v} 2$ for primer & $1.0 \mu \mathrm{L}$ \\
\hline $\mathrm{A} \beta 3-42 \mathrm{v} 2 \mathrm{rev}$ primer & $1.0 \mu \mathrm{L}$ \\
\hline $\mathrm{dNTPs}(2 \mathrm{mM})$ & $2.0 \mu \mathrm{L}$ \\
\hline $\mathrm{MgCl}_{2}(25 \mathrm{mM})$ & $1.6 \mu \mathrm{L}$ \\
\hline $10 \mathrm{x}$ reaction buffer & $2.0 \mu \mathrm{L}$ \\
\hline $\mathrm{ddH}_{2} \mathrm{O}$ & $10.2 \mu \mathrm{L}$ \\
\hline Taq polymerase $(5$ units $/ \mu \mathrm{L})$ & $0.2 \mu \mathrm{L}$ \\
\hline Total volume per sample & $20.0 \mu \mathrm{L}$ \\
\hline
\end{tabular}

TABLE 2.10: PCR reaction mixture for genotyping TBA and FAD42 mice. 


\begin{tabular}{|l|c|}
\hline Reagent & Volume \\
\hline DNA $(20 \mathrm{ng} / \mu \mathrm{L})$ & $2.0 \mu \mathrm{L}$ \\
\hline hAPP for primer & $0.5 \mu \mathrm{L}$ \\
\hline hAPP rev primer & $0.5 \mu \mathrm{L}$ \\
\hline $\mathrm{dNTPs}^{2}(\mathrm{mM})$ & $2.0 \mu \mathrm{L}$ \\
\hline $\mathrm{MgCl}_{2}(25 \mathrm{mM})$ & $3.2 \mu \mathrm{L}$ \\
\hline $10 \mathrm{x}$ reaction buffer & $2.0 \mu \mathrm{L}$ \\
\hline ddH $_{2} \mathrm{O}$ & $9.6 \mu \mathrm{L}$ \\
\hline Taq polymerase $(5$ units $/ \mu \mathrm{L})$ & $0.2 \mu \mathrm{L}$ \\
\hline Total volume per sample & $20.0 \mu \mathrm{L}$ \\
\hline
\end{tabular}

TABLE 2.11: PCR reaction mixture for genotyping 5XFAD and FAD42 mice.

\begin{tabular}{|c|c|c|}
\hline Step & Temperature & Duration \\
\hline 1 & $94{ }^{\circ} \mathrm{C}$ & 3 min \\
\hline 2 & $94{ }^{\circ} \mathrm{C}$ & $45 \mathrm{sec}$ \\
\hline 3 & $58{ }^{\circ} \mathrm{C}$ & 1 min \\
\hline 4 & $72{ }^{\circ} \mathrm{C}$ & 1 min \\
\hline 5 & repeat steps $2-4$ & a total of 35 times \\
\hline 6 & $72{ }^{\circ} \mathrm{C}$ & 5 min \\
\hline 7 & $4{ }^{\circ} \mathrm{C}$ & $\infty$ \\
\hline
\end{tabular}

TABLE 2.12: PCR program for genotyping TBA, 5XFAD and FAD42 mice.

\subsubsection{DNA electrophoresis}

PCR and restriction digestion products were analyzed using agarose gel electrophoresis. Ninety $\mathrm{mL}$ of the required $1 \mathrm{x}$ buffer were mixed with $2.25,1.8$ or $0.9 \mathrm{~g}$ of the appropriate agarose (see Table 2.13 ) to prepare $2.5 \%, 2 \%$ or $1 \%$ gels, respectively. The mixture was boiled in a microwave at $500 \mathrm{~W}$ until the agarose was completely dissolved. Ethidium bromide (10 mg/mL; Roth) was mixed into the agarose solution to yield a final concentration of $0.66 \mu \mathrm{g} / \mathrm{mL}$. Once the agarose solution was slightly cooled, it was poured into a casting tray with a 20-pocket sample comb, the air bubbles were removed, and it was left at RT until solidified. After the gel had set, the comb was removed. The gel was then placed in an electrophoresis chamber containing the same $1 \mathrm{x}$ buffer as used to prepare the gel. Ten $\mu \mathrm{L}$ of PCR product or $25 \mu \mathrm{L}$ of restriction digestion product were 
mixed with 1 or $2 \mu \mathrm{L}$ of $10 \mathrm{x}$ agarose gel sample buffer, respectively, and pipetted into individual wells. Five $\mu \mathrm{L}$ of the appropriate ladder were also added to a single well on each gel (see Table 2.13). The electrophoresis chamber was connected to a Powerpack P25 power supply (Biometra) set to $110 \mathrm{~V}$. The gel was run for $30-60 \mathrm{~min}$ to resolve the DNA and then visualized under UV light using the Gel Doc 2000 (Biorad). All gels were documented with the Quantity One software package (v4.30; Biorad).

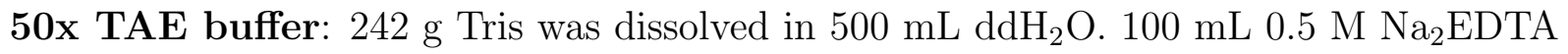
( $\mathrm{pH}$ 8.0; Roth) and $57.1 \mathrm{~mL}$ glacial acetic acid (Applichem) were then added. The volume was adjusted to $1 \mathrm{~L}$ with $\mathrm{ddH}_{2} \mathrm{O}$. This solution was diluted 1:50 in $\mathrm{ddH}_{2} \mathrm{O}$ prior to use.

10x Tris/borate/ethylenediaminetetraacetic acid (TBE) buffer: $108 \mathrm{~g}$ Tris and

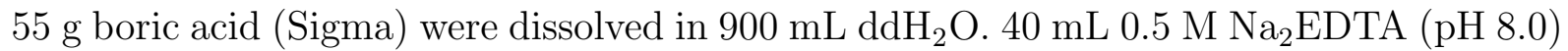
was added, and the volume was adjusted to $1 \mathrm{~L}$ with $\mathrm{ddH}_{2} \mathrm{O}$. This solution was diluted 1:10 in $\mathrm{ddH}_{2} \mathrm{O}$ before use.

10x agarose gel sample buffer: $250 \mathrm{mg}$ bromophenol blue (Riedel de Haen) was dis-

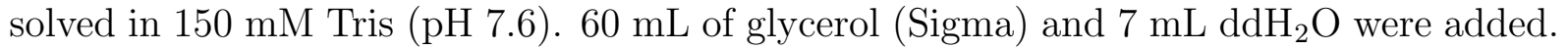
The completed buffer was diluted 1:10 directly in the sample of interest.

\begin{tabular}{|c|c|c|c|c|}
\hline Experiment & Gel \% & Agarose & Buffer & DNA ladder \\
\hline Genotyping & 2 & $\begin{array}{c}\text { standard agarose } \\
\text { (Axon) }\end{array}$ & TBE & $100 \mathrm{bp}$ (Bioron) \\
\hline Mutagenesis screening & 2.5 & standard agarose & TAE & Quick-load $1 \mathrm{~kb}(\mathrm{NEB}), 100 \mathrm{bp}$ \\
\hline Restriction digestion & 1 & $\begin{array}{c}\text { SeaKem GTG agarose } \\
\text { (Biozym) }\end{array}$ & TAE & Quick-load $1 \mathrm{~kb}$ \\
\hline Transgene verification & 1 & standard agarose & TAE & Quick-load $1 \mathrm{~kb}$ \\
\hline
\end{tabular}

TABLE 2.13: Parameters and reagents for agarose gel electrophoresis.

\subsubsection{Protein isolation from mouse brain}

All biochemical analyses were performed using protein extracted via the following method, unless otherwise noted. Frozen brains ( $\mathrm{n}=3-4$ per group) were homogenized on ice in Tris buffered saline (TBS; $120 \mathrm{mM} \mathrm{NaCl}, 50 \mathrm{mM}$ Tris, pH 8.0) containing complete protease inhibitor tablets (Roche) using an R50D homogenizer (CAT) at $800 \mathrm{rpm}$. The extraction ratio (brain tissue:TBS) was 1:8 (w/v). Samples were centrifuged at 27,000 g for $20 \mathrm{~min}$ at $4{ }^{\circ} \mathrm{C}$ (Heraeus Biofuge Stratos). Supernatants (TBS fractions) were removed, and the remaining pellets were resuspended in $0.8 \mathrm{~mL} 2 \%$ SDS $(\% \mathrm{w} / \mathrm{v})$ with complete 
protease inhibitor, sonicated with a Branson Sonifier 100 at intensity 2 (G. Heinemann Ultaschall und Labortechnik) and centrifuged at 27,000 g for 15 min at $4{ }^{\circ} \mathrm{C}$. The resulting supernatants (SDS fractions) were treated with $1 \mu \mathrm{L}$ benzonase (Novagen) and incubated 10 min at $4{ }^{\circ} \mathrm{C}$ on a rotary wheel. All fractions were stored at $-80{ }^{\circ} \mathrm{C}$ until use.

\subsubsection{Protein concentration determination}

Protein concentration was measured using the Roti ${ }^{\circledR}$-Quant universal colorimetric protein concentration analysis kit (Roth). Samples and standards were prepared in triplicate according to a modified version of the micro preparation protocol. In brief, a stock solution of $2 \mathrm{mg} / \mathrm{mL}$ albumin fraction $\mathrm{V}$ (Roth) in 0.01 M PBS was diluted to produce a standard curve of BSA (bovine serum albumin) versus optical density at $492 \mathrm{~nm}$. The following BSA standard dilutions were prepared in a total volume of $200 \mu \mathrm{L} 0.01 \mathrm{M}$ PBS: 2000, 1500, 1000, 750, 500, 250, 125 and $0 \mu \mathrm{g} / \mathrm{mL}$ (blank). TBS protein lysates were diluted 1:10 and SDS protein lysates were diluted 1:20 in 0.01 M PBS to give a total volume of $200 \mu \mathrm{L}$. Working solution was prepared by mixing 15 parts Reagent 1 with 1 part Reagent 2 from the Roti ${ }^{\circledR}$-Quant universal kit. Fifty $\mu$ L of each standard, sample and blank were pipetted in triplicate into a 96 well plate. One hundred $\mu \mathrm{L}$ of working solution were then added to each well using a repeat pipettor (Eppendorf). The samples were gently agitated on a plate mixer, incubated for $30 \mathrm{~min}$ at $37^{\circ} \mathrm{C}$ and cooled for $5 \mathrm{~min}$ at RT. Sample and standard absorbance values were measured at $492 \mathrm{~nm}$ using a $\mu$ Quant plate reader (BioTek Instruments, Inc.) controlled the MikroWin 2000 software package (v4.04; Mikrotek). Protein sample concentrations were calculated relative to the standard curve and multiplied by the dilution factor to give the final concentration.

\subsubsection{Enzyme-linked immunosorbent assay (ELISA)}

ELISA measurements were performed by the group of Stephan Schilling and HansUlrich Demuth at Probiodrug AG in Halle, Germany. Quantitative measurements of $\mathrm{A} \beta_{x-42}$ and $\mathrm{A} \beta_{p E 3-x}$ in the TBS and SDS mouse brain fractions were performed according to the manufacturer's instructions using the amyloid-beta (1-42) and amyloid-beta (N3pE42) ELISA kits, respectively (IBL International). All samples were run in triplicate, and $\mathrm{A} \beta$ levels were normalized to brain wet weight. 


\subsubsection{Glutaminyl cyclase enzyme activity measurement}

QC enzyme activity was measured by the group of Stephan Schilling and Hans-Ulrich Demuth at Probiodrug AG in Halle, Germany. The protocol has been previously described (Schilling et al., 2011). In brief, mouse brain hemispheres were homogenized in lysis buffer (10 mM Tris, $100 \mathrm{mM} \mathrm{NaCl,} 5 \mathrm{~mm}$ EDTA, 0.5\% Triton X-100, and 10\% glycerol, pH 7.5) using a Precellys homogenizer (Peqlab). The homogenate was further sonicated and centrifuged at $16,000 \mathrm{~g}$ for $30 \mathrm{~min}$ at $4{ }^{\circ} \mathrm{C}$. Reactions were carried out at $37^{\circ} \mathrm{C}$ in $25 \mathrm{mM} 3$ (N-morpholino)propanesulfonic acid (MOPS; pH 7.0, $0.1 \mathrm{mM}$ N-ethylmaleinimide). After centrifugation at 16,000 g for $10 \mathrm{~min}$, the supernatant was applied to high performance liquid chromatography (HPLC) analyses using an RP18 LiChroCART HPLC Cartridge and the HPLC system D-7000 (Merck-Hitachi). The samples were injected and separated by increasing the concentration of solvent $\mathrm{A}$ (acetonitrile containing $0.1 \%$ trifluoroacetic acid (TFA)) from 8 to $20 \%$ in solvent $\mathrm{B}\left(\mathrm{H}_{2} \mathrm{O}\right.$ containing $0.1 \%$ TFA). QC activity was quantified from a standard curve of pGlu-naphthylamide (Bachem) determined under assay conditions.

\subsection{Mass spectrometric analysis of mouse brain}

Mass spectrometric analysis of mouse brain tissue was carried out by the group of Erik Portelius and Kaj Blennow at the University of Gothenburg, Sweden. Homogenization of brain tissue was performed as described previously (Portelius et al., 2009). Briefly, the brains $\left(\approx 50 \mathrm{mg}\right.$ ) were homogenized (Pellet Pestle ${ }^{\circledR}$, Sigma-Aldrich) on ice in TBS (20mM Tris, $137 \mathrm{mM} \mathrm{NaCl}$, pH 7.6) with complete protease inhibitor tablets (Roche). The extraction ratio (brain tissue:TBS) was 1:5 (w/v). Formic acid (FA) was added to the sample (final concentration 70\%) and followed by sonication (Power: 15, Amplit.microns; TUne: "middle") and centrifugation at $30,000 \mathrm{~g}$ for $1 \mathrm{~h}$ at $4{ }^{\circ} \mathrm{C}$. The FA-soluble $\mathrm{A} \beta$ extract was dried and dissolved in FA and finally neutralized using 0.5 M Tris.

Immunoprecipitation (IP) using the KingFisher magnetic particle processor (Thermo Fischer Scientific) and mass spectrometric analysis using matrix-assisted-laser-desorption/ ionization time-of-flight/time-of-flight (MALDI TOF/TOF) mass spectrometry (MS) were performed as described earlier (Portelius et al., 2007). Briefly, an aliquot (4 $\mu \mathrm{L}, 1 \mathrm{mg} / \mathrm{mL}$ ) of the $\mathrm{A} \beta$-specific antibodies $6 \mathrm{E} 10$ and $4 \mathrm{G} 8$ was separately added to $50 \mu \mathrm{L}$ Dynabeads M-280 sheep anti-mouse IgG (Invitrogen) according to the manufacturer's product description. The washed beads with bound antibody (50 $\mu \mathrm{L} 6 \mathrm{E} 10$ and $50 \mu \mathrm{L} 4 \mathrm{G} 8$ ) were combined and used for IP of the neutralized FA fraction. IP of brain tissue with the 
antibody 1-57 was conducted as described above.

The bead/FA fraction was transferred to a KingFisher magnetic particle processor for automatic washing and elution of the $\mathrm{A} \beta$ isoforms. The collected supernatant was dried in a vacuum centrifuge and redissolved in $5 \mu \mathrm{L} 0.1 \% \mathrm{FA}$ in $20 \%$ acetonitrile. MS measurements were performed using a Bruker Daltonics UltraFlex MALDI TOF/TOF instrument (Bruker Daltonics).

\subsection{Antibodies}

\begin{tabular}{|c|c|c|c|c|c|c|}
\hline Name & Host & Epitope & Stock conc. & Working dilution & Company & Use \\
\hline $4 \mathrm{G} 8$ & mouse & $\mathrm{A} \beta_{18-22}$ & $1 \mathrm{mg} / \mathrm{mL}$ & $\begin{array}{c}1: 500(\mathrm{TBA} 42 \mathrm{IH}) \\
1: 1000(5 \mathrm{XFAD}, \mathrm{FAD} 42 \mathrm{IH}) \\
1: 13.5(\mathrm{IP})\end{array}$ & Covance & $\mathrm{IP}, \mathrm{IH}$ \\
\hline $2-48$ & mouse & $\mathrm{A} \beta_{p E 3-7}$ & $1 \mathrm{mg} / \mathrm{mL}$ & $\begin{array}{c}1: 250(\mathrm{TBA} 42 \mathrm{IH}) \\
1: 500(5 \mathrm{XFAD}, \mathrm{FAD} 42 \mathrm{IH})\end{array}$ & Synaptic Systems & $\mathrm{IH}$ \\
\hline $1-57$ & mouse & $\mathrm{A} \beta_{p E 3-5}$ & $1 \mathrm{mg} / \mathrm{mL}$ & $1: 13.5$ & Synaptic Systems & IP \\
\hline $6 \mathrm{E} 10$ & mouse & $\mathrm{A} \beta_{3-8}$ & $1 \mathrm{mg} / \mathrm{mL}$ & $1: 13.5$ & Covance & IP \\
\hline GFAP & rabbit & $\begin{array}{c}\text { GFAP } \\
\text { polyclonal }\end{array}$ & $1 \mathrm{mg} / \mathrm{mL}$ & $1: 2000$ & Synaptic Systems & $\mathrm{IH}$ \\
\hline G2-11 & mouse & $\mathrm{A} \beta_{33-42}$ & $1 \mathrm{mg} / \mathrm{mL}$ & $1: 2000$ & The Genetics Company & $\mathrm{IH}$ \\
\hline $\mathrm{A} \beta[\mathrm{N}]$ & rabbit & $\begin{array}{l}\mathrm{A} \beta \text { N-terminus } \\
\text { polyclonal }\end{array}$ & $0.1 \mathrm{mg} / \mathrm{mL}$ & $1: 2000$ & IBL & $\mathrm{IH}$ \\
\hline 24311 & rabbit & $\mathrm{A} \beta$ polyclonal & - & $1: 500$ & Bayer lab & $\mathrm{IH}$ \\
\hline CatD & rabbit & $\begin{array}{l}\text { cathepsin D } \\
\text { polyclonal }\end{array}$ & $11.7 \mathrm{mg} / \mathrm{mL}$ & $1: 500$ & Dako & $\mathrm{IH}$ \\
\hline Syn16 & rabbit & $\begin{array}{l}\text { syntaxin } 16 \mathrm{~b} \\
\text { polyclonal }\end{array}$ & $1 \mathrm{mg} / \mathrm{mL}$ & $1: 2000$ & Synaptic Systems & $\mathrm{IH}$ \\
\hline Vtilb & rabbit & $\begin{array}{c}\text { vti1b } \\
\text { polyclonal }\end{array}$ & - & $1: 250$ & Synaptic Systems & $\mathrm{IH}$ \\
\hline NeuN & mouse & $\begin{array}{l}\text { neuronal nuclei } \\
\text { clone A60 }\end{array}$ & $1 \mathrm{mg} / \mathrm{mL}$ & $1: 500$ & Millipore & $\mathrm{IH}$ \\
\hline
\end{tabular}

TABLE 2.14: Primary antibodies used for immunohistochemistry (IH) and IP/MS (IP). 


\begin{tabular}{|c|c|c|c|}
\hline Antibody & Stock conc. & Working dilution & Company \\
\hline $\begin{array}{c}\text { Rabbit anti-mouse immunoglobulins, } \\
\text { biotinylated }\end{array}$ & - & $1: 200$ & Dako \\
\hline $\begin{array}{c}\text { Swine anti-rabbit immunoglobulins, } \\
\text { biotinylated }\end{array}$ & - & $1: 200$ & Dako \\
\hline $\begin{array}{c}\text { Alexa Fluor }{ }^{\circledR} 594 \text {-conjugated } \\
\text { immunoglobulins, chicken anti-mouse }\end{array}$ & $2 \mathrm{mg} / \mathrm{mL}$ & $1: 300$ & Invitrogen \\
\hline $\begin{array}{c}\text { Alexa Fluor }{ }^{\circledR} 488 \text {-conjugated } \\
\text { immunoglobulins, chicken anti-rabbit }\end{array}$ & $2 \mathrm{mg} / \mathrm{mL}$ & $1: 300$ & $\begin{array}{c}\text { Thermo Fischer } \\
\text { Scientific }\end{array}$ \\
\hline $\begin{array}{c}\text { DyLight594 conjugated } \\
\text { immunoglobulins, goat anti-mouse }\end{array}$ & $1 \mathrm{mg} / \mathrm{mL}$ & $1: 300$ & $\begin{array}{c}\text { Thermo Fischer } \\
\text { Scientific }\end{array}$ \\
\hline $\begin{array}{c}\text { DyLight488 conjugated } \\
\text { immunoglobulins, goat anti-rabbit }\end{array}$ & $1 \mathrm{mg} / \mathrm{mL}$ & $1: 300$ & \\
\hline
\end{tabular}

TABLE 2.15: Polyclonal secondary antibodies used for immunohistochemistry.

\subsection{Immunohistochemistry}

\subsubsection{Paraffin embedding of mouse brain and spinal cord}

Following fixation (see Section 2.1.7), brain and spinal cord tissues were placed in the TP 1020 Automatic Tissue Processor (Leica) for dehydration and paraffin immersion. The following incubation protocol was used: $5 \mathrm{~min}$ in 4\% PBS-buffered formalin; $30 \mathrm{~min}$ in tap water; $1 \mathrm{~h}$ each in 50\%,60\%, 70\%, 80\% and 90\% EtOH solutions; $2 \mathrm{x} 1 \mathrm{~h}$ in 100\% EtOH; 1 h in xylol; 2 x 1 h in melted paraffin (Roth). Following processing, tissue was embedded in paraffin blocks using an EG1140 H Embedding Station (Leica).

\subsubsection{3,3'-Diaminobenzidine (DAB) immunohistochemistry}

Four $\mu \mathrm{m}$ sagittal brain sections or spinal cord cross sections were cut from paraffinembedded tissue blocks using an HM 335E microtome (Microm). Sections were transferred onto Superfrost ${ }^{\circledR}$ slides (Thermo Fischer Scientific) in a $\mathrm{RT} d \mathrm{ddH}_{2} \mathrm{O}$ bath. Sections were then affixed to the slides by immersing them into a $50-55{ }^{\circ} \mathrm{C} \mathrm{ddH_{2 }} \mathrm{O}$ bath (Medax). The slides were dried $15 \mathrm{~min}$ on a $55^{\circ} \mathrm{C}$ hot plate and then $\mathrm{ON}$ at $37^{\circ} \mathrm{C}$ before being used for immunohistochemistry.

For DAB staining, sections were deparaffinized and rehydrated using the following incubations: 2 x 5 min in xylol; $10 \mathrm{~min}$ in 100\% EtOH; 5 min in 95\% EtOH; 5 min in $70 \% \mathrm{EtOH}$; and $1 \mathrm{~min}$ in $\mathrm{ddH}_{2} \mathrm{O}$. Endogenous peroxidases were blocked by treating sections for $30 \mathrm{~min}$ a solution of $0.3 \% \mathrm{H}_{2} \mathrm{O}_{2}$ ( \%volume/volume, (\%v/v); Roth) in 0.01 $\mathrm{M}$ PBS. Antigen retrieval was accomplished by heating the sections in $0.01 \mathrm{M}$ citrate buffer (pH 6.0; Roth) for 10 min $(\approx 2$ min at 800 watts $(\mathrm{W})$ (until boiling), $\approx 8$ min at 
$80 \mathrm{~W}$ ) and then cooling them $15 \mathrm{~min}$ at RT. Following a short rinse in $\mathrm{ddH}_{2} \mathrm{O}$, sections were permeabilized by a 15 min incubation in a solution of $0.1 \%$ Triton X-100 (\%v/v; Roth) in 0.01 M PBS. Sections were briefly washed twice in 0.01 M PBS before a 3 min incubation in $88 \% \mathrm{FA}$ to reveal intracellular $\mathrm{A} \beta$. Two, 5 min washes in $0.01 \mathrm{M}$ PBS were performed to remove residual FA from the sections. Blocking of nonspecific antigens was accomplished by circling the sections with a lipid pen (Pap Pen, Kisker Biotech) and applying a solution of $10 \%$ FCS (fetal calf serum; \%v/v; Thermo Fischer Scientific) and $4 \%$ low-fat dried milk powder (\%w/v; Roth) in 0.01 M PBS. Sections were incubated $1 \mathrm{~h}$ at RT. Primary antibodies (see Table 2.14) were diluted to the desired concentration in a solution of $10 \%$ FCS in 0.01 M PBS. After removing the blocking solution, the diluted primary antibodies were applied to the sections at a volume of $\approx 100 \mu \mathrm{L}$ per section. Sections were incubated in primary antibody ON $(\approx 14-16 \mathrm{~h})$ at RT.

On the second day, sections were washed $3 \times 5 \mathrm{~min}$ in a solution of $0.1 \%$ Triton X-100, followed by two brief rinses in 0.01 M PBS. Biotinylated secondary antibodies (see Table 2.15 ) were diluted to the desired concentration in a solution of $10 \%$ FCS in 0.01 M PBS and applied to sections at a volume of $\approx 100 \mu \mathrm{L}$ per section. Incubation in secondary antibody occurred for $1 \mathrm{~h}$ at $37^{\circ} \mathrm{C}$. Avidin-biotin complex (ABC) solution was prepared using the VECTASTAIN Elite ABC Kit (Vector Laboratories). Kit components were added to a solution of $10 \%$ FCS in $0.01 \mathrm{M}$ PBS at a dilution of 1:100 each. The prepared $\mathrm{ABC}$ solution was incubated at $4{ }^{\circ} \mathrm{C}$ for a minimum of 30 min prior to use. Following three, 5 min washes in $0.01 \mathrm{M} \mathrm{PBS}$, sections were incubated in $\approx 100 \mu \mathrm{L} \mathrm{ABC}$ solution per section for $1.5 \mathrm{~h}$ at $37^{\circ} \mathrm{C}$. The $\mathrm{ABC}$ solution was then removed by $3 \times 5$ min washes in 0.01 $\mathrm{M}$ PBS. Staining was visualized using DAB as a chromagen. DAB developing solution was prepared by adding $100 \mu \mathrm{L}$ of DAB stock solution $(25 \mathrm{mg} / \mathrm{mL}$ DAB (Sigma) in 50 $\mathrm{mM}$ Tris $/ \mathrm{HCl}(\mathrm{pH} 7.5))$ to $5 \mathrm{~mL} 50 \mathrm{mM}$ Tris/ $\mathrm{HCl}$ followed by $2.5 \mu \mathrm{L} 30 \% \mathrm{H}_{2} \mathrm{O}_{2}$. Sections were incubated in DAB developing solution until the desired staining pattern was seen. After development, sections were washed $3 \times 5 \mathrm{~min}$ in $0.01 \mathrm{M} \mathrm{PBS}$ and counterstained with hematoxylin (Roth; $40 \mathrm{sec}$ hematoxylin immersion, 5 min wash in tap water). Prior to mounting, sections were dehydrated using the following incubations: $1 \mathrm{~min}$ in $70 \%$ EtOH; 5 min in 95\% EtOH; 10 min in 100\% EtOH; and $2 \times 5$ min in xylol. Each section received 1-2 drops of Roti ${ }^{\circledR}$-Histokitt mounting medium (Roth) before a cover slip was applied to the slide. 


\subsubsection{Combined DAB/HistoGreen immunohistochemistry}

The first day of DAB/HistoGreen double-staining was performed as described in Section 2.6.2. After development of the DAB chromagen on the second day, washing in $0.01 \mathrm{M}$ PBS, the endogenous peroxidase blocking step and the nonspecific antigen blocking step were repeated as on day one. A second primary antibody (raised in a different species than the first primary antibody, see Table 2.14) was diluted in a solution of $10 \%$ FCS in 0.01 M PBS. The antibody was applied to the sections and incubated ON at RT. On the third day of staining, washing, secondary antibody incubations and $\mathrm{ABC}$ incubations were performed as outlined in Section 2.6.2. The Histoprime HistoGreen chromagen (Linaris) was prepared and developed according to the manufacturer's instructions. Following washing in 0.01 M PBS and counterstaining with hematoxylin, sections were dehydrated as follows: $30 \mathrm{sec}$ in $70 \%$ EtOH; $30 \mathrm{sec}$ in $95 \%$ EtOH; 2 x $30 \mathrm{sec}$ in 100\% EtOH; and $30 \mathrm{sec}$ in xylol. Each section received 1-2 drops of Roti ${ }^{\circledR}{ }_{-}$Histokitt mounting medium before a cover slip was applied to the slide.

\subsubsection{Fluorescent immunohistochemistry}

Fluorescent immunohistochemistry was performed using the protocol for DAB immunohistochemistry with the following modifications: The endogenous peroxidase blocking step was omitted. For primary antibody incubation, a mixture of two primary antibodies derived from different species was applied to each section (see Table 2.14). A mixture of fluorophore-conjugated secondary antibodies (see Table 2.15) was applied for $1.5 \mathrm{~h}$ at $37^{\circ} \mathrm{C}$ for the secondary antibody incubation. During all subsequent steps, the sections were protected from light. Immediately following the secondary antibody incubation, sections were washed $3 \times 5 \mathrm{~min}$ in $0.01 \mathrm{M}$ PBS. Counterstaining was performed by immersing the sections for $1 \mathrm{~min}$ in a solution of 4',6-diamidino-2-phenylindole (DAPI, Sigma) dissolved in $\mathrm{ddH}_{2} \mathrm{O}(1.5 \mathrm{mg} / \mathrm{L})$ and then washing them twice for $1 \mathrm{~min}$ in $0.01 \mathrm{M}$ PBS. The lipid pen was carefully removed from around the sections using a cotton swab dipped in xylol. One drop of fluorescent mounting medium (Dako) was added to each section before a cover slip was applied.

\subsubsection{Microscopy and image preparation}

Bright field images of DAB-immunostained tissues were acquired using an Olympus BX51 microscope equipped with an Olympus DP-50 camera (Olympus). For fluorescentlylabeled samples, epi-fluorescent images were taken by employing the mercury arc lamp 
and filter cube set included in the BX51 system. Images were processed using the ImageJ (v1.41; NIH) and Photoshop CS3 (Adobe) software packages. Only adjustments in brightness and contrast were made, and these changes in no way misrepresented the content of the original images.

\subsubsection{Plaque load analysis}

Extracellular $\mathrm{A} \beta$ plaque load was calculated from serial images of the cortex $(100 \mathrm{x}$ magnification) taken from sagittal brain sections spaced a minimum of $20 \mu \mathrm{m}$ apart. Four sections were evaluated per animal ( $\mathrm{n}=5-7$ per group). Images were converted into an 8-bit black-and-white format using ImageJ. Image thresholds were then set to a fixed value to define the DAB-stained plaque regions. Thresholds were selected to maximize the plaque area detected while minimizing the contribution of intracellular $\mathrm{A} \beta$ accumulations to the measurement. Plaque load was calculated as the percentage area occupied by $\mathrm{A} \beta$ immunostaining.

\subsection{Data analysis}

Differences between groups were evaluated using either one-way, two-way or repeated measures analysis of variance (ANOVA). These analyses were followed by Bonferroni posthoc tests, paired t-tests or unpaired t-tests, as indicated. All statistical calculations were performed using GraphPad Prism (v5.0; GraphPad Software, Inc.) Data are presented as mean \pm standard error of the mean (SEM). 


\section{Chapter 3}

\section{Results}

\subsection{Project I: Generation and characterization of the TBA42 mouse model}

The pathological impact of $\mathrm{A} \beta_{p E}$ accumulation has been demonstrated in several $\mathrm{AD}$ mouse models. Among these are the TBA2 and TBA2.1/2.2 transgenic mouse lines. TBA2/2.1/2.2 mice neuronally express an N-terminally truncated version of $\mathrm{A} \beta$. The first two amino acids of the $\mathrm{A} \beta$ peptide sequence are deleted, and the glutamate at position three is mutated into a glutamine $\left(\mathrm{A} \beta_{3 Q-42}\right)$. This modified $\mathrm{A} \beta$ peptide is fused to the murine thyrotropin-releasing hormone $(\mathrm{TRH})$ single peptide sequence in order to route it through the secretory pathway. Together, these alterations facilitate the conversion of $\mathrm{A} \beta_{3 Q-42}$ to $\mathrm{A} \beta_{p E 3-42}$ by $\mathrm{QC}$ (Schilling et al., 2004; Cynis et al., 2006).

Unfortunately, the phenotype and the genetics of the TBA2/2.1/2.2 mouse lines hinder their ability to be bred with other transgenic mouse models. In order to overcome these weaknesses, we created a new mouse model designed to generate $\mathrm{A} \beta_{p E 3-42}$ (TBA42). The objective of this project was to characterize the TBA42 line on the neuropathological and behavioral levels. It was found that the heterozygous expression of the TBA4 transgene was sufficient to induce $\mathrm{A} \beta / \mathrm{A} \beta_{p E 3-42}$ accumulation and age-dependent behavioral deficits in TBA42 mice without premature lethality.

\subsubsection{Selection of the TBA42 mouse line}

To generate the TBA4 mouse lines, the TBA4 transgene (Fig. 3.1) was microinjected into the pronuclei of fertilized C57BL/6J oocytes. PCR-based genotyping of the resulting 
TBA4 transgene

Pre-pro-peptide

Pro-peptide

$A \beta_{3 Q-42}$

$A \beta_{p E 3-42}$

\begin{tabular}{|l|l|l|l|}
\hline Thy1 promoter & pre-pro-TRH & $\mathbf{A} \beta_{30-42}$ & Thy1 3' sequence \\
\hline
\end{tabular}
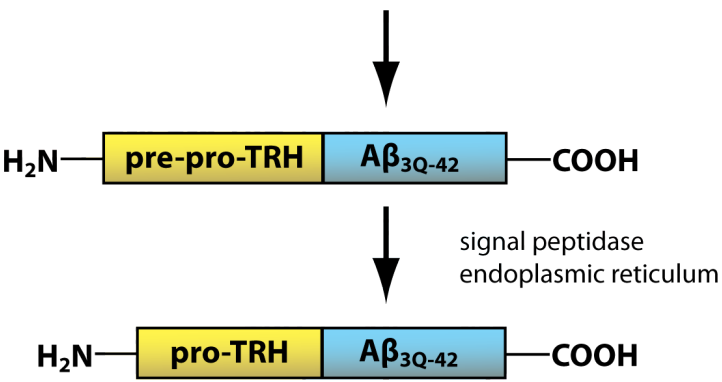

prohormone convertases

trans-Golgi, secretory granules

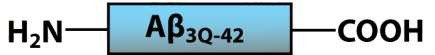

glutaminyl cyclase

trans-Golgi, secretory granules

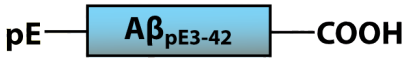

Figure 3.1: The TBA4 transgene. The murine Thy1 promoter drives the neuronal expression of the pre-pro-TRH-A $\beta_{3 Q-42}$ fusion peptide. An N-terminal signal sequence directs the pre-pro-TRH-A $\beta_{3 Q-42}$ fusion peptide into the ER where signal peptidases liberate the pro-TRH-A $\beta_{3 Q-42}$ peptide. Prohormone convertases in the trans-Golgi and secretory vesicles cleave the remainder of the TRH signal peptide to release $\mathrm{A} \beta_{3 Q-42}$. The free $\mathrm{A} \beta \mathrm{N}$-terminus can then undergo cyclization by glutaminyl cyclase to form $\mathrm{A} \beta_{p E 3-42}$. Figure modified from (Alexandru et al., 2011)

progeny identified three mice that carried the TBA4 transgene. These mice served as the founders for three independent TBA4 lines: TBA41, TBA42 and TBA45. Breeding each of the founder mice produced offspring positive for the TBA4 transgene, indicating stable genomic integration and germline transmission of the transgenic construct.

To determine which TBA4 line possessed the highest transgene expression, qPCR was performed on brain-derived cDNA from the F1 generation of TBA41, TBA42, and TBA45 mice. Analysis revealed that transgene levels were significantly higher in the brains of TBA42 mice relative to mice from both the TBA41 and TBA45 lines (Fig. 3.2; $p<0.05$ ). No significant difference in transgene levels was found between the TBA41 and TBA45 mice. As a result, the TBA42 mouse line was selected for further characterization. 


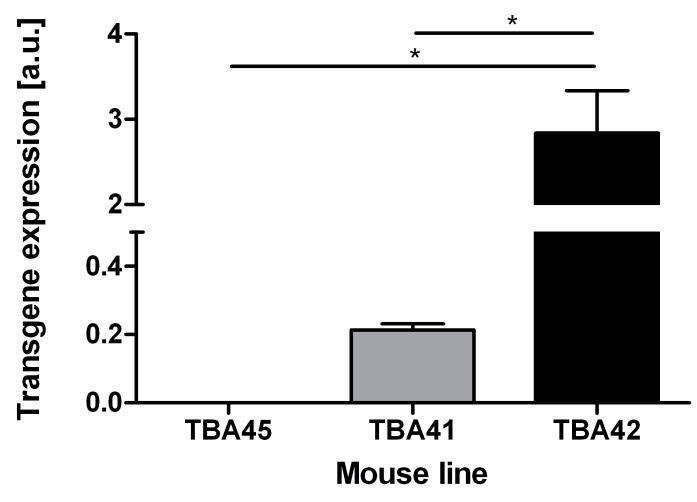

Figure 3.2: Transgene levels in TBA4 mice. qPCR-based measurement of TBA4 transgene cDNA derived from the brains of 2-to-4-monthold TBA 41, TBA45 and TBA42 mice. Transgene expression was highest in the TBA42 mice. In all cases, TBA4 transgene levels were normalized to $\beta$-actin expression. One-way ANOVA with Bonferroni post-hoc tests; ${ }^{*}, p<0.05$. Abbreviation: a.u., arbitrary units.

\subsubsection{Amyloid beta accumulation in TBA42 mice}

Transgene expression was assessed in TBA42 mice using immunohistochemistry. By employing the pan- $\mathrm{A} \beta$ antibody $4 \mathrm{G} 8$, substantial $\mathrm{A} \beta$ accumulation was identified in the hippocampus of TBA42 mice from the age of 3 months (Fig. $3.3 \mathrm{~A}$ ). These aggregates were comprised of both intracellular $\mathrm{A} \beta$ in the pyramidal neurons of the CA1 region as well as small extracellular granules (Fig. 3.3 B). A similar staining pattern was found with an antibody directed against the C-terminus of $\mathrm{A} \beta_{x-42}$ (Fig. 3.3 C).

Outside of the hippocampus, $\mathrm{A} \beta$ was found in the inferior colliculus, brainstem and cortex of 3-month-old TBA42 mice. In the inferior colliculus, A $\beta$ primarily accumulated inside neuronal cell bodies, with few extracellular granules observed. A $\beta$ deposition appeared to extend into the processes of some neurons in this region (Fig. 3.3 D). Brainstemlocalized $\mathrm{A} \beta$ was found both intraneuronally and in larger, extracellular aggregates (Fig. $3.3 \mathrm{E})$. Sparse $\mathrm{A} \beta$ deposition was seen in the cortex, with intraneuronal accumulations and extracellular granules infrequently detected (Fig. 3.3 F).

In older TBA42 mice, $\mathrm{A} \beta$ accumulations were also prominent in other regions of the CNS. Six-month-old TBA42 mice possessed substantial intraneuronal A $\beta$ in their cerebellar nuclei (Fig. $3.4 \mathrm{~A}$ and $\mathrm{B}$ ). In addition, occasional intraneuronal $\mathrm{A} \beta$ aggregates and extracellular granules were seen in the spinal cords of mice at this age (Fig. $3.4 \mathrm{C}$ ). Spinal cord A $\beta$ pathology noticeably increased in 12-month-old TBA42 mice, occupying a significant portion of the grey matter (Fig. $3.4 \mathrm{D}$ ). Both intraneuronal A $\beta$ aggregates and extracellular granules were more prevalent than in 6-month-old TBA42 mice (Fig. 3.4 E). Intraneuronal A $\beta$ in the spinal cords of 12-month-old TBA42 mice frequently adopted a punctate pattern, suggesting that it was sequestered into intracellular compartments (Fig. 3.4 F). Despite the abundance of intracellular $\mathrm{A} \beta$, no neuritic amyloid plaques were found in TBA42 mice at any of the ages analyzed.

Since TBA42 mice were designed to produce pyroglutamate-modified A $\beta, 2-48$, an 

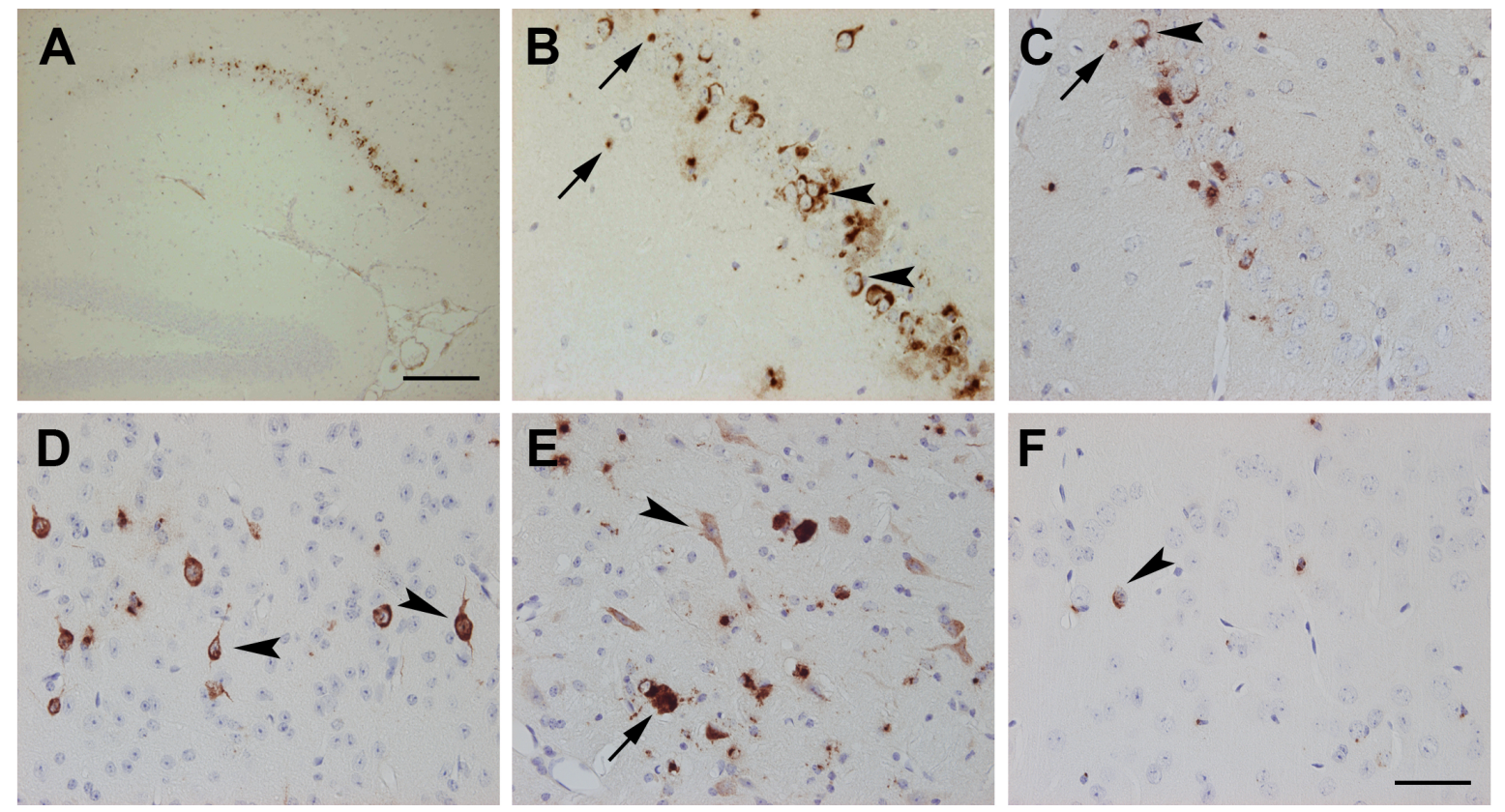

Figure 3.3: A $\beta$ aggregation in 3-month-old TBA42 mice. TBA42 mice accumulated abundant intracellular $\mathrm{A} \beta$ in $\mathrm{CA} 1$ pyramidal neurons by 3 months of age. These accumulations were detected using both an antibody recognizing all $\mathrm{A} \beta$ isoforms $(4 \mathrm{G} 8$; $\mathrm{A}$ and $\mathrm{B}$, arrowheads) and an antibody specific for the C-terminus of $\mathrm{A} \beta_{x-42}(\mathrm{G} 2-11$; $\mathrm{C}$, arrowhead). Small, extracellular A $\beta$ granules were also seen in the hippocampus (B and $\mathrm{C}$, arrows). $\mathrm{A} \beta$ is mainly deposited intraneuronally in the inferior colliculus ( $\mathrm{D}$, arrowheads), while both extracellular (E, arrow) and intraneuronal (E, arrowhead) A $\beta$ aggregates were found in the brainstem. Scarce intraneuronal $\mathrm{A} \beta$ deposits were observed in the cortex $(\mathrm{F}$, arrowhead). Scale bars, $\mathrm{A}=200 \mu \mathrm{m} ; \mathrm{B}-\mathrm{F}=50 \mu \mathrm{m}$.

antibody specific for $\mathrm{A} \beta_{p E 3-x}$, was used to assess the presence of this peptide. By the age of three months, TBA42 mice developed small, extracellular $\mathrm{A} \beta_{p E}$-positive granules in the hippocampus (Fig. 3.5 A) and inferior colliculus (Fig. 3.5 B). Extracellular granules and intracellular $\mathrm{A} \beta_{p E}$ accumulations were also identified in the brainstems of 3-month-old TBA42 mice. These deposits were specific to TBA42 mice; three-month-old WT mice lacked a similar staining pattern (Fig. 3.5 D). In 12-month-old TBA42 mice, extracellular and intracellular deposits of $\mathrm{A} \beta_{p E}$ had also formed in the spinal cord (Fig. 3.5 E) and the cortex (Fig. $3.5 \mathrm{~F}$ ).

\subsubsection{Gliosis in TBA42 mice}

Gliosis frequently accompanies $\mathrm{A} \beta$ plaque pathology in the brains of both $\mathrm{AD}$ patients and AD mouse models. Given the lack of neuritic plaques in the brains of TBA42 mice, it 

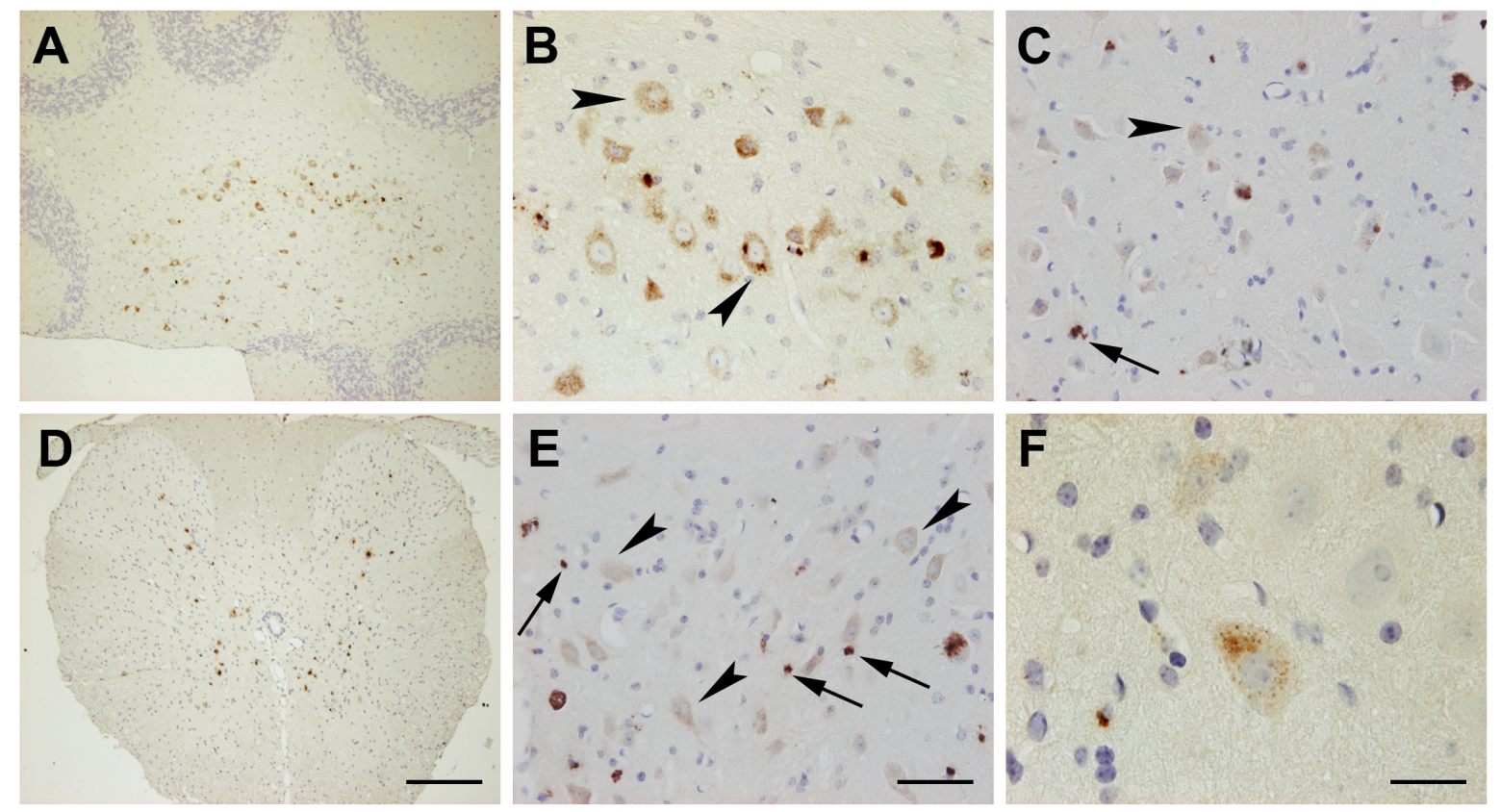

Figure 3.4: A $\beta$ aggregation in 6- and 12-month-old TBA42 mice. Six-month-old TBA42 mice showed marked intraneuronal $\mathrm{A} \beta$ accumulation in cerebellar nuclei (A and $\mathrm{B}$, arrowheads). Sparse intraneuronal (C, arrowhead) and extracellular (C, arrow) A $\beta$ aggregates were also found in the spinal cords of TBA42 mice at this age. In 12-monthold TBA42 mice, A $\beta$ pathology covered a large area of the spinal cord grey matter (D). Both intraneuronal (E, arrowheads) and extracellular (E, arrows) A $\beta$ deposits increased in the spinal cords of 12-month-old TBA42 mice, and punctate intraneuronal staining was commonly observed (F). Scale bars, A and D $=200 \mu \mathrm{m} ; \mathrm{B}, \mathrm{C}$ and $\mathrm{E}=50 \mu \mathrm{m} ; \mathrm{F}=20$ $\mu \mathrm{m}$.

might be presumed that gliosis is also absent. Immunohistochemical evaluation of brain regions with marked intraneuronal $\mathrm{A} \beta$ accumulation revealed the presence of reactive astrocytes in TBA42 mice. Relative to 3-month-old WT mice (Fig. 3.6 A), more GFAPpositive astrocytes were found in the CA1 region of age-matched TBA42 mice (Fig. 3.6 B). The degree of gliosis was further increased in 12-month-old TBA42 mice (Fig. 3.6 C). These findings suggest that gliosis is the consequence of ongoing $\mathrm{A} \beta$ accumulation and neurodegenerative processes in TBA42 mice. 

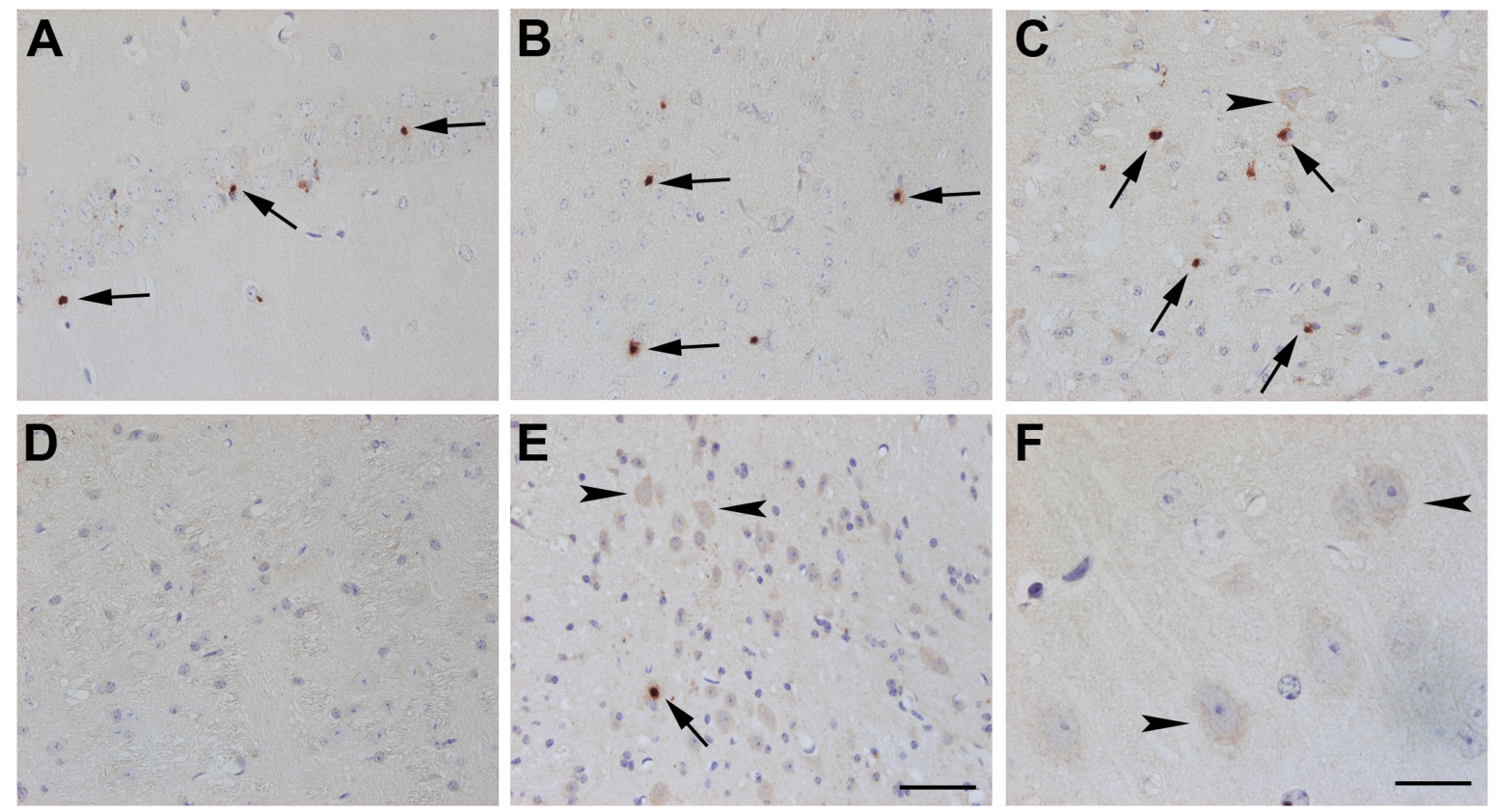

Figure 3.5: $\mathbf{A} \beta_{p E}$ accumulation in TBA42 mice. Extracellular, A $\beta_{p E}$-positive granules (arrows) developed in the hippocampus (A), inferior colliculus (B) and brainstem (C) of 3-month-old TBA42 mice. Intracellular $\mathrm{A} \beta_{p E}$ was also found in the brainstem of TBA42 mice at this age $\left(\mathrm{C}\right.$, arrowhead). $\mathrm{A} \beta_{p E}$ staining was absent from the brainstems of a 3month-old WT mice (D). By the age of 12 months, TBA42 mice possessed intraneuronal (arrowheads) and extracellular (arrow) $\mathrm{A} \beta_{p E}$ deposits in the spinal cord (E) and cortex (F). Scale bars, $\mathrm{A}-\mathrm{E}=50 \mu \mathrm{m} ; \mathrm{F}=20 \mu \mathrm{m}$.
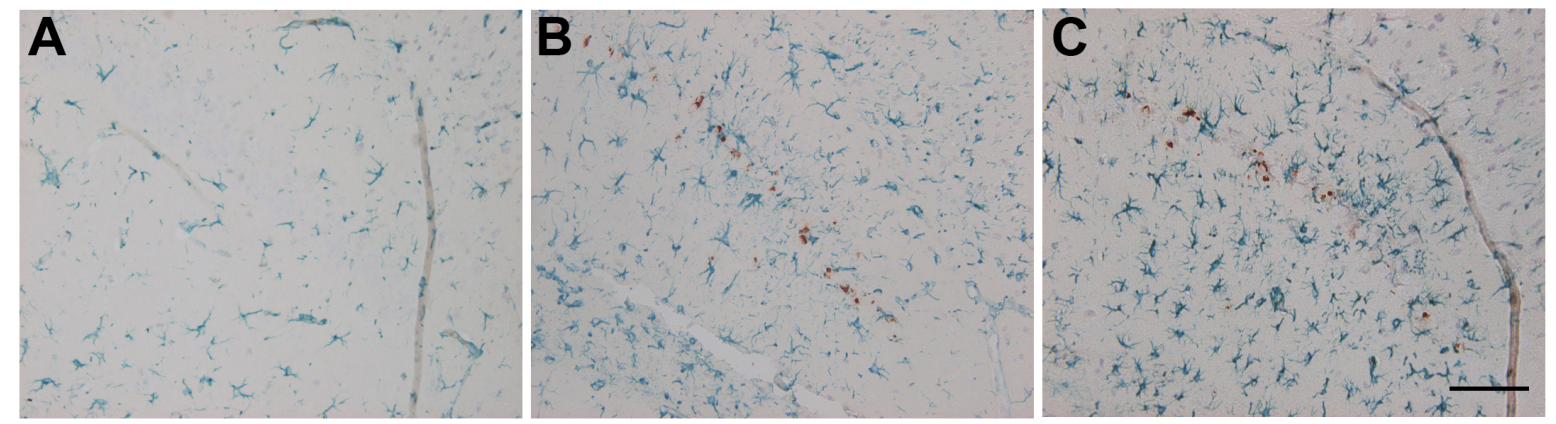

Figure 3.6: Gliosis in TBA42 mice. GFAP-staining revealed fewer astrocytes in the hippocampal CA1 region of 3-month-old WT mice (A) than in the same region of age-matched TBA42 mice (B). CA1 gliosis was further increased in 12-month-old TBA42 mice $(\mathrm{C})$. For all panels, GFAP staining appears in blue and $\mathrm{A} \beta$ staining in brown. Scale bar $=100 \mu \mathrm{m}$. 


\subsubsection{Intracellular localization of amyloid beta in TBA42 mice}

The pronounced intraneuronal pathology in TBA42 mice prompted an examination of the subcellular localization of A $\beta$. Immunofluorescent double-labeling showed no colocalization of $\mathrm{A} \beta$ with trans-Golgi marker syntaxin 16 (Syn16), indicating that $\mathrm{A} \beta$ was not retained in the trans-Golgi network (Fig. 3.7 A-D). However, A $\beta$ colocalized with soluble NSF attachment protein receptor (SNARE) protein Vti1b, thereby revealing the presence of $\mathrm{A} \beta$ within late endosomes (Fig. $3.8 \mathrm{~A}-\mathrm{D}$ ). Additionally, both $\mathrm{A} \beta$ (Fig. $3.9 \mathrm{~A}-\mathrm{D}$ ) and $\mathrm{A} \beta_{p E}$ (Fig. $3.9 \mathrm{E}-\mathrm{F}$ ) were found in lysosomes, as demonstrated by their colocalization with cathepsin $\mathrm{D}$ (CatD). Taken together, these findings indicate that intracellular $\mathrm{A} \beta$ resides within the endosomal-lysosomal system in TBA42 mice.
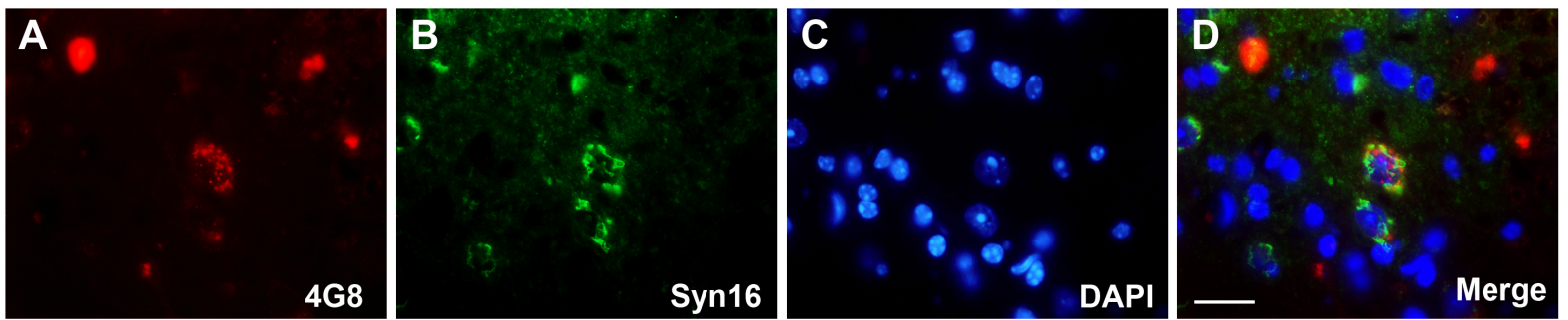

Figure 3.7: No colocalization of A $\beta$ with Syn16 in TBA42 mice. Immunofluorescent double-labeling of spinal cord tissue from 12-month-old TBA42 mice. Antibodies against $A \beta$ (4G8, red; A) and trans-Golgi marker Syn16 (Syn16, green; B) were used with DAPI counterstaining (blue; C). $A \beta$ failed to colocalize with Syn16 as demonstrated by the lack of overlapping signal (yellow) in the merged spinal cord motor neuron images (D). Scale bar $=20 \mu \mathrm{m}$.
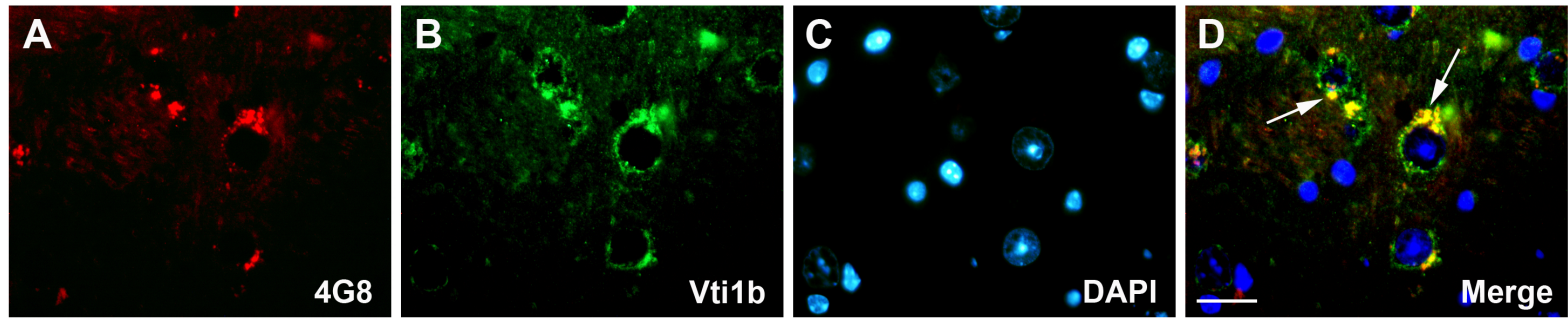

FiguRE 3.8: Colocalization of $\mathbf{A} \beta$ with Vti1b in TBA42 mice. Immunofluorescent double-labeling of brain tissue from 12-month-old TBA42 mice. Antibodies against $A \beta$ (4G8, red; A) and late-endosomal marker Vti1b (Vti1b, green; B) were used with DAPI counterstaining (blue; $\mathrm{C}$ ). A $\beta$ colocalized with Vti1b as shown by the merged brainstem neuron images (white arrows, yellow; D). Scale bar $=20 \mu \mathrm{m}$. 

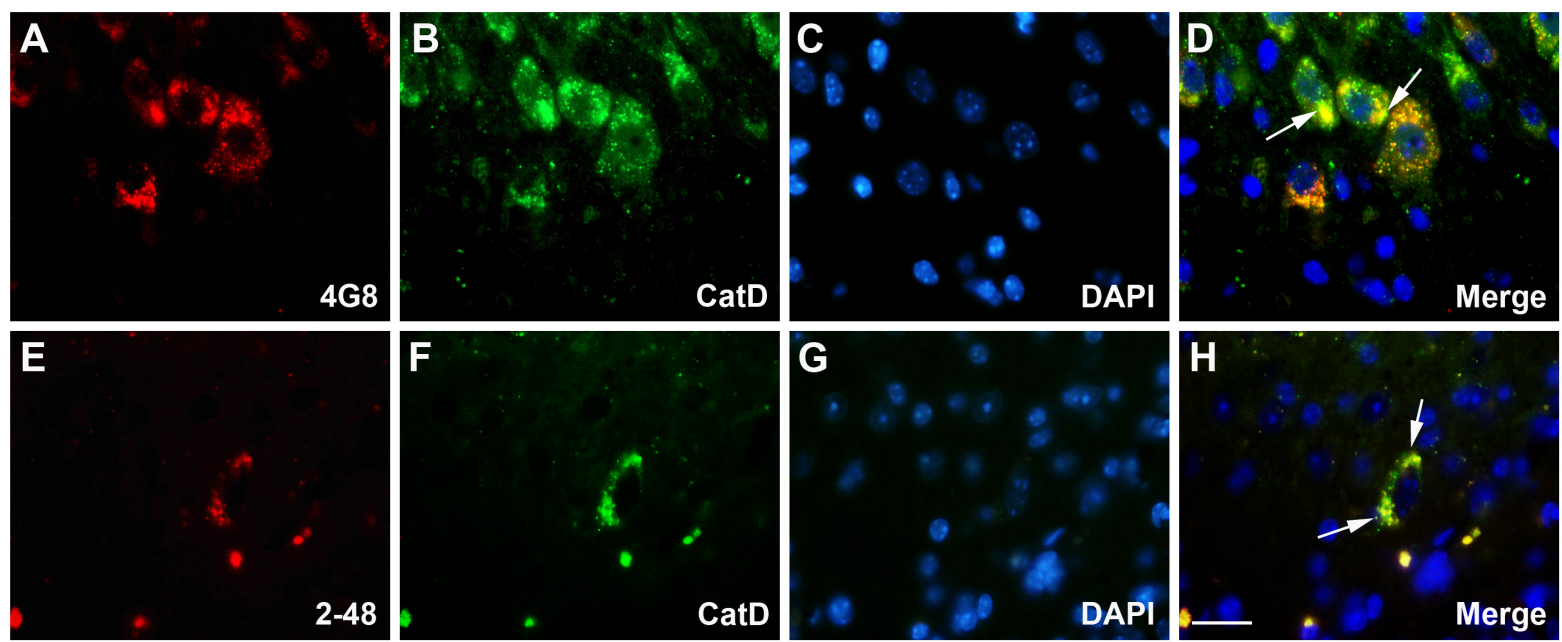

Figure 3.9: $\mathbf{A} \beta$ and $\mathbf{A} \beta_{p E}$ are found in the lysosomes of TBA42 mice. Antibodies against $\mathrm{A} \beta$ (4G8, red; $\mathrm{A}), \mathrm{A} \beta_{p E 3-x}(2-48$, red; $\mathrm{E}$ ) and lysosomal marker CatD (CatD, green; $\mathrm{B}$ and F) plus DAPI counterstaining (blue; C and $\mathrm{G}$ ) were used for fluorescent double-labeling of 12-month-old TBA42 brain tissue. Merged brainstem neuron images revealed the colocalization of $\mathrm{A} \beta$ and $\mathrm{A} \beta_{p E}$ with CatD (white arrows, yellow; $\mathrm{D}$ and $\mathrm{H}$ ). Scale bar $=20 \mu \mathrm{m}$.

\subsubsection{General physical assessment of TBA42 mice}

Behavioral deficits and other physiological changes commonly occur in AD transgenic mouse models. To determine if the $\mathrm{A} \beta$ pathology present in TBA42 mice was sufficient to cause functional impairments, cohorts of 3-, 6- and 12-month-old female TBA42 mice were subjected to a basic physical examination and a battery of behavioral tests. The clasping test has been used with other AD mouse models to screen for motor deficits resulting from spinal cord pathology (Wirths et al., 2008; Jawhar et al., 2012). For this test, mice are suspended from their tails for $30 \mathrm{sec}$ and scored on a scale from 0 to 3, depending on the limb clasping behavior they demonstrate. Healthy mice generally do not clasp their limbs and will attempt to escape the tail suspension by kicking and twisting their bodies. Three, 6- and 12-month-old TBA42 mice all displayed no limb clasping during tail suspension (score 0 ). Instead, hindlimb rigidity and tremors were observed in lieu of the normal escape behavior. This phenotype was present in TBA42 mice at 6 months of age and progressed in severity by the age of 12 months.

Weight loss can also accompany the degenerative phenotype in AD mouse models. The body weight of TBA42 mice was therefore measured at 3, 6, and 12 months of age. Relative to age-matched WT controls, there was no difference in the weight of 3- and 6-month-old TBA42 mice. In contrast, 12-month-old TBA42 mice were significantly lighter than their 


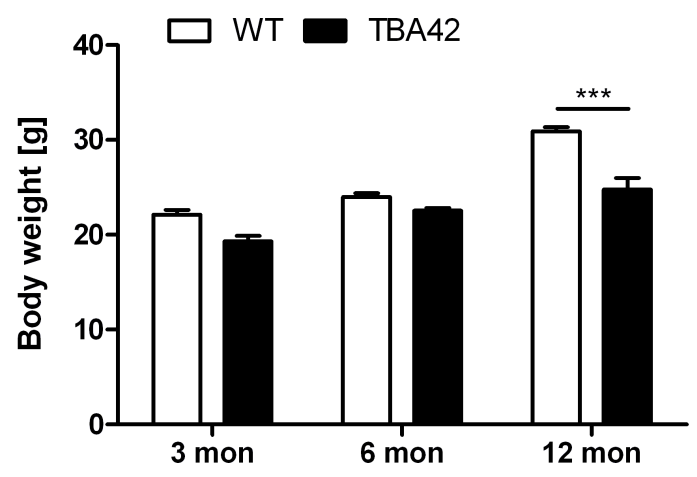

FiguRE 3.10: TBA42 body weight. TBA42 mice displayed normal body weight at 3 and 6 months of age. Twelvemonth-old TBA42 mice were significantly lighter than age-matched WT controls. Two-way ANOVA with Bonferroni posthoc tests; ***, $p<0.001 ; \mathrm{n}=8-12$ per group.

age-matched WT counterparts (Fig. 3.10; $p<0.001$ ). These findings suggest that the neuropathology present in TBA42 mice adversely affects basic physiological function in an age-dependent fashion.

\subsubsection{Motor function in TBA42 mice}

Motor function was further evaluated using the balance beam, string suspension and inverted grip hang tasks. The balance beam assesses balance and general motor ability (Arendash et al., 2001). In this task, TBA42 mice performed equivalently to WT controls until the age of 12 months, at which point they showed significant impairment (Fig. 3.11 A; $p<0.001)$. The string suspension test evaluates motor coordination and grip strength (Moran et al., 1995). As with the balance beam, only 12-month-old TBA42 mice displayed significant deficits in string suspension performance (Fig. $3.11 \mathrm{~B} ; p<0.001$ ). The inverted grip hang was used to gauge vestibular function and muscle strength (Erbel-Sieler et al.,

A

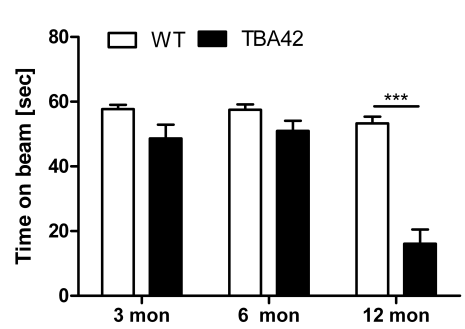

B

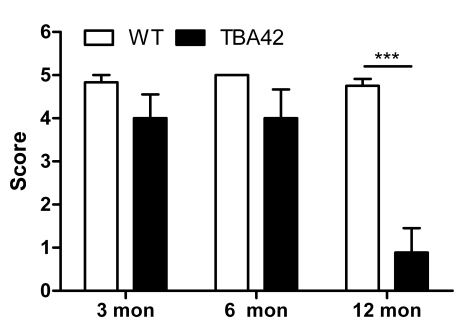

C

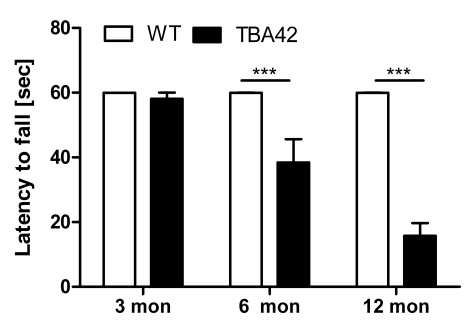

Figure 3.11: Age-dependent alterations in motor function in TBA42 mice. TBA42 mice displayed significantly reduced performance in the balance beam (A) and string suspension (B) at 12 months of age. Impairment in the inverted grip hang task was first observed in 6-month-old TBA42 mice and became more severe by the age of 12 months (C). Two-way ANOVA with Bonferroni post-hoc tests; ***, $p<0.001$; $\mathrm{n}=8-12$ per group. 
2004). Three-month-old TBA42 mice behaved comparably to WT controls in this task. However, the performance of 6 - and 12-month-old TBA42 mice was substantially worse than WT mice (Fig. 3.11 C; $p<0.001$ ).

\subsubsection{Working memory in TBA42 mice}

To measure working memory in TBA42 mice, spontaneous alternation tasks of varying complexity were utilized. Such tests are often conducted in three- or four-arm mazes and rely on the innate tendency of mice to explore novel environments. Cognitively normal mice exhibit a high degree of alternation behavior: they travel between the maze arms, visiting each arm in succession before returning to a previously entered arm. Conversely, AD transgenic mice often display a decreased alternation rate.

The Y- and cross mazes were employed to evaluate working memory in 3-, 6- and 12-month-old TBA42 mice. In the Y-maze, no difference in alternation rate was found between WT and TBA42 mice at any of the ages tested (Fig. 3.12 A). Using the cross maze, a significant decrease in alternation rate was detected in 12-month-old TBA42 mice relative to WT controls (Fig. $3.12 \mathrm{C} ; p<0.001$ ). Differences in motor function did not account for changes in alternation rate; WT and TBA42 mice performed a similar number of arm entries in both the Y- (Fig. 3.12 B) and cross mazes (Fig. 3.12 D).

\subsubsection{Anxiety and exploratory behavior in TBA42 mice}

Anxiety and exploratory behavior were analyzed with the elevated plus maze and open field, respectively. From the age of 3 months, TBA42 mice spent significantly more time in the open arms of the elevated plus maze, indicating decreased anxiety (Fig. $3.13 \mathrm{~A}$; $p<0.01$ at 6 mon; $p<0.001$ at 3 and 12 mon). No difference in overall activity in the elevated plus maze was seen between WT and TBA42 mice at any age (Fig. 3.13 B). The total distance traveled in the open field also did not differ between 3-, 6- and 12-month-old WT and TBA42 mice (Fig. 3.14 A). However, at all ages examined, the number of rearing episodes displayed during open field exploration was significantly lower in TBA42 mice compared to WT controls (Fig. $3.14 \mathrm{~B} ; p<0.01$ at 3 mon; $p<0.001$ at 6 and 12 mon). 
A

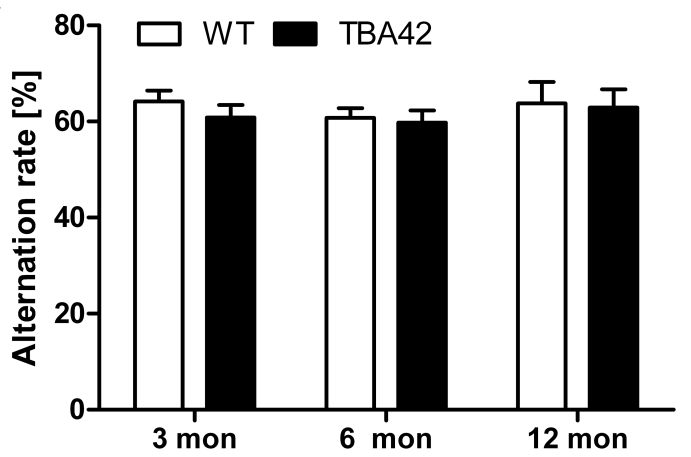

C

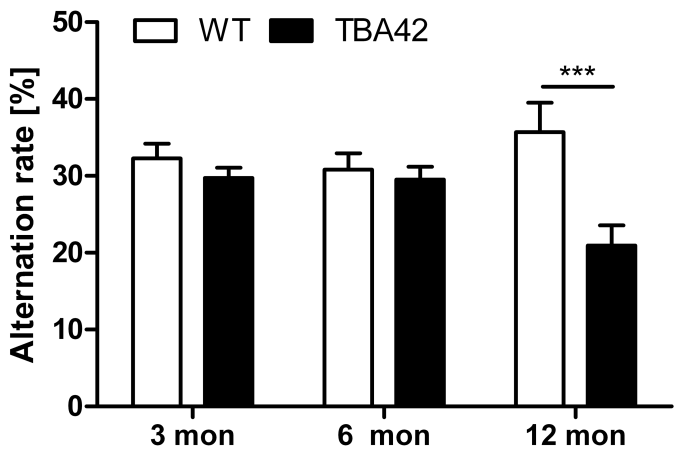

B

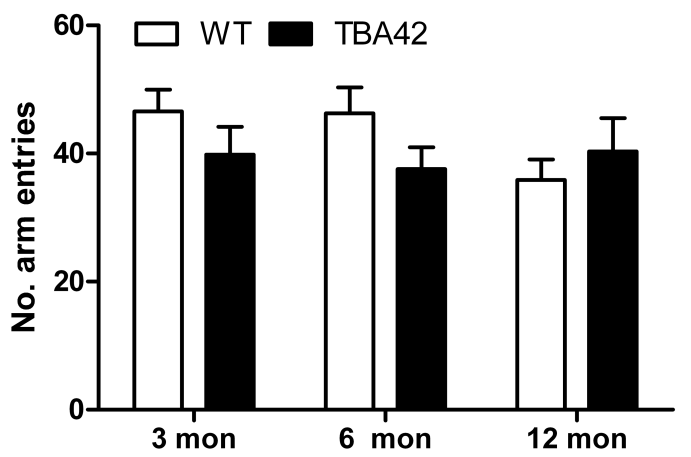

D

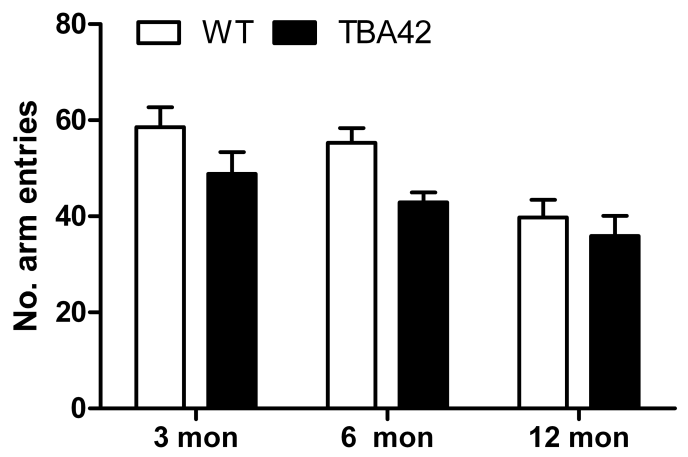

Figure 3.12: Age-dependent deficits in working memory in TBA42 mice. No differences in alternation rate (A) or number of arm entries (B) were found between TBA42 and WT mice in the Y-maze. Twelve-month-old TBA42 mice displayed a decreased alternation rate in the cross maze compared to WT controls (C). There was no difference between TBA42 and WT mice in the number of arm entries performed in the cross maze (D). Two-way ANOVA with Bonferroni post-hoc tests; ${ }^{* * *}, p<0.001 ; \mathrm{n}=8-12$ per group. 
A

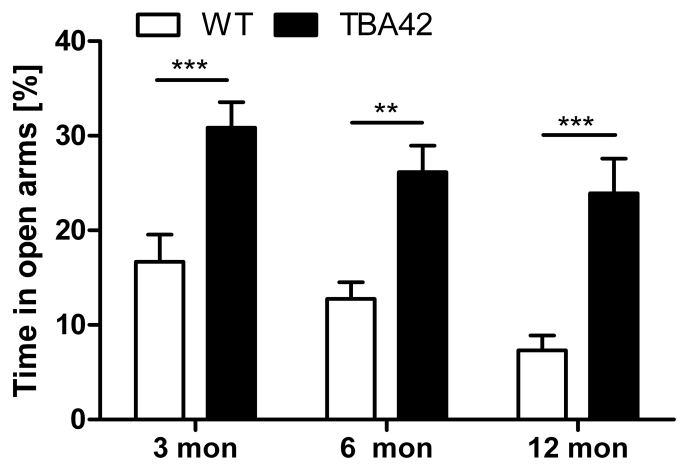

B

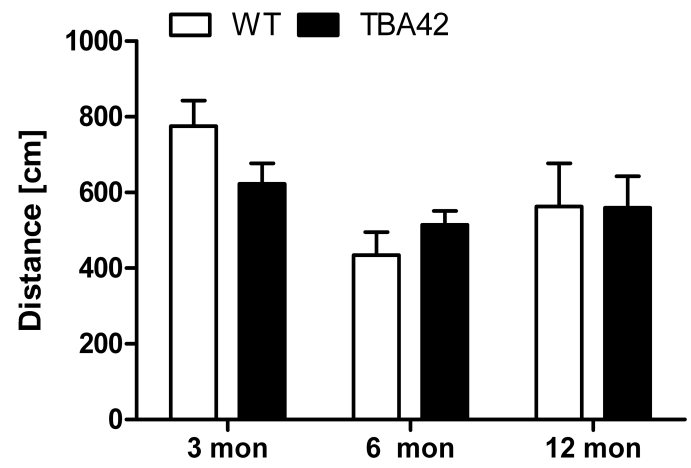

Figure 3.13: Decreased anxiety in TBA42 mice. TBA42 mice spent more time in the open arms of the elevated plus maze than WT controls at all ages tested (A). WT and TBA42 mice exhibited similar levels of activity in the elevated plus maze, as indicated by total distance traveled (B). Two-way ANOVA with Bonferroni post-hoc tests; ${ }^{* *}, p<$ $0.01 ; * * *, p<0.001 ; \mathrm{n}=8-12$ per group.

A

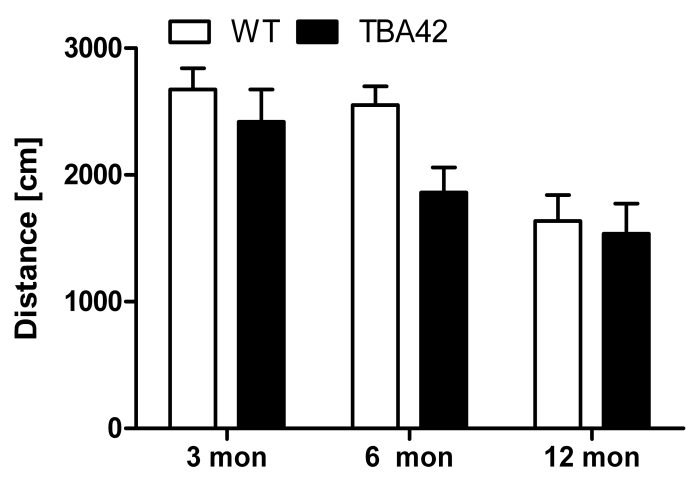

B

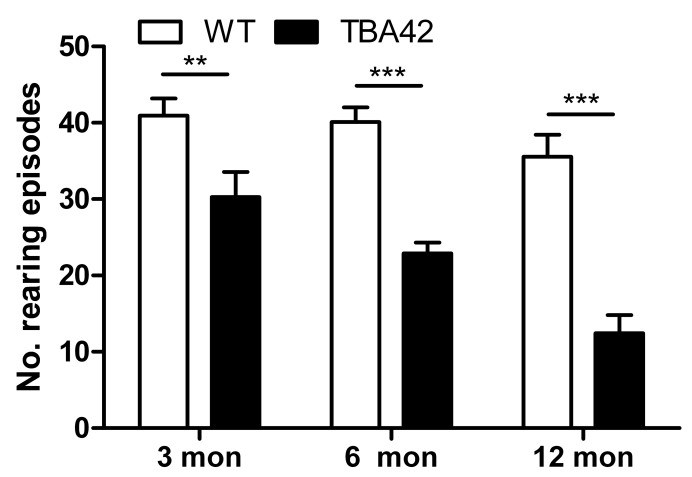

FiguRE 3.14: Exploratory behavior in TBA42 mice. In the open field, TBA42 mice traveled comparable distances to WT controls at all ages analyzed (A). Rearing behavior in the open field was decreased in the TBA42 mice beginning from the age of 3 months (B). Two-way ANOVA with Bonferroni post-hoc tests; ${ }^{* *}, p<0.01$; ${ }^{* *}, p<0.001 ; \mathrm{n}=$ 8-12 per group. 


\subsection{Project II: Exploring the pyroglutamate-modified amyloid beta seeding hypothesis using the FAD42 mouse model}

Previous studies have utilized either pharmacological inhibition or genetic manipulation of $\mathrm{QC}$ to directly affect the generation of $\mathrm{A} \beta_{p E}$ in transgenic $\mathrm{AD}$ mouse models (Schilling et al., 2008c; Jawhar et al., 2011b). The aim of the present study was to investigate how additional $\mathrm{A} \beta_{p E}$ impacts the progression of $\mathrm{AD}$ pathology independent of QC manipulations. To accomplish this, TBA42 transgenic mice (see Section 3.1) were crossed with the well-established 5XFAD mouse model to produce FAD42 mice. 5XFAD mice possess a robust neuropathological phenotype: they develop age-dependent behavioral deficits, axonopathy, neuron loss and extensive plaque pathology (Oakley et al., 2006; Jawhar et al., 2012). The effects of elevated $\mathrm{A} \beta_{p E 3-42}$ on behavioral phenotype, co-precipitation of other $\mathrm{A} \beta$ variants and plaque load pathology were evaluated in FAD42 transgenic mice. Taken together, these results demonstrate that an increase in $\mathrm{A} \beta_{p E 3-42}$ can adversely affect the strong AD phenotype of 5XFAD mice.

\subsubsection{Behavioral analysis of FAD42 mice}

To evaluate the effects of additional $\mathrm{A} \beta_{p E 3-42}$ on the behavioral phenotype of 5XFAD mice, 6-month-old female WT, 5XFAD, TBA42 and FAD42 mice were tested in the balance beam and elevated plus maze. Motor performance was significantly impaired in the FAD42 mice, as shown by the balance beam (Fig. $3.15 \mathrm{~A}$; p < 0.001). In addition, the elevated plus maze revealed that anxiety levels were even further decreased in FAD42 mice (Fig. $3.15 \mathrm{~B} ; \mathrm{p}<0.001$ ). These data indicate that the extra $\mathrm{A} \beta$ resulting from the TBA42 transgene in the FAD42 mice is sufficient to enhance the behavioral deficits observed in 5XFAD single transgenic mice. 
A

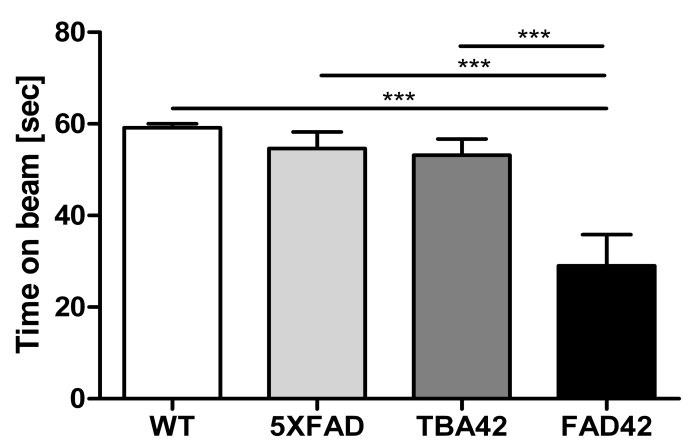

B

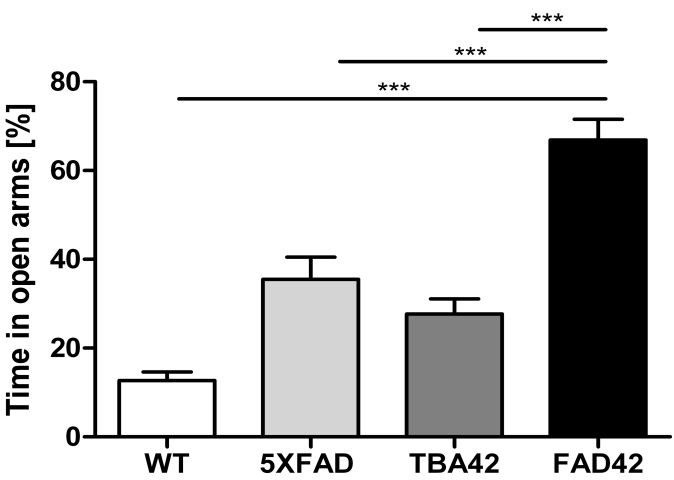

Figure 3.15: Aggravated behavioral impairments in FAD42 mice. Motor function and anxiety were assessed in 6-month-old WT, 5XFAD, TBA42 and FAD42 mice using the balance beam (A) and elevated plus maze (B), respectively. In both tasks, transgenic FAD42 mice showed increased impairment relative to the WT and single transgenic 5XFAD and TBA42 mice. One-way ANOVA with Bonferroni post-hoc tests; ${ }^{* * *}, p<$ $0.001 ; \mathrm{n}=5-9$ per group.

\subsubsection{Immunoprecipitation and mass spectrometric (IP/MS) char- acterization of wild-type, TBA42, 5XFAD and FAD42 mouse brain}

IP/MS was employed to determine if the additional $\mathrm{A} \beta_{p E 3-42}$ from the TBA42 transgene altered the profile of $\mathrm{A} \beta$ precipitated from brains of FAD42 mice. Combined IP with the $6 \mathrm{E} 10$ and $4 \mathrm{G} 8$ antibodies revealed an $\mathrm{A} \beta$ isoform pattern consisting of $\mathrm{A} \beta_{5-42}, \mathrm{~A} \beta_{4-42}$, $\mathrm{A} \beta_{1-40}$, and $\mathrm{A} \beta_{1-42}$ in the FA-extracted brain tissues from 5XFAD mice (See Fig. 3.16 A for representative mass spectra). The most dominant isoform was the peak representing $\mathrm{A} \beta_{1-42}$. A similar pattern was detected in the transgenic model FAD42. TBA42 mice displayed no peaks corresponding to $\mathrm{A} \beta$ following IP with $6 \mathrm{E} 10$ and $4 \mathrm{G} 8$. IP with the Nterminal-specific $A \beta$ antibody 1-57 detected $\mathrm{A} \beta_{p E 3-42}$ and unmodified $\mathrm{A} \beta_{3-42}$ in TBA42, 5XFAD and FAD42 mice. In all cases, unmodified $\mathrm{A} \beta_{3-42}$ was much less abundant than $\mathrm{A} \beta_{p E 3-42}$. $\mathrm{A} \beta_{p E 3-40}$ was only identified in 5XFAD mice. No peaks corresponding to $\mathrm{A} \beta$ were detected in WT mice using either the 4G8 and 6E10 or the 1-57 antibodies. These results confirm that 5XFAD mice harbor a heterogeneity of N-truncated and modified $\mathrm{A} \beta$ peptides, but TBA42 mice express only $\mathrm{A} \beta_{p E 3-42}$ and unmodified $\mathrm{A} \beta_{3-42}$. Furthermore, aside from the loss of the minor $\mathrm{A} \beta_{p E 3-40}$ peak, no gross difference in the pattern of $A \beta$ variants isolated after IP was found between 6-month-old 5XFAD and FAD42 mice. 

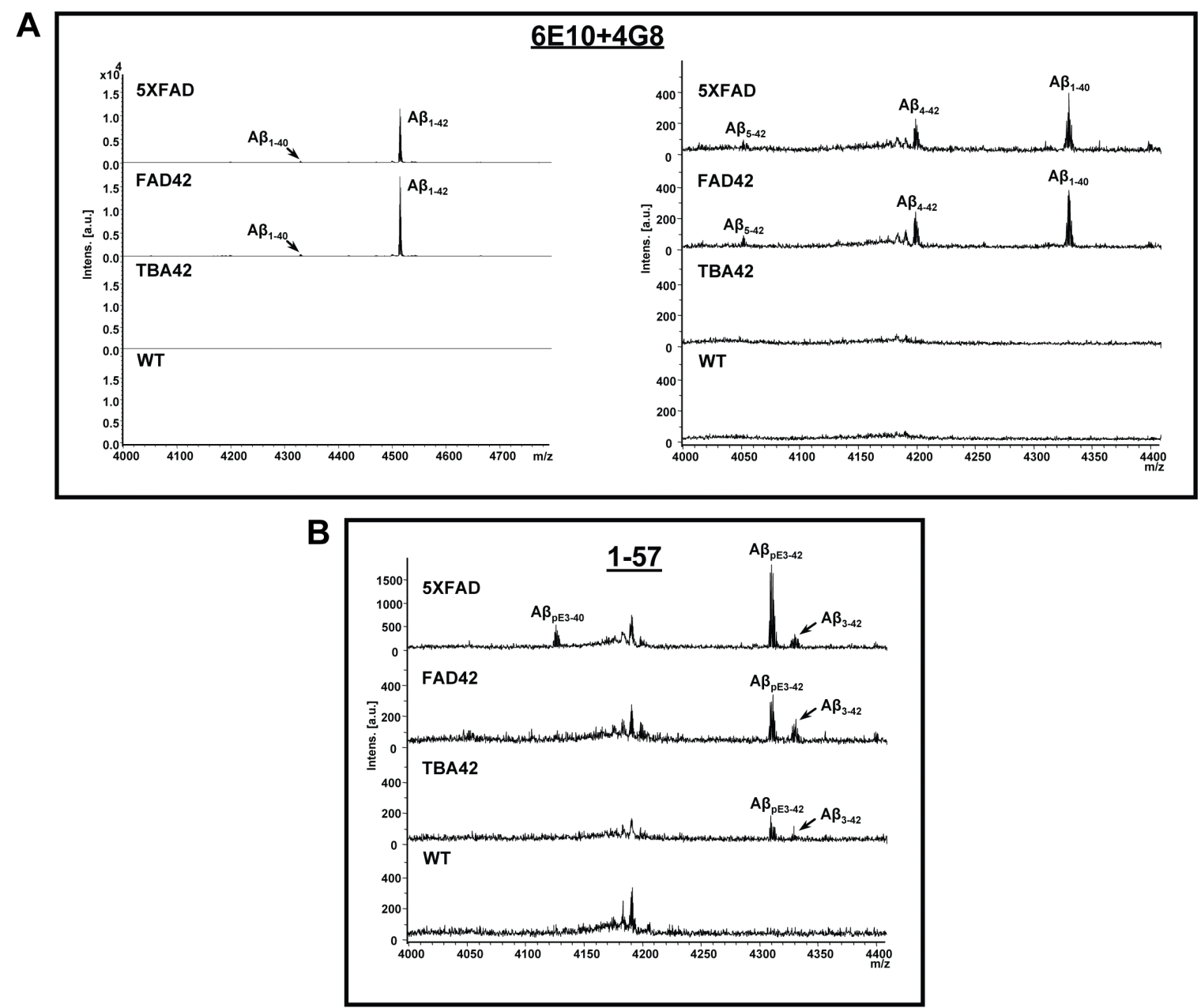

FIGURE 3.16: N-terminal heterogeneity of $\mathrm{A} \beta$ peptides in 5XFAD and FAD42 mice. Mass spectra of $\mathrm{A} \beta$ peptides immunoprecipitated from the brains of WT, TBA42, 5XFAD and FAD42 mice. Pan-A $\beta$ antibodies 6 E10 and $4 \mathrm{G} 8$ (A; used as a mix) and the N-terminal-specific antibody 1-57 (B), recognizing both $\mathrm{A} \beta_{p E 3-x}$ and unmodified $\mathrm{A} \beta_{3-x}$ peptides, were used for IP. The dominant $\mathrm{A} \beta$ fraction in 5XFAD and FAD42 mice was $\mathrm{A} \beta_{1-42}$ (A, left), followed by $\mathrm{A} \beta_{1-40}, \mathrm{~A} \beta_{p E 3-42}, \mathrm{~A} \beta_{4-42}, \mathrm{~A} \beta_{p E 3-40}$ and $\mathrm{A} \beta_{3-42}$. There was no significant difference in the A $\beta$ pattern between 5XFAD and FAD42 mice (A, right). Using the 1-57 antibody for IP, N-terminally truncated $\mathrm{A} \beta_{p E 3-42}$ was the major peptide detected in 5XFAD, FAD42 and TBA42 mice; $\mathrm{A} \beta_{p E 3-40}$ was only observed in 5XFAD mice (B). No A $\beta$ was found in WT mice. Sample preparation and IP/MS were carried out by the group of Erik Portelius and Kaj Blennow at the University of Gothenburg, Sweden. Abbreviation: a.u., arbitrary units. 


\subsubsection{Localization of cortical amyloid beta in 5XFAD and TBA42 mice}

5XFAD mice develop substantial plaque pathology and intraneuronal $\mathrm{A} \beta$ in the fifth layer of the cortex (Oakley et al., 2006; Jawhar et al., 2012). In contrast, intracellular and extracellular $A \beta$ accumulation is limited in TBA42 mice (See Section 3.1.2). Immunofluorescent double-labeling was therefore employed to confirm that $\mathrm{A} \beta$ deposition occurs in overlapping anatomical regions in the TBA42 and 5XFAD mice. Using antibodies against neuronal-marker NeuN (Fig. $3.17 \mathrm{~A}$ and $\mathrm{E}$ ) and $\mathrm{A} \beta$ (Fig. 3.17 B and F), intracellular $\mathrm{A} \beta$ was identified in the cortical neurons of 6-month-old 5XFAD (Fig. 3.17 D) and TBA42 mice (Fig. $3.17 \mathrm{H}$ ). These findings support the notion that the cortical A $\beta$ pathology resulting from the 5XFAD and TBA42 transgenes could interact in the FAD42 mice.

\subsubsection{Analysis of cortical plaque load in 5XFAD and FAD42 mice}

To assess the impact of additional $\mathrm{A} \beta_{p E 3-42}$ on total $\mathrm{A} \beta$ deposition, cortical plaque load was measured in 6-month-old 5XFAD and FAD42 mice. A significant increase in the ratio of $\mathrm{A} \beta_{p E 3-x}$ to $\mathrm{A} \beta_{1-x}$ plaque area was observed between 5XFAD (0.93 \pm 0.1 ; Fig. $3.18 \mathrm{~A}, \mathrm{C}$ and $\mathrm{G})$ and FAD42 mice $(1.5 \pm 0.12$; Fig. $3.18 \mathrm{D}, \mathrm{F}$ and $\mathrm{G} ; p<0.01)$. The ratio of $\mathrm{A} \beta_{x-42}$ to $\mathrm{A} \beta_{1-x}$ plaque area remained unchanged (5XFAD, $1.7 \pm 0.23$; Fig. 3.18 B, C and G; FAD42, $2.56 \pm 0.52$; Fig. 3.18 E-G). These data indicate that the additional $\mathrm{A} \beta_{p E 3-42}$ in FAD42 mice enhances seeding and increases plaque deposition relative to 5XFAD mice. No obvious changes in cortical intraneuronal $\mathrm{A} \beta$ were detected between 5XFAD and FAD42 mice (Fig. 3.19). 


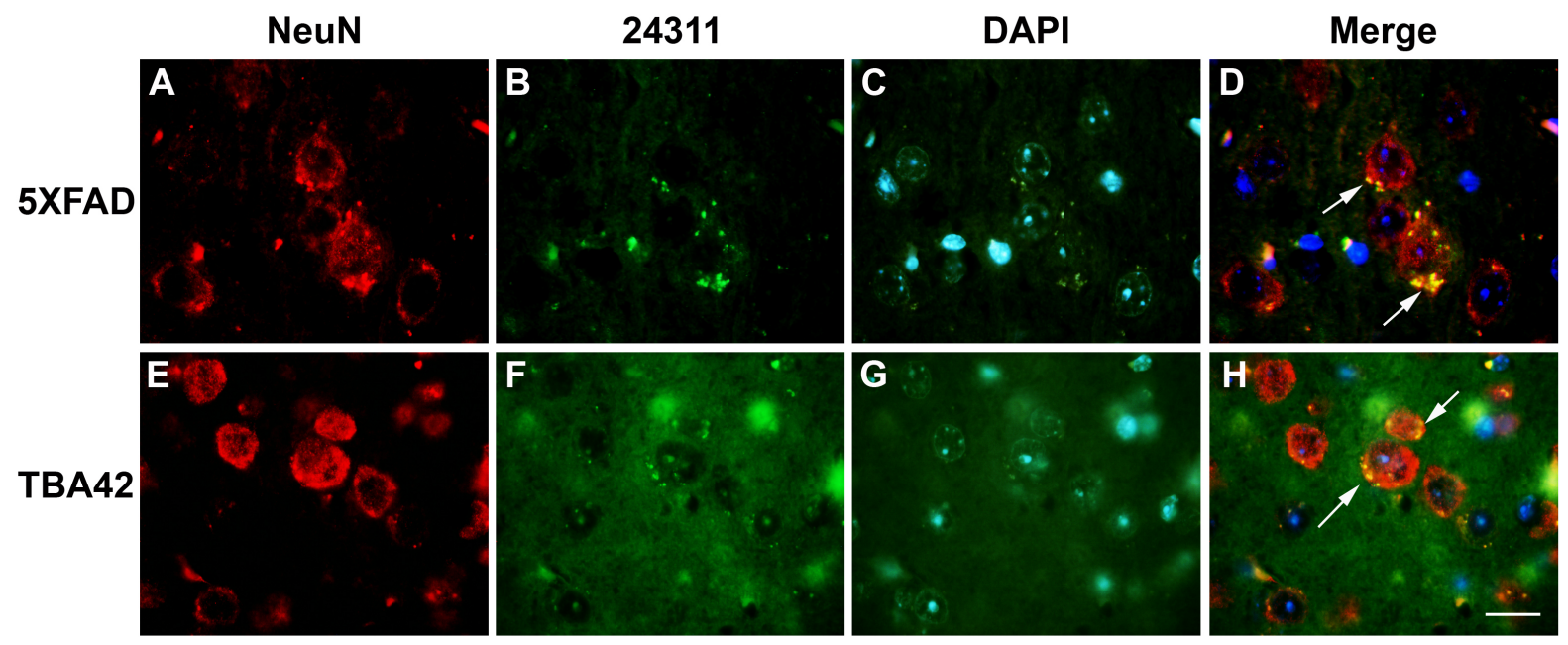

Figure 3.17: Intraneuronal $\mathrm{A} \beta$ in the cortices of 6-month-old TBA42 and 5XFAD mice. Immunofluorescent double-labeling was performed on the brains of 6month-old 5XFAD (A-D) and TBA42 (E-H) mice using antibodies against NeuN (A and $\mathrm{E})$ and pan-A $\beta$ (24311; $\mathrm{B}$ and $\mathrm{F}$ ) plus DAPI counterstaining $(\mathrm{C}$ and $\mathrm{D}) . \mathrm{A} \beta$ was found within cortical neurons in both 5XFAD (white arrows, yellow; D) and TBA42 mice (white arrows, yellow; H). Scale bar $=20 \mu \mathrm{m}$.

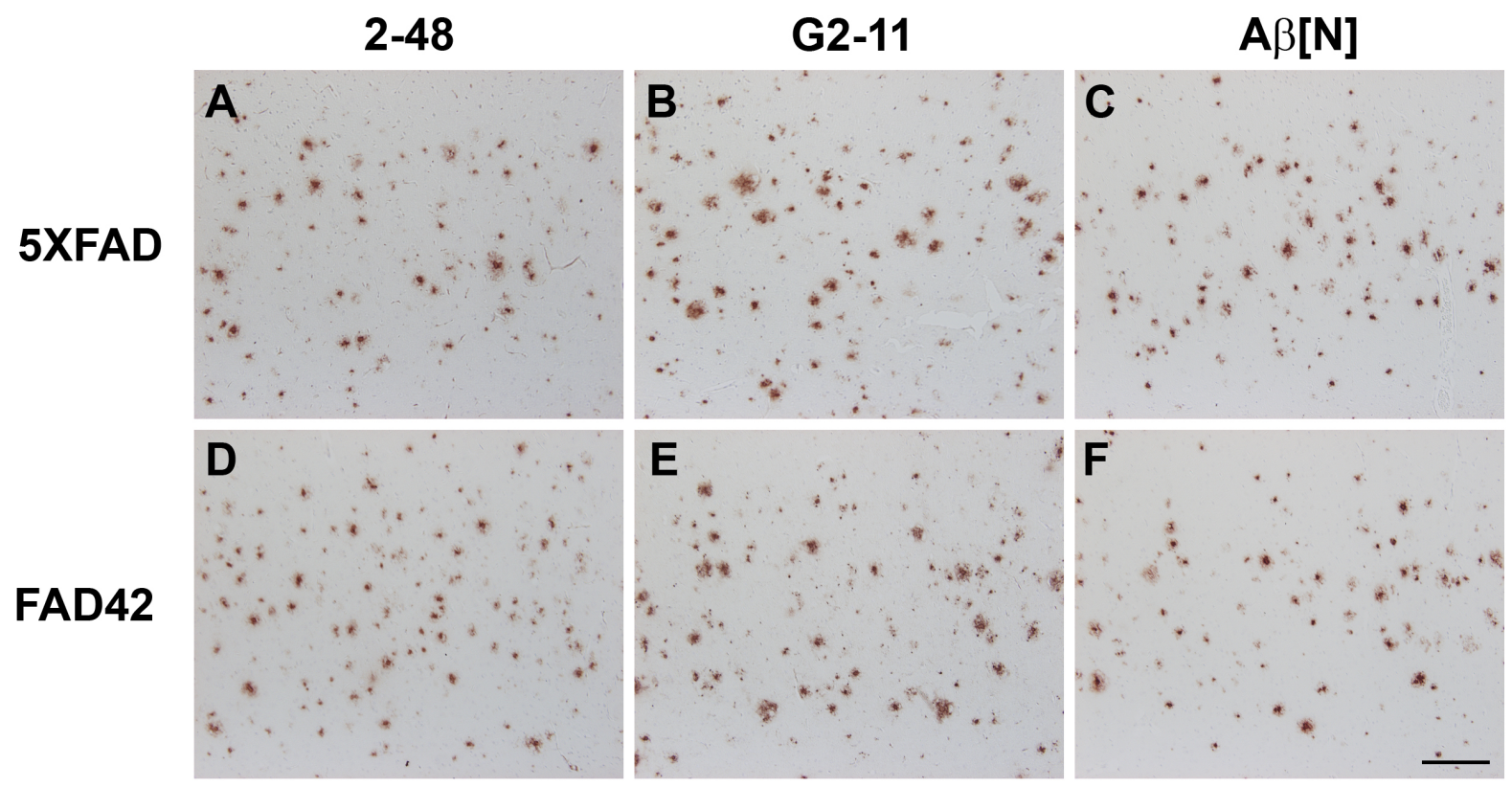




\section{G}

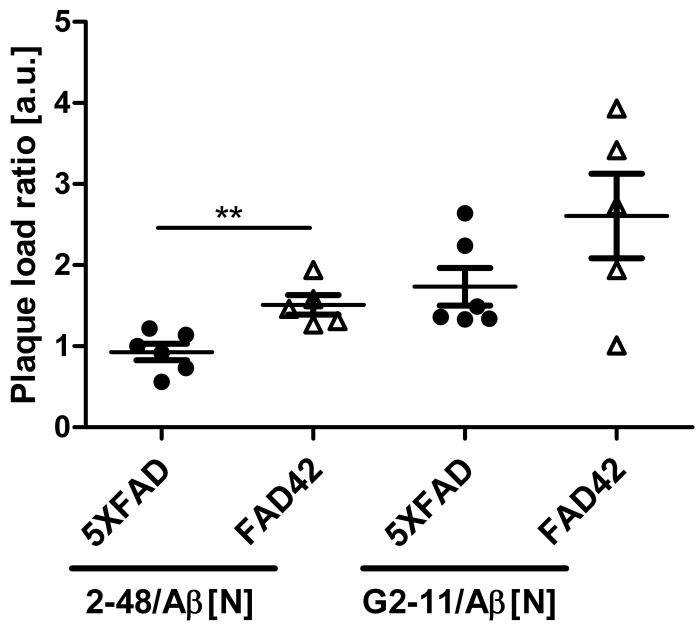

FIGURE 3.18: Elevated plaque pathology in the cortices of FAD42 mice. Immunostaining of 5XFAD (A-C) and FAD42 mice (D-F) with $\mathrm{A} \beta_{p E 3-x^{-}}$ specific antibody 2-48 (A, D), C-terminal specific antibody G2-11 against $\mathrm{A} \beta_{x-42}$ $(\mathrm{B}, \mathrm{E})$ and $\mathrm{N}$-terminal specific antibody $\mathrm{A} \beta[\mathrm{N}]$ against $\mathrm{A} \beta_{1-x}(\mathrm{C}, \mathrm{F})$. There was a significant difference between the plaque load of 5XFAD and FAD42 mice expressed as a ratio of antibody 2-48 to antibody $\mathrm{A} \beta[\mathrm{N}](\mathrm{G})$. No difference was found in the ratio of $\mathrm{G} 2-11$ to $\mathrm{A} \beta[\mathrm{N}]$. One-way ANOVA and unpaired t-test; **, $p<0.01$. Abbreviation: a.u., arbitrary units. Scale bar $=200 \mu \mathrm{m}$.

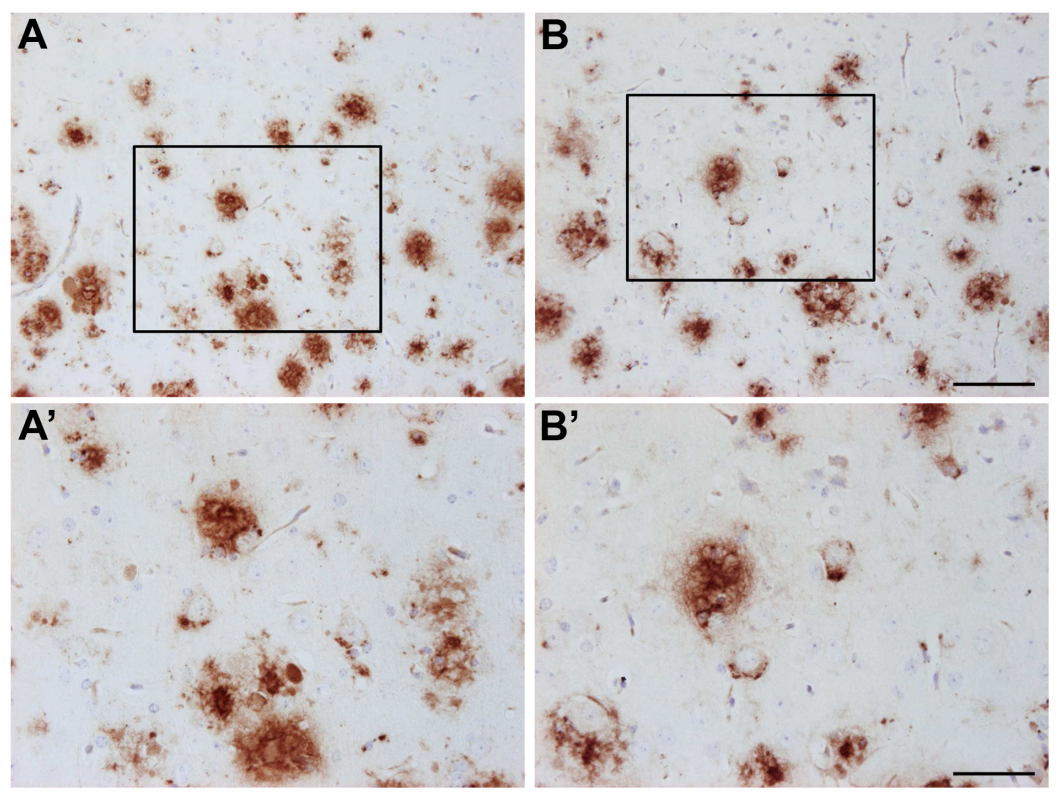

Figure 3.19: No change in cortical intraneuronal $\mathbf{A} \beta$ in FAD42 mice. FAD42 mice did not show evidence for increased intraneuronal $\mathrm{A} \beta$ accumulation in the cortex compared to 5XFAD mice at 6 months of age. Immunostaining against $A \beta$ (4G8) in 5XFAD (A) compared to FAD42 mice $(\mathrm{B})$. $\left(\mathrm{A}^{6}\right)$ and $\left(\mathrm{B}^{6}\right)$ represent magnifications of $\mathrm{A}$ and B. Scale bars, $\mathrm{A}$ and $\mathrm{B}=100 \mu \mathrm{m} ; \mathrm{A}^{\prime}$ and $\mathrm{B}^{6}=50 \mu \mathrm{m}$. 


\subsubsection{Measurement of soluble and insoluble amyloid beta in TBA42, 5XFAD and FAD42 mice}

To quantify different pools of $\mathrm{A} \beta$, frozen brains from 6-month-old 5XFAD, TBA42 and FAD42 mice were subjected to sequential protein extractions in TBS- and SDS-based buffers. ELISA was then used to measure levels of soluble (TBS) and insoluble (SDS) $\mathrm{A} \beta_{x-42}$ and $\mathrm{A} \beta_{p E 3-x}$ (mass $\mathrm{A} \beta / \mathrm{g}$ brain). Levels of TBS-soluble $\mathrm{A} \beta_{x-42}$ were significantly higher in 5XFAD $(162.8 \pm 22.2(\mathrm{ng} / \mathrm{g}))$ and FAD42 mice $(154.7 \pm 13.8(\mathrm{ng} / \mathrm{g}))$ than in TBA42 mice $(8.2 \pm 0.4$ (ng/g); Fig. 3.20 A; $p<0.001)$. Similarly, in the SDS-fraction, 5XFAD $(32,032 \pm 13,803(\mathrm{ng} / \mathrm{g}))$ and FAD42 mice $(31,771 \pm 14,234(\mathrm{ng} / \mathrm{g}))$ had more $\mathrm{A} \beta_{x-42}$ than TBA42 mice $(11 \pm 0.5(\mathrm{ng} / \mathrm{g})$; Fig. $3.20 \mathrm{C})$. TBS-soluble $\mathrm{A} \beta_{p E 3-x}$ levels were substantially higher in FAD42 mice $(238.4 \pm 67.8 \mathrm{pg} / \mathrm{g})$ than in TBA42 mice $(51.25$ $\pm 7.5 \mathrm{pg} / \mathrm{g} ; p<0.05)$ and elevated relative to 5 XFAD mice $(141 \pm 28.5 \mathrm{pg} / \mathrm{g}$; Fig. 3.20 B). Notably, the amount of SDS-soluble $\mathrm{A} \beta_{p E 3-x}$ was significantly higher in FAD42 mice $(29,061 \pm 2,805 \mathrm{pg} / \mathrm{g})$ in comparison to both TBA42 $(3,714 \pm 485 \mathrm{pg} / \mathrm{g} ; p<0.001)$ and $5 X F A D$ mice $(15,826 \pm 1,547 \mathrm{pg} / \mathrm{g} ; p<0.01)$. Significant differences in the levels of SDS-soluble $\mathrm{A} \beta_{p E 3-x}$ were also observed between TBA42 and 5XFAD mice $(p<0.01$; Fig. 3.20 D).

\subsubsection{Glutaminyl cyclase activity in wild-type, TBA42, 5XFAD and FAD42 mouse brain}

$\mathrm{QC}$ is the major enzyme implicated in the formation of $\mathrm{A} \beta_{p E}$, and its expression is upregulated in the brains of AD patients (Cynis et al., 2006; Schilling et al., 2008b). To determine how the pathology present in 6-month-old TBA42, 5XFAD and FAD42 mice influenced the catalytic function of QC, an enzyme activity assay was performed. As expected, QC activity was increased in the brain lysates of TBA42 $(p<0.05)$, 5XFAD $(p$ $<0.05)$ and FAD42 $(p<0.01)$ mice relative to WT controls (Fig. 3.21). No significant difference in QC activity was found between TBA42, 5XFAD and FAD42 mice. However, there was a strong trend toward increased QC activity in FAD42 mice. 
A

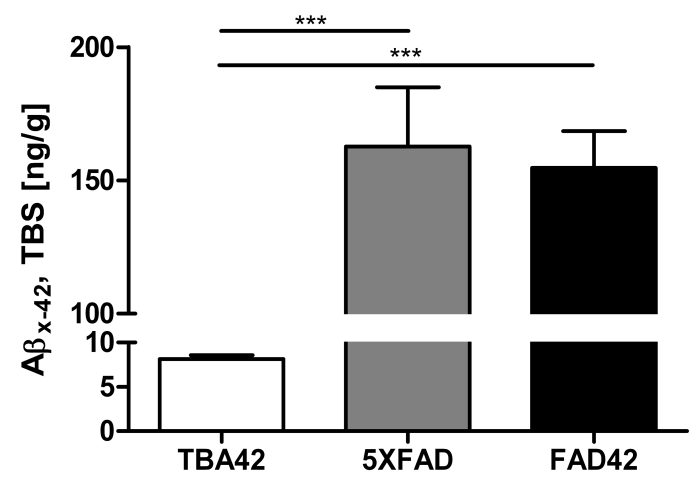

C

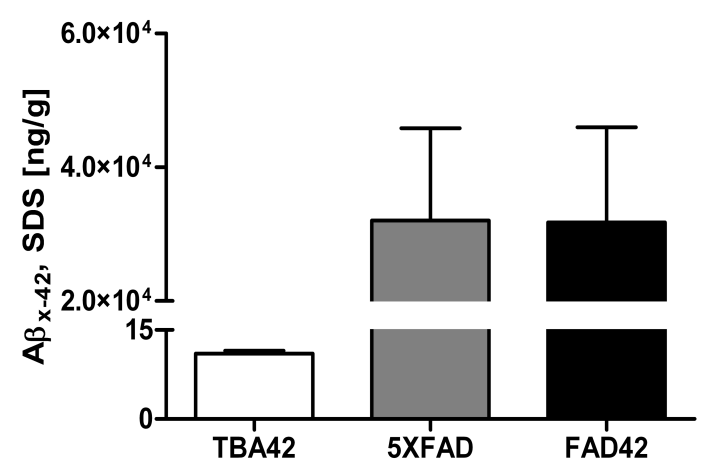

B

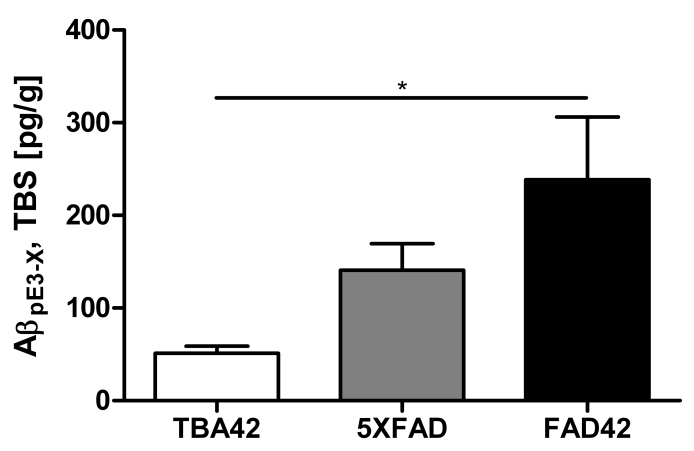

D

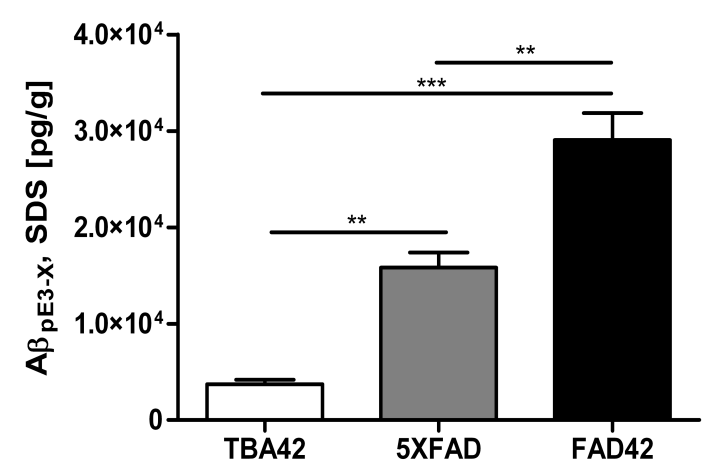

FIGURE 3.20: Increased levels of $\mathbf{A} \beta_{p E 3-x}$ in the brains of FAD42 mice as shown by ELISA. 5XFAD and FAD42 mice demonstrated elevated $\mathrm{A} \beta_{x-42}$ levels in the TBS- (A) and SDS- $(\mathrm{C})$ soluble brain fractions compared to TBA42 mice. There was no significant difference in $\mathrm{A} \beta_{x-42}$ levels between 5XFAD and FAD42 mice for either fraction. In all mouse lines, the $\mathrm{A} \beta_{x-42}$ SDS-soluble fraction contained the most $\mathrm{A} \beta$ peptide. The levels of TBS-soluble $\mathrm{A} \beta_{p E 3-x}$ were significantly higher in FAD42 mice compared to TBA42 mice (B). Substantially more SDS-soluble $\mathrm{A} \beta_{p E 3-x}$ was detected in FAD42 mice relative to both 5XFAD and TBA42 mice (D). ELISA measurements were performed by the group of Stephan Schilling and Hans-Ulrich Demuth at Probiodrug AG in Halle, Germany. Oneway ANOVA with Bonferroni post-hoc tests; ${ }^{*}, p<0.05$; $^{* *}, p<0.01$; ***,$p<0.001$. 


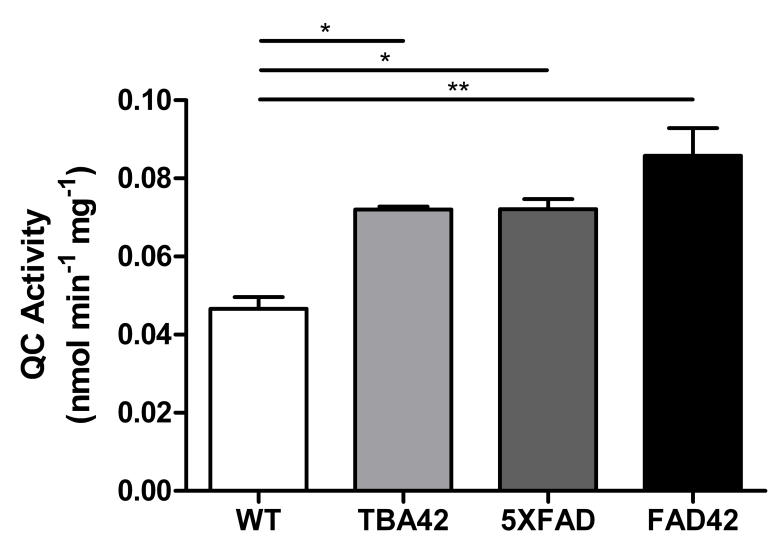

FIGURE 3.21: Increased QC activity in FAD42 mouse brain. Significantly increased QC activity was observed in TBA42, 5XFAD and FAD42 mice compared to WT controls. There was an insignificant trend toward higher QC activity in FAD42 mice relative to TBA42 and 5XFAD mice. QC activity measurements were performed by the group of Stephan Schilling and Hans-Ulrich Demuth at Probiodrug AG in Halle, Germany. One-way ANOVA with Bonferroni post-hoc tests; $*, p<0.05 ;{ }^{* *}, p<0.01$.

\subsection{Project III: Generation and characterization of the TBA83 mouse model}

The majority of AD mouse models rely on the overexpression of APP and/or PS1 to replicate aspects of AD pathology (Duyckaerts et al., 2008). While this approach results in mice that display behavioral deficits, gliosis and amyloid pathology, it creates a genetic situation never found in $\mathrm{AD}$ patients. $\mathrm{A} \beta_{4-42}$ represents a major N-terminally truncated $\mathrm{A} \beta$ species found in AD brain (Portelius et al., 2010). However, little is known about the contribution of this peptide to the progression of AD. We therefore aimed to create a transgenic mouse model that would allow us to study the physiological consequences of $\mathrm{A} \beta_{4-42}$ expression in vivo while avoiding overexpression of mutant APP and/or PS1.

To accomplish this, the TBA8 transgenic mouse lines were developed. TBA8 mice neuronally express $\mathrm{A} \beta_{4-42}$ fused to the murine TRH signal peptide (Fig. 3.22). As with the TBA42 mice (see Section 3.1), the TBA8 construct was designed to route $A \beta$ through the secretory pathway and allow for its extracellular release. However, aside from the removal of the TRH signal peptide, the $\mathrm{A} \beta_{4-42}$ produced by TBA8 mice does not need to undergo additional enzymatic modifications to reach its final form.

The objective of the present study was to generate and characterize a transgenic mouse model exclusively expressing $\mathrm{A} \beta_{4-42}$ (TBA83). Although amyloid pathology is mild in these mice, it is still capable of inducing behavioral impairments.

\subsubsection{Selection of the TBA83 mouse line}

To create the TBA8 transgenic construct, mutagenesis was performed on the TBA4 construct to delete the glutamine at position 3 of the $\mathrm{A} \beta$ sequence. This procedure thereby 
TBA8 transgene

\begin{tabular}{|l|l|l|l|} 
Thy1 promoter & pre-pro-TRH & $\mathbf{A} \boldsymbol{\beta}_{4-42}$ & Thy1 3' sequence \\
\hline
\end{tabular}

Pre-pro-peptide

Pro-peptide

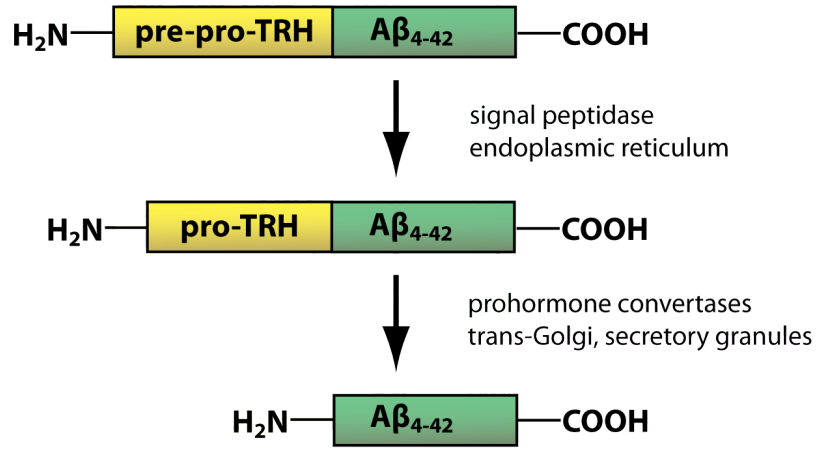

FiguRE 3.22: TBA8 transgene. The murine Thy1 promoter drives the neuronal expression of the pre-pro-TRH-A $\beta_{4-42}$ fusion peptide. An N-terminal signal sequence directs the pre-pro-TRH-A $\beta_{4-42}$ fusion peptide into the endoplasmic reticulum where signal peptidases liberate the pro-TRH-A $\beta_{4-42}$ peptide. Prohormone convertases in the trans-Golgi and secretory vesicles cleave the remainder of the TRH signal peptide to release $\mathrm{A} \beta_{4-42}$ and allow for its extracellular secretion. Figure modified from (Alexandru et al., 2011).

made the phenylalanine at position 4 the N-terminal amino acid of the $\mathrm{A} \beta$ sequence. Following sequencing and purification, the TBA 8 transgene was microinjected into the pronuclei of fertilized C57BL/6J oocytes. PCR-based genotyping of the resulting progeny identified seven mice that carried the TBA 8 transgene. Six of these mice served as the founders for independent TBA8 lines: TBA80, TBA81, TBA82, TBA83, TBA86 and TBA88. Following breeding, it was revealed that only the TBA82, TBA83, TBA86 and TBA88 founders produced offspring positive for the TBA 8 transgene. The TBA 80 and TBA81 lines were thus discontinued due to lack of stable germline transmission of the transgene.

Quantitative PCR was performed on brain-derived cDNA from the F1 generations of TBA82, TBA83, TBA88 and TBA86 mice to determine which line produced the highest transgene expression. Analysis showed that transgene levels were significantly greater in TBA83 mice relative to the other TBA8 lines (Fig. $3.23 ; p<0.05$ vs. TBA86 and TBA88; $p<0.01$ vs. TBA82). No significant difference in transgene levels was identified between the TBA82, TBA86 and TBA88 lines. As result, the TBA83 mouse line was selected for further characterization. 


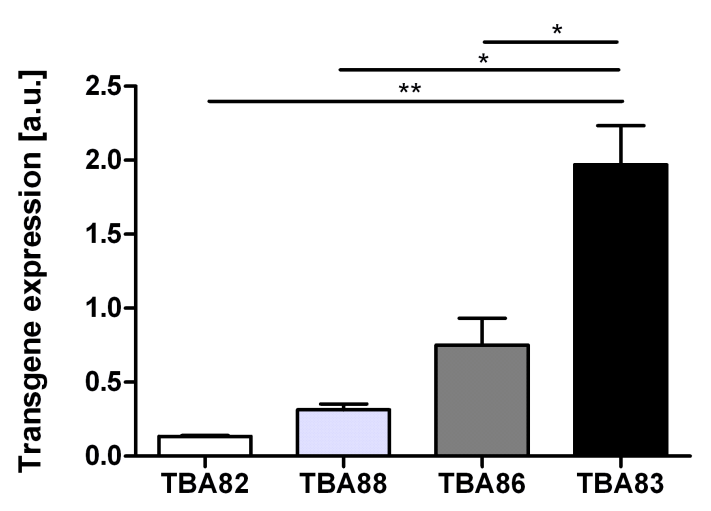

Figure 3.23: Transgene levels in TBA8 mice. qPCR measurement of TBA8 transgene cDNA derived from the brains of 2- to 4-month-old TBA82, TBA83, TBA86 and TBA88 mice. Transgene expression was highest in the TBA83 mice. In all cases, TBA8 transgene levels were normalized to $\beta$-actin expression. One-way ANOVA with Bonferroni posthoc tests; ${ }^{*}, p<0.05$; $* *, p<0.01$. Abbreviation: a.u., arbitrary units.

\subsubsection{Amyloid beta accumulation in TBA83 mice}

Transgene expression was analyzed in TBA83 mice using immunohistochemistry. Stainings with the pan-A $\beta$ antibody 24311 revealed both intraneuronal and small, extracellular $\mathrm{A} \beta$ granules in the CA1 region of the hippocampus in 4-month-old TBA83 mice (Fig. 3.24 A). By the age of 12 months, mainly larger, extracellular aggregates were found in the hippocampus (Fig. 3.24 D). Intraneuronal and extracellular $\mathrm{A} \beta$ were also observed in the spinal cord of 4-month-old TBA83 mice (Fig. 3.24 B). Spinal cord pathology was increased in 12-month-old TBA83 mice, as demonstrated by a greater number of extracellular $\mathrm{A} \beta$ accumulations and more prominent intraneuronal staining (Fig. $3.24 \mathrm{E}$ ). As in the hippocampus, intraneuronal and extracellular deposits were initially observed in the inferior colliculus and brainstem of 4-month-old TBA83 mice (Fig. 3.24 C). However, in 12-month-old TBA83 mice, predominantly extracellular aggregates were seen in these regions (Fig. 3.24 F).

\subsubsection{Gliosis in TBA83 mice}

Fluorescent immunohistochemistry was used to assess gliosis in 4- and 12-month-old TBA83 mice. Reactive astrocytes were identified in areas accumulating A $\beta$, as shown by labeling with a GFAP antibody. Gliosis was present in the CA1 region of the hippocampus in 4-month-old TBA83 mice (Fig. 3.25 A-C). TBA83 mice displayed an apparent increase in glial pathology in the CA1 region at the age of 12 months (Fig. 3.25 D-F). 

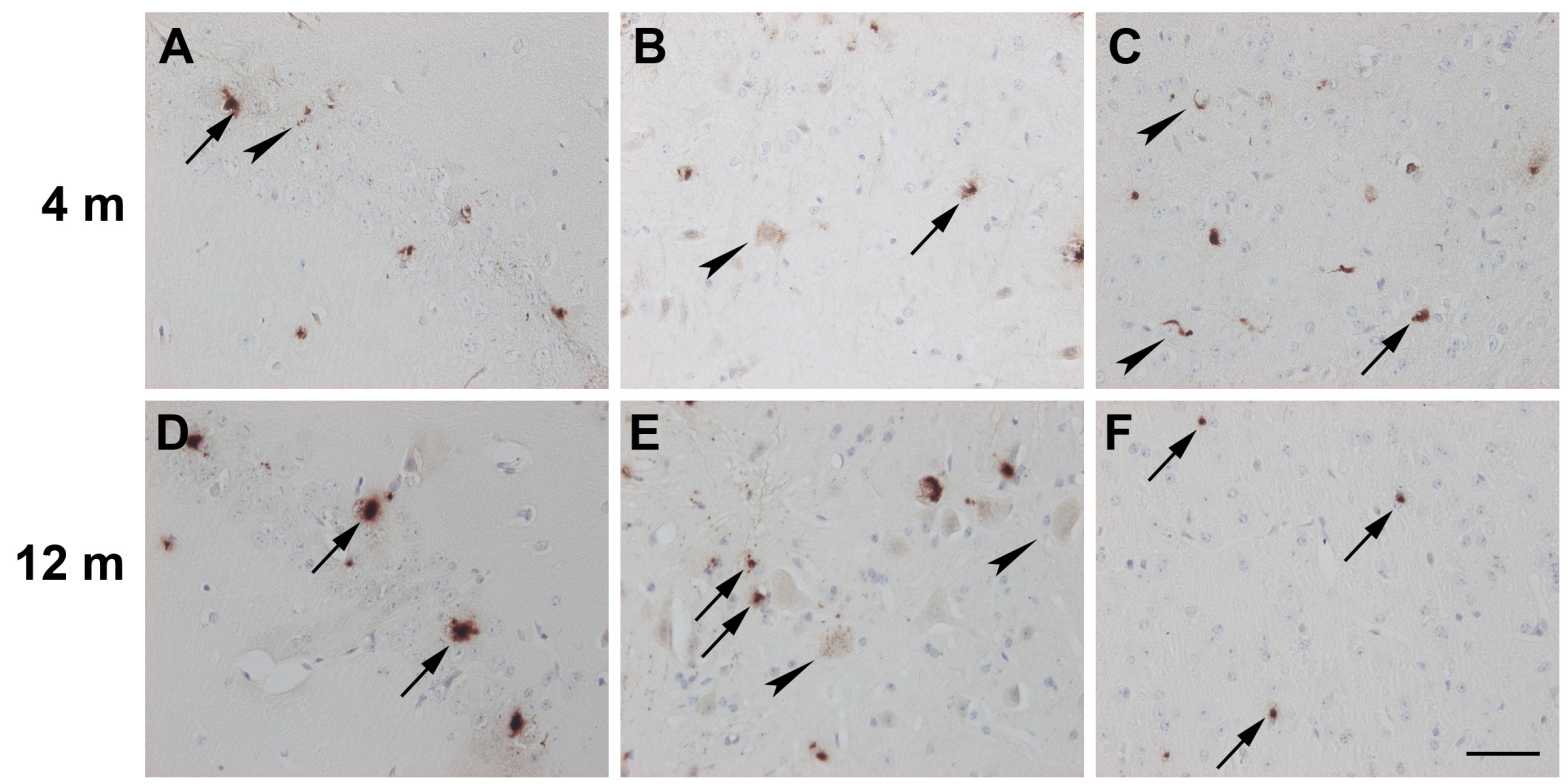

Figure 3.24: $\mathbf{A} \beta$ aggregation in 4- and 12-month-old TBA83 mice. Using the pan- $\beta$ antibody 24311, A $\beta$ accumulations were detected both intraneuronally (arrowheads) and extracellularly (arrows) in 4- (A-C) and 12-month-old (D-E) TBA83 mice. $\mathrm{A} \beta$ aggregates were identified in the CA1 region of the hippocampus (A and D), spinal cord (B and E), inferior colliculus (C and F), and brainstem (not shown). Scale bar $=50$ $\mu \mathrm{m}$.

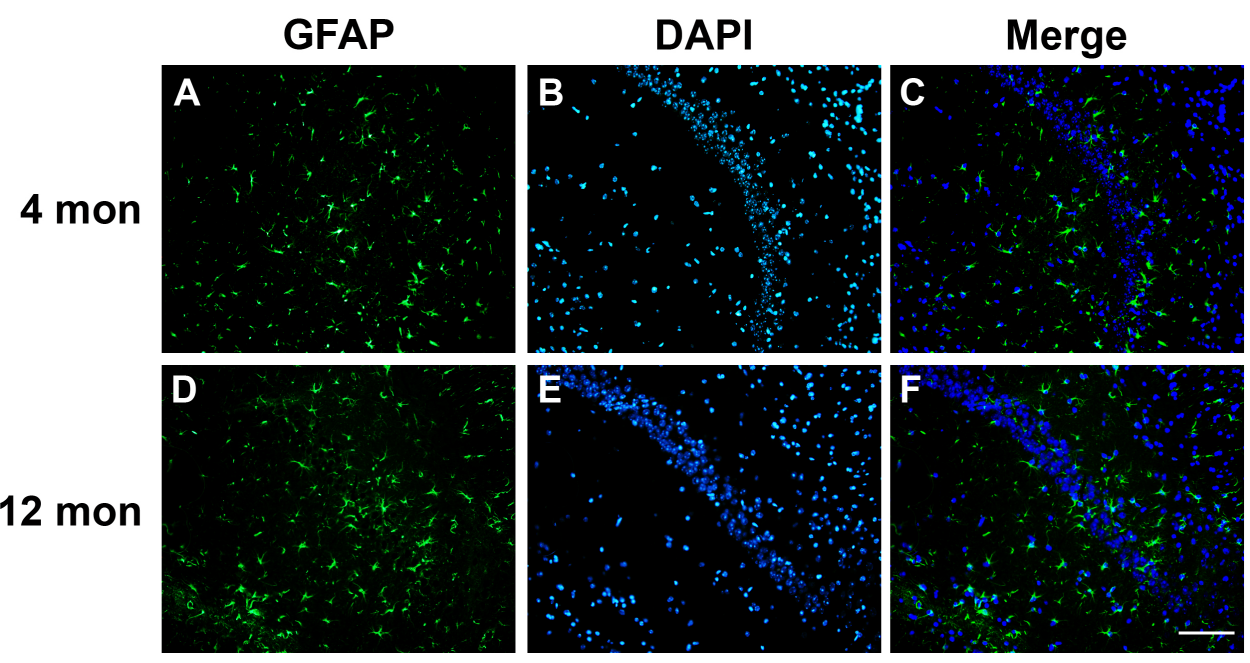

FiguRE 3.25: Gliosis in TBA83 mice. Fluorescent immunohistochemistry was performed on the brains of 4- (A-C) and 12-month-old (D-F) TBA83 mice using a GFAP antibody (green; A and D) and DAPI counterstaining (blue; B and E). There was a visible increase in gliosis between mice at the ages of 4 (C) and 12 months (F). Scale bar $=100$ $\mu \mathrm{m}$. 


\subsubsection{General physical assessment and motor function in TBA83 mice}

Physical examination of TBA83 mice revealed no gross abnormalities. No clasping behavior or tremor was observed upon tail suspension, and there was no difference in body weight between WT and TBA83 mice at 4 months of age (Fig. 3.26). Cohorts of 34, 6-7 and 11-12-month-old female TBA83 mice were subjected to a battery of behavioral tests. As with TBA42 mice, the balance beam, string suspension and inverted grip hang tasks were used to measure various aspects of motor function. Three-4-month-old and 6-7-month-old TBA83 mice performed comparably to WT controls in the balance beam test. However, 11-12-month-old mice were significantly impaired (Fig. $3.27 \mathrm{~A} ; p<0.01$ ). TBA83 mice exhibited no deficits in the string suspension (Fig. 3.27 B) or inverted grip hang tasks (Fig. 3.27 C) at any of the ages examined.

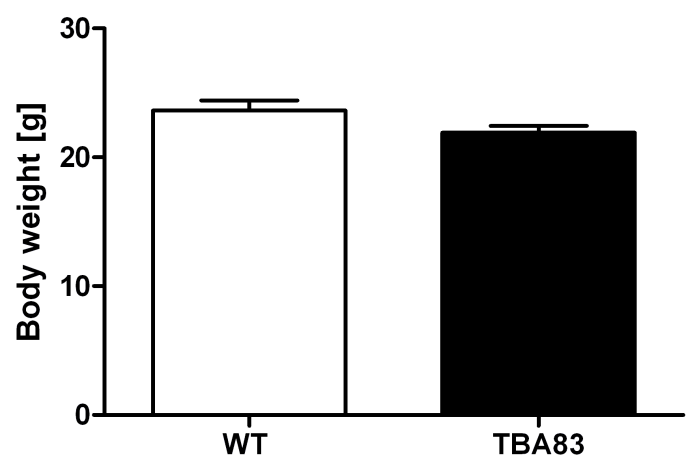

Figure 3.26: TBA83 body weight. No difference in body weight was found between 4-month-old WT and TBA83 mice. Unpaired t-test; $\mathrm{n}=7$-12 per group.

A

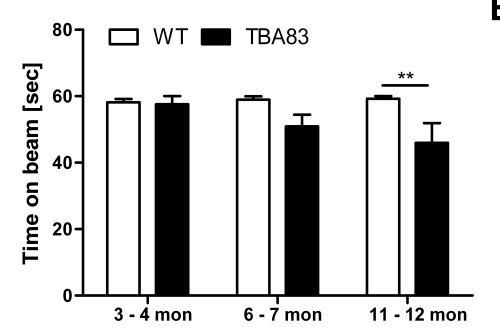

B

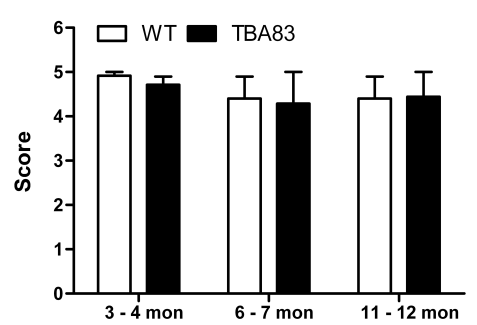

C

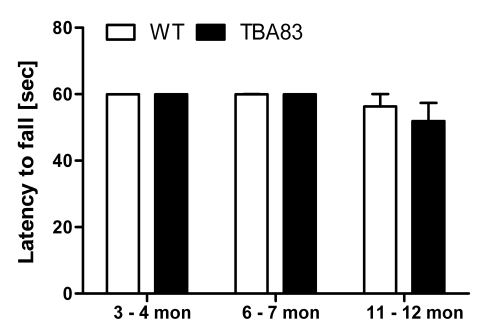

FIgURE 3.27: Subtle motor deficits in TBA83 mice. TBA83 mice showed a decline in performance in the balance beam test (A) relative to WT controls at 11-12 months of age. No deficits were found in the string suspension (B) or inverted grip hand tasks (C). Two-way ANOVA with Bonferroni post-hoc tests; ${ }^{* *}, p<0.01 ; \mathrm{n}=7-12$ per group. 


\subsubsection{Working memory in TBA83 mice}

Working memory was evaluated in TBA83 mice using the Y-and cross maze tests. No differences in alternation rate (Fig. $3.28 \mathrm{~A}$ ) or the number of arm entries (Fig. $3.28 \mathrm{~B}$ ) were found between TBA83 and WT mice in the Y-maze. TBA83 mice also performed similarly to WT controls in the cross maze, with no significant change in alteration rate (Fig. $3.28 \mathrm{C}$ ) or number of arm entries (Fig. $3.28 \mathrm{D}$ ) being detected at any of the ages examined.

A

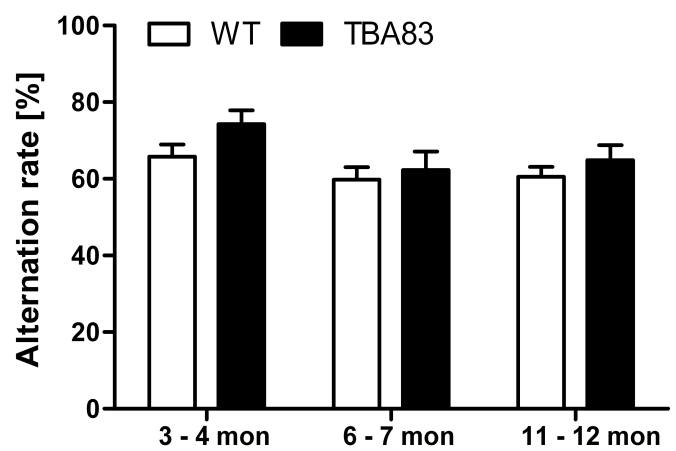

C

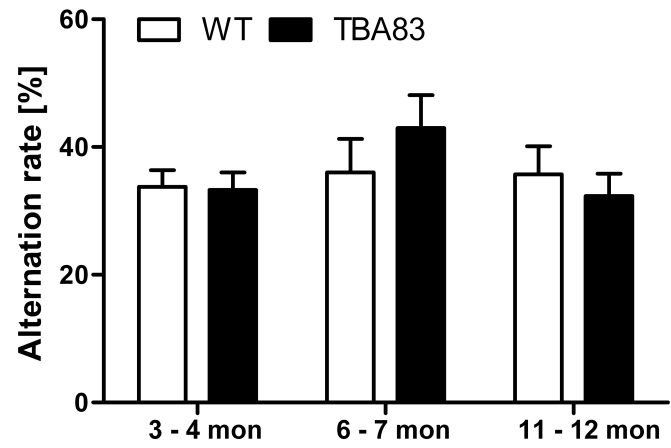

B

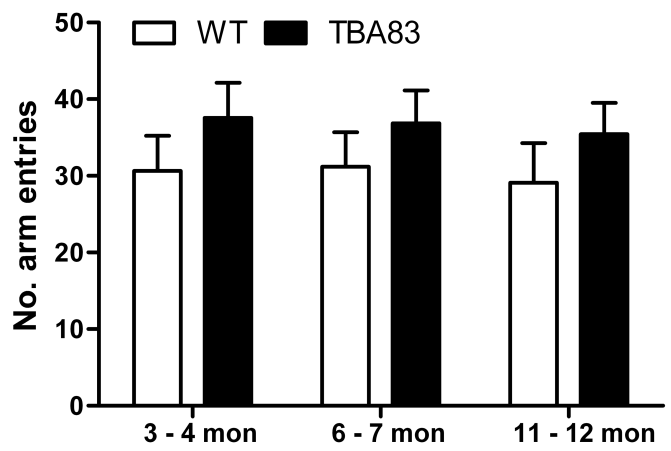

D

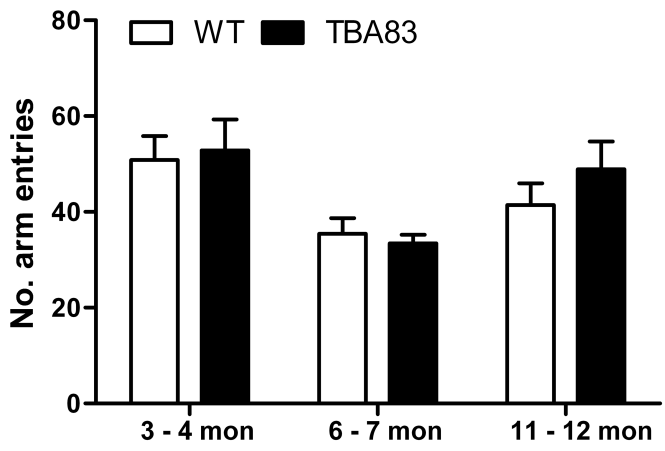

FiguRE 3.28: Normal working memory in TBA83 mice. Y-maze performance was unchanged between TBA83 and WT mice with respect to both alternation rate (A) and the number of arm entries (B). In the cross maze, alternation rate (C) and the number of arm entries (D) were also equivalent between $\mathrm{WT}$ and TBA83 mice. Two-way ANOVA with Bonferroni post-hoc tests; $\mathrm{n}=7-12$ per group.

\subsubsection{Anxiety and exploratory behavior in TBA83 mice}

The elevated plus maze was used to measure basal anxiety in TBA83 mice. The time spent in the open arms of the apparatus (Fig. $3.29 \mathrm{~A}$ ) and the total distance traveled during testing (Fig. 3.29 B) were unaltered between TBA83 and WT mice. Likewise, 
TBA83 mice displayed no changes in exploratory activity in the open field; both total distance traveled (Fig. 3.30 A) and rearing behavior (Fig. 3.30 B) were comparable to WT levels.

A

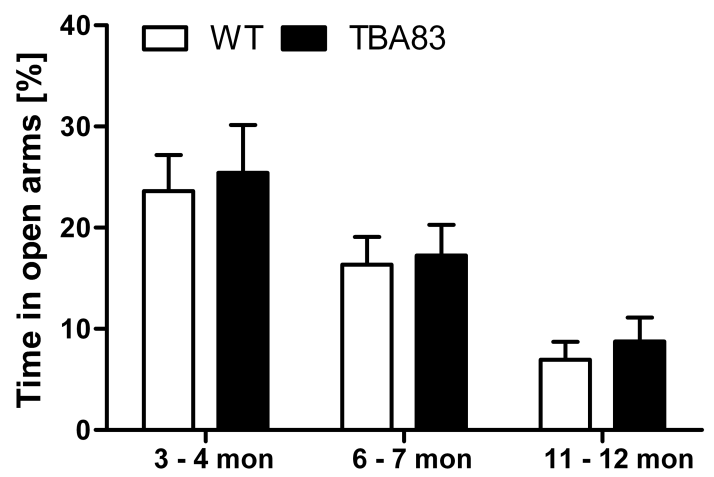

B

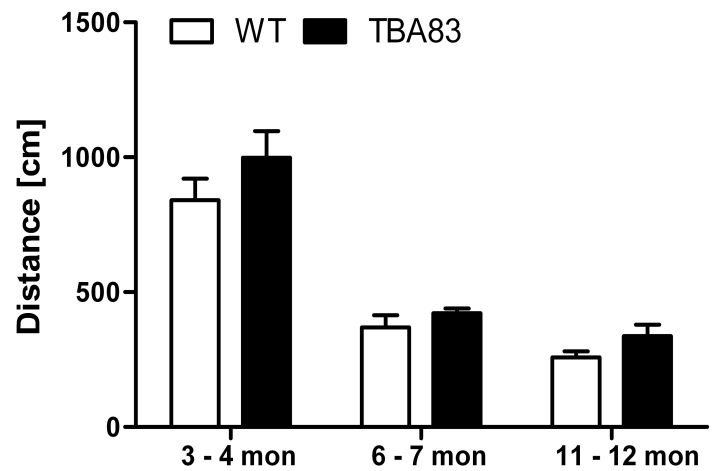

FIgURE 3.29: Unaltered anxiety levels in TBA83 mice. No changes in the percentage time spent in the open arms of the elevated plus maze (A) or the total distance traveled on the apparatus during testing (B) were observed between WT and TBA83 mice at any of the ages evaluated. Two-way ANOVA with Bonferroni post-hoc tests; $\mathrm{n}=7-12$ per group.

A

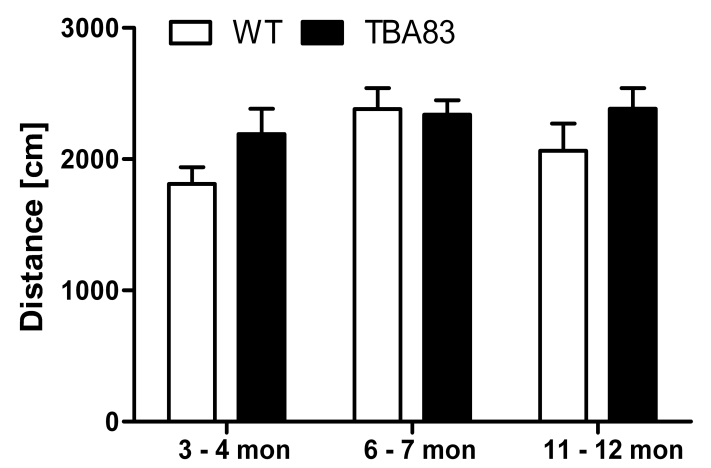

B

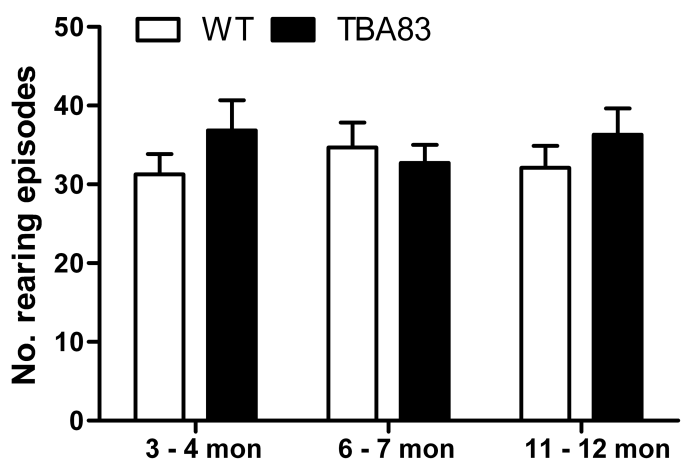

FiguRE 3.30: Unchanged exploratory behavior in TBA83 mice. There was no significant difference between TBA83 and WT mice in the distance traveled (A) or the number of rearing episodes (B) during testing in the open field. Two-way ANOVA with Bonferroni post-hoc tests; $\mathrm{n}=7-12$ per group.

\subsubsection{Spatial reference memory in TBA83 mice}

Spatial reference memory was measured in 8-9-month-old WT and TBA83 mice using the Morris water maze (MWM; see Section 2.2.9). Mice first underwent cued training 
with a marked platform to acclimate to the pool and rule-out confounding effects from previously unidentified motor or sensory deficits. Both WT and TBA83 mice demonstrated progressively shorter escape latencies in response to training. All mice were able to reach the escape criterion of $10 \mathrm{sec}$ after three consecutive training days (Fig. 3.31 A; $p<0.0001$ for time).

A

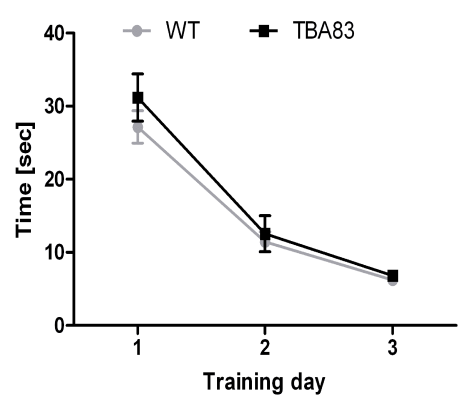

D

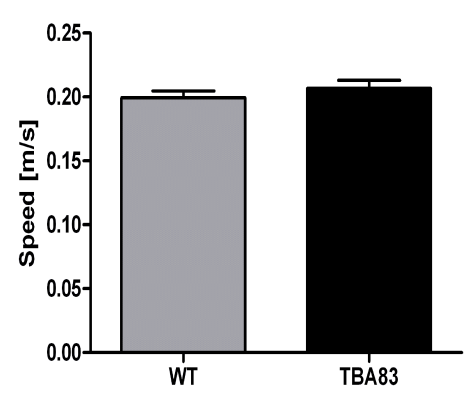

B

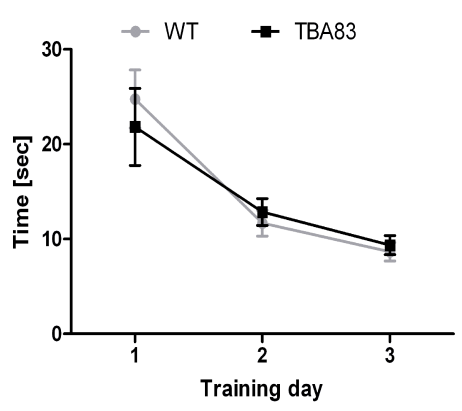

E

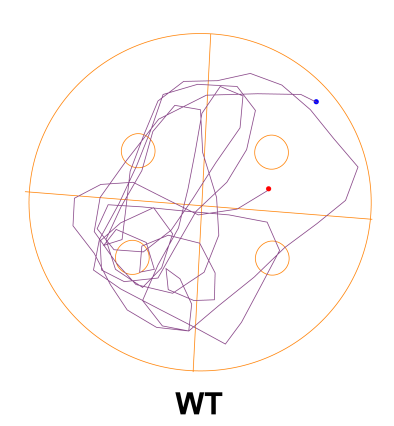

C

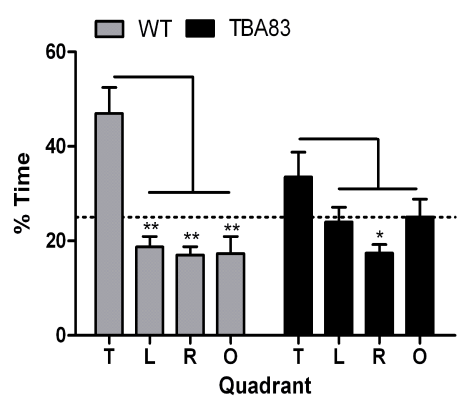

$\mathbf{F}$

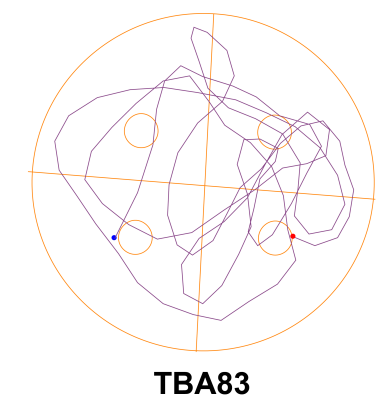

FIGURE 3.31: Impaired spatial reference memory in TBA83 mice. WT and TBA83 mice displayed similar learning curves during both the cued (A) and acquisition (B) phases of MWM training $(p<0.0001$ for time). The probe test revealed deficits in spatial references memory in TBA83 mice, as shown by their reduced preference for the target quadrant $(\mathrm{C})$. No differences in swimming speed between the TBA83 and WT mice were detected during the probe trial (D). Representative swimming paths from WT (E) and TBA83 mice (F) during the probe trial demonstrated different search strategies. Abbreviations: $\mathrm{T}=$ target quadrant, $\mathrm{L}=$ left quadrant, $\mathrm{R}=$ right quadrant, $\mathrm{O}=$ opposite quadrant; $\mathrm{A}$ and B, Two-way repeated measure ANOVA; C, paired t-tests; D, unpaired t-test; ${ }^{*}, p<0.05 ;{ }^{* *}, p<0.01 ; \mathrm{n}=7-12$ per group.

Twenty-four hours after the cued training phase, mice began acquisition training to learn the location of a submerged platform. Again, escape latencies decreased for both WT and TBA83 mice between each training day, and the mice achieved the 10 sec escape criterion after the third day (Fig. $3.31 \mathrm{~B} ; p<0.0001$ for time). Twenty-four hours after the final acquisition trial, a probe test was performed to assess spatial memory retention. 
WT mice displayed a significant preference for the target quadrant, as indicated by the percentage time spent in different quadrants of the pool (Fig. $3.31 \mathrm{C} ; p<0.001 \mathrm{~T}$ vs. all other quadrants). In contrast, the quadrant preference exhibited by TBA83 mice was less pronounced (Fig. $3.31 \mathrm{C} ; p<0.05 \mathrm{~T}$ vs. R quadrant). Swimming speed during the probe test was not different between the two groups, indicating that altered motor abilities could not account for the observed results (Fig. 3.31 D). Furthermore, a review of the swimming paths revealed that WT mice employed a more precise search strategy (Fig. $3.31 \mathrm{E}$ ) than TBA83 mice (Fig. 3.31 F). 


\section{Chapter 4}

\section{Discussion}

\subsection{Project I: Generation and characterization of the TBA42 mouse model}

$\mathrm{A} \beta_{p E}$ is being increasingly recognized as a key contributor to AD pathology. Its biochemical characteristics make it prone to aggregation and resistant to degradation (Saido et al., 1996; Kuo et al., 1998). In addition, the in vivo toxicity of $\mathrm{A} \beta_{p E}$ was demonstrated in several conventional AD mouse models. Removal of $\mathrm{A} \beta_{p E}$ through genetic manipulation, inhibitor treatment or passive vaccination restored cognitive function and ameliorated plaque pathology in various transgenic mice (Schilling et al., 2008b; Wirths et al., 2010b; Jawhar et al., 2011a). Strikingly, exclusive neuronal generation of $\mathrm{A} \beta_{p E 3-42}$ is sufficient to create a robust neurodegenerative phenotype, as demonstrated by the TBA2, TBA2.1 and TBA2.2 mouse models. While the previously characterized TBA mice provided valuable insights into the pathophysiological consequences of $\mathrm{A} \beta_{p E}$ accumulation, their usefulness for more complex transgenic studies is limited. The strong cerebellar pathology found in TBA2 mice caused neuron loss and motor abnormalities. As a result, the line was unable to be maintained (Wirths et al., 2009). Conversely, no phenotype was reported in heterozygous TBA2.1 and TBA2.2 mice. Pathology was only observed when mice were bred to homozygosity or carried both the TBA2.1 and TBA2.2 transgenes (Alexandru et al., 2011). Complicated breeding strategies would therefore be necessary to combine symptomatic TBA2.1/2.2 mice with other transgenic lines.

The primary objective of the present study was to create a transgenic mouse line that generates $\mathrm{A} \beta_{p E 3-42}$ in the heterozygous state but does not possess a lethal phenotype. The resulting TBA42 mice were then characterized on the neuropathological and behavioral 
levels. This allowed for confirmation of previous observations regarding $\mathrm{A} \beta_{p E}$ toxicity and the establishment of a useful model for further transgenic experiments.

\subsubsection{TBA42 mice develop intraneuronal and sparse extracellu- lar amyloid deposits}

Like the TBA2, TBA2.1 and TBA2.2 mice, the TBA42 mouse model expresses an A $\beta$ fusion peptide. This construct consists of an N-terminally truncated $\mathrm{A} \beta_{1-42}$ sequence in which the first two amino acids are removed and the glutamate normally at position three is replaced by glutamine $\left(\mathrm{A} \beta_{3 Q-42}\right)$. A murine TRH signal peptide is fused to the $\mathrm{A} \beta$ N-terminus. Prohormone convertases and signal peptidases in the secretory pathway liberate the $\mathrm{N}$-truncated $\mathrm{A} \beta$, thereby permitting $\mathrm{QC}$ to catalyze the formation of $\mathrm{A} \beta_{p E 3-42}$. Previous use of this construct in both cell culture and the TBA2/2.1/2.2 mouse lines demonstrated the efficaciousness of this conversion process (Cynis et al., 2006; Wirths et al., 2009; Alexandru et al., 2011).

The regional accumulations of $\mathrm{A} \beta$ in heterozygous TBA42 mice occur in a pattern consistent with transgene expression driven by the murine Thy1 promoter (Caroni, 1997). Using a pan- $\mathrm{A} \beta$ antibody, intraneuronal $\mathrm{A} \beta$ was observed in the hippocampus, inferior colliculus, brainstem and cortex of TBA42 mice beginning at the age of 3 months. Sixmonth-old mice also developed aggregates in certain cerebellar and spinal cord neurons. This pathology appeared to progress with age, as indicated by an increase in the number of aggregates found in the spinal cord (see Section 3.1.2).

The distribution and extent of these $\mathrm{A} \beta$ deposits differed noticeably from those found in the previously characterized TBA lines. $\mathrm{A} \beta$ staining was absent from cerebellar Purkinje neurons, precluding the development of the severe ataxic phenotype observed in TBA2 mice (Wirths et al., 2009). Likewise, hippocampal and brainstem pathology were less pronounced than in Hom TBA2.1 mice. While the degree of $\mathrm{A} \beta$ accumulation did provoke neuron loss, gliosis and paired-pulse inhibition deficits in the TBA2.1 model, it also resulted in early, progressive motor dysfunction. The authors were therefore unable to reliable detect cognitive deficits due to confounding motor symptoms (Alexandru et al., 2011). As a result of the milder pathology that occurs in heterozygous TBA42 mice, this model was able to be phenotyped and bred to another AD transgenic mouse line (see Sections 3.1.5 - 3.2).

In addition to intraneuronal deposits, granular, extracellular $\mathrm{A} \beta$ aggregates were seen in TBA42 mice. Alexandru and colleagues observed similar accumulations and attributed them to disintegrated cells (Alexandru et al., 2011). Such a process may also occur in 
TBA42 mice. However, the size of some of these aggregates (e.g. Fig. 3.3 E) suggests that they are not merely the product of a single cell lysis event. Wirths et al. observed plaque-associated $\mathrm{A} \beta$ pathology in several brain regions of the TBA2 mouse, including the hippocampus, cortex and superior colliculus. In this case, secreted $\mathrm{A} \beta$ was implicated in forming such large extracellular deposits (Wirths et al., 2011). Given these findings, the extracellular $\mathrm{A} \beta$ in TBA42 mice may be a product of both local neurodegeneration and the aggregation of secreted, extracellular $\mathrm{A} \beta$. Certain evidence suggests an intracellular origin for amyloid plaques; decreases in intraneuronal $\mathrm{A} \beta$ were affiliated with increases in plaque pathology in both human AD patients and transgenic mouse models (Gouras et al., 2000; Cataldo et al., 2004; Christensen et al., 2008; Moon et al., 2012). Establishing a correlation between intracellular and extracellular A $\beta$ deposition in TBA42 mice warrants further investigation.

Relative to the aggregates visualized by the pan- $\mathrm{A} \beta$ antibody, $\mathrm{A} \beta_{p E 3-x}$ accumulations in TBA42 mice were much less pronounced. $\mathrm{A} \beta_{p E 3-x}$-specific staining was observed in areas known to harbor $\mathrm{A} \beta$, and there was some evolution of this pathology over time. Again, both intraneuronal and extracellular $\mathrm{A} \beta$ deposits were noted (see Fig. 3.5). A similar situation was seen in the other TBA mouse models. For example, diffuse intraneuronal and extracellular $\mathrm{A} \beta_{p E}$ were present in the hippocampal regions of Hom TBA2.1 mice and in the Purkinje neurons of TBA2 mice (Wirths et al., 2009; Alexandru et al., 2011).

As mentioned earlier, $\mathrm{QC}$ is the enzyme primarily responsible for generating $\mathrm{A} \beta_{p E}$ (Cynis et al., 2006). QC expression may thus partially account for the location of $\mathrm{A} \beta_{p E}$ aggregates in the TBA2, TBA2.1 and TBA42 mouse lines. In WT mice, QC protein is found in specific neuronal populations, such as the interneurons of the cortex and the pyramidal neurons of the hippocampus (Hartlage-Rubsamen et al., 2009). A $\beta$ accumulated in these cell types could therefore be more readily converted into $\mathrm{A} \beta_{p E}$. In line with this assumption, immunohistochemical studies of pathologically vulnerable regions in AD brain identified an overlap between neurons expressing QC and intraneuronal $\mathrm{A} \beta_{p E}$ (Morawski et al., 2010). Alternatively, cell culture studies demonstrated that QC undergoes axonal transport and is constitutively secreted from neurons expressing it. These neurons could presumably release QC at their distal synaptic terminals, thereby allowing the enzyme to modify extracellular, N-terminally truncated A $\beta$ (Hartlage-Rübsamen et al., 2011b).

Notably, the presence of $\mathrm{A} \beta_{p E}$ correlates with neurodegenerative markers in each of the TBA mouse lines. Quantification of neuronal numbers in the hippocampal CA1 region confirmed a 35\% neuron loss in 3-month-old Hom TBA2.1 mice (Alexandru et al., 2011). In TBA2 mice, absence of calbindin, a marker for Purkinje neurons, and residual $\mathrm{A} \beta$ 
deposition indicated neurodegeneration (Wirths et al., 2009). While neuron loss was not directly quantified in TBA42 mice, progressive astrocytosis occurred in areas with $\mathrm{A} \beta_{p E}$ pathology, such as the CA1 region of the hippocampus (see Section 3.1.3).

In summary, TBA42 mice display pathological features comparable to the TBA2 and Hom TBA2.1 mouse lines. However, they produce a milder degree of $\mathrm{A} \beta$ accumulation while still allowing for the effects of $\mathrm{A} \beta_{p E 3-42}$ generation to be examined. As a result, TBA42 mice are amenable to behavioral phenotyping and can be successfully bred with other transgenic AD mouse models.

\subsubsection{Intraneuronal amyloid beta found in the endosomal/ lyso- somal system in TBA42 mice}

TBA42 mice rely on the murine TRH signal peptide to route $\mathrm{A} \beta_{3 Q-42}$ through the neuronal secretory pathway. The enzymes responsible for removing the TRH sequence consist of signal peptidases and prohormone convertases found in the trans-Golgi network and secretory granules (Nillni, 2010). Transfection of an mTRH-A $\beta_{3 Q-42}$ construct into a murine insulinoma cell line demonstrated the effective secretion of $\mathrm{A} \beta_{p E 3-42}$ into the cell culture media (Cynis et al., 2006). However, in vitro studies suggested that $\mathrm{A} \beta_{3 Q-42}$ could aggregate rapidly under the appropriate conditions (Pike et al., 1995b; Jarrett et al., 1993). Thus, to rule-out the possibility of premature aggregation and intracellular retention of $\mathrm{A} \beta_{3 Q-42}$, the subcellular localization of $\mathrm{A} \beta$ was examined in TBA42 mice (see Section 3.1.4).

Immunofluorescent double-labeling was first performed using antibodies against pan$\mathrm{A} \beta$ and Syn16, a marker for the trans-Golgi. Syn16 is a member of the SNARE family that participates in trans-Golgi network trafficking (Simonsen et al., 1998). Colocalization of the pan-A $\beta$ and Syn16 signals would indicate that $\mathrm{A} \beta$ was retained in the trans-Golgi network following cleavage of the TRH signal peptide. However, no colocalization was found, suggesting that the $\mathrm{A} \beta$ present in TBA42 mice was being appropriately trafficked beyond the Golgi.

Amyloidogenic processing of APP occurs in the endosomal/lysosomal system (Thinakaran and Koo, 2008). In line with this, examinations of brain tissue from both human $\mathrm{AD}$ patients and $\mathrm{AD}$ transgenic mice have found evidence for colocalization of $\mathrm{A} \beta$ with CatD, an aspartyl protease involved in lysosomal protein degradation (Faust et al., 1985; D'Andrea et al., 2001; Youmans et al., 2012). Furthermore, neuronal cell culture experiments indicated the presence of $\mathrm{A} \beta$ in late endosomes (Runz et al., 2002). As $\mathrm{APP}$ processing is not required to generate $\mathrm{A} \beta$ in TBA42 mice, any $\mathrm{A} \beta$ found in the 
endosomal/lysosomal system may represent a pool of secreted peptide that underwent intracellular uptake through unknown mechanisms (Mohamed et al., 2011).

To determine if $\mathrm{A} \beta$ accumulates in endosomal/lysosomal structures in TBA42 mice, additional double-labeling experiments were performed. $\mathrm{A} \beta$ colocalized with the late endosomal marker Vti1b. In addition to late endosomes, Vti1b labels trans-Golgi compartments (Kreykenbohm et al., 2002). However, the lack of colocalization between Syn16 and $\mathrm{A} \beta$ suggests that the $\mathrm{Vti1b} / \mathrm{A} \beta$ positive compartments seen in TBA42 mice are endosomal in origin. The endosomal/lysosomal localization of intraneuronal A $\beta$ in TBA42 mice was further confirmed using a CatD antibody. Colocalization with CatD was seen using antibodies against both pan- $\mathrm{A} \beta$ and $\mathrm{A} \beta_{p E}$.

$\mathrm{A} \beta$ accumulation in the endosomal/lysosomal system could result in several consequences. $\mathrm{A} \beta$ has been shown to insert into endosomal/lysosomal membranes, thereby causing leakage and possibly contributing to neuron loss (Ditaranto et al., 2001; Liu et al., 2010) In addition, $A \beta$ oligomerization is known to occur in MVBs (Takahashi et al., 2004). $\mathrm{A} \beta_{p E 3-x}$ oligomers were recently shown to contribute to neuronal dysfunction both in vitro and in vivo (Wirths et al., 2010b; Schlenzig et al., 2012). The presence of $\mathrm{A} \beta / \mathrm{A} \beta_{p E 3-42}$ in the endosomal/lysosomal system of TBA42 mice may thus have broad pathophysiological implications that remain to be elucidated.

\subsubsection{Age-dependent increase in gliosis in TBA42 mice}

Under physiological conditions, astrocytes act as "housekeeping" cells in the CNS. They recycle neurotransmitters, maintain local ion concentrations, remove waste and offer general metabolic support to neurons. When neuronal injury occurs, oxidative stressors accumulate. In response, astrocytes display a more ramified morphology and upregulate GFAP expression, thereby becoming "reactive" (Li et al., 2011).

Given the extensive neurodegeneration in $\mathrm{AD}$, it is not surprising that activated astrocytes are an early, prominent feature. They associate closely with neuritic plaques and may contribute to the evolution of AD pathology in human patients (Pike et al., 1995b). In $\mathrm{AD}$ mouse models, reactive astrocytes are also affiliated with extracellular $\mathrm{A} \beta$ deposits. The amount of gliosis typically increases linearly with plaque burden, as observed in the PDAPP, Tg2576 and 5XFAD mouse models (Games et al., 1995; Hsiao et al., 1996; Oakley et al., 2006).

TBA42 mice develop an age-dependent change in astrocyte activation without classical neuritic plaque deposition. GFAP levels in the hippocampal CA1 region increased noticeably between the ages of 3 and 12 months (see Fig. 3.6). This astrocyte activation 
occurred in the vicinity of $\mathrm{A} \beta$ accumulations. In contrast, gliosis in the hippocampal CA1 region peaks in 3-month-old Hom TBA2.1 mice and declines with age. This period of astrocyte activity corresponds tightly to $\mathrm{A} \beta / \mathrm{A} \beta_{p E}$ deposition and measurable neuron loss (Alexandru et al., 2011). Given these findings in the Hom TBA2.1 model, the progressive gliosis present in TBA42 mice may be indicative of on-going neurodegeneration. However, stereological methods should be employed to confirm this assumption.

The correlation between $\mathrm{A} \beta$ aggregates and GFAP staining suggests that $\mathrm{A} \beta$ itself directly impacts the astrocyte profile seen in the Hom TBA2.1 and TBA42 models. Studies of $\mathrm{AD}$ brain revealed that astrocytes preferentially localize to extracellular deposits consisting of N-terminally truncated $\mathrm{A} \beta$ (Thal et al., 2000). Once surrounding these aggregates, astrocytes may participate in $\mathrm{A} \beta$ degradation (Wyss-Coray et al., 2003). The prevalence of proteolytic-resistant $\mathrm{A} \beta_{p E}$ in Hom TBA2.1 and TBA42 mice, however, might impede this beneficial astrocyte function (Russo et al., 2002). Furthermore, the presence of $\mathrm{A} \beta_{p E}$-stabilized oligomers might cause astrocytes to adopt a more damaging pro-inflammatory profile (White et al., 2005; D'Arrigo et al., 2009).

Taken together, these observations suggest that the composition of the $\mathrm{A} \beta$ deposits found in TBA42 mice might promote a more aggressive astrocyte phenotype, thereby aggravating neuropathology.

\subsubsection{Age-dependent motor deficits and weight loss in TBA42 mice}

AD is characterized by a host of symptoms aside from memory impairment. Among them are weight loss and motor dysfunction. Decreased body mass is commonly observed in end-stage AD patients (Tamura et al., 2007). Similarly, 12-month-old TBA42 mice exhibited reduced weight relative to WT controls. Weight loss is also seen in other AD mouse models, such as the 5XFAD and TASTPM mice (Pugh et al., 2007; Jawhar et al., 2012). Hom TBA2.1 mice experience slower weight gain from the age of 2 months, while TBA2 mice were generally smaller than WT controls (Wirths et al., 2009; Alexandru et al., 2011). Given these findings, weight loss appears to correlate with overall phenotype severity in the TBA and other transgenic mouse models.

Motor deficits are a less commonly recognized feature of AD. They can appear early in the disease, affecting over $10 \%$ of AD patients at diagnosis (Scarmeas et al., 2004). Prospective studies revealed that poor motor performance is affiliated with an increased risk of AD (Wang et al., 2006). Motor dysfunction is also indicative of the speed of disease progression. Disturbed gait and rigidity can help to distinguish rapidly-progressing AD 
from cases that evolve more slowly (Schmidt et al., 2010).

TBA42 mice displayed their first signs of motor disturbance at the age of 6 months. The inverted grip hang revealed impaired vestibular function and muscle weakness at this time point (Erbel-Sieler et al., 2004). Motor symptoms worsened with age. Twelvemonth-old TBA42 mice exhibited deficits in the balance beam and string suspension, and inverted grip hang performance continued to decline. These results are in line with the motor phenotype observed in both TBA2 and Hom TBA2.1 mice (Wirths et al., 2009; Alexandru et al., 2011). However, the deficits shown by TBA42 mice are less severe, likely due to the milder underlying pathology.

An age-dependent decline in motor ability is not unique to the TBA mouse models. Motor impairments have been observed in 5XFAD, APP/PS1 KI and Tg2576 mice, among other AD transgenic lines (Lalonde et al., 2003b; Wirths et al., 2008; Seo et al., 2010; Jawhar et al., 2012). In these cases, motor deficits correlate with the presence of a clasping phenotype. On a neuropathological level, motor problems are associated with axonopathy, neuron loss and marked amyloid pathology in the spinal cord (Bayer et al., 2008; Seo et al., 2010; Jawhar et al., 2012).

Motor function is coordinated by a variety of brain regions, including cortical motor areas, the basal ganglia, cerebellum and spinal cord (Lalonde and Strazielle, 2007). As a result, neuron loss or disrupted connections in any of these locations can cause motor impairment. Administering the tail suspension test to TBA42 and Hom TBA2.1 mice did not provoke the clasping phenotype observed in other AD mouse models. Instead, the mice presented with hindlimb rigidity and tremors. This phenotype is characteristic of upper rather than lower motor neuron loss (Mayer, 1997). Mice with deteriorating spinal motor neurons, such as the P301S tau transgenic mouse model, experience muscle atrophy and progressive paralysis (Allen et al., 2002; Yoshiyama et al., 2007). Lack of such a phenotype in TBA42 and Hom TBA2.1 mice further suggests that the observed motor impairments originate in higher motor regions.

In summary, TBA42 mice exhibit motor impairments comparable to those seen in human $\mathrm{AD}$ patients and some $\mathrm{AD}$ mouse models. However, the tremor and rigidity present in this model imply that these deficits are caused by the dysfunction of motor neurons outside of the spinal cord.

\subsubsection{Age-dependent working memory deficits in TBA42 mice}

The progressive cognitive impairment in AD ultimately affects multiple memory domains, including working memory. Complex connections between regions of the prefrontal 
cortex and the hippocampus are necessary to maintain working memory in human subjects (Linden, 2007). In rodents, working memory relates to spatial search strategies needed for foraging in the wild (Dember and Fowler, 1958). Spontaneous alternation tasks are commonly used to evaluate working memory in mice. These tests rely on a mouse's innate exploratory tendencies to drive their movement through multi-arm mazes. Importantly, spontaneous alternation rates are sensitive to lesions in the hippocampus and prefrontal cortex, making them ideal for detecting memory impairments relevant to AD pathology (Lalonde, 2002).

Age-dependent changes in spontaneous alternation are variably found in transgenic AD mouse models. Decreased alternation rates have been observed in Tg2576, 5XFAD and APP/PS1 mice (Hsiao et al., 1996; Holcomb et al., 1998; Oakley et al., 2006; Jawhar et al., 2012). Conversely, the APPswe + PS1/DeltaE9 model displayed no such phenotype (Lalonde et al., 2004). Differences in transgene promoter, transgene expression levels, and strain background can partially account for such behavioral variability (Lassalle et al., 2008; Philipson et al., 2010).

Deficits in working memory were observed in 12-month-old TBA42 mice using the cross maze. Alternation rates in the Y-maze were unchanged between TBA42 mice and WT controls at all of the ages evaluated. The discrepancy between the cross maze and Y-maze data likely relates to the differences in maze structure. The cross maze consists of four arms instead of three, making it a more complex task and thus better able to detect subtle deficits. Notably, the number of arm entries made by TBA42 mice in both mazes did not differ significantly from WT levels. This finding indicates that the decrease in spontaneous alternation rate observed in 12-month-old mice reflects working memory impairment rather than motor dysfunction.

The prominent hippocampal pathology found in TBA42 mice may account for the observed working memory deficits; both intraneuronal $\mathrm{A} \beta$ and robust gliosis were present in 12 -month-old mice. Similarly, $\operatorname{ArcA} \beta$ mice show impaired Y-maze performance at an age when only intraneuronal $\mathrm{A} \beta$ accumulations are present (Knobloch et al., 2007). Soluble, extracellular forms of $\mathrm{A} \beta_{p E}$ might also contribute to the TBA42 phenotype. Perisynaptic $\mathrm{A} \beta_{p E}$ aggregates have been detected in $\beta$-APP mice at an age when behavioral impairments begin to manifest (Mandler et al., 2011). Furthermore, $\mathrm{A} \beta_{p E 3-42}$ oligomers were found to be potent inhibitors of LTP in hippocampal slices (Schlenzig et al., 2012).

In conclusion, TBA42 mice develop age-dependent deficits in working memory, thereby replicating one of the cognitive features of AD. Previous studies suggest that the hippocampal intraneuronal $\mathrm{A} \beta$ present in this model, and potentially soluble forms of $\mathrm{A} \beta_{p E}$, might cause this phenotype. 


\subsubsection{Decreased anxiety and altered exploratory activity in TBA42 mice}

Anxiety and disinhibition are two symptoms at opposite ends of the spectrum of behavioral and psychological changes accompanying AD. Certain AD patients may be severely withdrawn due to anxiety, while others may exhibit socially unacceptable behavior characteristic of disinhibition (Chung and Cummings, 2000; Lyketsos et al., 2002). Anxiety levels in mice can be measured using the elevated plus maze. More time spent in the open arms of the maze indicates reduced anxiety and disinhibition, while more time spent in the closed arms signifies enhanced anxiety. As measured by the elevated plus maze, AD mouse models display a range of anxiety levels. Tg2576, APP/PS1 KI, APPswe + PS1/DeltaE9 and 5XFAD mice all exhibit reduced anxiety tendencies (Lalonde et al., 2003a, 2004; Cotel et al., 2010; Jawhar et al., 2012). In contrast, anxiety levels are increased or unchanged in the APPSwe + PS1A246E and APP23 models (Lalonde, 2002; Puoliväli et al., 2002).

TBA42 mice spent more time in the open arms of the elevated plus maze beginning from the age of three months. This phenotype remained constant as the mice aged, thereby demonstrating a stable reduction in anxiety. Altered connectivity between the hippocampus, septum and amygdala have all been linked to changes in anxiety levels (Lalonde et al., 2012). Evidence suggests that the ventral hippocampus may be a more critical determinant of elevated plus maze behavior than the amygdala (Bannerman et al., 2004). Supporting the findings with TBA42 mice, $\mathrm{A} \beta_{p E 3}$ oligomers have also been shown to influence anxiety behaviors. Passive vaccination of 5XFAD mice with an antibody specific for low molecular weight $\mathrm{A} \beta_{p E 3}$ oligomers stabilized the age-dependent decrease in anxiety typically found in this model (Wirths et al., 2010c). Given that $\mathrm{A} \beta / \mathrm{A} \beta_{p E}$ pathology is already present in the hippocampi of 3-month-old TBA42 mice, alterations in hippocampal function could be a plausible cause of the observed decrease in anxiety.

The open field serves as a measure of exploratory drive and motor behavior in mice (Archer, 1973). As with the elevated plus maze, a variety of phenotypes have been recorded in transgenic AD mouse models using this task. Some models, such as the APP23, display hypoactivity in the open field; others, like the Tg2576, are hyperactive (Lalonde, 2002; Deacon et al., 2009). TBA42 mice showed no differences in open field activity relative to WT controls. However, the rearing behavior of TBA42 mice was already significantly reduced from the age of 3 months. A similar phenotype has been observed in the APP/PS1 KI mice (Wirths et al., 2008). Since APP/PS1 KI mice traveled the same distance as WT mice while in the open field, the authors suggested that altered rearing behavior reflected 
impaired motor activity. Alternatively, expression of a dominant negative cadherin protein in cortical and hippocampal neurons also decreases rearing behavior without altering exploratory activity (Edsbagge et al., 2004). Taken together, these findings suggest that the rearing phenotype observed in TBA42 mice could reflect either an early manifestation of motor dysfunction or changes in hippocampal cytoarchitecture.

In conclusion, the current studies revealed that TBA42 mice possess a disinhibition phenotype similar to that seen in AD patients. Additionally, the decreased rearing behavior observed in the open field might serve as an early indicator of pathological changes in these mice.

\subsubsection{Conclusions of Project I}

Based on the results of the current work:

- Heterozygous TBA42 mice recapitulated aspects of the $\mathrm{A} \beta / \mathrm{A} \beta_{p E}$ aggregation and astrocytosis seen in TBA2 and Hom TBA2.1 mice without producing an early, debilitating phenotype.

- Intraneuronal A $\beta$ accumulations in TBA42 mice occurred in pathologically-relevant intracellular compartments.

- Age-dependent deficits in motor function and working memory were observable in TBA42 mice.

- Reduced anxiety and decreased rearing behavior were identified in TBA42 mice; they represented the earliest and most persistent phenotypic changes.

- The milder underlying pathology and behavioral deficits present in TBA42 mice make this model suitable for further transgenic studies. 


\subsection{Project II: Exploring the pyroglutamate-modified amyloid beta seeding hypothesis using the FAD42 mouse model}

In vitro and in vivo studies have demonstrated that $\mathrm{QC}$ catalyzes the formation of $\mathrm{A} \beta_{p E}$ (Cynis et al., 2008; Schilling et al., 2008b; Alexandru et al., 2011; Jawhar et al., 2011a). Manipulation of QC through either pharmacological or genetic means effectively ameliorates cognitive deficits and reduces pathology in certain AD mouse models (Schilling et al., 2008b; Jawhar et al., 2011a). In line with these findings, ectopic overexpression of hQC increases $\mathrm{A} \beta_{p E}$ levels, enhances $\mathrm{A} \beta$ deposition and aggravates behavioral impairments in 5XFAD mice (Jawhar et al., 2011a). However, QC has targets other than A $\beta$. Overexpression of QC could affect its activity toward these substrates, thereby influencing the phenotype observed in 5XFAD/hQC mice.

To avoid this confounding factor, we aimed to increase $\mathrm{A} \beta_{p E 3-42}$ levels without relying on QC overexpression. The previous project showed that TBA42 mice are a viable model for exploring $\mathrm{A} \beta_{p E 3-42}$ toxicity. The objective of the current study was to examine the pathological and behavioral consequences of enhanced $\mathrm{A} \beta_{p E 3-42}$ production by crossing TBA42 mice and 5XFAD mice to produce the FAD42 mouse model.

\subsubsection{Enhanced behavioral deficits in FAD42 mice}

In previous work from our lab, 6-month-old 5XFAD/hQC mice demonstrated impairments in several behavioral domains. Relative to 5XFAD single transgenics, 5XFAD/hQC mice displayed worse performance in the balance beam, string suspension, Y-maze and cross maze. These changes correlated directly with increased levels of $\mathrm{A} \beta_{p E 3-x}$ in protein extracts from 5XFAD/hQC mouse brain (Jawhar et al., 2011a). Normally, 5XFAD mice exhibit no abnormalities in string suspension, balance beam or Y-maze performance at 6 months of age (Jawhar et al., 2011a, 2012). The sudden appearance of these impairments, plus the exacerbation of preexisting deficits in the cross maze, thus revealed how increased levels of $\mathrm{A} \beta_{p E 3-x}$ can enhance underlying pathology.

The data of Jawhar et al. also suggest that minor deficits may be present in single transgenic hQC mice (Jawhar et al., 2011a). If this is the case, then hQC overexpression might influence the phenotype of $5 \mathrm{XFAD} / \mathrm{hQC}$ mice independent of $\mathrm{A} \beta_{p E 3-x}$ production. However, since no direct comparisons were made between the performance of hQC mice and WT controls, this observation requires further experimental validation. 
In agreement with our findings in the 5XFAD/hQC mice, behavioral deficits were identified in 6-month-old FAD42 mice relative to TBA42, 5XFAD and WT controls. The impairments manifested as worsened performance in the balance beam and elevated plus maze. The specificity of these deficits likely relates to the particular pattern of $\mathrm{A} \beta$ accumulation observed in TBA42 mice (see Section 3.1.2). This is in direct contrast to the situation in 5XFAD/hQC mice, where hQC and APP expression overlap throughout the brain (Jawhar et al., 2011a).

Taken together, the behavioral data from FAD42 mice highlight the potent toxicity of $\mathrm{A} \beta_{p E 3-42}$. Despite the region-specific overexpression of $\mathrm{A} \beta_{p E 3-42}$, the TBA42 transgene is sufficient to aggravate the phenotype found in 5XFAD mice, a model with aggressive amyloid pathology.

\subsubsection{Minor alterations in the amyloid beta profile of FAD42 mice as determined by IP/MS}

Given the results of our behavioral tests, we wanted to explore precisely how additional $\mathrm{A} \beta_{p E 3-42}$ alters amyloid pathology in FAD42 mice. $\mathrm{A} \beta_{p E}$ displays enhanced aggregation kinetics and speeds the sedimentation of other A $\beta$ species in vitro (He and Barrow, 1999; Kuo et al., 1998; Schilling et al., 2006; Schlenzig et al., 2009). We reasoned that such a phenomenon occurring in vivo might alter the pattern of $\mathrm{A} \beta$ isoforms isolated from FAD42 brain.

To test this hypothesis, we employed IP/MS to analyze the A $\beta$ species found in TBA42, 5XFAD and FAD42 mice. Using antibodies against total $\mathrm{A} \beta, \mathrm{A} \beta_{1-42}$ was identified as the dominant isoform in the brains of $5 \mathrm{XFAD}$ mice. This result is in line with previous studies reporting the overproduction of $\mathrm{A} \beta_{1-42}$ in this model (Oakley et al., 2006; Jawhar et al., 2012). Minor peaks representing $\mathrm{A} \beta_{1-40}$ and N-terminally truncated species of $\mathrm{A} \beta_{1-42}$ were also observed. A similar pattern of $\mathrm{A} \beta$ isoforms was found in FAD42 mice.

Using the N-terminal-specific antibody 1-57, $\mathrm{A} \beta_{p E 3-42}$ and $\mathrm{A} \beta_{3-42}$ were found in the brains of TBA42, 5XFAD and FAD42 mice. In all cases, $\mathrm{A} \beta_{p E 3-42}$ was the dominant isoform. As TBA42 mice initially produce $\mathrm{A} \beta_{3 Q-42}$, the presence of unmodified, N-truncated $\mathrm{A} \beta_{3-42}$ peptide was not unexpected. The ratio of the $\mathrm{A} \beta_{3-42}$ and $\mathrm{A} \beta_{p E 3-42}$ peaks suggests that most $\mathrm{A} \beta$ in TBA42 mice undergoes pyroglutamate modification. However, it cannot be excluded that unmodified $\mathrm{A} \beta_{3-42}$ also contributes to the observed pathology in this model.

Ultimately, the only difference between the $\mathrm{A} \beta$ isoform patterns in the 5XFAD and FAD42 models was the absence of a minor $\mathrm{A} \beta_{p E 3-40}$ peak in FAD42 mice. MS is a quali- 
tative rather than a quantitative measurement, and ionization efficiency can vary between different peptides. Overproduction of $\mathrm{A} \beta_{1-42}$ has been associated with the suppression of $\mathrm{A} \beta_{p E 3-x}$ signals in previous MS experiments (Piccini et al., 2005). Such a phenomenon may also account for the lack of $\mathrm{A} \beta_{p E 3-40}$ signal in FAD42 mouse brain. Nevertheless, a significant precipitation of $\mathrm{A} \beta_{p E 3-40}$ in 5XFAD mice alone cannot be ruled out. It also cannot be excluded that the different levels of $\mathrm{A} \beta_{p E}$ variants observed between the $5 \mathrm{XFAD}$ and FAD42 spectra result from highly aggregated $\mathrm{A} \beta_{p E 3-x}$ in FAD42 mice. An overly compact $\mathrm{A} \beta$ aggregation state could potentially interfere with the binding of the 1-57 antibody, thus preventing the efficient extraction of some forms of $\mathrm{A} \beta_{p E}$ for IP/MS analysis.

Despite not finding a dramatic difference in the $\mathrm{A} \beta$ isoform pattern between 5XFAD and FAD42 mice, our data illustrate a unique feature of the 5XFAD model. N-terminally modified forms of $\mathrm{A} \beta$ occur in low amounts in many AD transgenic mice (Kawarabayashi et al., 2001; Kuo et al., 2001; Kalback et al., 2002). This contrasts the situation in human $\mathrm{AD}$ patients, where a variety of N-truncated $\mathrm{A} \beta$ species have been observed (Rüfenacht et al., 2005; Güntert et al., 2006; Portelius et al., 2010). It has therefore been hypothesized that a lack of these N-terminally modified $\mathrm{A} \beta$ species might partially account for the difference in plaque solubility and NFT pathology observed between AD patients and transgenic mice (Kawarabayashi et al., 2001; Kuo et al., 2001; Kalback et al., 2002). Mice that possess such isoforms, like the APP/PS1 KI mouse, often exhibit neuron loss and more aggressive pathology (Casas et al., 2004).

The prevalence of $\mathrm{A} \beta_{p E}$ and other N-terminally truncated forms of $\mathrm{A} \beta$ in 5XFAD and FAD42 mice might account for their severe phenotypes. However, targeted removal of low-molecular weight $\mathrm{A} \beta_{p E 3}$ oligomers using passive immunization produces beneficial therapeutic effects in 5XFAD mice (Wirths et al., 2010c). These data imply that a selective alteration of $\mathrm{A} \beta_{p E}$ levels is sufficient to affect pathology despite the presence of other $\mathrm{N}$ terminally modified $\mathrm{A} \beta$ isoforms.

\subsubsection{Altered levels of pyroglutamate-modified amyloid beta and increased plaque pathology in FAD42 mice}

To confirm the seeding effect of $\mathrm{A} \beta_{p E}$ in vivo, the cortical plaque loads of 5XFAD and FAD42 mice were compared. Prior to this, it was established that $\mathrm{A} \beta$ could be found in overlapping neuronal populations in TBA42 and 5XFAD mice. Immunofluorescent double-labeling indicated that both 5XFAD and TBA42 mice possess intraneuronal A $\beta$ in cortical neurons. In vivo microdialysis experiments have shown that local concentra- 
tions of $\mathrm{A} \beta$ in the interstitial fluid are critical to plaque development (Yan et al., 2009; Bero et al., 2011). Furthermore, cell culture studies suggested that aggregation of A $\beta$ in intracellular compartments, followed by the release of these aggregates extracellularly, may also spur plaque formation (Hu et al., 2009; Friedrich et al., 2010). The presence of $\mathrm{A} \beta$ in overlapping cortical neuron populations in the TBA42 and 5XFAD mouse models therefore ensures that their respective $\mathrm{A} \beta$ pools have an opportunity to interact and increase plaque load.

It was previously demonstrated in $5 \mathrm{XFAD} / \mathrm{hQC}$ mice that elevated $\mathrm{A} \beta_{p E}$ levels increase cortical plaque load (Jawhar et al., 2011a). Accordingly, lowering A $\beta_{p E}$ levels through QC inhibition, antibody treatment or QC KO is sufficient to ameliorate plaque pathology (Schilling et al., 2008b; Wirths et al., 2010c; Jawhar et al., 2011a). In line with these findings, the ratio of $\mathrm{A} \beta_{p E 3-x}$ to $\mathrm{A} \beta_{1-x}$ plaque area was significantly higher in FAD42 mice relative to 5XFAD controls. No increase in intraneuronal $\mathrm{A} \beta$ staining was seen in FAD42 mice. It is therefore unlikely that the observed change in plaque load is attributable to the detection of more intraneuronal aggregates. The average ratio of $\mathrm{A} \beta_{x-42}$ to $\mathrm{A} \beta_{1-x}$ plaque area was also elevated in FAD42 mice. However, a high degree of variation in the FAD42 cohort prevented this measure from reaching statistical significance. Taken together, these data confirm that $\mathrm{A} \beta_{p E 3-x}$ can seed amyloid deposition in vivo.

Analysis of TBS- and SDS brain fractions revealed significantly higher levels of SDSsoluble $\mathrm{A} \beta_{p E 3-x}$ in the FAD42 model relative to both TBA42 and 5XFAD mice. The extent of this increase supports the seeding of amyloid deposition observed earlier; absolute amounts of $\mathrm{A} \beta_{p E 3-x}$ in FAD42 mice were more than just a simple sum of the TBA42 and $5 \mathrm{XFAD}$ levels. FAD42 mice also displayed a trend toward increased amounts of $\mathrm{A} \beta_{p E 3-x}$ in the TBS-soluble fraction. The lack of change in the levels of TBS and SDS-soluble $\mathrm{A} \beta_{x-42}$ in FAD42 mice is likely due to $\mathrm{A} \beta_{x-42}$ being over 1000 times more abundant than $\mathrm{A} \beta_{p E 3-x}$. Such a discrepancy was previously observed in 5XFAD/hQC mice (Jawhar et al., 2011a). This finding suggests that a subtle elevation of $\mathrm{A} \beta_{p E 3-x}$ might have limited ability to increase total $\mathrm{A} \beta$ aggregation if there is already a saturation effect caused by $\mathrm{A} \beta_{x-42}$.

Relative amounts of different $\mathrm{A} \beta$ species are of pathological importance. It was recently shown that the relative ratio of $\mathrm{A} \beta_{1-42}$ to $\mathrm{A} \beta_{1-40}$, rather than absolute peptide amount, is a key determinant of dynamic $\mathrm{A} \beta$ fibrillization and the stabilization of toxic oligomeric intermediates (Kuperstein et al., 2010). Along these lines, biochemical extraction experiments suggested that an increased ratio of water-soluble $\mathrm{A} \beta_{p E 3-42}$ to $\mathrm{A} \beta_{1-42}$ is associated with a more severe phenotype in $\mathrm{AD}$ (Piccini et al., 2005, 2007). Given 
these data, the increase in TBS-soluble $\mathrm{A} \beta_{p E 3-x}$ observed in FAD42 mice may still have a pathological impact since TBS-soluble $\mathrm{A} \beta_{x-42}$ is unchanged from 5XFAD levels.

\subsubsection{Elevated glutaminyl cyclase activity in FAD42 mice}

Due to the tight correlations between $\mathrm{A} \beta_{p E}$ formation and $\mathrm{QC}$, alterations in $\mathrm{QC}$ activity might accompany the pathology observed in FAD42 mice. To determine if this was the case, a QC activity assay was performed on brain lysates from WT, TBA42, 5XFAD and FAD42 mice. In line with the amyloid pathology found in TBA42, 5XFAD and FAD42 mice, QC activity in all three models was significantly elevated relative to WT controls. FAD42 mice displayed a non-significant trend toward increased QC activity relative to TBA42 and 5XFAD mice. Along these lines, increased levels of QC mRNA and protein have been observed in the brains of $\mathrm{AD}$ patients. These elevations correlated with both disease stage and $\mathrm{A} \beta_{p E}$ levels (Schilling et al., 2008c). Furthermore, QC activity corresponded with $\mathrm{A} \beta_{p E}$ levels in Hom TBA2.1 mice (Alexandru et al., 2011). Together, these data support a close association between $\mathrm{A} \beta_{p E}$ formation and the pathophysiological upregulation of QC activity.

The exact cause of increased QC activity is presently unknown. QC has been found in neurons and astrocytes and can be secreted from both cell types (Hartlage-Rubsamen et al., 2009; Hartlage-Rübsamen et al., 2011b; Schilling et al., 2011). Under normal physiological conditions, QC protein is undetectable in glial cells in the mouse brain (HartlageRubsamen et al., 2009). However, there is evidence suggesting that QC expression can be induced in astrocytes in response to inflammatory stimulation (Iwata et al., 2010). Likewise, QC activity is elevated in peripheral monocytes after lipopolysaccharide treatment, but this occurs in the absence of changes in QC mRNA or protein levels (Chen et al., 2012).

In summary, these findings demonstrate that elevated activity of endogenous QC accompanies the pathology of TBA42, 5XFAD and FAD42 mice. This increase in QC activity could result from a combination of several factors, such as higher substrate levels or inflammation-induced increases in QC expression/activity in glial cells. 


\subsubsection{Conclusions of Project II}

Based on the results of the current work:

- Addition of $\mathrm{A} \beta_{p E 3-42}$ into 5XFAD mice via the TBA42 transgene produced an aggravated behavioral phenotype in the resulting FAD42 mouse model.

- The heterogeneity of N-terminally truncated $\mathrm{A} \beta$ peptides in 5XFAD mice was demonstrated for the first time using IP/MS. Furthermore, $\mathrm{A} \beta_{p E 3-42}$ was identified as a major $\mathrm{A} \beta$ species in TBA42 mice.

- Elevation of $\mathrm{A} \beta_{p E 3-42}$ without ectopic $\mathrm{QC}$ overexpression enhanced cortical plaque load and raised levels of TBS and SDS soluble $\mathrm{A} \beta_{p E 3-x}$ in FAD42 mice.

- Increased QC activity in transgenic AD mouse models suggests a relation between endogenous QC and pathological processes, such as inflammation. 


\subsection{Project III: Generation and characterization of the TBA83 mouse model}

A critical flaw of most transgenic AD mouse models is their reliance on artificial combinations of APP/PS1 mutations to recapitulate certain aspects of AD pathology. Direct, moderate expression of a particular $\mathrm{A} \beta$ species in vivo may therefore create a more physiologically relevant $\mathrm{AD}$ model. Despite being one of the major $\mathrm{A} \beta$ isoforms in $\mathrm{AD}$ brain, little is known about the individual characteristics of $\mathrm{A} \beta_{4-42}$ (Portelius et al., 2010). The objective of the present study was to examine the effects of $A \beta_{4-42}$ expression in vivo by generating a transgenic mouse model that exclusively produces this $\mathrm{A} \beta$ isoform.

\subsubsection{Age-dependent gliosis and amyloid beta accumulation in TBA83 mice}

As with the TBA42, TBA2 and Hom TBA2.1 mouse models, TBA83 mice rely on a TRH fusion peptide to route $\mathrm{A} \beta$ through the secretory pathway. Following liberation of the TRH signal peptide, $\mathrm{A} \beta_{4-42}$ is released into the trans-Golgi and secretory granules in its final form. This is in contrast to TBA42/TBA2 mice, which require QC activity to produce their desired $\mathrm{A} \beta$ product, $\mathrm{A} \beta_{p E 3-42}$ (Wirths et al., 2009; Alexandru et al., 2011). As a result, the TBA42/TBA2 mice accumulate two different $\mathrm{A} \beta$ isoforms. TBA83 mice therefore represent a "cleaner" AD mouse model since they generate only one $\mathrm{A} \beta$ species.

Aside from TBA42/TBA2 and TBA83 mice, other transgenic mouse models have been designed to exclusively generate certain $\mathrm{A} \beta$ isoforms without mutant APP/PS1 overexpression. Many of these models directly express $\mathrm{A} \beta_{1-42}$, such as the G2 mice, APP48 mice, and BRI-A $\beta 42$ mice (LaFerla et al., 1995; McGowan et al., 2005; Abramowski et al., 2012). G2 and APP48 mice promote the specific intraneuronal accumulation of $\mathrm{A} \beta_{1-42}$, and both models demonstrate its intracellular toxicity. Extracellular $\mathrm{A} \beta$ deposits are largely absent from these mice (LaFerla et al., 1995; Abramowski et al., 2012). In contrast, the BRI-A $\beta 42$ mice express a fusion construct of the BRI protein and $\mathrm{A} \beta_{1-42}$, resulting in efficient secretion of $\mathrm{A} \beta_{1-42}$ into the extracellular space. Consistent with high extracellular concentrations of $\mathrm{A} \beta_{1-42}$, BRI-A $\beta 42$ mice develop age-dependent plaque pathology. Intraneuronal $\mathrm{A} \beta$ accumulations, however, are not found in this model (McGowan et al., 2005).

TBA83 mice developed both intracellular and extracellular $\mathrm{A} \beta$ deposits. The expression of $\mathrm{A} \beta_{4-42}$ in TBA83 mice occurred in a region-specific manner consistent with a transgene driven by the murine Thy1 promoter (Caroni, 1997). Unlike TBA42 mice, 
TBA83 mice displayed minimal intraneuronal $\mathrm{A} \beta$ pathology in the CA1 region of the hippocampus. Instead, they primarily developed extracellular $\mathrm{A} \beta$ granules which grew as the mice aged. This finding suggests that $\mathrm{A} \beta_{4-42}$ is being efficiently secreted. Similarly, spinal cord pathology increased in TBA83 mice between the ages of 4 and 12 months, with larger numbers of both intracellular and extracellular $\mathrm{A} \beta$ deposits found in older mice. Age-dependent gliosis was also present in regions with $\mathrm{A} \beta$ accumulation. However, the increase in astrocyte activation observed by GFAP staining was comparatively minor between 4 - and 12-month-old TBA83 mice. This finding is in line with the relatively mild $\mathrm{A} \beta$ pathology observed.

The similarities between the $\mathrm{A} \beta$ accumulation patterns in TBA42 and TBA83 mice likely result from the Thy1 promoter and the TRH-fusion constructs utilized in these models. However, it is possible that the larger extracellular deposits found in TBA83 mice reflect a true difference in the aggregation behavior of $\mathrm{A} \beta_{p E 3-42}$ and $\mathrm{A} \beta_{4-42}$. In support of this idea, in vitro studies have demonstrated that $\mathrm{A} \beta_{4-42}$ aggregates more rapidly than $\mathrm{A} \beta$ species with longer $\mathrm{N}$-termini (Pike et al., 1995b).

It should also be noted that transgene expression levels determine the pathology observed in AD transgenic mice. For example, the later onset of pathology in heterozygous TBA2.1/TBA2.2 mice relative to Hom TBA2.1 mice correlates with a lower amount of $\mathrm{A} \beta_{p E 3-42}$ (Alexandru et al., 2011). It would therefore be intriguing to examine the differences in transgene expression between TBA42 and TBA83 mice and determine whether lower levels of $\mathrm{A} \beta_{4-42}$ or $\mathrm{A} \beta_{p E 3-42}$ are more effective at exerting toxicity in vivo.

In summary, TBA83 mice represent a unique $\mathrm{AD}$ mouse model that exclusively generates $\mathrm{A} \beta_{4-42}$ without overexpressing mutated APP/PS1. These mice develop both intraneuronal and extracellular $\mathrm{A} \beta$ deposits, thereby allowing the behavior of $\mathrm{A} \beta_{4-42}$ to be examined in different in vivo environments.

\subsubsection{Selective deficits in motor function and spatial working memory in TBA83 mice}

To determine if the $\mathrm{A} \beta_{4-42}$ expression found in the TBA83 model resulted in cognitive impairment, 4-to-12-month-old TBA83 mice were subjected to our standard behavioral test battery. No changes between TBA83 mice and WT controls were found in measures of anxiety, general motor activity or working memory. The only significant deficit observed was impaired performance in the balance beam in 12-month-old TBA83 mice. Intraneuronal $\mathrm{A} \beta$ in spinal cord motor neurons has been correlated with motor performance in other AD mouse models (Wirths et al., 2007; Jawhar et al., 2012). Given these 
observations, the $\mathrm{A} \beta$ pathology present in the spinal cords of 12-month-old TBA83 mice might account for their performance in the balance beam.

In light of the hippocampal pathology observed in TBA83 mice, we employed the MWM to evaluate spatial reference memory. The water maze paradigm is the most widely used test to assess cognitive impairment in AD mouse models (Duyckaerts et al., 2008). Lesion studies have demonstrated that the water maze is extremely sensitive to changes in hippocampal structure (Moser et al., 1995). Furthermore, the connection between NMDA and alpha-amino-3-hydroxyl-5-methyl-4-isoxazole propionate (AMPA) receptor function and water maze learning is well established (Liang et al., 1994). Both of these receptor subtypes participate in the induction and maintenance of LTP, a process critical for memory formation (Malenka and Bear, 2004).

No differences in the learning curves were observed between 8-9-month-old TBA83 mice and WT controls during the cued and acquisition phases of the MWM. However, the absence of a clear quadrant preference in the probe trial ultimately revealed a spatial memory deficit in TBA83 mice. The sparse hippocampal A $\beta$ deposits found in TBA83 mice suggest that soluble $\mathrm{A} \beta$ may underlie this memory impairment. A lack of appropriate ELISA antibodies has currently prevented quantitative measurements of soluble $\mathrm{A} \beta$ in TBA83 mice. Efforts are underway to resolve this issue.

Multiple lines of evidence support a role for soluble $\mathrm{A} \beta$ in promoting cognitive dysfunction in AD transgenic mice. Memory deficits and synaptic changes have been observed in several AD mouse models before amyloid plaques appear (Holcomb et al., 1998; Hsia et al., 1999; Mucke et al., 2000). Soluble A $\beta$-dimers derived from AD brains were shown to impair LTP in hippocampal slice cultures and affect memory recall when injected intraventricularly (Shankar et al., 2008). Along these lines, directly elevating levels of $\mathrm{A} \beta$ oligomers through genetic $\mathrm{KO}$ of the $\mathrm{A} \beta$ degrading enzyme neprilysin impaired synaptic plasticity and learning in APP23 mice (Huang et al., 2006).

In conclusion, deficits in motor function and spatial reference memory were identified in TBA83 mice. A lack of hippocampal $\mathrm{A} \beta$ depositions suggests a role for soluble $\mathrm{A} \beta_{4-42}$ in the observed memory dysfunction. However, further studies are required to confirm this hypothesis. 


\subsubsection{Conclusions of Project III}

Based on the results of the current work:

- TBA83 mice, a novel transgenic AD mouse model that exclusively produces $\mathrm{A} \beta_{4-42}$, were successfully generated.

- Region-specific extracellular and intraneuronal $\mathrm{A} \beta$ deposits were observed in TBA83 mice, accompanied by mild, age-dependent gliosis.

- Expression of $\mathrm{A} \beta_{4-42}$ in TBA83 mice was sufficient to induce deficits in motor function and hippocampal-dependent memory. These impairments may result from soluble forms of $\mathrm{A} \beta_{4-42}$, thereby identifying a novel pathological function of this $\mathrm{A} \beta$ isoform. 


\section{Chapter 5}

\section{Summary}

A heterogeneous mixture of amyloid beta $(\mathrm{A} \beta)$ isoforms exists in the brains of Alzheimer's disease $(\mathrm{AD})$ patients. Despite decades of research, relatively little is known about the precise contribution of these various $\mathrm{A} \beta$ species to the development and progression of $\mathrm{AD}$. Recent work has identified pyroglutamate-modified amyloid beta $\left(\mathrm{A} \beta_{p E}\right)$ as a particularly abundant and toxic peptide. Transgenic mice designed to specifically overproduce $\mathrm{A} \beta_{p E}$ exhibit neuron loss and behavioral deficits. Unfortunately, general breeding issues and the severe pathology found in these models restrict their use for additional transgenic studies.

In the first project of this thesis, the TBA42 mouse model was generated to overcome these problems and further explore the consequences of $\mathrm{A} \beta_{p E}$ accumulation in vivo. Using immunohistochemistry, it was shown that TBA42 mice develop region-specific intraneuronal and extracellular $\mathrm{A} \beta / \mathrm{A} \beta_{p E}$ deposits accompanied by progressive gliosis. Decreased anxiety and altered rearing behavior were the earliest and most persistent behavioral changes identified in this model. TBA42 mice also displayed age-dependent deficits in motor performance and working memory. The phenotype observed in the TBA42 model

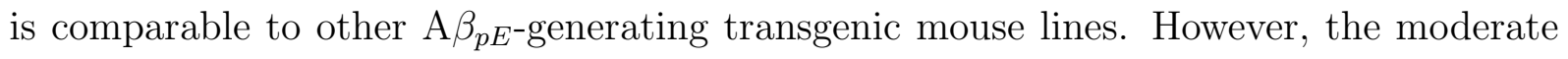
pathology and behavioral impairments of TBA42 mice make them suitable for further transgenic experiments.

Numerous studies have explored the therapeutic benefits of reducing $\mathrm{A} \beta_{p E}$ in $\mathrm{AD}$ mouse models. However, few have addressed whether elevating $\mathrm{A} \beta_{p E}$ levels is sufficient to aggravate ongoing disease processes. Earlier attempts to answer this question relied on the ectopic overexpression of human glutaminyl cyclase (hQC) in an established AD mouse model. $\mathrm{QC}$ is the primary enzyme responsible for catalyzing the formation of $\mathrm{A} \beta_{p E}$. Since 
QC has multiple targets, it cannot be excluded that ectopic QC overexpression affected these other substrates, thereby influencing the results of previous experiments.

To study how an exclusive increase in $\mathrm{A} \beta_{p E}$ affects $\mathrm{AD}$ pathology, the TBA42 and 5XFAD mouse models were crossed to produce FAD42 mice for the second project of this thesis. The 5XFAD mouse model is a well-characterized AD transgenic model with aggressive amyloid deposition. FAD42 mice exhibited aggravated behavioral deficits compared to 5XFAD and TBA42 mice. ELISA and plaque load measurements also revealed elevated $\mathrm{A} \beta_{p E}$ in FAD42 mice. These results were accompanied by an increase in endogenous QC activity in FAD42 mouse brain. However, FAD42 mice displayed no changes in $\mathrm{A} \beta_{x-42}$ or other $\mathrm{A} \beta$ isoforms, as determined by ELISA and mass spectrometry. In total, these observations support a key pathogenic role for $\mathrm{A} \beta_{p E}$ in $\mathrm{AD}$ and argue for its ability to seed $\mathrm{A} \beta$ deposition.

$\mathrm{A} \beta_{4-42}$ is another major $\mathrm{A} \beta$ species in $\mathrm{AD}$ brain. Sedimentation studies suggested that $\mathrm{A} \beta_{4-42}$ displays rapid aggregation kinetics, but nothing is known about the in vivo toxicity of this peptide. Most transgenic AD mouse models rely on artificial combinations of mutations to study amyloid pathology. However, the majority of AD patients do not possess mutations. Direct, moderate expression of a particular $\mathrm{A} \beta$ species in vivo may therefore create a more physiologically relevant $\mathrm{AD}$ model.

Given these considerations, the third project of this thesis focused on the creation of TBA83 mice, a transgenic model which exclusively expresses $\mathrm{A} \beta_{4-42}$. TBA83 mice exhibited sparse, region-specific intraneuronal and extracellular $\mathrm{A} \beta$ deposits and mild gliosis. In addition, TBA83 mice displayed deficits in motor function and hippocampaldependent memory. The lack of severe $\mathrm{A} \beta$ deposition in TBA83 mice ultimately suggests a pathological function for soluble $\mathrm{A} \beta_{4-42}$.

Taken together, the results of this thesis confirm the relevance of $\mathrm{A} \beta_{p E}$ to AD progression. The pathogenic properties of $\mathrm{A} \beta_{4-42}$ were also identified for the first time in vivo, warranting further studies of this $\mathrm{A} \beta$ isoform. 


\section{Bibliography}

Abdul, H. M., Sama, M. A., Furman, J. L., et al. (2009). Cognitive decline in Alzheimer's disease is associated with selective changes in calcineurin/NFAT signaling. The Journal of neuroscience : the official journal of the Society for Neuroscience, 29(41):12957-69.

Abramov, A. Y., Canevari, L., and Duchen, M. R. (2004). Beta-amyloid peptides induce mitochondrial dysfunction and oxidative stress in astrocytes and death of neurons through activation of NADPH oxidase. The Journal of neuroscience : the official journal of the Society for Neuroscience, 24(2):56575 .

Abramowski, D., Rabe, S., Upadhaya, a. R., et al. (2012). Transgenic Expression of Intraneuronal A42 But Not A40 Leads to Cellular A Lesions, Degeneration, and Functional Impairment without Typical Alzheimer's Disease Pathology. Journal of Neuroscience, 32(4):1273-1283.

Acero, G., Manoutcharian, K., Vasilevko, V., et al. (2009). Immunodominant epitope and properties of pyroglutamate-modified Abeta-specific antibodies produced in rabbits. Journal of neuroimmunology, 213(1-2):39-46.

Albert, M. S., DeKosky, S. T., Dickson, D., et al. (2011). The diagnosis of mild cognitive impairment due to Alzheimer's disease: recommendations from the National Institute on Aging-Alzheimer's Association workgroups on diagnostic guidelines for Alzheimer's disease. Alzheimer's $\&$ dementia : the journal of the Alzheimer's Association, 7(3):270-9.

Alexandru, a., Jagla, W., Graubner, S., et al. (2011). Selective Hippocampal Neurodegeneration in Transgenic Mice Expressing Small Amounts of Truncated A\{beta\} Is Induced by PyroglutamateA \{beta\} Formation. Journal of Neuroscience, 31(36):12790-12801.

Allen, B., Ingram, E., Takao, M., et al. (2002). Abundant tau filaments and nonapoptotic neurodegeneration in transgenic mice expressing human P301S tau protein. The Journal of neuroscience : the official journal of the Society for Neuroscience, 22(21):9340-51.

Almeida, C. G., Takahashi, R. H., and Gouras, G. K. (2006). Beta-amyloid accumulation impairs multivesicular body sorting by inhibiting the ubiquitin-proteasome system. The Journal of neuroscience : the official journal of the Society for Neuroscience, 26(16):4277-88.

Alonso, A., Zaidi, T., Novak, M., Grundke-Iqbal, I., and Iqbal, K. (2001). Hyperphosphorylation induces self-assembly of tau into tangles of paired helical filaments/straight filaments. Proceedings of the National Academy of Sciences of the United States of America, 98(12):6923-8.

Alonso, A. C., Grundke-Iqbal, I., and Iqbal, K. (1996). Alzheimer's disease hyperphosphorylated tau sequesters normal tau into tangles of filaments and disassembles microtubules. Nature medicine, $2(7): 783-7$.

Alzheimer, A. (1907). Über eine eigenartige Erkrankung der Hirnrinde. Allgemeine Zeitschrift fur Psychiatrie und Psychisch-gerichtliche Medizin, 64:146-8.

Alzheimer's Association (2011). 2011 Alzheimer's Disease Facts and Figures. Alzheimer's and Dementia, $7(2)$.

American Psychiatric Association (2000). Diagnostic and statistical manual of mental disorders, 4th 
edition. Washington, DC: Author.

Ancolio, K., Dumanchin, C., Barelli, H., et al. (1999). Unusual phenotypic alteration of beta amyloid precursor protein (betaAPP) maturation by a new Val-715 - ; Met betaAPP-770 mutation responsible for probable early-onset Alzheimer's disease. Proceedings of the National Academy of Sciences of the United States of America, 96(7):4119-24.

Aoki, M., Volkmann, I., Tjernberg, L. O., Winblad, B., and Bogdanovic, N. (2008). Amyloid betapeptide levels in laser capture microdissected cornu ammonis 1 pyramidal neurons of Alzheimer's brain. Neuroreport, 19(11):1085-9.

Archer, J. (1973). Tests for emotionality in rats and mice: a review. Animal behaviour, 21(2):205-35.

Arendash, G. W., King, D. L., Gordon, M. N., et al. (2001). Progressive, age-related behavioral impairments in transgenic mice carrying both mutant amyloid precursor protein and presenilin-1 transgenes. Brain research, 891(1-2):42-53.

Arendt, T., Bigl, V., Arendt, A., and Tennstedt, A. (1983). Loss of neurons in the nucleus basalis of Meynert in Alzheimer's disease, paralysis agitans and Korsakoff's Disease. Acta neuropathologica, 61(2):101-8.

Arnold, S. E., Hyman, B. T., Flory, J., Damasio, A. R., and Van Hoesen, G. W. (1991). The topographical and neuroanatomical distribution of neurofibrillary tangles and neuritic plaques in the cerebral cortex of patients with Alzheimer's disease. Cerebral cortex (New York, N.Y. : 1991), 1(1):103-16.

Arriagada, P. V., Growdon, J. H., Hedley-Whyte, E. T., and Hyman, B. T. (1992). Neurofibrillary tangles but not senile plaques parallel duration and severity of Alzheimer's disease. Neurology, $42(3$ Pt 1):631-9.

Atri, A., Shaughnessy, L. W., Locascio, J. J., and Growdon, J. H. (2008). Long-term course and effectiveness of combination therapy in Alzheimer disease. Alzheimer disease and associated disorders, 22(3):209-21.

Bakkour, A., Morris, J. C., and Dickerson, B. C. (2009). The cortical signature of prodromal AD: regional thinning predicts mild AD dementia. Neurology, 72(12):1048-55.

Bannerman, D. M., Rawlins, J. N. P., McHugh, S. B., et al. (2004). Regional dissociations within the hippocampus-memory and anxiety. Neuroscience and biobehavioral reviews, 28(3):273-83.

Bard, F., Cannon, C., Barbour, R., et al. (2000). Peripherally administered antibodies against amyloid beta-peptide enter the central nervous system and reduce pathology in a mouse model of Alzheimer disease. Nat Med, 6(8):916-919.

Baumann, K., Mandelkow, E. M., Biernat, J., Piwnica-Worms, H., and Mandelkow, E. (1993). Abnormal Alzheimer-like phosphorylation of tau-protein by cyclin-dependent kinases cdk2 and cdk5. FEBS Lett, 336(3):417-424.

Bayer, T. a., Breyhan, H., Duan, K., Rettig, J., and Wirths, O. (2008). Intraneuronal beta-amyloid is a major risk factor-novel evidence from the APP/PS1KI mouse model. Neuro-degenerative diseases, $5(3-4): 140-2$.

Bayer, T. A., Cappai, R., Masters, C. L., Beyreuther, K., and Multhaup, G. (1999). It all sticks togetherthe APP-related family of proteins and Alzheimer's disease. Molecular psychiatry, 4(6):524-8.

Bayer, T. a. and Wirths, O. (2010). Intracellular accumulation of amyloid-Beta - a predictor for synaptic dysfunction and neuron loss in Alzheimer's disease. Frontiers in aging neuroscience, 2(March):8.

Beatty, W. W., Salmon, D. P., Butters, N., Heindel, W. C., and Granholm, E. L. (1988). Retrograde amnesia in patients with Alzheimer's disease or Huntington's disease. Neurobiology of aging, 9(2):181-6.

Benilova, I., Karran, E., and De Strooper, B. (2012). The toxic A $\beta$ oligomer and Alzheimer's disease: an emperor in need of clothes. Nature neuroscience, 15(3):1-9.

Bero, A. W., Yan, P., Roh, J. H., et al. (2011). Neuronal activity regulates the regional vulnerability to amyloid- $\beta$ deposition. Nature neuroscience, 14(6):750-6.

Bertram, L., Lill, C. M., and Tanzi, R. E. (2010). The genetics of Alzheimer disease: back to the future. Neuron, 68(2):270-281.

Birren, J. E. and Fisher, L. M. (1995). Aging and speed of behavior: possible consequences for psycho- 
logical functioning. Annual review of psychology, 46:329-53.

Braak, H. and Braak, E. (1991). Neuropathological stageing of Alzheimer-related changes. Acta Neuropathol, 82(4):239-259.

Brodaty, H. and Moore, C. M. (1997). The Clock Drawing Test for dementia of the Alzheimer's type: A comparison of three scoring methods in a memory disorders clinic. International journal of geriatric psychiatry, 12(6):619-27.

Brunden, K. R., Trojanowski, J. Q., and Lee, V. M.-Y. (2009). Advances in tau-focused drug discovery for Alzheimer's disease and related tauopathies. Nature reviews. Drug discovery, 8(10):783-93.

Burdick, D., Soreghan, B., Kwon, M., et al. (1992). Assembly and aggregation properties of synthetic Alzheimer's A4/beta amyloid peptide analogs. The Journal of biological chemistry, 267(1):546-54.

Busch, C., Bohl, J., and Ohm, T. G. (1997). Spatial, temporal and numeric analysis of Alzheimer changes in the nucleus coeruleus. Neurobiology of aging, 18(4):401-6.

Buxbaum, J. D., Liu, K. N., Luo, Y., et al. (1998). Evidence that tumor necrosis factor alpha converting enzyme is involved in regulated alpha-secretase cleavage of the Alzheimer amyloid protein precursor. $J$ Biol Chem, 273(43):27765-27767.

Cai, H., Wang, Y., McCarthy, D., et al. (2001). BACE1 is the major beta-secretase for generation of Abeta peptides by neurons. Nat Neurosci, 4(3):233-234.

Cai, X. D., Golde, T. E., and Younkin, S. G. (1993). Release of excess amyloid beta protein from a mutant amyloid beta protein precursor. Science (New York, N.Y.), 259(5094):514-6.

Campion, D., Dumanchin, C., Hannequin, D., et al. (1999). Early-onset autosomal dominant Alzheimer disease: prevalence, genetic heterogeneity, and mutation spectrum. American journal of human genetics, 65(3):664-70.

Cao, X. and Südhof, T. C. (2001). A transcriptionally [correction of transcriptively] active complex of APP with Fe65 and histone acetyltransferase Tip60. Science (New York, N.Y.), 293(5527):115-20.

Capell, A., Steiner, H., Willem, M., et al. (2000). Maturation and pro-peptide cleavage of beta-secretase. The Journal of biological chemistry, 275(40):30849-54.

Caroni, P. (1997). Overexpression of growth-associated proteins in the neurons of adult transgenic mice. Journal of neuroscience methods, 71(1):3-9.

Carson, J. A. and Turner, A. J. (2002). Beta-amyloid catabolism: roles for neprilysin (NEP) and other metallopeptidases? Journal of neurochemistry, 81(1):1-8.

Casas, C., Sergeant, N., Itier, J.-M. M., et al. (2004). Massive CA1/2 neuronal loss with intraneuronal and N-terminal truncated Abeta42 accumulation in a novel Alzheimer transgenic model. Am J Pathol, 165(4):1289-1300.

Cataldo, A. M., Petanceska, S., Terio, N. B., et al. (2004). Abeta localization in abnormal endosomes: association with earliest Abeta elevations in AD and Down syndrome. Neurobiology of aging, 25(10):126372 .

Chartier-Harlin, M. C., Parfitt, M., Legrain, S., et al. (1994). Apolipoprotein E, epsilon 4 allele as a major risk factor for sporadic early and late-onset forms of Alzheimer's disease: analysis of the 19q13.2 chromosomal region. Human molecular genetics, 3(4):569-74.

Chauhan, N. B., Davis, F., and Xiao, C. (2011). Wheat germ agglutinin enhanced cerebral uptake of anti-A $\beta$ antibody after intranasal administration in 5XFAD mice. Vaccine, 29(44):7631-7.

Chelius, D., Jing, K., Lueras, A., et al. (2006). Formation of pyroglutamic acid from N-terminal glutamic acid in immunoglobulin gamma antibodies. Analytical chemistry, 78(7):2370-6.

Chen, G., Chen, K. S., Knox, J., et al. (2000). A learning deficit related to age and beta-amyloid plaques in a mouse model of Alzheimer's disease. Nature, 408(6815):975-979.

Chen, H. S., Pellegrini, J. W., Aggarwal, S. K., et al. (1992). Open-channel block of N-methyl-Daspartate (NMDA) responses by memantine: therapeutic advantage against NMDA receptor-mediated neurotoxicity. The Journal of neuroscience : the official journal of the Society for Neuroscience, 12(11):4427-36.

Chen, Y.-L., Huang, K.-F., Kuo, W.-C., et al. (2012). Inhibition of glutaminyl cyclase attenuates cell 
migration modulated by monocyte chemoattractant proteins. The Biochemical journal, 442(2):403-12.

Cheng, D., Noble, J., Tang, M. X., et al. (2011). Type 2 diabetes and late-onset Alzheimer's disease. Dementia and geriatric cognitive disorders, 31(6):424-30.

Chishti, M. A., Yang, D. S., Janus, C., et al. (2001). Early-onset amyloid deposition and cognitive deficits in transgenic mice expressing a double mutant form of amyloid precursor protein 695. The Journal of biological chemistry, 276(24):21562-70.

Chow, S.-K., Yu, D., Macdonald, C. L., Buibas, M., and Silva, G. A. (2010). Amyloid $\beta$-peptide directly induces spontaneous calcium transients, delayed intercellular calcium waves and gliosis in rat cortical astrocytes. ASN neuro, 2(1):e00026.

Christensen, D. Z., Bayer, T. a., and Wirths, O. (2010). Intracellular Aßtriggers neuron loss in the cholinergic system of the APP/PS1KI mouse model of Alzheimer's disease. Neurobiology of aging, 31(7):1153-63.

Christensen, D. Z., Kraus, S. L., Flohr, A., et al. (2008). Transient intraneuronal A beta rather than extracellular plaque pathology correlates with neuron loss in the frontal cortex of APP/PS1KI mice. Acta neuropathologica, 116(6):647-55.

Chung, J. A. and Cummings, J. L. (2000). Neurobehavioral and neuropsychiatric symptoms in Alzheimer's disease: characteristics and treatment. Neurologic clinics, 18(4):829-46.

Cirrito, J. R., Yamada, K. a., Finn, M. B., et al. (2005). Synaptic activity regulates interstitial fluid amyloid-beta levels in vivo. Neuron, 48(6):913-22.

Citron, M., Oltersdorf, T., Haass, C., et al. (1992). Mutation of the beta-amyloid precursor protein in familial Alzheimer's disease increases beta-protein production. Nature, 360(6405):672-4.

Citron, M., Teplow, D. B., and Selkoe, D. J. (1995). Generation of amyloid beta protein from its precursor is sequence specific. Neuron, 14(3):661-670.

Citron, M., Westaway, D., Xia, W., et al. (1997). Mutant presenilins of Alzheimer's disease increase production of 42-residue amyloid beta-protein in both transfected cells and transgenic mice. Nature medicine, 3(1):67-72.

Colton, C. A. (2009). Heterogeneity of microglial activation in the innate immune response in the brain. Journal of neuroimmune pharmacology : the official journal of the Society on NeuroImmune Pharmacology, 4(4):399-418.

Corder, E. H., Saunders, A. M., Strittmatter, W. J., et al. (1993). Gene dose of apolipoprotein E type 4 allele and the risk of Alzheimer's disease in late onset families. Science (New York, N.Y.), 261(5123):921-3.

Cotel, M.-C., Jawhar, S., Christensen, D. Z., Bayer, T. a., and Wirths, O. (2010). Environmental enrichment fails to rescue working memory deficits, neuron loss, and neurogenesis in APP/PS1KI mice. Neurobiology of aging, pages 1-12.

Cras, P., Kawai, M., Lowery, D., et al. (1991). Senile plaque neurites in Alzheimer disease accumulate amyloid precursor protein. Proceedings of the National Academy of Sciences of the United States of America, 88(17):7552-6.

Cras, P., Smith, M. A., Richey, P. L., et al. (1995). Extracellular neurofibrillary tangles reflect neuronal loss and provide further evidence of extensive protein cross-linking in Alzheimer disease. Acta neuropathologica, 89(4):291-5.

Crook, R., Ellis, R., Shanks, M., et al. (1997). Early-onset Alzheimer's disease with a presenilin-1 mutation at the site corresponding to the Volga German presenilin-2 mutation. Annals of neurology, 42(1):124-8.

Cruts, M. and Brouwers, N. (1999). Alzheimer Disease \& Frontotemporal Dementia Mutation Database.

Cruts, M. and Van Broeckhoven, C. (1998). Molecular genetics of Alzheimer's disease. Annals of medicine, 30(6):560-5.

Cynis, H., Rahfeld, J.-U., Stephan, A., et al. (2008). Isolation of an isoenzyme of human glutaminyl cyclase: retention in the Golgi complex suggests involvement in the protein maturation machinery. Journal of molecular biology, 379(5):966-80. 
Cynis, H., Schilling, S., Bodnár, M., et al. (2006). Inhibition of glutaminyl cyclase alters pyroglutamate formation in mammalian cells. Biochimica et biophysica acta, 1764(10):1618-25.

D'Andrea, M. R., Nagele, R. G., Wang, H. Y., Peterson, P. A., and Lee, D. H. (2001). Evidence that neurones accumulating amyloid can undergo lysis to form amyloid plaques in Alzheimer's disease. Histopathology, 38(2):120-34.

D'Arrigo, C., Tabaton, M., and Perico, A. (2009). N-terminal truncated pyroglutamyl beta amyloid peptide Abetapy3-42 shows a faster aggregation kinetics than the full-length Abeta1-42. Biopolymers, 91(10):861-73.

Dawson, G. R., Seabrook, G. R., Zheng, H., et al. (1999). Age-related cognitive deficits, impaired longterm potentiation and reduction in synaptic marker density in mice lacking the beta-amyloid precursor protein. Neuroscience, 90(1):1-13.

De Strooper, B. and Annaert, W. (2010). Novel research horizons for presenilins and $\gamma$-secretases in cell biology and disease. Annual review of cell and developmental biology, 26:235-60.

Deacon, R. M. J., Koros, E., Bornemann, K. D., and Rawlins, J. N. P. (2009). Aged Tg2576 mice are impaired on social memory and open field habituation tests. Behavioural brain research, 197(2):466-8.

DeKosky, S. T. and Scheff, S. W. (1990). Synapse loss in frontal cortex biopsies in Alzheimer's disease: correlation with cognitive severity. Annals of neurology, 27(5):457-64.

Dember, W. N. and Fowler, H. (1958). Spontaneous alternation behavior. Psychological bulletin, 55(6):412-28.

Deutsche Alzheimer Gesellschaft (2010). Die Epidemiologie der Demenz.

Devanand, D. P., Jacobs, D. M., Tang, M. X., et al. (1997). The course of psychopathologic features in mild to moderate Alzheimer disease. Archives of general psychiatry, 54(3):257-63.

Devi, L., Alldred, M. J., Ginsberg, S. D., and Ohno, M. (2012). Mechanisms Underlying Insulin DeficiencyInduced Acceleration of $\beta$-Amyloidosis in a Mouse Model of Alzheimer's Disease. PloS one, 7(3):e32792.

Devi, L. and Ohno, M. (2010a). Genetic reductions of beta-site amyloid precursor protein-cleaving enzyme 1 and amyloid-beta ameliorate impairment of conditioned taste aversion memory in 5XFAD Alzheimer's disease model mice. Eur J Neurosci, 31(1):110-118.

Devi, L. and Ohno, M. (2010b). Phospho-eIF2 $\alpha$ level is important for determining abilities of BACE1 reduction to rescue cholinergic neurodegeneration and memory defects in 5XFAD mice. PloS one, $5(9): \mathrm{e} 12974$.

Dickerson, B. C., Stoub, T. R., Shah, R. C., et al. (2011). Alzheimer-signature MRI biomarker predicts AD dementia in cognitively normal adults. Neurology, 76(16):1395-402.

Dickson, D. W., Crystal, H. A., Mattiace, L. A., et al. (1992). Identification of normal and pathological aging in prospectively studied nondemented elderly humans. Neurobiology of aging, 13(1):179-89.

Dickson, D. W., Wertkin, A., Mattiace, L. A., et al. (1990). Ubiquitin immunoelectron microscopy of dystrophic neurites in cerebellar senile plaques of Alzheimer's disease. Acta neuropathologica, 79(5):486-93.

Dickson, T. C., King, C. E., McCormack, G. H., and Vickers, J. C. (1999). Neurochemical diversity of dystrophic neurites in the early and late stages of Alzheimer's disease. Experimental neurology, 156(1):100-10.

Ditaranto, K., Tekirian, T. L., and Yang, A. J. (2001). Lysosomal membrane damage in soluble Abetamediated cell death in Alzheimer's disease. Neurobiology of disease, 8(1):19-31.

Dodart, J. C., Mathis, C., Saura, J., et al. (2000). Neuroanatomical abnormalities in behaviorally characterized APP(V717F) transgenic mice. Neurobiol Dis, 7(2):71-85.

Drechsel, D. N., Hyman, A. A., Cobb, M. H., and Kirschner, M. W. (1992). Modulation of the dynamic instability of tubulin assembly by the microtubule-associated protein tau. Molecular biology of the cell, 3(10):1141-54.

Drew, S. C., Masters, C. L., and Barnham, K. J. (2010). Alzheimer's A $\beta$ peptides with disease-associated N-terminal modifications: influence of isomerisation, truncation and mutation on $\mathrm{Cu} 2+$ coordination. PloS one, 5(12):e15875.

Drewes, G., Lichtenberg-Kraag, B., Doring, F., et al. (1992). Mitogen activated protein (MAP) kinase 
transforms tau protein into an Alzheimer-like state. Embo J, 11(6):2131-2138.

Duyckaerts, C., Delatour, B., and Potier, M.-C. (2009). Classification and basic pathology of Alzheimer disease. Acta neuropathologica, 118(1):5-36.

Duyckaerts, C., Potier, M.-C., and Delatour, B. (2008). Alzheimer disease models and human neuropathology: similarities and differences., volume 115.

Dyrks, T., Weidemann, A., Multhaup, G., et al. (1988). Identification, transmembrane orientation and biogenesis of the amyloid A4 precursor of Alzheimer's disease. The EMBO journal, 7(4):949-57.

Edbauer, D., Winkler, E., Regula, J. T., et al. (2003). Reconstitution of gamma-secretase activity. Nature cell biology, 5(5):486-8.

Edsbagge, J., Zhu, S., Xiao, M.-Y., et al. (2004). Expression of dominant negative cadherin in the adult mouse brain modifies rearing behavior. Molecular and cellular neurosciences, 25(3):524-35.

Erbel-Sieler, C., Dudley, C., Zhou, Y., et al. (2004). Behavioral and regulatory abnormalities in mice deficient in the NPAS1 and NPAS3 transcription factors. Proceedings of the National Academy of Sciences of the United States of America, 101(37):13648-53.

Esch, F. S., Keim, P. S., Beattie, E. C., et al. (1990). Cleavage of amyloid beta peptide during constitutive processing of its precursor. Science (New York, N.Y.), 248(4959):1122-4.

Esler, W. P., Kimberly, W. T., Ostaszewski, B. L., et al. (2000). Transition-state analogue inhibitors of gamma-secretase bind directly to presenilin-1. Nature cell biology, 2(7):428-34.

Evans, D. A., Hebert, L. E., Beckett, L. A., et al. (1997). Education and other measures of socioeconomic status and risk of incident Alzheimer disease in a defined population of older persons. Archives of neurology, 54(11):1399-405.

Farrer, L. A., Cupples, L. A., Haines, J. L., et al. (1997). Effects of age, sex, and ethnicity on the association between apolipoprotein E genotype and Alzheimer disease. A meta-analysis. APOE and Alzheimer Disease Meta Analysis Consortium. JAMA : the journal of the American Medical Association, 278(16):1349-56.

Faust, P. L., Kornfeld, S., and Chirgwin, J. M. (1985). Cloning and sequence analysis of cDNA for human cathepsin D. Proceedings of the National Academy of Sciences of the United States of America, 82(15):4910-4.

Fernández-Vizarra, P., Fernández, A. P., Castro-Blanco, S., et al. (2004). Intra- and extracellular Abeta and PHF in clinically evaluated cases of Alzheimer's disease. Histology and histopathology, 19(3):82344.

Fischer, P., Jungwirth, S., Zehetmayer, S., et al. (2007). Conversion from subtypes of mild cognitive impairment to Alzheimer dementia. Neurology, 68(4):288-91.

Folstein, M. F., Folstein, S. E., and McHugh, P. R. (1975). "Mini-mental state". A practical method for grading the cognitive state of patients for the clinician. Journal of psychiatric research, 12(3):189-98.

Francis, P. T. (2003). Glutamatergic systems in Alzheimer's disease. International journal of geriatric psychiatry, 18(Suppl 1):S15-21.

Friedrich, R. P., Tepper, K., Rönicke, R., et al. (2010). Mechanism of amyloid plaque formation suggests an intracellular basis of Abeta pathogenicity. Proceedings of the National Academy of Sciences of the United States of America, 107(5):1942-7.

Frost, J. L., Liu, B., Kleinschmidt, M., et al. (2012). Passive Immunization against Pyroglutamate3 Amyloid- $\beta$ Reduces Plaque Burden in Alzheimer-Like Transgenic Mice: A Pilot Study. Neurodegenerative diseases, 02115:1-6.

Games, D., Adams, D., Alessandrini, R., et al. (1995). Alzheimer-type neuropathology in transgenic mice overexpressing V717F beta-amyloid precursor protein. Nature, 373(6514):523-527.

Gatz, M., Reynolds, C. a., Fratiglioni, L., et al. (2006). Role of genes and environments for explaining Alzheimer disease. Archives of general psychiatry, 63(2):168-74.

Gauthier, S., Reisberg, B., Zaudig, M., et al. (2006). Mild cognitive impairment. Lancet, 367(9518):126270.

Giannakopoulos, P., Herrmann, F. R., Bussière, T., et al. (2003). Tangle and neuron numbers, but not 
amyloid load, predict cognitive status in Alzheimer's disease. Neurology, 60(9):1495-500.

Goate, A., Chartier-Harlin, M. C., Mullan, M., et al. (1991). Segregation of a missense mutation in the amyloid precursor protein gene with familial Alzheimer's disease. Nature, 349(6311):704-6.

Goate, A. M., Haynes, A. R., Owen, M. J., et al. (1989). Predisposing locus for Alzheimer's disease on chromosome 21. Lancet, 1(8634):352-5.

Goedert, M., Spillantini, M. G., Jakes, R., Rutherford, D., and Crowther, R. A. (1989). Multiple isoforms of human microtubule-associated protein tau: sequences and localization in neurofibrillary tangles of Alzheimer's disease. Neuron, 3(4):519-26.

Golde, T. E., Estus, S., Younkin, L. H., Selkoe, D. J., and Younkin, S. G. (1992). Processing of the amyloid protein precursor to potentially amyloidogenic derivatives. Science (New York, N.Y.), 255(5045):72830 .

Gómez-Isla, T., Hollister, R., West, H., et al. (1997). Neuronal loss correlates with but exceeds neurofibrillary tangles in Alzheimer's disease. Annals of neurology, 41(1):17-24.

Gomez-Isla, T., Price, J. L., McKeel Jr., D. W., et al. (1996). Profound loss of layer II entorhinal cortex neurons occurs in very mild Alzheimer's disease. J Neurosci, 16(14):4491-4500.

Gouras, G. K., Tampellini, D., Takahashi, R. H., and Capetillo-Zarate, E. (2010). Intraneuronal beta-amyloid accumulation and synapse pathology in Alzheimer's disease. Acta neuropathologica, $119(5): 523-41$.

Gouras, G. K., Tsai, J., Naslund, J., et al. (2000). Intraneuronal Abeta42 accumulation in human brain. Am J Pathol, 156(1):15-20.

Greenamyre, J. T., Penney, J. B., Young, A. B., et al. (1985). Alterations in L-glutamate binding in Alzheimer's and Huntington's diseases. Science (New York, N.Y.), 227(4693):1496-9.

Greenamyre, J. T. and Young, A. B. (1989). Excitatory amino acids and Alzheimer's disease. Neurobiology of aging, 10(5):593-602.

Grundke-Iqbal, I., Iqbal, K., George, L., et al. (1989). Amyloid protein and neurofibrillary tangles coexist in the same neuron in Alzheimer disease. Proceedings of the National Academy of Sciences of the United States of America, 86(8):2853-7.

Grundke-Iqbal, I., Iqbal, K., Tung, Y. C., et al. (1986). Abnormal phosphorylation of the microtubuleassociated protein tau (tau) in Alzheimer cytoskeletal pathology. Proc Natl Acad Sci U S A, 83(13):4913-4917.

Gu, Y., Luchsinger, J. A., Stern, Y., and Scarmeas, N. (2010). Mediterranean diet, inflammatory and metabolic biomarkers, and risk of Alzheimer's disease. Journal of Alzheimer's disease : JAD, 22(2):48392.

Gu, Y., Misonou, H., Sato, T., et al. (2001). Distinct intramembrane cleavage of the beta-amyloid precursor protein family resembling gamma-secretase-like cleavage of Notch. The Journal of biological chemistry, 276(38):35235-8.

$\mathrm{Gu}$, Y., Oyama, F., and Ihara, Y. (1996). Tau is widely expressed in rat tissues. Journal of neurochemistry, $67(3): 1235-44$.

Güntert, A., Döbeli, H., and Bohrmann, B. (2006). High sensitivity analysis of amyloid-beta peptide composition in amyloid deposits from human and PS2APP mouse brain. Neuroscience, 143(2):461-75.

Gustke, N., Trinczek, B., Biernat, J., Mandelkow, E. M., and Mandelkow, E. (1994). Domains of tau protein and interactions with microtubules. Biochemistry, 33(32):9511-22.

Haass, C., Hung, A. Y., Schlossmacher, M. G., Teplow, D. B., and Selkoe, D. J. (1993). beta-Amyloid peptide and a $3-\mathrm{kDa}$ fragment are derived by distinct cellular mechanisms. The Journal of biological chemistry, 268(5):3021-4.

Haass, C., Hung, A. Y., Selkoe, D. J., and Teplow, D. B. (1994). Mutations associated with a locus for familial Alzheimer's disease result in alternative processing of amyloid beta-protein precursor. The Journal of biological chemistry, 269(26):17741-8.

Haass, C., Koo, E. H., Mellon, A., Hung, A. Y., and Selkoe, D. J. (1992a). Targeting of cell-surface beta-amyloid precursor protein to lysosomes: alternative processing into amyloid-bearing fragments. 
Nature, 357(6378):500-3.

Haass, C., Schlossmacher, M. G., Hung, A. Y., et al. (1992b). Amyloid beta-peptide is produced by cultured cells during normal metabolism. Nature, 359(6393):322-5.

Haass, C. and Selkoe, D. J. (2007). Soluble protein oligomers in neurodegeneration: lessons from the Alzheimer's amyloid beta-peptide. Nature reviews. Molecular cell biology, 8(2):101-12.

Hall, C. B., Lipton, R. B., Sliwinski, M., et al. (2009). Cognitive activities delay onset of memory decline in persons who develop dementia. Neurology, 73(5):356-61.

Hardy, J. and Allsop, D. (1991). Amyloid deposition as the central event in the aetiology of Alzheimer's disease. Trends in pharmacological sciences, 12(10):383-8.

Hardy, J., Cowburn, R., Barton, A., et al. (1987). Region-specific loss of glutamate innervation in Alzheimer's disease. Neuroscience letters, 73(1):77-80.

Hardy, J. and Selkoe, D. J. (2002). The amyloid hypothesis of Alzheimer's disease: progress and problems on the road to therapeutics. Science (New York, N.Y.), 297(5580):353-6.

Harigaya, Y., Saido, T. C., Eckman, C. B., et al. (2000). Amyloid beta protein starting pyroglutamate at position 3 is a major component of the amyloid deposits in the Alzheimer's disease brain. Biochemical and biophysical research communications, 276(2):422-7.

Harold, D., Abraham, R., Hollingworth, P., et al. (2009). Genome-wide association study identifies variants at CLU and PICALM associated with Alzheimer's disease. Nature genetics, 41(10):1088-93.

Härtig, W., Goldhammer, S., Bauer, U., et al. (2010). Concomitant detection of beta-amyloid peptides with N-terminal truncation and different C-terminal endings in cortical plaques from cases with Alzheimer's disease, senile monkeys and triple transgenic mice. Journal of chemical neuroanatomy, 40(1):82-92.

Hartlage-Rübsamen, M., Morawski, M., Waniek, A., et al. (2011a). Glutaminyl cyclase contributes to the formation of focal and diffuse pyroglutamate (pGlu)-A $\beta$ deposits in hippocampus via distinct cellular mechanisms. Acta neuropathologica, 121(6):705-19.

Hartlage-Rübsamen, M., Morawski, M., Waniek, A., et al. (2011b). Glutaminyl cyclase contributes to the formation of focal and diffuse pyroglutamate (pGlu)-A $\beta$ deposits in hippocampus via distinct cellular mechanisms. Acta neuropathologica, 121(6):705-19.

Hartlage-Rubsamen, M., Staffa, K., Waniek, A., et al. (2009). Developmental expression and subcellular localization of glutaminyl cyclase in mouse brain. Int J Dev Neurosci, 27(8):825-835.

Hashimoto, M., Bogdanovic, N., Volkmann, I., et al. (2010). Analysis of microdissected human neurons by a sensitive ELISA reveals a correlation between elevated intracellular concentrations of Abeta42 and Alzheimer's disease neuropathology. Acta neuropathologica, 119(5):543-54.

Hashimoto, T., Wakabayashi, T., Watanabe, A., et al. (2002). CLAC: a novel Alzheimer amyloid plaque component derived from a transmembrane precursor, CLAC-P/collagen type XXV. The EMBO journal, 21(7):1524-34.

He, W. and Barrow, C. J. (1999). The A beta 3-pyroglutamyl and 11-pyroglutamyl peptides found in senile plaque have greater beta-sheet forming and aggregation propensities in vitro than full-length $\mathrm{A}$ beta. Biochemistry, 38(33):10871-10877.

He, X., Li, F., Chang, W.-P., and Tang, J. (2005). GGA proteins mediate the recycling pathway of memapsin 2 (BACE). The Journal of biological chemistry, 280(12):11696-703.

Hebert, L. E., Scherr, P. A., Beckett, L. A., et al. (1995). Age-specific incidence of Alzheimer's disease in a community population. JAMA : the journal of the American Medical Association, 273(17):1354-9.

Hendriks, L., van Duijn, C. M., Cras, P., et al. (1992). Presenile dementia and cerebral haemorrhage linked to a mutation at codon 692 of the beta-amyloid precursor protein gene. Nature genetics, 1(3):218-21.

Hillmann, A., Hahn, S., Schilling, S., et al. (2012). No improvement after chronic ibuprofen treatment in the 5XFAD mouse model of Alzheimer's disease. Neurobiology of aging, 33(4):833.e39-50.

Hodges, J. R., Salmon, D. P., and Butters, N. (1991). The nature of the naming deficit in Alzheimer's and Huntington's disease. Brain : a journal of neurology, 114 ( Pt 4:1547-58.

Holcomb, L., Gordon, M. N., McGowan, E., et al. (1998). Accelerated Alzheimer-type phenotype in 
transgenic mice carrying both mutant amyloid precursor protein and presenilin 1 transgenes. Nature medicine, 4(1):97-100.

Hollingworth, P., Harold, D., Sims, R., et al. (2011). Common variants at ABCA7, MS4A6A/MS4A4E, EPHA1, CD33 and CD2AP are associated with Alzheimer's disease. Nature genetics, 43(5):429-35.

Holmes, C., Boche, D., Wilkinson, D., et al. (2008). Long-term effects of Abeta42 immunisation in Alzheimer's disease: follow-up of a randomised, placebo-controlled phase I trial. Lancet, 372(9634):21623.

Holtzman, D. M., Morris, J. C., and Goate, A. M. (2011a). Alzheimer's disease: the challenge of the second century. Science translational medicine, $3(77): 77 \mathrm{sr} 1$.

Holtzman, D. M., Morris, J. C., and Goate, A. M. (2011b). Alzheimer's disease: the challenge of the second century. Science translational medicine, 3(77):77sr1.

Hongpaisan, J., Sun, M.-K., and Alkon, D. L. (2011). PKC $\epsilon$ activation prevents synaptic loss, A $\beta$ elevation, and cognitive deficits in Alzheimer's disease transgenic mice. The Journal of neuroscience : the official journal of the Society for Neuroscience, 31(2):630-43.

Hort, J., O'Brien, J. T., Gainotti, G., et al. (2010). EFNS guidelines for the diagnosis and management of Alzheimer's disease. European journal of neurology : the official journal of the European Federation of Neurological Societies, 17(10):1236-48.

Hosoda, R., Saido, T. C., Otvos Jr., L., et al. (1998). Quantification of modified amyloid beta peptides in Alzheimer disease and Down syndrome brains. J Neuropathol Exp Neurol, 57(11):1089-1095.

Hsia, A. Y., Masliah, E., McConlogue, L., et al. (1999). Plaque-independent disruption of neural circuits in Alzheimer's disease mouse models. Proceedings of the National Academy of Sciences of the United States of America, 96(6):3228-33.

Hsiao, K., Chapman, P., Nilsen, S., et al. (1996). Correlative memory deficits, Abeta elevation, and amyloid plaques in transgenic mice. Science (New York, N.Y.), 274(5284):99-102.

$\mathrm{Hu}$, X., Crick, S. L., Bu, G., et al. (2009). Amyloid seeds formed by cellular uptake, concentration, and aggregation of the amyloid-beta peptide. Proceedings of the National Academy of Sciences of the United States of America, 106(48):20324-9.

$\mathrm{Hu}$, X., Hicks, C. W., He, W., et al. (2006). Bace1 modulates myelination in the central and peripheral nervous system. Nature neuroscience, 9(12):1520-5.

Huang, S.-M., Mouri, A., Kokubo, H., et al. (2006). Neprilysin-sensitive synapse-associated amyloidbeta peptide oligomers impair neuronal plasticity and cognitive function. The Journal of biological chemistry, 281(26):17941-51.

Huse, J. T., Liu, K., Pijak, D. S., et al. (2002). Beta-secretase processing in the trans-Golgi network preferentially generates truncated amyloid species that accumulate in Alzheimer's disease brain. J Biol Chem, 277(18):16278-16284.

Huse, J. T., Pijak, D. S., Leslie, G. J., Lee, V. M., and Doms, R. W. (2000). Maturation and endosomal targeting of beta-site amyloid precursor protein-cleaving enzyme. The Alzheimer's disease beta-secretase. The Journal of biological chemistry, 275(43):33729-37.

Hussain, I., Powell, D., Howlett, D. R., et al. (1999). Identification of a novel aspartic protease (Asp 2) as beta-secretase. Molecular and cellular neurosciences, 14(6):419-27.

Hutton, M., Lendon, C. L., Rizzu, P., et al. (1998). Association of missense and 5'-splice-site mutations in tau with the inherited dementia FTDP-17. Nature, 393(6686):702-5.

Hyman, B. T. and Trojanowski, J. Q. (1997). Consensus recommendations for the postmortem diagnosis of Alzheimer disease from the National Institute on Aging and the Reagan Institute Working Group on diagnostic criteria for the neuropathological assessment of Alzheimer disease. Journal of neuropathology and experimental neurology, 56(10):1095-7.

Ingelsson, M., Fukumoto, H., Newell, K. L., et al. (2004). Early Abeta accumulation and progressive synaptic loss, gliosis, and tangle formation in AD brain. Neurology, 62(6):925-31.

Irizarry, M. C., Soriano, F., McNamara, M., et al. (1997). Abeta deposition is associated with neuropil changes, but not with overt neuronal loss in the human amyloid precursor protein V717F (PDAPP) transgenic mouse. The Journal of neuroscience : the official journal of the Society for Neuroscience, 
17(18):7053-9.

Itagaki, S., McGeer, P. L., Akiyama, H., Zhu, S., and Selkoe, D. (1989). Relationship of microglia and astrocytes to amyloid deposits of Alzheimer disease. Journal of neuroimmunology, 24(3):173-82.

Ittner, L. M. and Götz, J. (2007). Pronuclear injection for the production of transgenic mice. Nature protocols, 2(5):1206-15.

Iwata, N., Higuchi, M., Tsubuki, S., Staufenbiel, M., and Saido, T. C. (2010). Reactive astrogliosis enhances pyroGlu-A $\beta$ formation via up regulation of glutaminyl cyclase, and reduced neprilysin activity exacerbates this process. Alzheimer's and Dementia, 6(4):S245.

Iwatsubo, T., Odaka, A., Suzuki, N., et al. (1994). Visualization of A beta 42(43) and A beta 40 in senile plaques with end-specific A beta monoclonals: evidence that an initially deposited species is A beta 42(43). Neuron, 13(1):45-53.

Jankowsky, J. L., Younkin, L. H., Gonzales, V., et al. (2007). Rodent A beta modulates the solubility and distribution of amyloid deposits in transgenic mice. J Biol Chem, 282(31):22707-22720.

Jarrett, J. T., Berger, E. P., and Lansbury, P. T. (1993). The carboxy terminus of the beta amyloid protein is critical for the seeding of amyloid formation: implications for the pathogenesis of Alzheimer's disease. Biochemistry, 32(18):4693-7.

Jawhar, S., Trawicka, A., Jenneckens, C., Bayer, T. a., and Wirths, O. (2012). Motor deficits, neuron loss, and reduced anxiety coinciding with axonal degeneration and intraneuronal $\mathrm{A} \beta$ aggregation in the 5XFAD mouse model of Alzheimer's disease. Neurobiology of aging, 33(1):196.e29-40.

Jawhar, S., Wirths, O., and Bayer, T. a. (2011a). Pyroglutamate Abeta - a hatchet man in Alzheimer disease. The Journal of biological chemistry, 286(45):38825-38832.

Jawhar, S., Wirths, O., Schilling, S., et al. (2011b). Overexpression of glutaminyl cyclase, the enzyme responsible for pyroglutamate $\mathrm{A}\{$ beta\} formation, induces behavioral deficits, and glutaminyl cyclase knock-out rescues the behavioral phenotype in 5XFAD mice. The Journal of biological chemistry, 286(6):4454-60.

Jin, M., Shepardson, N., Yang, T., et al. (2011). Soluble amyloid beta-protein dimers isolated from Alzheimer cortex directly induce Tau hyperphosphorylation and neuritic degeneration. Proceedings of the National Academy of Sciences of the United States of America, 108(14):5819-24.

Kalback, W., Watson, M. D., Kokjohn, T. A., et al. (2002). APP transgenic mice Tg2576 accumulate Abeta peptides that are distinct from the chemically modified and insoluble peptides deposited in Alzheimer's disease senile plaques. Biochemistry, 41(3):922-8.

Kalinin, S., Richardson, J. C., and Feinstein, D. L. (2009). A PPARdelta agonist reduces amyloid burden and brain inflammation in a transgenic mouse model of Alzheimer's disease. Current Alzheimer research, 6(5):431-7.

Kalová, E., Vlcek, K., Jarolímová, E., and Bures, J. (2005). Allothetic orientation and sequential ordering of places is impaired in early stages of Alzheimer's disease: corresponding results in real space tests and computer tests. Behavioural brain research, 159(2):175-86.

Kamino, K., Orr, H. T., Payami, H., et al. (1992). Linkage and mutational analysis of familial Alzheimer disease kindreds for the APP gene region. American journal of human genetics, 51(5):998-1014.

Kang, J., Lemaire, H. G., Unterbeck, A., et al. (1987). The precursor of Alzheimer's disease amyloid A4 protein resembles a cell-surface receptor. Nature, 325(6106):733-736.

Kang, J.-E., Lim, M. M., Bateman, R. J., et al. (2009). Amyloid-beta dynamics are regulated by orexin and the sleep-wake cycle. Science (New York, N.Y.), 326(5955):1005-7.

Katzman, R., Brown, T., Fuld, P., et al. (1983). Validation of a short Orientation-Memory-Concentration Test of cognitive impairment. The American journal of psychiatry, 140(6):734-9.

Kawarabayashi, T., Younkin, L. H., Saido, T. C., et al. (2001). Age-dependent changes in brain, CSF, and plasma amyloid (beta) protein in the Tg2576 transgenic mouse model of Alzheimer's disease. $J$ Neurosci, 21(2):372-381.

Kidd, M. (1963). Paired helical filaments in electron microscopy of Alzheimer's disease. Nature, 197:192193. 
Kim, D. Y., Ingano, L. A. M., Carey, B. W., Pettingell, W. H., and Kovacs, D. M. (2005). Presenilin/gamma-secretase-mediated cleavage of the voltage-gated sodium channel beta2-subunit regulates cell adhesion and migration. The Journal of biological chemistry, 280(24):23251-61.

Kim, J., Basak, J. M., and Holtzman, D. M. (2009). The role of apolipoprotein E in Alzheimer's disease. Neuron, 63(3):287-303.

Kim, J., Onstead, L., Randle, S., et al. (2007). Abeta40 inhibits amyloid deposition in vivo. The Journal of neuroscience : the official journal of the Society for Neuroscience, 27(3):627-33.

Kimberly, W. T., LaVoie, M. J., Ostaszewski, B. L., et al. (2003). Gamma-secretase is a membrane protein complex comprised of presenilin, nicastrin, Aph-1, and Pen-2. Proceedings of the National Academy of Sciences of the United States of America, 100(11):6382-7.

Kimura, R. and Ohno, M. (2009). Impairments in remote memory stabilization precede hippocampal synaptic and cognitive failures in 5XFAD Alzheimer mouse model. Neurobiol Dis, 33(2):229-235.

Kitaguchi, N., Takahashi, Y., Tokushima, Y., Shiojiri, S., and Ito, H. (1988). Novel precursor of Alzheimer's disease amyloid protein shows protease inhibitory activity. Nature, 331(6156):530-2.

Kivipelto, M., Ngandu, T., Fratiglioni, L., et al. (2005). Obesity and vascular risk factors at midlife and the risk of dementia and Alzheimer disease. Archives of neurology, 62(10):1556-60.

Knobloch, M., Konietzko, U., Krebs, D. C., and Nitsch, R. M. (2007). Intracellular Abeta and cognitive deficits precede beta-amyloid deposition in transgenic arcAbeta mice. Neurobiology of aging, 28(9):1297-306.

Knopman, D. S., Parisi, J. E., Salviati, A., et al. (2003). Neuropathology of cognitively normal elderly. Journal of neuropathology and experimental neurology, 62(11):1087-95.

Knopman, D. S. and Ryberg, S. (1989). A verbal memory test with high predictive accuracy for dementia of the Alzheimer type. Archives of neurology, 46(2):141-5.

Koenigsknecht-Talboo, J., Meyer-Luehmann, M., Parsadanian, M., et al. (2008). Rapid microglial response around amyloid pathology after systemic anti-Abeta antibody administration in PDAPP mice. The Journal of neuroscience : the official journal of the Society for Neuroscience, 28(52):14156-64.

Koffie, R. M., Meyer-Luehmann, M., Hashimoto, T., et al. (2009). Oligomeric amyloid beta associates with postsynaptic densities and correlates with excitatory synapse loss near senile plaques. Proceedings of the National Academy of Sciences of the United States of America, 106(10):4012-7.

Koike, H., Tomioka, S., Sorimachi, H., et al. (1999). Membrane-anchored metalloprotease MDC9 has an alpha-secretase activity responsible for processing the amyloid precursor protein. The Biochemical journal, $343 \mathrm{Pt} 2: 371-5$.

Koo, E. H., Sisodia, S. S., Archer, D. R., et al. (1990). Precursor of amyloid protein in Alzheimer disease undergoes fast anterograde axonal transport. Proc Natl Acad Sci U S A, 87(4):1561-1565.

Kreykenbohm, V., Wenzel, D., Antonin, W., Atlachkine, V., and von Mollard, G. F. (2002). The SNAREs vtila and vti1b have distinct localization and SNARE complex partners. European journal of cell biology, 81(5):273-80.

Kuhn, P.-H., Wang, H., Dislich, B., et al. (2010). ADAM10 is the physiologically relevant, constitutive alpha-secretase of the amyloid precursor protein in primary neurons. The EMBO journal, 29(17):302032 .

Kumar, S., Rezaei-Ghaleh, N., Terwel, D., et al. (2011). Extracellular phosphorylation of the amyloid $\beta$-peptide promotes formation of toxic aggregates during the pathogenesis of Alzheimer's disease. The EMBO journal, 30(11):2255-65.

Kumar-Singh, S., De Jonghe, C., Cruts, M., et al. (2000). Nonfibrillar diffuse amyloid deposition due to a gamma(42)-secretase site mutation points to an essential role for N-truncated A beta(42) in Alzheimer's disease. Human molecular genetics, 9(18):2589-98.

Kummer, M. P., Hermes, M., Delekarte, A., et al. (2011). Nitration of Tyrosine 10 Critically Enhances Amyloid $\beta$ Aggregation and Plaque Formation. Neuron, 71(5):833-44.

Kuo, Y. M., Emmerling, M. R., Woods, a. S., Cotter, R. J., and Roher, a. E. (1997). Isolation, chemical characterization, and quantitation of A beta 3-pyroglutamyl peptide from neuritic plaques and vascular amyloid deposits. Biochemical and biophysical research communications, 237(1):188-91. 
Kuo, Y. M., Kokjohn, T. A., Beach, T. G., et al. (2001). Comparative analysis of amyloid-beta chemical structure and amyloid plaque morphology of transgenic mouse and Alzheimer's disease brains. The Journal of biological chemistry, 276(16):12991-8.

Kuo, Y. M., Webster, S., Emmerling, M. R., De Lima N, and Roher, A. E. (1998). Irreversible dimerization/tetramerization and post-translational modifications inhibit proteolytic degradation of A beta peptides of Alzheimer's disease. Biochimica et biophysica acta, 1406(3):291-8.

Kuperstein, I., Broersen, K., Benilova, I., et al. (2010). Neurotoxicity of Alzheimer's disease A $\beta$ peptides is induced by small changes in the $\mathrm{A} \beta 42$ to $\mathrm{A} \beta 40$ ratio. The EMBO journal, 29(19):3408-20.

LaFerla, F. M., Tinkle, B. T., Bieberich, C. J., Haudenschild, C. C., and Jay, G. (1995). The Alzheimer's A beta peptide induces neurodegeneration and apoptotic cell death in transgenic mice. Nat Genet, $9(1): 21-30$.

Lalonde, R. (2002). The neurobiological basis of spontaneous alternation. Neuroscience and biobehavioral reviews, 26(1):91-104.

Lalonde, R., Fukuchi, K., and Strazielle, C. (2012). APP transgenic mice for modelling behavioural and psychological symptoms of dementia (BPSD). Neuroscience and biobehavioral reviews, pages 1-19.

Lalonde, R., Kim, H. D., and Fukuchi, K. (2004). Exploratory activity, anxiety, and motor coordination in bigenic APPswe + PS1/DeltaE9 mice. Neuroscience letters, 369(2):156-61.

Lalonde, R., Lewis, T. L., Strazielle, C., Kim, H., and Fukuchi, K. (2003a). Transgenic mice expressing the betaAPP695SWE mutation: effects on exploratory activity, anxiety, and motor coordination. Brain research, $977(1): 38-45$.

Lalonde, R., Qian, S., and Strazielle, C. (2003b). Transgenic mice expressing the PS1-A246E mutation: effects on spatial learning, exploration, anxiety, and motor coordination. Behavioural brain research, 138(1):71-9.

Lalonde, R. and Strazielle, C. (2007). Brain regions and genes affecting postural control. Progress in neurobiology, 81(1):45-60.

Lambert, J.-C., Heath, S., Even, G., et al. (2009). Genome-wide association study identifies variants at CLU and CR1 associated with Alzheimer's disease. Nature genetics, 41(10):1094-9.

Lammich, S., Kojro, E., Postina, R., et al. (1999). Constitutive and regulated alpha-secretase cleavage of Alzheimer's amyloid precursor protein by a disintegrin metalloprotease. Proceedings of the National Academy of Sciences of the United States of America, 96(7):3922-7.

Larson, M. E. and Lesné, S. E. (2011). Soluble A $\beta$ oligomer production and toxicity. Journal of neurochemistry, 120:125-139.

Lassalle, J. M., Halley, H., Daumas, S., Verret, L., and Francés, B. (2008). Effects of the genetic background on cognitive performances of TG2576 mice. Behavioural brain research, 191(1):104-10.

Laurin, D., Verreault, R., Lindsay, J., MacPherson, K., and Rockwood, K. (2001). Physical activity and risk of cognitive impairment and dementia in elderly persons. Archives of neurology, 58(3):498-504.

Lee, G., Neve, R. L., and Kosik, K. S. (1989). The microtubule binding domain of tau protein. Neuron, $2(6): 1615-24$.

Lee, V. M., Balin, B. J., Otvos Jr., L., and Trojanowski, J. Q. (1991). A68: a major subunit of paired helical filaments and derivatized forms of normal Tau. Science, 251(4994):675-678.

Lemere, C. A., Blusztajn, J. K., Yamaguchi, H., et al. (1996). Sequence of deposition of heterogeneous amyloid beta-peptides and APO E in Down syndrome: implications for initial events in amyloid plaque formation. Neurobiol Dis, 3(1):16-32.

Lenders, M. B., Peers, M. C., Tramu, G., et al. (1989). Dystrophic peptidergic neurites in senile plaques of Alzheimer's disease hippocampus precede formation of paired helical filaments. Brain research, 481(2):344-9.

Levy-Lahad, E., Wasco, W., Poorkaj, P., et al. (1995a). Candidate gene for the chromosome 1 familial Alzheimer's disease locus. Science (New York, N.Y.), 269(5226):973-7.

Levy-Lahad, E., Wijsman, E. M., Nemens, E., et al. (1995b). A familial Alzheimer's disease locus on chromosome 1. Science (New York, N.Y.), 269(5226):970-3. 
Lewis, H., Beher, D., Cookson, N., et al. (2006). Quantification of Alzheimer pathology in ageing and dementia: age-related accumulation of amyloid-beta(42) peptide in vascular dementia. Neuropathol Appl Neurobiol, 32(2):103-118.

Lewis, J., Dickson, D. W., Lin, W. L., et al. (2001). Enhanced neurofibrillary degeneration in transgenic mice expressing mutant tau and APP. Science, 293(5534):1487-1491.

Li, C., Zhao, R., Gao, K., et al. (2011). Astrocytes: implications for neuroinflammatory pathogenesis of Alzheimer's disease. Current Alzheimer research, 8(1):67-80.

Li, Y. M., Xu, M., Lai, M. T., et al. (2000). Photoactivated gamma-secretase inhibitors directed to the active site covalently label presenilin 1. Nature, 405(6787):689-94.

Liang, K. C., Hon, W., Tyan, Y. M., and Liao, W. L. (1994). Involvement of hippocampal NMDA and AMPA receptors in acquisition, formation and retrieval of spatial memory in the Morris water maze. The Chinese journal of physiology, 37(4):201-12.

Lin, X., Koelsch, G., Wu, S., et al. (2000). Human aspartic protease memapsin 2 cleaves the beta-secretase site of beta-amyloid precursor protein. Proceedings of the National Academy of Sciences of the United States of America, 97(4):1456-60.

Linden, D. E. J. (2007). The working memory networks of the human brain. The Neuroscientist : a review journal bringing neurobiology, neurology and psychiatry, 13(3):257-67.

Lister, R. G. (1987). The use of a plus-maze to measure anxiety in the mouse. Psychopharmacology, 92(2):180-5.

Liu, R.-Q., Zhou, Q.-H., Ji, S.-R., et al. (2010). Membrane localization of beta-amyloid 1-42 in lysosomes: a possible mechanism for lysosome labilization. The Journal of biological chemistry, 285(26):19986-96.

Locascio, J. J., Growdon, J. H., and Corkin, S. (1995). Cognitive test performance in detecting, staging, and tracking Alzheimer's disease. Arch Neurol, 52(11):1087-1099.

Lue, L. F., Kuo, Y. M., Roher, A. E., et al. (1999). Soluble amyloid beta peptide concentration as a predictor of synaptic change in Alzheimer's disease. The American journal of pathology, 155(3):853-62.

Lue, L. F., Rydel, R., Brigham, E. F., et al. (2001). Inflammatory repertoire of Alzheimer's disease and nondemented elderly microglia in vitro. Glia, 35(1):72-9.

Luo, Y., Bolon, B., Damore, M. A., et al. (2003). BACE1 (beta-secretase) knockout mice do not acquire compensatory gene expression changes or develop neural lesions over time. Neurobiology of disease, 14(1):81-8.

Lyketsos, C. G., Lopez, O., Jones, B., et al. (2002). Prevalence of neuropsychiatric symptoms in dementia and mild cognitive impairment: results from the cardiovascular health study. JAMA : the journal of the American Medical Association, 288(12):1475-83.

Maeda, J., Ji, B., Irie, T., et al. (2007). Longitudinal, quantitative assessment of amyloid, neuroinflammation, and anti-amyloid treatment in a living mouse model of Alzheimer's disease enabled by positron emission tomography. J Neurosci, 27(41):10957-10968.

Majumdar, A., Cruz, D., Asamoah, N., et al. (2007). Activation of microglia acidifies lysosomes and leads to degradation of Alzheimer amyloid fibrils. Molecular biology of the cell, 18(4):1490-6.

Malenka, R. C. and Bear, M. F. (2004). LTP and LTD: an embarrassment of riches. Neuron, 44(1):5-21.

Mandelkow, E. M., Drewes, G., Biernat, J., et al. (1992). Glycogen synthase kinase-3 and the Alzheimerlike state of microtubule-associated protein tau. FEBS Lett, 314(3):315-321.

Mandler, M., Rockentsein, E., Ubhi, K., et al. (2011). Detection of Peri-Synaptic Amyloid- $\beta$ Pyroglutamate Aggregates in Early Stages of Alzheimer's Disease and in A $\beta$ PP Transgenic Mice Using a Novel Monoclonal Antibody. Journal of Alzheimer's disease : JAD, 28:1-12.

Mann, D. M., Yates, P. O., and Marcyniuk, B. (1985). Some morphometric observations on the cerebral cortex and hippocampus in presenile Alzheimer's disease, senile dementia of Alzheimer type and Down's syndrome in middle age. Journal of the neurological sciences, 69(3):139-59.

Masliah, E., Sisk, A., Mallory, M., and Games, D. (2001). Neurofibrillary pathology in transgenic mice overexpressing V717F beta-amyloid precursor protein. Journal of neuropathology and experimental neurology, 60(4):357-68. 
Masliah, E., Terry, R. D., Mallory, M., Alford, M., and Hansen, L. A. (1990). Diffuse plaques do not accentuate synapse loss in Alzheimer's disease. The American journal of pathology, 137(6):1293-7.

Masters, C. L., Multhaup, G., Simms, G., et al. (1985a). Neuronal origin of a cerebral amyloid: neurofibrillary tangles of Alzheimer's disease contain the same protein as the amyloid of plaque cores and blood vessels. The EMBO journal, 4(11):2757-63.

Masters, C. L., Simms, G., Weinman, N. A., et al. (1985b). Amyloid plaque core protein in Alzheimer disease and Down syndrome. Proceedings of the National Academy of Sciences of the United States of America, 82(12):4245-9.

Mayer, N. H. (1997). Clinicophysiologic concepts of spasticity and motor dysfunction in adults with an upper motoneuron lesion. Muscle \& nerve. Supplement, 6:S1-13.

McGowan, E., Pickford, F., Kim, J., et al. (2005). Abeta42 is essential for parenchymal and vascular amyloid deposition in mice. Neuron, 47(2):191-9.

McKhann, G., Drachman, D., Folstein, M., et al. (1984). Clinical diagnosis of Alzheimer's disease: report of the NINCDS-ADRDA Work Group under the auspices of Department of Health and Human Services Task Force on Alzheimer's Disease. Neurology, 34(7):939-44.

McLean, C. A., Cherny, R. A., Fraser, F. W., et al. (1999). Soluble pool of Abeta amyloid as a determinant of severity of neurodegeneration in Alzheimer's disease. Ann Neurol, 46(6):860-866.

Meyer-Luehmann, M., Spires-Jones, T. L., Prada, C., et al. (2008). Rapid appearance and local toxicity of amyloid-beta plaques in a mouse model of Alzheimer's disease. Nature, 451(7179):720-4.

Miller, B. R., Dorner, J. L., Shou, M., et al. (2008). Up-regulation of GLT1 expression increases glutamate uptake and attenuates the Huntington's disease phenotype in the R6/2 mouse. Neuroscience, 153(1):329-37.

Miller, D. L., Papayannopoulos, I. A., Styles, J., et al. (1993). Peptide compositions of the cerebrovascular and senile plaque core amyloid deposits of Alzheimer's disease. Archives of biochemistry and biophysics, 301(1):41-52.

Miravalle, L., Calero, M., Takao, M., et al. (2005a). Amino-terminally truncated Abeta peptide species are the main component of cotton wool plaques. Biochemistry, 44(32):10810-21.

Miravalle, L., Calero, M., Takao, M., et al. (2005b). Amino-terminally truncated Abeta peptide species are the main component of cotton wool plaques. Biochemistry, 44(32):10810-21.

Mirra, S. S., Heyman, A., McKeel, D., et al. (1991). The Consortium to Establish a Registry for Alzheimer's Disease (CERAD). Part II. Standardization of the neuropathologic assessment of Alzheimer's disease. Neurology, 41(4):479-86.

Mohamed, A., Cortez, L., and de Chaves, E. P. (2011). Aggregation state and neurotoxic properties of alzheimer $\beta$-amyloid peptide. Current protein $\&$ peptide science, 12(3):235-57.

Mohamed, A. and Posse de Chaves, E. (2011). A $\beta$ internalization by neurons and glia. International journal of Alzheimer's disease, 2011:127984.

Moon, M., Hong, H.-S., Nam, D. W., et al. (2012). Intracellular Amyloid- $\beta$ Accumulation in CalciumBinding Protein-Deficient Neurons Leads to Amyloid- $\beta$ Plaque Formation in Animal Models of Alzheimer's Disease. Journal of Alzheimer's disease : JAD, 28:1-14.

Moran, P. M., Higgins, L. S., Cordell, B., and Moser, P. C. (1995). Age-related learning deficits in transgenic mice expressing the 751-amino acid isoform of human beta-amyloid precursor protein. Proceedings of the National Academy of Sciences of the United States of America, 92(12):5341-5.

Morawski, M., Hartlage-Rübsamen, M., Jäger, C., et al. (2010). Distinct glutaminyl cyclase expression in Edinger-Westphal nucleus, locus coeruleus and nucleus basalis Meynert contributes to pGlu-Abeta pathology in Alzheimer's disease. Acta neuropathologica, 120(2):195-207.

Mori, H., Takio, K., Ogawara, M., and Selkoe, D. J. (1992). Mass spectrometry of purified amyloid beta protein in Alzheimer's disease. The Journal of biological chemistry, 267(24):17082-6.

Morris, R. G. (1981). Spatial localization does not require the presence of local cues. Learning and Motivation, 12(2):239-260.

Moser, M. B., Moser, E. I., Forrest, E., Andersen, P., and Morris, R. G. (1995). Spatial learning with a 
minislab in the dorsal hippocampus. Proceedings of the National Academy of Sciences of the United States of America, 92(21):9697-701.

Mucke, L., Masliah, E., Yu, G. Q., et al. (2000). High-level neuronal expression of abeta 1-42 in wild-type human amyloid protein precursor transgenic mice: synaptotoxicity without plaque formation. The Journal of neuroscience : the official journal of the Society for Neuroscience, 20(11):4050-8.

Mullan, M., Crawford, F., Axelman, K., et al. (1992). A pathogenic mutation for probable Alzheimer's disease in the APP gene at the N-terminus of beta-amyloid. Nature genetics, 1(5):345-7.

Nagele, R. G., D'Andrea, M. R., Lee, H., Venkataraman, V., and Wang, H.-Y. (2003). Astrocytes accumulate A beta 42 and give rise to astrocytic amyloid plaques in Alzheimer disease brains. Brain research, 971(2):197-209.

Naj, A. C., Jun, G., Beecham, G. W., et al. (2011). Common variants at MS4A4/MS4A6E, CD2AP, CD33 and EPHA1 are associated with late-onset Alzheimer's disease. Nature genetics, 43(5):436-41.

Naslund, J., Schierhorn, A., Hellman, U., et al. (1994). Relative abundance of Alzheimer A beta amyloid peptide variants in Alzheimer disease and normal aging. Proc Natl Acad Sci U S A, 91(18):8378-8382.

Nestor, S. M., Rupsingh, R., Borrie, M., et al. (2008). Ventricular enlargement as a possible measure of Alzheimer's disease progression validated using the Alzheimer's disease neuroimaging initiative database. Brain : a journal of neurology, 131(Pt 9):2443-54.

Neve, R. L., Harris, P., Kosik, K. S., Kurnit, D. M., and Donlon, T. A. (1986). Identification of cDNA clones for the human microtubule-associated protein tau and chromosomal localization of the genes for tau and microtubule-associated protein 2. Brain research, 387(3):271-80.

Nillni, E. a. (2010). Regulation of the hypothalamic thyrotropin releasing hormone (TRH) neuron by neuronal and peripheral inputs. Frontiers in neuroendocrinology, 31(2):134-56.

Oakley, H., Cole, S. L., Logan, S., et al. (2006). Intraneuronal beta-amyloid aggregates, neurodegeneration, and neuron loss in transgenic mice with five familial Alzheimer's disease mutations: potential factors in amyloid plaque formation. The Journal of neuroscience : the official journal of the Society for Neuroscience, 26(40):10129-40.

Oddo, S., Billings, L., Kesslak, J. P., Cribbs, D. H., and LaFerla, F. M. (2004). Abeta immunotherapy leads to clearance of early, but not late, hyperphosphorylated tau aggregates via the proteasome. Neuron, 43(3):321-32.

Oddo, S., Caccamo, A., Shepherd, J. D., et al. (2003). Triple-transgenic model of Alzheimer's disease with plaques and tangles: intracellular Abeta and synaptic dysfunction. Neuron, 39(3):409-21.

Ohno, M., Chang, L., Tseng, W., et al. (2006). Temporal memory deficits in Alzheimer's mouse models: rescue by genetic deletion of BACE1. The European journal of neuroscience, 23(1):251-60.

Ohno, M., Cole, S. L., Yasvoina, M., et al. (2007). BACE1 gene deletion prevents neuron loss and memory deficits in 5XFAD APP/PS1 transgenic mice. Neurobiol Dis, 26(1):134-145.

Palop, J. J. and Mucke, L. (2010). Amyloid-beta-induced neuronal dysfunction in Alzheimer's disease: from synapses toward neural networks. Nature neuroscience, 13(7):812-8.

Paresce, D. M., Chung, H., and Maxfield, F. R. (1997). Slow degradation of aggregates of the Alzheimer's disease amyloid beta-protein by microglial cells. The Journal of biological chemistry, 272(46):29390-7.

Parsons, C. G., Gruner, R., Rozental, J., Millar, J., and Lodge, D. (1993). Patch clamp studies on the kinetics and selectivity of N-methyl-D-aspartate receptor antagonism by memantine (1-amino-3,5dimethyladamantan). Neuropharmacology, 32(12):1337-50.

Parsons, C. G., Stöffler, A., and Danysz, W. (2007). Memantine: a NMDA receptor antagonist that improves memory by restoration of homeostasis in the glutamatergic system-too little activation is bad, too much is even worse. Neuropharmacology, 53(6):699-723.

Perez-Tur, J., Croxton, R., Wright, K., et al. (1996). A further presenilin 1 mutation in the exon 8 cluster in familial Alzheimer's disease. Neurodegeneration : a journal for neurodegenerative disorders, neuroprotection, and neuroregeneration, 5(3):207-12.

Pericak-Vance, M. A., Bebout, J. L., Gaskell, P. C., et al. (1991). Linkage studies in familial Alzheimer disease: evidence for chromosome 19 linkage. American journal of human genetics, 48(6):1034-50. 
Perry, R. J. and Hodges, J. R. (1999). Attention and executive deficits in Alzheimer's disease. A critical review. Brain : a journal of neurology, 122 ( Pt 3:383-404.

Petersen, R. C., Roberts, R. O., Knopman, D. S., et al. (2009). Mild cognitive impairment: ten years later. Archives of neurology, 66(12):1447-55.

Petry, S., Cummings, J. L., Hill, M. A., and Shapira, J. (1988). Personality alterations in dementia of the Alzheimer type. Archives of neurology, 45(11):1187-90.

Philipson, O., Lord, A., Gumucio, A., et al. (2010). Animal models of amyloid-beta-related pathologies in Alzheimer's disease. Febs J, 277(6):1389-1409.

Piccini, A., Russo, C., Gliozzi, A., et al. (2005). beta-amyloid is different in normal aging and in Alzheimer disease. The Journal of biological chemistry, 280(40):34186-92.

Piccini, A., Zanusso, G., Borghi, R., et al. (2007). Association of a presenilin 1 S170F mutation with a novel Alzheimer disease molecular phenotype. Archives of neurology, 64(5):738-45.

Pike, C. J., Cummings, B. J., and Cotman, C. W. (1995a). Early association of reactive astrocytes with senile plaques in Alzheimer's disease. Experimental neurology, 132(2):172-9.

Pike, C. J., Overman, M. J., and Cotman, C. W. (1995b). Amino-terminal deletions enhance aggregation of beta-amyloid peptides in vitro. J Biol Chem, 270(41):23895-23898.

Polidori, M. C., Praticó, D., Mangialasche, F., et al. (2009). High fruit and vegetable intake is positively correlated with antioxidant status and cognitive performance in healthy subjects. Journal of Alzheimer's disease : JAD, 17(4):921-7.

Portelius, E., Bogdanovic, N., Gustavsson, M. K., et al. (2010). Mass spectrometric characterization of brain amyloid beta isoform signatures in familial and sporadic Alzheimer's disease. Acta neuropathologica, 120(2):185-93.

Portelius, E., Tran, A. J., Andreasson, U., et al. (2007). Characterization of amyloid beta peptides in cerebrospinal fluid by an automated immunoprecipitation procedure followed by mass spectrometry. Journal of proteome research, 6(11):4433-9.

Portelius, E., Zhang, B., Gustavsson, M. K., et al. (2009). Effects of gamma-secretase inhibition on the amyloid beta isoform pattern in a mouse model of Alzheimer's disease. Neuro-degenerative diseases, $6(5-6): 258-62$.

Pugh, P. L., Richardson, J. C., Bate, S. T., Upton, N., and Sunter, D. (2007). Non-cognitive behaviours in an APP/PS1 transgenic model of Alzheimer's disease. Behavioural brain research, 178(1):18-28.

Puoliväli, J., Wang, J., Heikkinen, T., et al. (2002). Hippocampal A beta 42 levels correlate with spatial memory deficit in APP and PS1 double transgenic mice. Neurobiology of disease, 9(3):339-47.

Puzzo, D., Privitera, L., Leznik, E., et al. (2008). Picomolar amyloid-beta positively modulates synaptic plasticity and memory in hippocampus. The Journal of neuroscience : the official journal of the Society for Neuroscience, 28(53):14537-45.

Riddell, D. R., Christie, G., Hussain, I., and Dingwall, C. (2001). Compartmentalization of beta-secretase (Asp2) into low-buoyant density, noncaveolar lipid rafts. Current biology : CB, 11(16):1288-93.

Roberts, S. B., Ripellino, J. A., Ingalls, K. M., Robakis, N. K., and Felsenstein, K. M. (1994). Nonamyloidogenic cleavage of the beta-amyloid precursor protein by an integral membrane metalloendopeptidase. The Journal of biological chemistry, 269(4):3111-6.

Rockenstein, E., Mallory, M., Mante, M., Sisk, A., and Masliaha, E. (2001). Early formation of mature amyloid-beta protein deposits in a mutant APP transgenic model depends on levels of Abeta(1-42). Journal of neuroscience research, 66(4):573-82.

Rockenstein, E. M., McConlogue, L., Tan, H., et al. (1995). Levels and alternative splicing of amyloid beta protein precursor (APP) transcripts in brains of APP transgenic mice and humans with Alzheimer's disease. J Biol Chem, 270(47):28257-28267.

Rogaev, E. I., Sherrington, R., Rogaeva, E. A., et al. (1995). Familial Alzheimer's disease in kindreds with missense mutations in a gene on chromosome 1 related to the Alzheimer's disease type 3 gene. Nature, 376(6543):775-8.

Roher, A. E., Lowenson, J. D., Clarke, S., et al. (1993a). Structural alterations in the peptide backbone 
of beta-amyloid core protein may account for its deposition and stability in Alzheimer's disease. The Journal of biological chemistry, 268(5):3072-83.

Roher, A. E., Lowenson, J. D., Clarke, S., et al. (1993b). beta-Amyloid-(1-42) is a major component of cerebrovascular amyloid deposits: implications for the pathology of Alzheimer disease. Proc Natl Acad Sci US A, 90(22):10836-10840.

Rovelet-Lecrux, A., Hannequin, D., Raux, G., et al. (2006). APP locus duplication causes autosomal dominant early-onset Alzheimer disease with cerebral amyloid angiopathy. Nature genetics, 38(1):246.

Rubin, E. H., Storandt, M., Miller, J. P., et al. (1998). A prospective study of cognitive function and onset of dementia in cognitively healthy elders. Archives of neurology, 55(3):395-401.

Rüfenacht, P., Güntert, A., Bohrmann, B., Ducret, A., and Döbeli, H. (2005). Quantification of the A beta peptide in Alzheimer's plaques by laser dissection microscopy combined with mass spectrometry. Journal of mass spectrometry : JMS, 40(2):193-201.

Runz, H., Rietdorf, J., Tomic, I., et al. (2002). Inhibition of intracellular cholesterol transport alters presenilin localization and amyloid precursor protein processing in neuronal cells. The Journal of neuroscience : the official journal of the Society for Neuroscience, 22(5):1679-89.

Russo, C., Saido, T. C., DeBusk, L. M., et al. (1997). Heterogeneity of water-soluble amyloid beta-peptide in Alzheimer's disease and Down's syndrome brains. FEBS letters, 409(3):411-6.

Russo, C., Schettini, G., Saido, T. C., et al. (2000). Presenilin-1 mutations in Alzheimer's disease. Nature, 405(6786):531-532.

Russo, C., Violani, E., Salis, S., et al. (2002). Pyroglutamate-modified amyloid beta-peptidesAbetaN3(pE)-strongly affect cultured neuron and astrocyte survival. Journal of neurochemistry, $82(6): 1480-9$.

Saido, T. C., Iwatsubo, T., Mann, D. M., et al. (1995). Dominant and differential deposition of distinct beta-amyloid peptide species, A beta N3(pE), in senile plaques. Neuron, 14(2):457-66.

Saido, T. C., Yamao-Harigaya, W., Iwatsubo, T., and Kawashima, S. (1996). Amino- and carboxylterminal heterogeneity of beta-amyloid peptides deposited in human brain. Neuroscience letters, $215(3): 173-6$.

Saito, T., Suemoto, T., Brouwers, N., et al. (2011). Potent amyloidogenicity and pathogenicity of A $\beta 43$. Nature neuroscience, 14(8):1023-32.

Sanders, H. M., Lust, R., and Teller, J. K. (2009). Amyloid-beta peptide Abetap3-42 affects early aggregation of full-length Abeta1-42. Peptides, 30(5):849-54.

Scarmeas, N., Hadjigeorgiou, G. M., Papadimitriou, A., et al. (2004). Motor signs during the course of Alzheimer disease. Neurology, 63(6):975-82.

Scheff, S. W., Price, D. A., Schmitt, F. A., DeKosky, S. T., and Mufson, E. J. (2007). Synaptic alterations in CA1 in mild Alzheimer disease and mild cognitive impairment. Neurology, 68(18):1501-8.

Scheff, S. W., Price, D. A., and Sparks, D. L. (2001). Quantitative assessment of possible age-related change in synaptic numbers in the human frontal cortex. Neurobiology of aging, 22(3):355-65.

Schellenberg, G. D., Bird, T. D., Wijsman, E. M., et al. (1992). Genetic linkage evidence for a familial Alzheimer's disease locus on chromosome 14. Science (New York, N. Y.), 258(5082):668-71.

Scheuner, D., Eckman, C., Jensen, M., et al. (1996). Secreted amyloid beta-protein similar to that in the senile plaques of Alzheimer's disease is increased in vivo by the presenilin 1 and 2 and APP mutations linked to familial Alzheimer's disease. Nature medicine, 2(8):864-70.

Schilling, S., Appl, T., Hoffmann, T., et al. (2008a). Inhibition of glutaminyl cyclase prevents pGlu-Abeta formation after intracortical/hippocampal microinjection in vivo/in situ. J Neurochem, 106(3):12251236.

Schilling, S., Cynis, H., von Bohlen, A., et al. (2005). Isolation, catalytic properties, and competitive inhibitors of the zinc-dependent murine glutaminyl cyclase. Biochemistry, 44(40):13415-24.

Schilling, S., Hoffmann, T., Manhart, S., Hoffmann, M., and Demuth, H. U. (2004). Glutaminyl cyclases unfold glutamyl cyclase activity under mild acid conditions. FEBS Lett, 563(1-3):191-196. 
Schilling, S., Kohlmann, S., Bäuscher, C., et al. (2011). Glutaminyl cyclase knock-out mice exhibit slight hypothyroidism but no hypogonadism: implications for enzyme function and drug development. The Journal of biological chemistry, 286(16):14199-208.

Schilling, S., Lauber, T., Schaupp, M., et al. (2006). On the seeding and oligomerization of pGlu-amyloid peptides (in vitro). Biochemistry, 45(41):12393-9.

Schilling, S., Niestroj, A. J., Rahfeld, J.-U. U., et al. (2003). Identification of human glutaminyl cyclase as a metalloenzyme. Potent inhibition by imidazole derivatives and heterocyclic chelators. The Journal of biological chemistry, 278(50):49773-9.

Schilling, S., Wasternack, C., and Demuth, H. U. (2008b). Glutaminyl cyclases from animals and plants: a case of functionally convergent protein evolution. Biol Chem, 389(8):983-991.

Schilling, S., Zeitschel, U., Hoffmann, T., et al. (2008c). Glutaminyl cyclase inhibition attenuates pyroglutamate Abeta and Alzheimer's disease-like pathology. Nature medicine, 14(10):1106-11.

Schlenzig, D., Manhart, S., Cinar, Y., et al. (2009). Pyroglutamate formation influences solubility and amyloidogenicity of amyloid peptides. Biochemistry, 48(29):7072-8.

Schlenzig, D., Rönicke, R., Cynis, H., et al. (2012). N-terminal Pyroglutamate (pGlu) formation of $\mathrm{A} \beta 38$ and $\mathrm{A} \beta 40$ Enforces Oligomer Formation and Potency to Disrupt Hippocampal LTP. Journal of neurochemistry.

Schmidt, C., Redyk, K., Meissner, B., et al. (2010). Clinical features of rapidly progressive Alzheimer's disease. Dementia and geriatric cognitive disorders, 29(4):371-8.

Schmitz, C., Rutten, B. P. F., Pielen, A., et al. (2004). Hippocampal neuron loss exceeds amyloid plaque load in a transgenic mouse model of Alzheimer's disease. The American journal of pathology, 164(4):1495-502.

Selkoe, D. J., Abraham, C. R., Podlisny, M. B., and Duffy, L. K. (1986). Isolation of low-molecular-weight proteins from amyloid plaque fibers in Alzheimer's disease. Journal of neurochemistry, 46(6):1820-34.

Selznick, L. A., Holtzman, D. M., Han, B. H., et al. (1999). In situ immunodetection of neuronal caspase-3 activation in Alzheimer disease. Journal of neuropathology and experimental neurology, 58(9):1020-6.

Seo, J.-S., Leem, Y.-H., Lee, K.-W., et al. (2010). Severe motor neuron degeneration in the spinal cord of the Tg2576 mouse model of Alzheimer disease. Journal of Alzheimer's disease : JAD, 21(1):263-76.

Sergeant, N., Bombois, S., Ghestem, A., et al. (2003). Truncated beta-amyloid peptide species in preclinical Alzheimer's disease as new targets for the vaccination approach. Journal of Neurochemistry, 85(6):1581-1591.

Seshadri, S., Beiser, A., Kelly-Hayes, M., et al. (2006). The lifetime risk of stroke: estimates from the Framingham Study. Stroke; a journal of cerebral circulation, 37(2):345-50.

Sevalle, J., Amoyel, A., Robert, P., et al. (2009). Aminopeptidase A contributes to the N-terminal truncation of amyloid beta-peptide. J Neurochem, 109(1):248-256.

Shankar, G. M., Li, S., Mehta, T. H., et al. (2008). Amyloid-beta protein dimers isolated directly from Alzheimer's brains impair synaptic plasticity and memory. Nature medicine, 14(8):837-42.

Shapira, R., Austin, G. E., and Mirra, S. S. (1988). Neuritic plaque amyloid in Alzheimer's disease is highly racemized. Journal of neurochemistry, 50(1):69-74.

Sherrington, R., Rogaev, E. I., Liang, Y., et al. (1995). Cloning of a gene bearing missense mutations in early-onset familial Alzheimer's disease. Nature, 375(6534):754-60.

Shin, R. W., Ogino, K., Kondo, A., et al. (1997). Amyloid beta-protein (Abeta) 1-40 but not Abeta1-42 contributes to the experimental formation of Alzheimer disease amyloid fibrils in rat brain. J Neurosci, 17(21):8187-8193.

Shirotani, K., Tsubuki, S., Lee, H.-J., Maruyama, K., and Saido, T. C. (2002). Generation of amyloid beta peptide with pyroglutamate at position 3 in primary cortical neurons. Neuroscience letters, $327(1): 25-8$.

Shoji, M., Golde, T. E., Ghiso, J., et al. (1992). Production of the Alzheimer amyloid beta protein by normal proteolytic processing. Science (New York, N.Y.), 258(5079):126-9.

Simonsen, A., Bremnes, B., Rø nning, E., Aasland, R., and Stenmark, H. (1998). Syntaxin-16, a putative 
Golgi t-SNARE. European journal of cell biology, 75(3):223-31.

Sinha, S., Anderson, J. P., Barbour, R., et al. (1999). Purification and cloning of amyloid precursor protein beta-secretase from human brain. Nature, 402(6761):537-540.

Sisodia, S. S. (1992). Beta-amyloid precursor protein cleavage by a membrane-bound protease. Proceedings of the National Academy of Sciences of the United States of America, 89(13):6075-9.

Sisodia, S. S., Koo, E. H., Beyreuther, K., Unterbeck, A., and Price, D. L. (1990). Evidence that betaamyloid protein in Alzheimer's disease is not derived by normal processing. Science (New York, N.Y.), 248(4954):492-5.

Skovronsky, D. M., Doms, R. W., and Lee, V. M. (1998). Detection of a novel intraneuronal pool of insoluble amyloid beta protein that accumulates with time in culture. The Journal of cell biology, 141(4):1031-9.

Snowdon, D. A. (2003). Healthy aging and dementia: findings from the Nun Study. Ann Intern Med, $139(5$ Pt 2):450-454.

Sola, C., Mengod, G., Probst, A., and Palacios, J. M. (1993). Differential regional and cellular distribution of beta-amyloid precursor protein messenger RNAs containing and lacking the Kunitz protease inhibitor domain in the brain of human, rat and mouse. Neuroscience, 53(1):267-295.

Solomon, A., Kivipelto, M., Wolozin, B., Zhou, J., and Whitmer, R. A. (2009). Midlife serum cholesterol and increased risk of Alzheimer's and vascular dementia three decades later. Dementia and geriatric cognitive disorders, 28(1):75-80.

Spillantini, M. G., Murrell, J. R., Goedert, M., et al. (1998). Mutation in the tau gene in familial multiple system tauopathy with presenile dementia. Proceedings of the National Academy of Sciences of the United States of America, 95(13):7737-41.

St George-Hyslop, P. H., Tanzi, R. E., Polinsky, R. J., et al. (1987). The genetic defect causing familial Alzheimer's disease maps on chromosome 21. Science, 235(4791):885-890.

Steinerman, J. R., Irizarry, M., Scarmeas, N., et al. (2008). Distinct pools of beta-amyloid in Alzheimer disease-affected brain: a clinicopathologic study. Archives of neurology, 65(7):906-12.

Stenh, C., Nilsberth, C., Hammarback, J., et al. (2002). The Arctic mutation interferes with processing of the amyloid precursor protein. Neuroreport, 13(15):1857-60.

Stern, Y., Gurland, B., Tatemichi, T. K., et al. (1994). Influence of education and occupation on the incidence of Alzheimer's disease. JAMA : the journal of the American Medical Association, 271(13):100410 .

Strittmatter, W. J., Saunders, a. M., Schmechel, D., et al. (1993). Apolipoprotein E: high-avidity binding to beta-amyloid and increased frequency of type 4 allele in late-onset familial Alzheimer disease. Proceedings of the National Academy of Sciences of the United States of America, 90(5):1977-81.

Su, J. H., Cummings, B. J., and Cotman, C. W. (1993). Identification and distribution of axonal dystrophic neurites in Alzheimer's disease. Brain research, 625(2):228-37.

Sullivan, C. P., Berg, E. a., Elliott-Bryant, R., et al. (2011). Pyroglutamate-A $\beta 3$ and 11 colocalize in amyloid plaques in Alzheimer's disease cerebral cortex with pyroglutamate-A $\beta 11$ forming the central core. Neuroscience letters, pages 9-12.

Suzuki, N., Cheung, T. T., Cai, X. D., et al. (1994a). An increased percentage of long amyloid beta protein secreted by familial amyloid beta protein precursor (beta APP717) mutants. Science (New York, N.Y.), 264(5163):1336-40.

Suzuki, N., Iwatsubo, T., Odaka, A., et al. (1994b). High tissue content of soluble beta 1-40 is linked to cerebral amyloid angiopathy. The American journal of pathology, 145(2):452-60.

Suzuki, T. and Nakaya, T. (2008). Regulation of amyloid beta-protein precursor by phosphorylation and protein interactions. The Journal of biological chemistry, 283(44):29633-7.

Tabaton, M. and Piccini, A. (2005). Role of water-soluble amyloid-beta in the pathogenesis of Alzheimer's disease. Int J Exp Pathol, 86(3):139-145.

Takahashi, R. H., Almeida, C. G., Kearney, P. F., et al. (2004). Oligomerization of Alzheimer's betaamyloid within processes and synapses of cultured neurons and brain. J Neurosci, 24(14):3592-3599. 
Takahashi, R. H., Milner, T. A., Li, F., et al. (2002). Intraneuronal Alzheimer abeta42 accumulates in multivesicular bodies and is associated with synaptic pathology. Am J Pathol, 161(5):1869-1879.

Takasugi, N., Tomita, T., Hayashi, I., et al. (2003). The role of presenilin cofactors in the gamma-secretase complex. Nature, 422(6930):438-41.

Tamura, B. K., Masaki, K. H., and Blanchette, P. (2007). Weight loss in patients with Alzheimer's disease. Journal of nutrition for the elderly, 26(3-4):21-38.

Tanzi, R. E., Gusella, J. F., Watkins, P. C., et al. (1987). Amyloid beta protein gene: cDNA, mRNA distribution, and genetic linkage near the Alzheimer locus. Science (New York, N. Y.), 235(4791):880-4.

Tanzi, R. E., McClatchey, A. I., Lamperti, E. D., et al. (1988). Protease inhibitor domain encoded by an amyloid protein precursor mRNA associated with Alzheimer's disease. Nature, 331(6156):528-30.

Tekirian, T. L., Saido, T. C., Markesbery, W. R., et al. (1998). N-terminal heterogeneity of parenchymal and cerebrovascular Abeta deposits. J Neuropathol Exp Neurol, 57(1):76-94.

Tekirian, T. L., Yang, A. Y., Glabe, C., and Geddes, J. W. (1999). Toxicity of pyroglutaminated amyloid beta-peptides 3(pE)-40 and -42 is similar to that of A beta1-40 and -42. Journal of neurochemistry, 73(4):1584-9.

Terry, R. D., Masliah, E., Salmon, D. P., et al. (1991). Physical basis of cognitive alterations in Alzheimer's disease: synapse loss is the major correlate of cognitive impairment. Ann Neurol, 30(4):572-580.

Thal, D. R., Rüb, U., Orantes, M., and Braak, H. (2002). Phases of A beta-deposition in the human brain and its relevance for the development of AD. Neurology, 58(12):1791-800.

Thal, D. R., Schultz, C., Dehghani, F., et al. (2000). Amyloid beta-protein (Abeta)-containing astrocytes are located preferentially near N-terminal-truncated Abeta deposits in the human entorhinal cortex. Acta neuropathologica, 100(6):608-17.

Thathiah, A. and De Strooper, B. (2011). The role of G protein-coupled receptors in the pathology of Alzheimer's disease. Nature reviews. Neuroscience, 12(2):73-87.

Thinakaran, G. and Koo, E. H. (2008). Amyloid precursor protein trafficking, processing, and function. The Journal of biological chemistry, 283(44):29615-9.

Tomidokoro, Y., Lashley, T., Rostagno, A., et al. (2005). Familial Danish dementia: co-existence of Danish and Alzheimer amyloid subunits (ADan AND A\{beta\}) in the absence of compact plaques. $J$ Biol Chem, 280(44):36883-36894.

Tomita, S., Kirino, Y., and Suzuki, T. (1998). Cleavage of Alzheimer's amyloid precursor protein (APP) by secretases occurs after O-glycosylation of APP in the protein secretory pathway. Identification of intracellular compartments in which APP cleavage occurs without using toxic agents that interfere. The Journal of biological chemistry, 273(11):6277-84.

Trojanowski, J. Q., Schuck, T., Schmidt, M. L., and Lee, V. M. (1989). Distribution of tau proteins in the normal human central and peripheral nervous system. The journal of histochemistry and cytochemistry : official journal of the Histochemistry Society, 37(2):209-15.

Troncoso, J. C., Sukhov, R. R., Kawas, C. H., and Koliatsos, V. E. (1996). In situ labeling of dying cortical neurons in normal aging and in Alzheimer's disease: correlations with senile plaques and disease progression. Journal of neuropathology and experimental neurology, 55(11):1134-42.

Tsivgoulis, G., Alexandrov, A. V., Wadley, V. G., et al. (2009). Association of higher diastolic blood pressure levels with cognitive impairment. Neurology, 73(8):589-95.

Turner, R. S., Suzuki, N., Chyung, A. S., Younkin, S. G., and Lee, V. M. (1996). Amyloids beta40 and beta42 are generated intracellularly in cultured human neurons and their secretion increases with maturation. J Biol Chem, 271(15):8966-8970.

Urbanc, B., Cruz, L., Le, R., et al. (2002). Neurotoxic effects of thioflavin S-positive amyloid deposits in transgenic mice and Alzheimer's disease. Proceedings of the National Academy of Sciences of the United States of America, 99(22):13990-5.

Van Dam, D. and De Deyn, P. P. (2006). Drug discovery in dementia: the role of rodent models. Nature reviews. Drug discovery, 5(11):956-70.

Vassar, R., Bennett, B. D., Babu-Khan, S., et al. (1999). Beta-secretase cleavage of Alzheimer's amyloid 
precursor protein by the transmembrane aspartic protease BACE. Science, 286(5440):735-741.

Verkhratsky, A., Olabarria, M., Noristani, H. N., Yeh, C.-y., and Rodriguez, J. J. (2010). Astrocytes in Alzheimer's disease. Neurotherapeutics : the journal of the American Society for Experimental NeuroTherapeutics, 7(4):399-412.

Villemagne, V. L., Pike, K. E., Chételat, G., et al. (2011). Longitudinal assessment of A $\beta$ and cognition in aging and Alzheimer disease. Annals of neurology, 69(1):181-92.

Vlassenko, A. G., Mintun, M. A., Xiong, C., et al. (2011). Amyloid-beta plaque growth in cognitively normal adults: longitudinal [11C]Pittsburgh compound B data. Annals of neurology, 70(5):857-61.

Vorhees, C. V. and Williams, M. T. (2006). Morris water maze: procedures for assessing spatial and related forms of learning and memory. Nature protocols, 1(2):848-58.

Wada, H., Nakajoh, K., Satoh-Nakagawa, T., et al. (2001). Risk factors of aspiration pneumonia in Alzheimer's disease patients. Gerontology, 47(5):271-6.

Wahle, T., Prager, K., Raffler, N., et al. (2005). GGA proteins regulate retrograde transport of BACE1 from endosomes to the trans-Golgi network. Molecular and cellular neurosciences, 29(3):453-61.

Walker, D. G., Lue, L. F., and Beach, T. G. (2001). Gene expression profiling of amyloid beta peptidestimulated human post-mortem brain microglia. Neurobiology of aging, 22(6):957-66.

Walsh, D. A., Williams, M. V., and Hertzog, C. K. (1979). Age-related differences in two stages of central perceptual processes: the effects of short duration targets and criterion differences. Journal of gerontology, 34(2):234-41.

Walsh, D. M., Klyubin, I., Fadeeva, J. V., et al. (2002). Naturally secreted oligomers of amyloid beta protein potently inhibit hippocampal long-term potentiation in vivo. Nature, 416(6880):535-9.

Walter, J., Fluhrer, R., Hartung, B., et al. (2001). Phosphorylation regulates intracellular trafficking of beta-secretase. The Journal of biological chemistry, 276(18):14634-41.

Wang, L., Larson, E. B., Bowen, J. D., and van Belle, G. (2006). Performance-based physical function and future dementia in older people. Archives of internal medicine, 166(10):1115-20.

Wasco, W., Bupp, K., Magendantz, M., et al. (1992). Identification of a mouse brain cDNA that encodes a protein related to the Alzheimer disease-associated amyloid beta protein precursor. Proceedings of the National Academy of Sciences of the United States of America, 89(22):10758-62.

Wasco, W., Gurubhagavatula, S., Paradis, M. D., et al. (1993). Isolation and characterization of APLP2 encoding a homologue of the Alzheimer's associated amyloid beta protein precursor. Nature genetics, $5(1): 95-100$.

Weidemann, A., König, G., Bunke, D., et al. (1989). Identification, biogenesis, and localization of precursors of Alzheimer's disease A4 amyloid protein. Cell, 57(1):115-26.

Weingarten, M. D., Lockwood, A. H., Hwo, S. Y., and Kirschner, M. W. (1975). A protein factor essential for microtubule assembly. Proceedings of the National Academy of Sciences of the United States of America, 72(5):1858-62.

Welsh, K., Butters, N., Hughes, J., Mohs, R., and Heyman, A. (1991). Detection of abnormal memory decline in mild cases of Alzheimer's disease using CERAD neuropsychological measures. Archives of neurology, 48(3):278-81.

Wertkin, a. M., Turner, R. S., Pleasure, S. J., et al. (1993). Human neurons derived from a teratocarcinoma cell line express solely the 695-amino acid amyloid precursor protein and produce intracellular betaamyloid or A4 peptides. Proceedings of the National Academy of Sciences of the United States of America, 90(20):9513-7.

West, M., Coleman, P., Flood, D., and Troncoso, J. (1994). Differences in the pattern of hippocampal neuronal loss in normal ageing and Alzheimer's disease. The Lancet, 344(8925):769-772.

White, J. A., Manelli, A. M., Holmberg, K. H., Van Eldik, L. J., and Ladu, M. J. (2005). Differential effects of oligomeric and fibrillar amyloid-beta 1-42 on astrocyte-mediated inflammation. Neurobiology of disease, 18(3):459-65.

Wilkinson, D. and Andersen, H. F. (2007). Analysis of the effect of memantine in reducing the worsening of clinical symptoms in patients with moderate to severe Alzheimer's disease. Dementia and geriatric 
cognitive disorders, 24(2):138-45.

Wilson, R. S., Mendes De Leon, C. F., Barnes, L. L., et al. (2002). Participation in cognitively stimulating activities and risk of incident Alzheimer disease. JAMA : the journal of the American Medical Association, 287(6):742-8.

Wirths, O., Bethge, T., Marcello, A., et al. (2010a). Pyroglutamate Abeta pathology in APP/PS1KI mice, sporadic and familial Alzheimer's disease cases. Journal of neural transmission (Vienna, Austria : 1996), 117(1):85-96.

Wirths, O., Breyhan, H., Cynis, H., et al. (2009). Intraneuronal pyroglutamate-Abeta 3-42 triggers neurodegeneration and lethal neurological deficits in a transgenic mouse model. Acta Neuropathol, 118(4):487-496.

Wirths, O., Breyhan, H., Marcello, A., et al. (2010b). Inflammatory changes are tightly associated with neurodegeneration in the brain and spinal cord of the APP/PS1KI mouse model of Alzheimer's disease. Neurobiology of aging, 31(5):747-57.

Wirths, O., Breyhan, H., Schafer, S., et al. (2008). Deficits in working memory and motor performance in the APP/PS1ki mouse model for Alzheimer's disease. Neurobiology of aging, 29(6):891-901.

Wirths, O., Dins, A., and Bayer, T. a. (2011). A $\beta$ PP Accumulation and/or Intraneuronal Amyloid- $\beta$ Accumulation? The 3xTg-AD Mouse Model Revisited. Journal of Alzheimer's disease : JAD, 28:1-8.

Wirths, O., Erck, C., Martens, H., et al. (2010c). Identification of low molecular weight pyroglutamate A \{beta\} oligomers in Alzheimer disease: a novel tool for therapy and diagnosis. The Journal of biological chemistry, 285(53):41517-24.

Wirths, O., Multhaup, G., and Bayer, T. a. (2004). A modified beta-amyloid hypothesis: intraneuronal accumulation of the beta-amyloid peptide-the first step of a fatal cascade. J Neurochem, 91(3):513-520.

Wirths, O., Weis, J., Kayed, R., Saido, T. C., and Bayer, T. a. (2007). Age-dependent axonal degeneration in an Alzheimer mouse model. Neurobiol Aging, 28(11):1689-1699.

Wisniewski, K. E., Dalton, A. J., McLachlan, C., Wen, G. Y., and Wisniewski, H. M. (1985). Alzheimer's disease in Down's syndrome: clinicopathologic studies. Neurology, 35(7):957-61.

Witman, G. B., Cleveland, D. W., Weingarten, M. D., and Kirschner, M. W. (1976). Tubulin requires tau for growth onto microtubule initiating sites. Proceedings of the National Academy of Sciences of the United States of America, 73(11):4070-4.

Wong, H.-K., Sakurai, T., Oyama, F., et al. (2005). beta Subunits of voltage-gated sodium channels are novel substrates of beta-site amyloid precursor protein-cleaving enzyme (BACE1) and gammasecretase. The Journal of biological chemistry, 280(24):23009-17.

World Alzheimer Report (2010). Alzheimer's Disease International.

Wyss-Coray, T., Loike, J. D., Brionne, T. C., et al. (2003). Adult mouse astrocytes degrade amyloid-beta in vitro and in situ. Nature medicine, 9(4):453-7.

Yan, P., Bero, A. W., Cirrito, J. R., et al. (2009). Characterizing the appearance and growth of amyloid plaques in APP/PS1 mice. The Journal of neuroscience: the official journal of the Society for Neuroscience, 29(34):10706-14.

Yoshikai, S., Sasaki, H., Doh-ura, K., Furuya, H., and Sakaki, Y. (1990). Genomic organization of the human amyloid beta-protein precursor gene. Gene, 87(2):257-63.

Yoshiyama, Y., Higuchi, M., Zhang, B., et al. (2007). Synapse loss and microglial activation precede tangles in a P301S tauopathy mouse model. Neuron, 53(3):337-51.

Youmans, K. L., Tai, L. M., Kanekiyo, T., et al. (2012). Intraneuronal Abeta detection in 5xFAD mice by a new Abeta-specific antibody. Molecular neurodegeneration, 7(1):8.

Youssef, I., Florent-Bechard, S., Malaplate-Armand, C., et al. (2008). N-truncated amyloid-beta oligomers induce learning impairment and neuronal apoptosis. Neurobiol Aging, 29(9):1319-1333.

Yu, L., Vizel, A., Huff, M. B., et al. (2006). Investigation of N-terminal glutamate cyclization of recombinant monoclonal antibody in formulation development. Journal of pharmaceutical and biomedical analysis, 42(4):455-63.

Zhang, X.-M. M., Cai, Y., Xiong, K., et al. (2009). Beta-secretase-1 elevation in transgenic mouse models 
of Alzheimer's disease is associated with synaptic/axonal pathology and amyloidogenesis: implications for neuritic plaque development. Eur J Neurosci, 30(12):2271-2283.

Zhang, Y.-w., Thompson, R., Zhang, H., and Xu, H. (2011). APP processing in Alzheimer's disease. Molecular brain, 4:3.

Zheng, H., Jiang, M., Trumbauer, M. E., et al. (1995). beta-Amyloid precursor protein-deficient mice show reactive gliosis and decreased locomotor activity. Cell, 81(4):525-31.

Zheng, H. and Koo, E. H. (2011). Biology and pathophysiology of the amyloid precursor protein. Molecular neurodegeneration, $6(1): 27$. 


\section{List of Symbols and Abbreviations}

\begin{tabular}{|c|c|}
\hline Abbreviation & Description \\
\hline 5XFAD & five familial Alzheimer's disease mutations \\
\hline $\mathrm{A} \beta$ & amyloid beta \\
\hline $\mathrm{A} \beta_{1-40}$ & amyloid beta starting with amino acid 1 , ending with amino acid 40 \\
\hline $\mathrm{A} \beta_{1-42}$ & amyloid beta starting with amino acid 1 , ending with amino acid 42 \\
\hline $\mathrm{A} \beta_{1-x}$ & $\begin{array}{l}\text { amyloid beta of variable C-terminal lengths, starting with an un- } \\
\text { modified N-terminus }\end{array}$ \\
\hline $\mathrm{A} \beta_{3-42}$ & $\begin{array}{l}\text { amyloid beta N-terminally truncated at amino acid } 3 \text {, ending with } \\
\text { amino acid } 42\end{array}$ \\
\hline $\mathrm{A} \beta_{3-x}$ & $\begin{array}{l}\text { amyloid beta of variable C-terminal lengths, starting with amino acid } \\
3\end{array}$ \\
\hline $\mathrm{A} \beta_{3 Q-42}$ & $\begin{array}{l}\text { amyloid beta starting with a glutamine at position } 3 \text {, ending with } \\
\text { amino acid } 42\end{array}$ \\
\hline $\mathrm{A} \beta_{4-42}$ & $\begin{array}{l}\text { amyloid beta N-terminally truncated at amino acid } 4 \text {, ending with } \\
\text { amino acid } 42\end{array}$ \\
\hline $\mathrm{A} \beta_{5-42}$ & $\begin{array}{l}\text { amyloid beta N-terminally truncated at amino acid } 5 \text {, ending with } \\
\text { amino acid } 42\end{array}$ \\
\hline $\mathrm{A} \beta_{p E}$ & amyloid beta with a pyroglutamate modification at the $\mathrm{N}$-terminus \\
\hline $\mathrm{A} \beta_{p E 3-42}$ & $\begin{array}{l}\text { amyloid beta with a pyroglutamate modification at position } 3 \text { of the } \\
\text { N-terminus, ending with amino acid } 42\end{array}$ \\
\hline $\mathrm{A} \beta_{p E 3-x}$ & $\begin{array}{l}\text { amyloid beta of variable } \mathrm{C} \text {-terminal lengths, staring with a pyroglu- } \\
\text { tamate modification at position } 3 \text { of the N-terminus }\end{array}$ \\
\hline $\mathrm{A} \beta_{p E 11-x}$ & $\begin{array}{l}\text { amyloid beta of variable C-terminal lengths, staring with a pyroglu- } \\
\text { tamate modification at position } 11 \text { of the N-terminus }\end{array}$ \\
\hline $\mathrm{A} \beta_{x-40}$ & $\begin{array}{l}\text { amyloid beta of variable N-terminal lengths, ending with amino acid } \\
40 \text { at the C-terminus }\end{array}$ \\
\hline
\end{tabular}




\begin{tabular}{|c|c|}
\hline Abbreviation & Description \\
\hline $\mathrm{A} \beta_{x-42}$ & $\begin{array}{l}\text { amyloid beta of variable N-terminal lengths, ending with amino acid } \\
42 \text { at the C-terminus }\end{array}$ \\
\hline $\mathrm{ABC}$ & avidin-biotin complex \\
\hline $\mathrm{AD}$ & Alzheimer's disease \\
\hline ADAM & a disintegrin and metalloproteinase \\
\hline $\mathrm{AICD}$ & amyloid precursor protein intracellular domain \\
\hline ANOVA & analysis of variance \\
\hline APH1 & anterior pharynx defective 1 \\
\hline APLP & amyloid precursor-like protein \\
\hline ApoE & apolipoprotein E \\
\hline $\mathrm{APP}$ & amyloid precursor protein \\
\hline$\beta-\mathrm{ME}$ & beta-mercaptoethanol \\
\hline BACE1 & beta-site cleaving enzyme 1 \\
\hline $\mathrm{bp}$ & base pair(s) \\
\hline BSA & bovine serum albumin \\
\hline CatD & cathepsin D \\
\hline $\mathrm{CNS}$ & central nervous system \\
\hline DAB & 3,3'-diaminobenzidine \\
\hline DAPI & 4',6-diamidino-2-phenylindole \\
\hline $\mathrm{dd}_{2} \mathrm{O}$ & distilled, deionized water \\
\hline DNA & deoxyribonucleic acid \\
\hline DNase & deoxyribonuclease \\
\hline DS & Down syndrome \\
\hline E. coli & Escherichia coli \\
\hline EDTA & ethylenediaminetetraacetic acid \\
\hline ELISA & enzyme-linked immunosorbent assay \\
\hline EOAD & early-onset Alzheimer's disease \\
\hline ER & endoplasmic reticulum \\
\hline FA & formic acid \\
\hline FAD & familial Alzheimer's disease \\
\hline FCS & fetal calf serum \\
\hline GFAP & glial fibrillary acidic protein \\
\hline $\mathrm{h}$ & hour(s) \\
\hline hAPP & human amyloid precursor protein \\
\hline Hom & homozygous \\
\hline HPLC & high performance liquid chromatography \\
\hline IP & immunoprecipitation \\
\hline
\end{tabular}




\begin{tabular}{|c|c|}
\hline Abbreviation & Description \\
\hline $\mathrm{kb}$ & kilobase(s) \\
\hline $\mathrm{kDa}$ & kilodalton(s) \\
\hline $\mathrm{KI}$ & knockin \\
\hline $\mathrm{KO}$ & knockout \\
\hline $\mathrm{LB}$ & lysogeny broth \\
\hline LOAD & late-onset Alzheimer's disease \\
\hline LTP & long-term potentiation \\
\hline $\mathrm{M}$ & molar \\
\hline \multirow[t]{2}{*}{ MALDI TOF/TOF } & matrix-assisted-laser-desorption/ionization \\
\hline & time-of-flight/time-of-flight \\
\hline MCI & mild cognitive impairment \\
\hline $\min$ & minute(s) \\
\hline mon & $\operatorname{month}(\mathrm{s})$ \\
\hline (m)RNA & (messenger) ribonucleic acid \\
\hline MS & mass spectrometry \\
\hline MVBs & multivesicular bodies \\
\hline MWM & Morris water maze \\
\hline NEB & New England Biolabs \\
\hline NFT & neurofibrillary tangle \\
\hline NMDA & N-methyl- D-aspartate \\
\hline NT2N & neuronally-differentiated NT2 cells \\
\hline $\mathrm{ON}$ & overnight \\
\hline PBS & phosphate buffered saline \\
\hline PCR & polymerase chain reaction \\
\hline PEN-2 & presenilin enhancer 2 \\
\hline PFA & paraformaldehyde \\
\hline PHF & paired helical filament \\
\hline PS1 & presenilin 1 \\
\hline PS2 & presenilin 2 \\
\hline $\mathrm{QC}$ & glutaminyl cyclase \\
\hline qPCR & quantitative real-time polymerase chain reaction \\
\hline $\mathrm{rpm}$ & revolutions per minute \\
\hline $\mathrm{RT}$ & room temperature \\
\hline $\mathrm{sAPP} \alpha$ & soluble alpha amyloid precursor protein fragment \\
\hline $\operatorname{sAPP} \beta$ & soluble beta amyloid precursor protein fragment \\
\hline SDS & sodium dodecyl sulfate \\
\hline sec & second $(\mathrm{s})$ \\
\hline
\end{tabular}




\begin{tabular}{ll}
\hline Abbreviation & Description \\
\hline SNARE & soluble NSF attachment protein receptor \\
SOC & super optimal broth with catabolite repression \\
Syn16 & syntaxin 16 \\
TAE & Tris base/acetic acid \\
TBA & truncated beta-amyloid \\
TBE & Tris/borate/ethylenediaminetetraacetic acid \\
TBS & Tris buffered saline \\
TE & Tris/ethylenediaminetetraacetic acid \\
TFA & trifluoroacetic acid \\
TRH & thyrotropin-releasing hormone \\
UV & ultraviolet \\
v/v & volume/volume \\
W & watt(s) \\
WT & wild-type \\
w/v & weight/volume \\
\hline
\end{tabular}




\section{List of Figures}

1.1 Amyloid plaques . . . . . . . . . . . . . . . . . . 7

1.2 Neurofibrillary tangles . . . . . . . . . . . . . . . . . . . 8

1.3 Brain atrophy in $\mathrm{AD} \ldots \ldots \ldots \ldots$. . . . . . . . . . . . . . . . . .

1.4 Gliosis in $\mathrm{AD} \ldots \ldots \ldots \ldots \ldots \ldots$

1.5 APP processing . . . . . . . . . . . . . . . . 11

1.6 APP mutations in $\mathrm{AD} \ldots \ldots \ldots \ldots \ldots \ldots$

1.7 A schematic of $\mathrm{A} \beta$ aggregation . . . . . . . . . . . . . . 18

1.8 A diagram illustrating the intraneuronal $\mathrm{A} \beta$ hypothesis . . . . . . . . . . . 20

1.9 The generation of $\mathrm{A} \beta_{p E 3-x} \ldots \ldots \ldots \ldots \ldots \ldots \ldots$

1.10 The 5 XFAD transgenes . . . . . . . . . . . . . . . . . 30

3.1 The TBA4t transgene . . . . . . . . . . . . . . . . . . . . . . 6 64

3.2 Transgene levels in TBA4 mice . . . . . . . . . . . . . . . . . . . . 65

$3.3 \mathrm{~A} \beta$ aggregation in 3 -month-old TBA42 mice . . . . . . . . . . . . . . . 66

$3.4 \mathrm{~A} \beta$ aggregation in 6 - and 12 -month-old TBA42 mice . . . . . . . . . . . 67

$3.5 \mathrm{~A} \beta_{p E}$ accumulation in TBA42 mice . . . . . . . . . . . . . . . 68

3.6 Gliosis in TBA42 mice . . . . . . . . . . . . . . . . . . . . 68

3.7 No colocalization of $\mathrm{A} \beta$ with Syn16 in TBA42 mice . . . . . . . . . . . . . . 69

3.8 Colocalization of $\mathrm{A} \beta$ with Vti1b in TBA42 mice . . . . . . . . . . . . . . 69

$3.9 \mathrm{~A} \beta$ and $\mathrm{A} \beta_{p E}$ are found in the lysosomes of TBA42 mice . . . . . . . . . 70

3.10 TBA42 body weight . . . . . . . . . . . . . . . . . 71

3.11 Age-dependent alterations in motor function in TBA42 mice . . . . . . . . . . 71

3.12 Age-dependent deficits in working memory in TBA42 mice . . . . . . . . . . . 73

3.13 Decreased anxiety in TBA42 mice . . . . . . . . . . . . . . . . 74

3.14 Exploratory behavior in TBA42 mice . . . . . . . . . . . . . . . 74

3.15 Aggravated behavioral impairments in FAD42 mice . . . . . . . . . . . . 76 
3.16 N-terminal heterogeneity of $\mathrm{A} \beta$ peptides in 5XFAD and FAD42 mice $\ldots . . .77$

3.17 Intraneuronal $\mathrm{A} \beta$ in the cortices of 6 -month-old TBA42 and 5XFAD mice . . . 79

3.18 Elevated plaque pathology in the cortices of FAD42 mice . . . . . . . . . 80

3.19 No change in cortical intraneuronal $\mathrm{A} \beta$ in FAD42 mice . . . . . . . . . . . . 80

3.20 Increased levels of $\mathrm{A} \beta_{p E 3-x}$ in the brains of FAD42 mice as shown by ELISA . 82

3.21 Increased QC activity in FAD42 mouse brain . . . . . . . . . . . . 83

3.22 TBA8 transgene . . . . . . . . . . . . . . . . . . . . . . . . . . 84

3.23 Transgene levels in TBA8 mice . . . . . . . . . . . . . . . . . . . . 85

$3.24 \mathrm{~A} \beta$ aggregation in 4 - and 12 -month-old TBA83 mice . . . . . . . . . . . 86

3.25 Gliosis in TBA83 mice . . . . . . . . . . . . . . . . . . . . . . 86

3.26 TBA83 body weight . . . . . . . . . . . . . . . . 87

3.27 Subtle motor deficits in TBA83 mice . . . . . . . . . . . . . . . . . . 87

3.28 Normal working memory in TBA83 mice . . . . . . . . . . . . . . . . . 88

3.29 Unaltered anxiety levels in TBA83 mice . . . . . . . . . . . . . . . . . . . . . 89

3.30 Unchanged exploratory behavior in TBA83 mice . . . . . . . . . . . . . . . . . 89

3.31 Impaired spatial reference memory in TBA83 mice . . . . . . . . . . . . . . 90 


\section{List of Tables}

2.1 Reaction mixture for EcoRI digestion of TBA8 plasmid. . . . . . . . . . . . . 46

2.2 List of primers used for qPCR, mouse genotyping and plasmid mutagenesis. . 49

2.3 qPCR reaction mixture using Qiagen primers. . . . . . . . . . . . . . . 50

2.4 qPCR reaction mixture using TBA transgene primers. . . . . . . . . . . . 50

2.5 qPCR program for TBA transgene expression analysis. . . . . . . . . . . . 51

2.6 PCR reaction mixture for TBA1 plasmid mutagenesis. . . . . . . . . . . . . 51

2.7 PCR program for TBA1 plasmid mutagenesis. . . . . . . . . . . . . . 52

2.8 PCR reaction mixture for screening bacterial cultures for mutagenized plasmids. 52

2.9 PCR program for screening bacterial cultures for mutagenized plasmids. . . . 53

2.10 PCR reaction mixture for genotyping TBA and FAD42 mice. . . . . . . . . . . 53

2.11 PCR reaction mixture for genotyping 5XFAD and FAD42 mice. . . . . . . . . 54

2.12 PCR program for genotyping TBA, 5XFAD and FAD42 mice. . . . . . . . . . 54

2.13 Parameters and reagents for agarose gel electrophoresis. . . . . . . . . . . 55

2.14 Primary antibodies used for immunohistochemistry (IH) and IP/MS (IP). . . 58

2.15 Polyclonal secondary antibodies used for immunohistochemistry. . . . . . . . . 59 